

\section{BOSTON}

MEDICAL LIBRARY

8 THE FENWAY 






Digitized by the Internet Archive in 2010 with funding from University of Ottawa 



\section{LES CRIMINELS}

ÉTUDE CONCERNANT 859 CONDAMNÉS

PAR LE

\section{D $^{\text {r }}$ Charles PERRIER}

Médecin des Prisons 



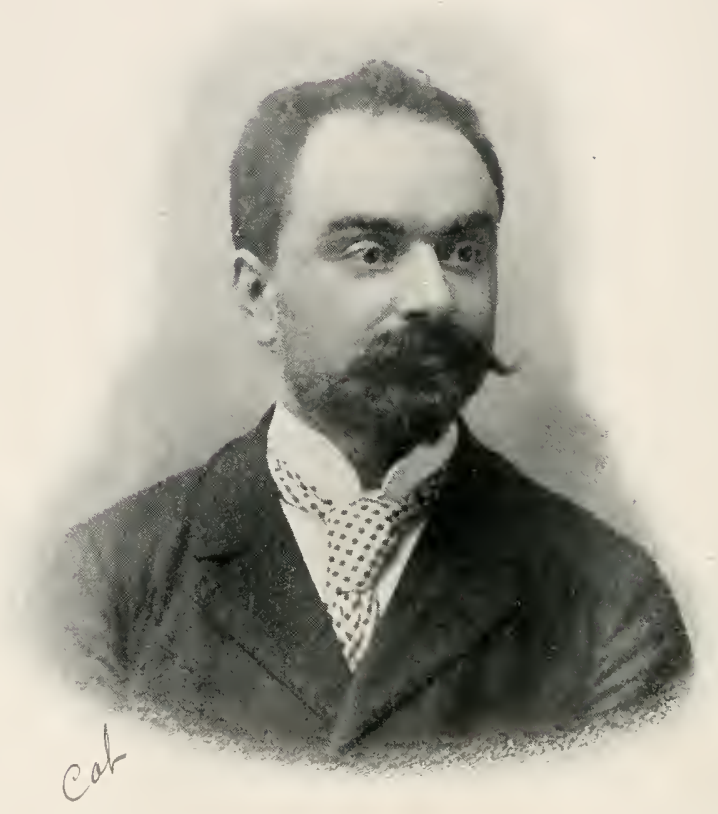

1) Charles Periner 


\section{BIBLIOTHÈQUE DE CRIMINOLOGIE}

XXII

\section{LES CRIMINELS}

Étude concernant 859 condamnés

\section{e \\ Par le $\mathrm{D}^{\mathrm{r}}$ Charles PERRIER}

Médecin des Prisons
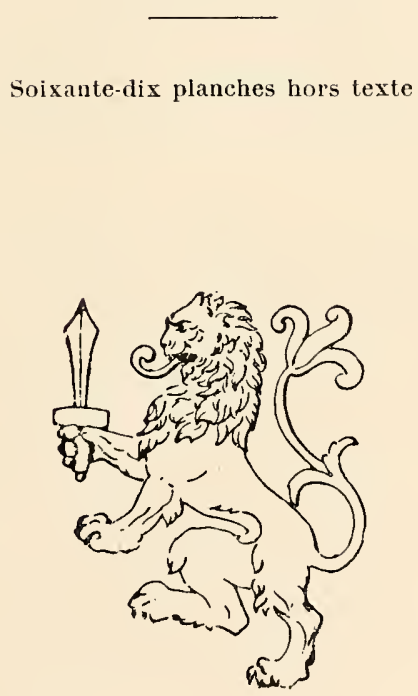

\begin{tabular}{c|c} 
LYON & PARIS \\
A. STORCK et Cie, ÉdTeurs & MASSON et Cie. Émeurs \\
8, hue de la Méditerrance & 120, Boulevard Saint-fiermain
\end{tabular}

\begin{tabular}{c|c} 
LYON & PARIS \\
A. STORCK et Cie, ÉdTeurs & MASSON et Cie. Émeurs \\
8, hue de la Méditerrance & 120, Boulevard Saint-fiermain
\end{tabular} 


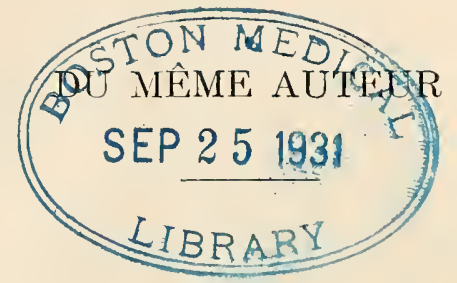

La maison centrale de Nimes, ses organes, ses fonctions. sa vie. Masson, Paris 1896.

Du tatouage chez les criminels. - Archives d'Anthropologie criminelle, $1^{\circ} 71$ (15 septembre 1897); et une brochure, Storck, Lyon 1897.

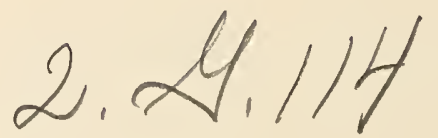


A MON PERE

\section{SCIPION PERRIER}

Juge de Paix, à Valleraugue (Gard).

Vimes, le 21 seplembre 1899.

Charles Perrier. 


\section{ERRATA}

Page 6, ligne 21; au lieu de planche 1, lire: planche 65.

- I\%, - 23; au lieu de planche 1, lire: planche 65.

- $\quad 24$ et 30. ligne 23: au lieu de et lui asait dérobé, lire: et avail dérobé.

- 6́, ligne 2; au lieu de $4 S$ libertins et débauchés, lire: 46 , ete.

- 95, - 4; au lieu de céphaluique, lire: céphalique.

- 13\%, - 2 et 3: au lieu de 2 sacent lire, écrire et calculer, il faut: I sait lire, écrire ct calculer; $I$ a regu l'instruction primaire.

- 13;, - 4; au lieu de l'un des deux derniers, il faut: celui qui saut lire, écrire et calculer.

- ı̆г, - ı2; au lieu de 1892 , lire: 1995 .

- 25̃o, - 5; au lieu de commune, lire: Commune.

- 336, - z; au lieu de vols qualifiés (obs. 22 à 40), lire: vols qualifiés (obs. 22 a 39 ).

- 345, (tableau): au lieu de au-dessus de 13 ans, lire: au-dessous de 13 ans.

- 354, - ; lire, en regard de la dernière aceolade, le chiffre:4.88, placé trop haut. 


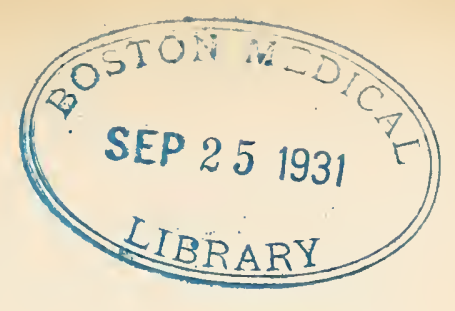

\section{LES CRIMINELS}

\section{ÉTUDE CONGERNANT 859 CONDAMNÉS}

\section{INTRODUCTION}

A la date du 24 mars 1896, la maison centrale de Nîmes renfermait 859 condamnés, soit :

$$
\begin{aligned}
& \text { YoMBRE P. CEYT ENSEMBIE P. GENT }
\end{aligned}
$$

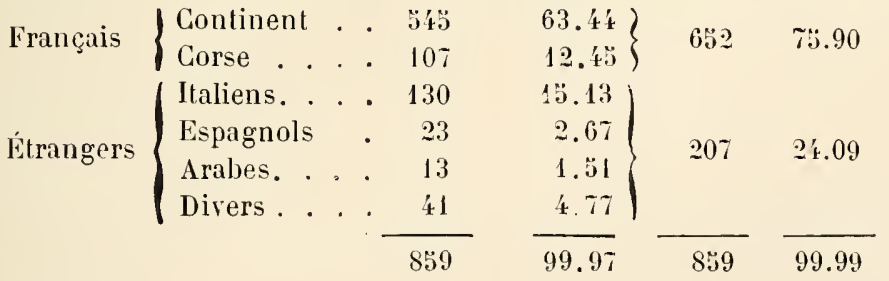

Les Français sont originaires :

2 de l'Ain, 6 de l'Allier, 8 des Basses-Alpes, 2 des HautesAlpes, 35 des Alpes-Maritimes, 21 de l'Ardèche, 1 des Ardennes, 2 de l'Ariège, 9 de l'Aude, 22 de l'Aveyron, 109 des Bouchesdu-Rhône, 13 du Cantal, 1 de la Charente, 2 de la CharenteInférieure, 107 de la Corse, 4 de la Côte-d'Or, 1 des DeuxSèvres, 1 de la Dordogne, 5 du Doúbs, 8 de la Drôme, 3 du Finistère, 36 du Gard, 12 de la Haute-Garonne, 1 du Gers, 
2 de la Gironde, 20 de l'Hérault, 1 de l'Hlle-et-Vilaine. 3 d'Indre-et-Loire, 8 de l'Isère, 1 du Jura, 1 des Landes, 2 de Loir-et-Cher, 20 de la Loire, 30 de la Haute-Loire, 3 du Lot; 1 du Lot-et-Garonne, 4 de la Lozère, 1 de Maine-et-Loire, 1 de la Manche, 1 de la Marne, 1 de la Haute-Marne, 1 du Nord, 1 de l'Oise, 3 du Pas-de-Calais, 1 des Basses-Pyrénées, 5 des Hautes-Pyrénées, 10 des Pyrénées-Orientales, 21 du Puy-deDôme, 20 du Rhône, 2 de la Haute-Saône, 4 de Saône-etLoire, 3 de la Savoie, 2 de la Haute-Savoie, 5 de la Seine, 1 de Seine-et-Oise, 2 de la Seine-Inférieure, 1 de la Somme. 2 du Tarn, 1 du Tarn-et-Garonne, 25 du Var, 28 de Vaucluse, 2 des Vosges, 1 de la Guadeloupe.

De l'Algérie viennent les 13 Arabes.

Les Italiens se disent :

99 du Piémont, 10 de la Lombardie, $S$ de Naples, 6 de la Romagne, 3 de la Sardaigne, 2 de la Sicile, 1 de la Toscane. 1 de Gênes.

Par leur na issance, les Espagnols appartiennent :

19 à la Catalogne, 1 à l'Andalousie, 1 à la Biscaye, 1 à Murcie, 1 à la province de Léon.

Parmi les individus de nationalités diverses, on rencontre :

7 Autrichiens, 7 Suisses, 3 Allemands, 3 Anglais, 3 Argentins, 3 Égyptiens, 2 Alsaciens-Lorrains, 2 Américains (Amérique du Nord), 2 Belges, 2 Grecs, 2 Maltais, 1 Monégasque, 1 Hollandais, 1 Mauricien, 1 Brésilien, 1 citoyen de l'Uruguay.

- Le Francais, à l'exception du nervi (souteneur), s'habitue vite dans la prison.

Il est bon garçon, rigole, bonimente et blague au besoin ses malheurs: " Ça se tire! ça se tire ! disait certain quidam condamné pour vol, plus que trente-sept mois !"

Un rien le met de belle humeur.

Sa joie déborde quand il peut jouer aux surveillants un tour 
de sa tête. Alors de s'écrier, en ricanant: "Sont-ils c... les pantes qui nous détiennent! Tout échappe à leur attention. En avant les violons! Hardi!"

Il n'y a pas pire farceur.

Gagner assez d'argent pour se payer plus tard un bon fusil, voila toute l'ambition du Corse.

Les mœurs de ce dernier sont assez pures. Quand il se prostitue - ce qui arrive rarement - il ne fait miché que parmi les compatriotes.

Tous les Corses se connaissent. Beaucoup passent ici pour beaux-frères ou cousins. Ils s'encouragent, se conseillent, s'entr'aident. Le sentiment de solidarité qui les lie est poussé au plus haut degré.

Il faut distinguer entre les Italiens.

Chez les Napolitains, les Siciliens et autres péninsulaires du midi, la paresse, la lâcheté et la délation sont les qualités dominantes.

La plupart portent sur la joue la cicatrice qui flétrit à jamais les traîtres et les faux amis.

Moins assoiffé de farniente, l'Italien du Nord travaille de bon gré et travaille à la tâche.

Mais tous - enfants du Nord et enfants du Midi - ont la colère facile ; ils s'arment volontiers du couteau.

Tireurs au flanc et grincheux, les Espagnols se plaignent à tout propos.

Parlez-moi des Anglais! Froids et corrects, ces messieury n'ont qu'une pensée : se procurer le confortable.

Ils prennent du souci pour leurs effets et font leur toilette au robinet commun avec autant de sravité que s'ils opéraient devant un magnifique lavabo, ne négligeant ni les soins de la bouche, ni ceux de la main.

Ils se soutiennent. Quotidiennement, des secours leur arrivent.

Leur unique ambition est d'avoir du travail " propre " et de vivre en paix.

Détail à noter, la mère patrie veille encore sur eux et, quand ils en expriment le désir, l'ambassade leur fait parvenir des livres. 
Que penser des Autrichiens, Suisses, Allemands, Belges, Grees, etc...?

Ce sont des modestes qui passent inaperçus ; leur conduite est sage.

Une extrême indifférence et un énorme égoïsme caractérisent l'Arabe.

Non content de reposer la nuit, il se plairait à dormir tout le jour. On ne le chasse de la visite médicale qu'à force de lavements.

Quoique foncièrement contemplatif, le fils du désert fait admirablement le coup de poing et surtout le coup de tête.

Avis aux amateurs!

Toutes les professions y sont représentées, depuis le marchand de poil de lapin jusqu au banquier à la manque (véreux). soit :

\begin{tabular}{|c|c|c|}
\hline & NOMBRE & P. GENT \\
\hline Propriétaires, rentiers. . . . . & 11 & 1.28 \\
\hline Employés de banque el de commerce. . . . & 66 & 7.68 \\
\hline Commerçants, fabricants . . . . . . . . & 32 & 3.72 \\
\hline Professions alimentaires. . & 63 & 7.56 \\
\hline Ouvriers d'ateliers et de fabriques . . . . . . & 131 & 17.57 \\
\hline Ouvriers du bàtiment et du mobilier . . . & 92 & 10.71 \\
\hline Professions agricoles (journaliers, domestiques). & 348 & 40.51 \\
\hline Nomades. . . . . . . . . . . . . . . & 46 & 5.35 \\
\hline Sans profession. . . . . . . . . . . & 48 & 5.58 \\
\hline & 859 & 99.96 \\
\hline
\end{tabular}

On remarque 9 propriétaires et 2 retraités : 1 gendarme et 1 facteur des postes.

Les employés de banque et de commerce comprennent : 20 individus remplissant des emplois divers (encaisseurs, commis-voyageurs, etc.), 20 garçons d'hôtel et de café, 13 coiffeurs, 5 comptables, 4 employés du chemin de fer, 2 courtiers de vin, 1 agent d'affaires, 1 pianiste.

Nous avons classé :

Parmi les commerçants et fabricants : 14 marchands (de vins, 
grains, étoffes, volailles, cochons, chevaux), 11 commerçants et négociants, 1 banquier, 1 liquoriste, 1 limonadier, 1 aubergiste, 1 mercier, 1 coutelier, 1 brocanteur.

Dans les professions alimentaires : 23 boulangers, 17 marins et pêcheurs, 13 cuisiniers, 10 bouchers, 2 pâtissiers.

Au nombre des ouvriers d'ateliers et de fabriques : 34 cordonniers, 18 mécaniciens et ajusteurs, 15 tailleurs d'habits, 9 mineurs, 9 imprimeurs, relieurs, typographes, lithographes, 6 forgerons et maréchaux-ferrants, 6 chaudronniers, 5 galochiers, sabotiers et sandaliers, 5 carriers et marbriers, 4 tanneurs et mégissiers, 4 fileurs et tisserands, 4 foudriers et tonneliers, 4 fondeurs (mouleur, tourneur, manœuvre de fonderie), 3 chauffeurs, 3 ferblantiers, 2 horlogers, 2 bouchonniers, 2 bijoutiers, 2 électriciens, 2 potiers et faïenciers, 2 charrons et carrossiers, 1 photographe, 1 layetier, 1 matelassier, 1 verrier, 1 coloriste, 1 armurier, 1 puddleur, 1 chiffonnier-trieur, 1 chemisier, 1 scieur d'usine.

Figurent parmi les ouvriers du bâtiment et du mobilier : 33 maçons, 21 menuisiers et ébénistes, 9 charpentiers et scieurs de long, 8 peintres, 7 serruriers, 4 plâtriers, 2 tuiliers, 2 carreleurs, 2 tapissiers, 1 ferblantier-zingueur, 1 chaisier, 1 cimenteur, 1 tailleur de pierres.

Dans les professions agricoles (journaliers, domestiques) se trouvent : 128 journaliers, 97 cultivateurs et laboureurs, 25 charretiers, voituriers et camionneurs, 18 terrassiers, 15 portefaix, chargeurs et hommes de peine, 15 manœuvres, 11 jardiniers, 10 cochers, 10 bergers, 9 domestiques et valets de chambre, 2 fermiers, 2 bûcherons, 1 vigneron, 1 charbonnier en forêt, 1 infirmier, 1 garçon laitier, 1 garçon d'écurie, 1 toucheur.

Nous avons considéré comme nomades : 25 marchands ambulants (étalagistes forains, marchands de bonbons, chiffonniers, camelots, colporteurs, revendeurs), 8 artistes lyriques (musiciens, acrobates et bateleurs), 7 contrebandiers, 1 tondeur de chevaux, 1 remouleur, 1 archéologue, 1 ancien militaire, 1 fabricant d'allumettes, 1 ex-commissaire de police.

Dans les sans profession, qualifiés ainsi par le Parquet, on compte 48 individus. 


$$
\text { **** }
$$

Ces 859 condamnés peuvent être groupés en 6 catégories :

- $1^{\circ}$ En tête se placent les pickpockets, chevaliers d'industrie et rats d'hôtel.

Chez la plupart, l'instruction fait défaut; en revanche, ils ont l'intelligence vive.

C'est à la façon de soutenir le regard qu'ils se reconnaissent. Tandis que le mecque baisse les yeux, l'ouvrier, lui, regarde hardiment et en face, tâchant de découvrir les membres de sa famille.

Ceux-ci sont pour le nouveau venu une Providence. Ils s'enquièrent de ses besoins, lui évitent les ennuis du bleu et le mettent à l'abri.

Il existe entre eux la plus étroite solidarité : le lettré fait la correspondance; le tailleur fournit les bérets de fantaisie et recoupe les pantalons. D'autres se chargent de procurer des petites femmes.

Ce sont eux les véritables organisateurs de la camelote, les pourvoyeurs du tabac à chiquer, à priser et à fumer.

Les trois quarts, il est vrai, possèdent de l'argent clandestin, enfoui dans les profondeurs du rectum. Un étui en métal leur sert de pochette (porte-monnaie). Cet étui (voir planche I), connu sous le nom de planq, se visse par le milieu et peut contenir jusqu'à 300 francs en jonc (or).

Pour rouler le guet pénitentiaire, ils ne sont pas à court de moyens. Ils font tout à petit bruit et se dérobent avec la souplesse du serpent aux exigences administratives.

Leur atelier préféré est celui oủ la fatigue est nulle.

Ils sont, en général, très propres dans leur personne; souvent actifs, rarement passifs. Les vieux seuls se laissent, aller parfois, à jouter au bouchon. Et encore s'arrangent-ils de facon à ne pas ébruiter le secret de leurs petites manies.

Ils sont si malins les ouvriers de la machinette!

$-2^{\circ}$ Cette catégorie ne manque pas de variétés. 
Les individus qui la composent (faillis, banqueroutiers, employés infidèles, etc., escrocs médiocres ou faiseurs) sont généralement intelligents et jouissent d'une certaine considération.

Même ici, le prestige de l'éducation s'impose.

C'est parmi eux que l'administration recrute les comptables, moniteurs, etc.

A quelques exceptions près, leur mise est règlementaire.

Ce qui les différencie des piclipockets, c'est un moindre raffinement dans les moyens employés pour se procurer "l'impossible ".

Un sentiment de fiertẻ les distingue; chez quelques-uns, il est poussé jusqu'au ridicule.

D'aucuns cherchent à épater les copains par des phrases ronflantes.

D'autres ne sauraient manger sans la traditionnelle serviette; ils se lèvent à minuit, s'attachent le mouchoir au cou et grignotent un morceau de pain, traduisant ainsi leur habitude de souper " au café anglais 》.

Pour forcer les nigauds à les appeler " Monsieur », il en est qui appellent " Monsieur ) tout le monde; ils disent: " Monsieur le balayeur », "Monsieur le vidangeur », Monsieur le voisin ". Ceux-lá, quand ils se saluent, se donnent du "bonjour, marquis », "salut, baron ", etc.

Ils font bande à part, ne fréquentant volontiers que les chevaliers d'industrie.

Pleins de mépris pour le menu fretin dont la grossièreté les choque, ils se gardent de toute impolitesse à son égard et ne veulent pas entrer en discussion avec lui.

Toujours bien vus par l'administration lorsqu'ils s'acquittent de leurs devoirs, ils parviennent à favoriser des amis.

Ils les passent en consigne au comptable général qui les propose, le cas échéant: "Essayez d'un tel », dit-il. Et si les débuts sont difficiles, on se mettra trois et même quatre pour aider le titulaire à arrêter sa fin de mois.

Beaucoup en sont. On fait venir la fille à l'atelier, dimanches et fêtes, sous prétexte de travailler, et on turbine sur le flanc. 
Un cervelas, un fromage, quelques cigarettes, etc., sont le prix de l'opération.

Quelquefois même le comptable y va à l'œil; le môme espérant ainsi gagner ses bonnes grâces.

Ils forment la société chic de la prison.

C'est là qu'on se rit des paperasseries administratives, qu'on épluche toutes les imperfections de la procédure et qu'on revise le Code deux et trois fois par an.

- $3^{\circ}$ Ici se rangent: les paysans, les ouvriers et tous ceux qu'un accident a jetés en dehors de la route, les violents chez qui la colère a pu obnubiler momentanément la raison et les individus condamnés pour crimes contre les mœurs, sujets ordinairement à des impulsions maladives.

Sans qu'il y paraisse, la plupart n'ont que du mépris pour le monde dans lequel ils sont appelés à vivre.

On les voit toujours doux, paisibles et taciturnes, ne récriminant jamais, "faisant les morts".

L'administration les qualifie: bons détenus.

- $4^{\circ} \mathrm{Vol}$, mendicité, vagabondage, outrages à magistrats, souventes fois aussi attentats à la pudeur, tels sont les motifs de leur condamnation.

Petits voyous, trimards, souteneurs timides, voilà les noms qu'on leur donne.

On les rencontre éparpillés un peu partout. Sous les verrous, ils vivent sans groupement, isolés, volant leurs codétenus et se volant entre eux.

Dans les situations diverses où ils se sont trouvés, quelques intervalles ont été marqués par un tel sentiment de bien-être, qu'en les remémorant, ils en sont affectés comme s'ils y étaient encore (J.-J. Rousseau).

Ils fournissent des tuyaux sur les fermes et hôtelleries de leur connaissance et s'initient à la façon de dévaliser un poivrot (ivrogne) étendu sur un banc.

La grande majorité ne possède aucune instruction.

Ceux qui ont l'esprit vif ne l'ont pas juste.

Toutes leurs actions ont le caractère de l'insouciance. 
Comme malpropreté, à eux le pompon.

Sans cesse ils se plaignent; ils ont toujours peur de trop travailler.

C'est parmi eux que se recrute " le bataillon des demoiselles $)$.

Les plus connues sont: "le Niston ", "Marcelle ", " la Lyonnaise ", "le Minon ", "la Cantinière ", " l'Espagnole aux grands yeux ", "la Négresse, à la peau noire, mais au cour blanc $\gg$.

$\mathrm{Au}$ premier plan brillent deux étoiles que n'approche pas qui veut: " la belle G... " et " la parisienne S... ".

Généralement, c'est à la "salle de repos " qu'elles vont se faire taper dans les baguettes. "Là, c'est franc; on peut marcher toute la nuit. ")

A leurs allures, on distingue aisément ces dames des autres détenus.

Elles cherchentà se donner une voix douce et portent des sabots à pointes lisses et à talons Louis XV.

Volontiers, elles se décollètent et couchent "á poil ", sous prétexte qu'il fait trop chaud.

Quelques-unes se maquillent et il n'est pas de ruses qu'elles n'emploient pour attirer à elles les pigeons de leur sexe.

Une d'entre elles que la nature a moins bien traitée plastiquement que ses rivales, naguère encore, arborait crânement le strapontin, pour se donner des airs de Vénus callipyge.

Toutes affichent cyniquement leur passion dégoûtante: "Oh! ce vieux chameau! il me donne un jupon (caleçon) tout froissé. " Ainsi parlait au prévôt qui distribuait le linge de corps, l'une de ces impudentes créatures.

Elles excellent d'ailleurs dans l'art de faire "casquer » les bibassons douillards (vieux riches) et se moquent d'eux avec un micheton de leur monde.

Pour avoir leurs aises, les individus de cette catégorie vendraient père et mère; ce sont des moucliards. Ames viles, cœurs lâches, ils sont capables de toutes les infamies, de toutes l's déchéances.

- 5n C'est le rebut non seulement de la sociétć, mais méme de la prison. 
Souteneurs avérés et voyous tragiques rentrent dans cette catẻgorie.

Leur nombre est grand.

Sous la livrée pénitentiaire perce chez la plupart une pointe de fantaisie.

De larges brides en cuir verni garnissent leurs sabots très souvent sculptés.

Pour montrer leurs chaussettes bigarrées de noir, de rouge et de blanc, ils retroussent le pantalon à la facon des gentlemen.

Leur béret, de travers sur la tête, a des allures de casquette par devant.

Ne pouvant s'offrir une large ceinture " couleur arc-en-ciel », ils se sanglent d'une bande de flanelle blanche qu'ils. font descendre très bas, au-dessous des reins.

Ils prennent en marchant un grand air débraillè et gondolent le buste sur les hanches - cela s'appelle : faire la chaloupe.

Dès leur condamnation, leur marmite les plaqua; aussi. se racontent-ils leurs malheurs.

Quand, par hasard, l'un d'eux reçoit une tune (écu de 5 francs) de son ancienne persilleuse, il faut voir avec quel orgueil il répand cette heureuse nouvelle.

La soif de la célébrité les dévore: "Comment! on ne me reconnaît pas! Je suis André dit le Tonnerre. " - "Et moi, reprend un long et stupide sécot, on m'a nommé : Cervellele-Grand. ")

Et quelle morgue!

Habitués à frapper, ils veulent paraître terribles, quittes à adoucir leur voix quand ils trouvent à qui parler.

Il ny a pas gens plus bornés ni plus têtus que ces prétendus fins d'esprit qui étalent avec un cynisme révoltant leur grossièreté, leur ignorance et leur présomption.

Chez, eux, l'argot est très en honneur; les tatouages abondent.

Pour tirer' une goulée (fumer) ou griller un peu, comme ils disent, d'aucuns se priveraient du nécessaire et même donneraient un mauvais coup.

Chose curieuse, tel qui hausserait les épaules d'avoir été pris 
en flagrant délit de crime, rougirait d'être soupconné d'un acte de pédérastie passive.

Ils aiment a vanter le faux éclat de leurs exploits et se consolent de leur condamnation par la préparation de nouvelles affaires.

Le mal, ils le font aussi consciemment qu'ils auraient fait le bien si l'éducation et les exemples reçus avaient été autres.

Pour eux, surtout, la prison est l'école du vice.

$-6^{\circ}$ En général, les peines infligées pour crime anarchiste (attentats ou actes préparatifs) ne sont pas subies sous le régime de la vie en commun.

A l'exception d'un seul, les individus considérés comme anarchistes ont été condamnés pour des faits étrangers à ce crime.

Anarchistes! mais six sur huit ne le sont pas. Et s'ils ont parfois affiché des idées subversives, ç'a été par pose ou dans le but d'exploiter la bonne foi des anarchistes convaincus.

Il est même à croire que les seules idées de réforme qui ont pu germer dans leur cerveau visaient les perfectionnements a apporter aux divers systèmes de perforation des coffres-forts; le vol qualifié étant, communément, leur principal moyen dexistence.

Contrairement à ces faux anarchistes, les deux autres - les vrais, ceux-là - sont portés à l'étude et ne manquent pas d'intelligence.

Ils ne cherchent pas à faire d'adeptes; la prison les rend plutôt réservés.

L'un d'eux possède quelque instruction.

Les détenus au milieu desquels ils vivent les déclarent excellents camarades et d'une conduite toujours franche et correcte.

"Je suis étonné, nous écrit un rat d'hótel, de l'importance que le gouvernement a donné aux attentats anarchistes, persuadé que la plupart des explosions qui ont eu lieu à Paris, en 1893 et 1894, n'ont pas eu pour auteurs des anarchistes, Émile Henri et Vaillant exceptés.

" Cẹs attentats ont été le fait de malfaiteurs se disant anar- 
chistes et voulant se venger des rigueurs de la justice en l'effrayant.

( Je connais en effet un café - lieu de réunion des voleurs qui a servi d'officine pour la préparation des engins explosifs.

“De là, partaient les lettres anonymes (composées au milieu de grands éclats de rire) à l'adresse des membres du parquet.

"Quelques-unes de ces lettres furent prises dans le sérieux; et, au grand contentement de tous, la police garda pendant plusieurs semaines les maisons des citoyens menacés.

"Lors du procès Ravachol, le président du jury de la Seine en reçut trois en pleine audience.

“ C'est bien a tort qu'on les mit sur le compte des anarchistes. "

$$
\text { 蒋㫧 }
$$

Les crimes et délits qui ont motivé la condamnation sont les suivants:

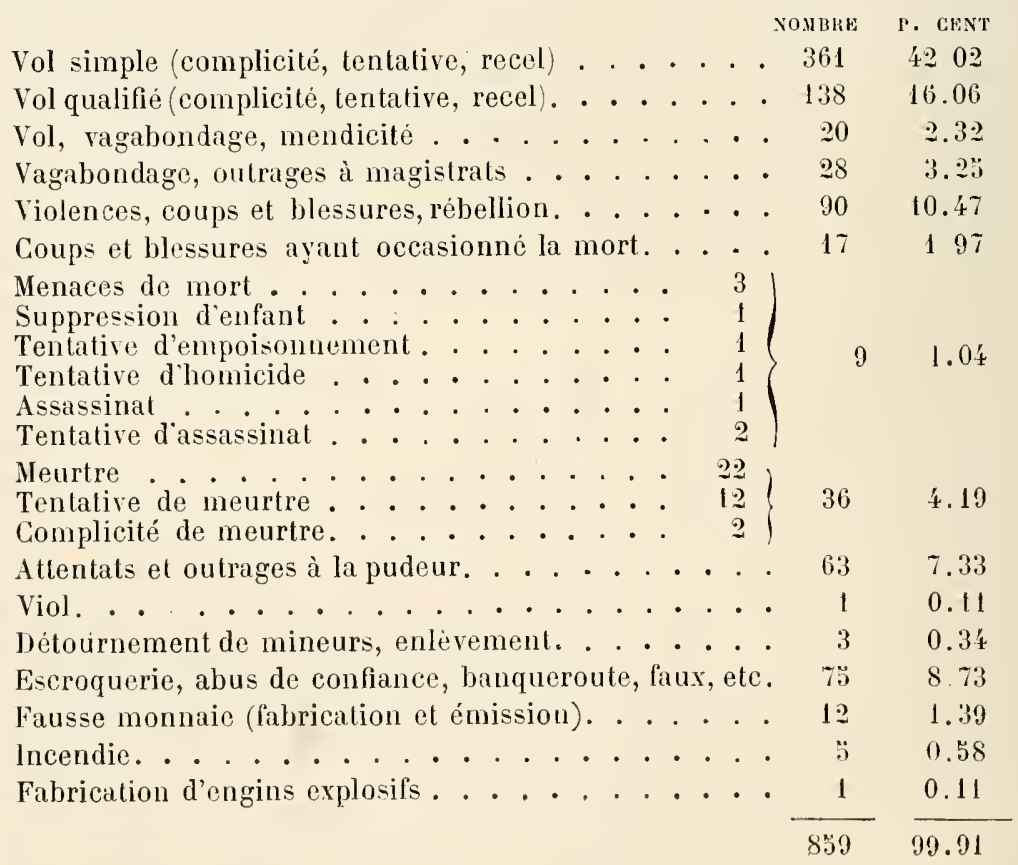


Tel est le classement que nous avons adopté.

Il nous a été suggéré par la notice épinglée au dossier de chaque condamné, précieux document qui émane de l'autorité judiciaire et qu'il nous a été permis de consulter à titre de médecin de l'établissement.

Après avoir réparti, dans chacune de ces catégories de crimes et délits, les observations qui nous ont paru les plus intéressantes, nous avons groupé nos pensionnaires en " criminels contre les personnes" et en " criminels contre les propriétés ».

Cela fait, nous les avons considérés dans leur ensemble et les arons examinés à 38 points de vue différents. 



\title{
CHAPITRE PREMIER
}

\author{
$\longrightarrow$ \\ VOL. SIMPIE - COMPLICITÉ - TEATATIVE - RECEL \\ 361 individus
}

1. Au point de vue de la naissance:

349 enfants légitimes; 9 enfants naturels; 3 enfants trouvés.

Au nombre des enfants trouvés, on remarque un Marseillais, âgé de quarante-quatre ans, marié, illettré, charretier, se livrant au libertinage et à la débauche, antérieurement condamné, pour vol, à 6 jours d'emprisonnement.

Par arrêt du 12 février 1895, la cour d'assises des Bouchesdu-Rhône lui a infligé 3 ans de prison.

En octobre 1894, il remit à un camarade les clefs de l'entrepôt de son patron pour lui permettre d'y voler des sacs de blé. 17 sacs furent enlevés et vendus au prix de 204 francs, somme partagée entre eux.

Taille $1 \mathrm{~m}$. 63. Envergure $1 \mathrm{~m}$. 67. Buste 0,880. Pied gauche 0,254. Tète : longueur 0,190; largeur 0,167. Indice céphalique 87,89.

Oreille droite: longueur 0,063 ; largeur 0,036 . Indice auriculaire 55,38 . Forme triangulaire ; écartement supérieur. 
Front: arcades moyennes; inclinaison intermédiaire; hauteur et largeur petites.

Nez : cavité (de la racine) moyenne; dos rectiligne ; base horizontale ; hauteur, saillie et largeur moyennes.

Bouche: moyenne, à coins abaissés; ouverture intermédiaire.

Menton: rond, droit; hauteur intermédiaire.

Visage ovale, sans physionomie. Iris pigmenté de jaune.

Teint clair. Barbe, cheveux et sourcils châtain foncé.

Carrure moyenne. Petite santé. Artérite chronique avec dégénérescence athéromateuse.

Il ne veut pas en foutre un coup; paresseux et vieux drille. - Cordonnerie. - Obs. 1.

\section{$2^{\circ}$ A u point de vue de la nationalité:}

245 Français (dont 30 Corses); 116 Étrangers (66 Italiens. 14 Espagnols, 11 Arabes, 25 divers).

Un Égyptien, âgé de trente-cinq ans, célibataire, sachant lire et écrire, tailleur in partibus, urbain, domicilié à Nice, à la première peine, a été condamné, pour " complicité de vol ", à 4 ans d'emprisonnement, par arrêt de la cour d'Aix, en date du $1^{\text {er }}$ juin 1894, sur l'appel du ministère public. (Le tribunal de Nice ne lui avait infligé que 18 mois).

Il faisait partie d'une bande de malfaiteurs qui, profitant des fêtes du carnaval, dévalisaient les passants par le procédé dit " vol à la tire ).

On l'arrêta au moment où une femme, sa complice, lui glissait un objet qu'elle venait de dérober.

Un certain nombre de bijoux (montres, chaînes, bagues, etc.) étaient en sa possession.

L'expulsion suivra la peine.

Jusqu'à dix-huit ans, sa conduite fut exempte de blâme. Les circonstances aidant, il devint contrebandier. Un jour, les douaniers cernèrent sa maison. Pour s'ouvrir un passage à 
travers cette barrière vivante, il dut employer la violence; il alla même jusqu'à jouer du couteau.

Plus tard, sous l'empire de nouveaux besoins, pour la satisfaction desquels ce rude métier ne lui donnait que d'insuffisantes ressources, il se fit bonneteur et pickpocket.

On croit généralement, dit-il, que pour pratiquer le métier de pickpocket, une main fine et de l'adresse sont nécessaires. C'est une erreur. Il faut surtout du sang-froid ; l'adresse ne vient qu'après. Quant à la dimension de la main, elle n'a qu'une importance relative. Et il montre la sienne qui est de longueur et de largeur moyennes.

D'ailleurs, l'association facilite singulièrement le travail. Pour opérer un pante, un mecque ou un cavé (bon à exploiter), on se met 4, 5 et même 6 machinettes. Ainsi font les Anglais, aux abords des banques, à la descente des trains, à la sortie des théâtres, etc. Ils contournent la victime, la compriment et quand, gênée dans ses mouvements, celle-ci relève les coudes pour se dégager, l'ouvrier le mieux placé lui introduit la main dans la poche, en cachant ce mouvement à l'aide d'un journal, chapeau, mouchoir, etc.

L'Italien, le Français et l'Espagnol travaillent volontiers seuls. L'Espagnol se sert beaucoup du canif dit sacagne (voir planche I); l'Italien, moins ; le Français, très peu.

Taille 1 m.613. Euvergure 1 m. 66. Buste 0,842. Pied gauche 0,260. Tète : longueur 0,187 ; largeur 0,163 . Indice céphalique 87,16 .

Oreille droite: longueur 0,063 ; largeur 0,039 . Indice auriculaire 61,90 .

Forme ovale.

Front: arcades moyennes; inclinaison intermédiaire; largeur et hauteur moyennes.

Nez: cavité (de la racine) moyenne; dos rectiligne; base horizontale; hauteur petite; saillie moyenne; largeur grande.

Bouche : en cœur (petite, à coins relevés; lèvre supérieure retroussée). Menton: rond, droit, bas, à houppe.

Visage arrondi. Iris pigmenté d'orange. OEil vif. 
Teint brun. Barbe, cheveux et sourcils châtain moyen (cheveux frisés).

Carrure grande. Santé bonne. Esprit métiant.

Il se plaît au travail et a de la conduite. - Talons. - Obs. 2.

\section{$3^{3}$ Au point de vue de l'âge :}

43 de 16 à 20 ans; 164 de 20 à 30 ans ( $7 \%$ de 20 à 25 ans et 87 de 25 à $30 \mathrm{ans}$ ).

Un Mâconnais, âgé de vingt ans, célibataire, sachant lire et écrire, sans profession, sans domicile, 5 fois condamné, attire l'attention.

Il subit la peine de 2 ans de prison, prononcée, le 31 octobre 1895, par la cour de Nîmes - sur appel d'un jugement le condamnant à 15 mois - pour avoir entraîné derrière les ponts, le 18 septembre 1895, un Privadois de passage dans la ville, et l'avoir dépouillé, à l'aide d'un camarade, d'une somme de 24 francs.

A huit ans, il perdit ses parents et devint l'enfant gâté de son grand-père qui tenait un petit café. Dès qu'il pouvait aller rejoindre ses camarades plus âgés que lui, il partait courir les caboulots de filles. On l'y débaucha et c'est le tendre c cur de sa maîtresse qui lui valut la place de garçon dans un de ces établissements interlopes.

Ainsi qu'un brochet à la mie de pain (jeune souteneur), il se mit à vivre de la braise qu'endiguait sa truqueuse, grinchant à l'occasion le bourgeois. Sa dernière marmite le vendit. Pourtant, il la caressait de soins si délicats que de l'avoir choisi jamais elle ne gémit. "Nom d'une pipe, dit-il : Foi de femme est plume sur l'eau! ) La chose saute aux yeux.

Taille $1 \mathrm{~m}$. 70. Envergure $1 \mathrm{~m}$. 74. Buste 0,897. Pied gauche 0,245. Tète: longueur 0,186 ; largeur 0,160 . Indice céphalique 86,02 . 
Oreille droite : Iongueur 0,0 \% 6 ; largueur 0,037 . Indice au riculaire 66,07 .

Forme ronde.

Front: arcades moyennes; inclinaison intermédiaire; hauteur et largeur petites.

Nez : cavité (de la racine) moyenne; dos rectiligne; base relevée; hauteur, largeur et saillie moyennes.

Bouche: moyenne, à coins relevés; ouverture intermédiaire.

Menton: Fuyant, rond; hauteur intermédiaire.

Visage ovale. Iris pigmenté d'orange, légèrement truité. Yeux saillants.

Teint clair. Barbe, cheveux et sourcils blonds.

Carrure moyenne. Constitution et état général médiocres. Caractère timide.

C'est un boulo(travailleur enragé) très bien en cour. - Ébénisterie. - Obs. 3.

101 de 30 à 40 ans.

Entre autres, un Savoisien, âgé de trente-cinq ans, célibataire, sachant lire, écrire et calculer, cuisinier, urbain, ayant un domicile, 3 fois condamné.

La cour d'appel d'Aix a confirmé, par arrêt du 31 janvier 1895, le jugement rendu par le tribunal de Marseille, lui infligeant 7 ans de prison et 5 ans d'interdiction de séjour, pour "vols et escroquerie".

En septembre 1894, il avait soustrait une montre, une valise, des effets d'habillement, une sacoche et deux jumelles de théâtre, au préjudice de diverses personnes; il avait, en même temps, pris un faux nom et une fausse qualité pour se faire délivrer des aliments.

$\mathrm{Au}$ début de sa carrière de voleur, ce coureur de villes d'eaux se contentait de s'introduire, soit le matin, soit pendant la journée, à l'heure des bains, dans les chambres des voyageurs, pour fouiller les malles. Souvent, il ne trouvait pas d'argent, mais, presque toujours, il mettait la main sur des bijoux qu'il 
vendait à un receleur parisien, à raison de 2 francs le gramme. Quant aux brillants, il les détachait de leur monture et les cachait dans un pain au milieu de la mie. "Cette cachette si simple a résisté victorieusement à toutes les perquisitions. ")

Mais, sur les conseils de sa maîtresse qui avait remarqué que les fortes sommes étaient toujours placées dans le portefeuille, il n'opéra plus que la nuit, pendant le premier sommeil. Le voyageur qui s'enferme dans sa chambre, à double tour, se croit en sûreté. Il n'en est rien. A l'aide d'un tube fendu longitudinalement, ayant la forme d'un porte-crayon à dessin et désigné sous le nom de queue de rat, on ouvre les portes ayant la clef à l'intérieur aussi facilement que si celle-ci était à l'extérieur et on les referme de même.

Bien entendu, notre homme ne pénètre dans les chambres (plié en deux et vêtu d'effets sombres) qu'après s'être assuré, par un léger frottement à la porte, que la victime dort. Malheureusement, le succès n'est' pas toujours au bout de ces visites nocturnes. Tém oin sa dernière et " plaisante " équipée à l'hôtel de Russie, à Marseille, où il resta six jours avant d'opérer, faute d'instrument convenable, "les clefs étant de dimension énorme ». Il mit le pied dans une "cuvette " qui se cassa avec bruit et interrompit fort désagréablement le sommeil d'un jeune couple brisé de fatigue : Ils voulurent crier, dit-il, mais leurs voix défaillantes expirèrent de frayeur sur leurs lèvres béantes (Delille).

L'impunité par trop fréquente, le désœuvrement et un désir immodéré deluxe et de bonne. chère ont implanté profondément dans son cerveau l'idée de vol. Il ne rêve quelouis et billets de mille.

Taille $1 \mathrm{~m}$. 71. Envergure $1 \mathrm{~m}$. 79. Buste 0,908. Pied gauche 0,258. Tète: Iongueur 0,198 ; largeur $0,18 ̈ 9$. Indice céphalique 80,30 . Oreille droite : longueur 0,064 ; largeur 0,037 . Indice auriculaire 57,81 . Forme ovale; écartement total.

Front: arcades grandes; inclinaison intermédiaire; hauteur et largeur moyennes. 
Nez: cavité (de la racine) moyenne; dos rectiligne; base relevée; hauteur, largeur et saillie moyennes.

Bouche : en cœur (petite, à coins relevés ; lèvre supérieure retroussée). Menton : fuyant, rond; hauteur intermédiaire.

Visage ovale. Iris impigmenté. OEil vif.

Teint clair. Barbe, cheveux et sourcils chàtain clair ; sourcils écartés. Carrure moyenne. Excellente santé. Bonne physionomie.

Il tourne tout en plaisanterie et estampe (vole) son patron jusqu'à concurrence de la tâche. - Pipes. - Obs. 4.

53 de 40 ans et plus (34 de 40 a 50 ans et 19 de 50 ans et audessus).

A citer : un Lozérien, àgé de quarante-sept ans, veuf, père de deux enfants, sachant lire, cultivateur, urbain, ayant un domicile, bien noté dans sa commune, condamné par la cour d'assises du Gard, le 5 août 1895, à 15 mois d'emprisonnement, pour " vol domestique ".

Dans les premiers jours du mois de juin, il avait dérobé à son patron - dans la cave où ce dernier cachait son argent une somme de 920 francs et en avait remis une grande partie $\dot{a}$ sa maîtresse pour faire l'acquisition d'une buvette.

Taille $1 \mathrm{~m}$. 54. Euvergure $1 \mathrm{~m}$. 59. Buste 0,836. Pied gauche 0,247. Tète : longueur 0,176 ; largeur 0,157 . Indice céphalique 89,20 .

Oreille droite : longueur 0,039 ; largeur 0,033. Indice auriculaire $\dddot{30}, 93$.

Front : arcades moyennes; inclinaison fuyante; hauteur moyenue ; largeur petite.

Nez : cavité (de la racine) moyenne ; dos concave ; base horizontale ; hauleur petite; largeur grande; saillie moyenne.

Bouche : moyenne, à coins abaissés ; ouverture intermédiaire.

Menton : fuyant, rond; hauteur intermédiaire.

Visage arrondi. Iris pigmenté de chàtain. Expression dı regard banale. 
Teint brun. Barbe, cheveux et sourcils noirs.

Carrure petite. Santé délicate.

C'est un bon ouvrier dont la conduite ne mérite que des éloges. - Empaillage. - Obs. 5.

\section{$4^{\circ} \mathrm{Au}$ point de vue de l'ètat civil :}

294 célibataires, 56 mariés, 8 veufs, 3 divorcés.

On distingue, parmi les divorcés, un Arabe, âgé de trentesept ans, illettré, maquignon, rural, ayant un domicile, sans condamnation antérieure, mal noté, adonné à l'ivrognerie.

Par arrêt, en date du 8 mai 1895, la cour d'appel d'Aix lui a infligé 3 ans de prison, pour avoir soustrait, dans la nuit du 28 au 29 mars, à Constantine, "un cheval et quinze vaches " qui étaient remisés dans un parc.

Taille $1 \mathrm{~m}$. 66. Envergure $1 \mathrm{~m}$. 63. Buste 0,880. Pied gauche 0,245 . Tête : longueur 0,197 ; largeur 0,441 . Indice céphalique 71,57 .

Oreille droite : longueur 0,060 ; largeur 0,037 . Indice auriculaire 61,66 . Front : arcades moyennes; inclinaison fuyante; hauteur et largeur moyennes.

Nez : cavité (de la racine) petite; dos rectiligne; base horizontale ; hauteur, saillie et largeur moyennes.

Bouche : moyenne, rectiligne, bée ; lèvres épaisses.

Menton: fuyant, rond ; hauteur intermédiaire.

Visage ovale. Iris pigmenté de châtain.

Teint brun. Barbe, cheveux et sourcils noirs; sourcils clairsemés. Tatoué.

Carrure moyenne. Santé vigoureuse. Nature abrutie.

I! travaille paresseusement, implorant la miséricorde d'Allah et le secours de Mahomet. - Cordonnerie, - Obs, 6. 


\section{$5^{n}$ Au point de vue de l'instruction :}

53 sont illettrés.

Notons : un Italien, âgé de vingt-cinq ans, célibataire, journalier, urbain, domieilié à Marseille, sans antécédents judiciaires, qui subit la peine de 5 ans de prison, prononcée, le 18 février 1895 - avec 5 ans d'interdiction de séjour — par la cour d'assises des Bouches-du-Rhône, pour " tentative de vol ):

Dans la soirée du 29 octobre 1894, s'avançant, à pas de loup, dans l'ombre d'une rue, il avait pris, par derrière, un pacifique passant (maçon qui rentrait cliez lui portant la paye de la semaine) et lui avait serré fortement la gorge pendant qu'un camarade le fouillait.

En argot, cela s'appelle : faire un homme au ráble ou $\dot{a}$ la cure, indifféremment.

Ainsi que la plupart des individus qui pratiquent l'attaque nocturne, c'est un féroce. Toute victime, mal saisie, qui se débat, reçoit des coups de poing américain et des coups de pied dans le ventre jusqu'à complet évanouissement.

D'où, le conseil de se earesser le menton, de la main gauche, en tenant le milieu de la rue, quand on rentre tard chez soi. Un agresseur de métier n'attaque jamais un homme ainsi sur ses gardes. La force de la dure repose sur la rapidité avec laquelle les membres deviennent inertes, l'appareil respiratoire ne fonctionnant plus.

Taille $1 \mathrm{~m}$. 58. Envergure $1 \mathrm{~m}$. 60. Buste 0,87:3. Pied gauche 0,238. Tète : longueur 0,180 ; Iargeur 0,1:59. Indice céphalique 88,33.

Oreille droite : longueur 0,0:3; largeur 0,033 . Indice auriculaire 60 . Écartement supérieur.

Front: arcades proéminentes; inclinaison intermédiaire; hauteur moyenne ; largeur petite. 
Nez : cavité (de la racine) petite; dos rectiligne ; base horizontale ; hauteur et saillie grandes; largeur petite.

Bouche : petite, rectiligne; ouverture intermédiaire.

Menton : droit, large, haut.

Visage large. Iris pigmenté d'orange, truité. Physionomie insignifiante.

Teint brun. Barbe, cheveux et sourcils châtain foncé; sourcils réunis. Carrure moyenne. Santé robuste. A expulser.

Il prend plaisir à faire de la rouspétance (résister aux injonctions des agents) tout en massant dur (travaillant ferme). Chaises. - Obs. $\%$

34 savent lire ; 240 savent lire et écrire; 30 savent lire, écrire et calculer; 3 possèdent une instruction primaire complète.

Seul, un Anglais, âgé de vingt-quatre ans, célibataire, urbain, à la première peine, affirme avoir reçu une instruction supérieure.

Dans ses prétentions cet homme est sans bornes.

Le tribunal correctionnel de Nice l'a condamné, le 12 mai 1893, à 5 ans de prison, pour "vols ".

Il s'était introduit, à la date du 10 janvier de la même année, dans la chambre de $\mathrm{M}^{\mathrm{me}}$ Théo, à "l'hôtel des Anglais », à Nice, et lui avait dérobé une grande quantité de bijoux, exploit renouvelé à Menton, le 12 février, au préjudice d'une autre personne.

Le parquet le signale comme n'ayant ni profession, ni domicile, et comme faisant partie d'une bande de voleurs qui avaient mis en coupe réglée les palanquins (hôtels) du littoral.

Il voyageait avec un larbin et traînait en tout lieu deux grandes dindes, la mère et la fille, ses maîtresses.

A l'expiration de sa peine, on le contraindra a sortir de France. 
Taille $1 \mathrm{~m}$. 652. Envergure $1 \mathrm{~m}$. 68. Buste 0.877. Pied gauche 0, 2:32. Tète : longueur 0,190 ; largeur 0,146 . Indice céphalique 76,84 .

Oreille droite : longueur 0,060 ; largeur 0,034 . Indice auriculaire 56,66. Écartement inférieur.

Front: arcades moyennes; inclinaison intermédiaire; hauteur grande; largeur moyenne.

Nez: cavité (de la racine) moyenne; dos rectiligne; base relevéc; hauteur, saillie et largeur moyennes.

Bouche : moyenne, rectiligne; ouverture intermédiaire.

Menton : rond, droit; hisuteur intermédiaire.

Visage arrondi. Iris impigmenté.

Teint clair. Barbe, cheveux et sourcils châtain clair (cheveux grisonnants).

Carrure moyenne. Santé bonne. Physionomie agréable.

Ce jeune homme remplit les délicates fonctions de " tisanier ». On l'appelle: "Quinquina ), en souvenir du vin qu'il chahute à la pharmacie. - Obs. 8 .

Certainement, le plus intéressant de tous ces voleurs est un soi-disant Parisien, âgé de vingt-sept ans, célibataire, possédant une instruction primaire complète, "chevalier d'industrie ", sans domicile, 5 fois condamné sous des noms divers.

Il subit la peine de cinq ans infligée - avec 10 ans d'interdiction de séjour - par arrêt de la cour d'appel de Lyon, en date du 18 mars 1895, pour avoir soustrait, de concert avec un camarade, le 12 juin 1894, une somme de 400 francs et deux montres, au préjudice d'un marchand de primeurs.

" Je fis, dit-il, sa rencontre à Montélimar et l'accompagnai à son domicile, à Valence. Là, je lui promis 50 francs s'il voulait m'aider à acheter un café ou tout autre établissement analogue.

"Il accepta et nous nous donnâmes rendez-vous à l'hôtel de la Croix-Blanche où j'étais descendu sur sa recommandation. Je le retins à déjeuner; puis, nous allâmes au café. Mon complice 
s'y trouvait. Il se disait nouveau débarqué de Buenos-Ayres et porteur de 40,000 francs.

" Bientôt, feignant d'être inquiet au sujet de cette somme, celui-ci nous pria de la lui garder. Le marchand s'offrit tout de suite et nous partîmes la déposer chez lui, où l'Américain se souvint, fort à propos, d'un conseil que lui avait donné son père au lit de mort: “ Ne confie jamais ton argent à quiconque, si on ne te fournit pas la preuve qu'il sera mis avec celui de la personne à qui tu le confies. ') Et, ce disant, il tendit au plaignant un portefeuille tout neuf, cadeau de l'évêque de Buenos-Ayres, béni avant le départ.

"Alors, me tournant vers mon complice, j'affirmai voir dans l'heureuse rencontre qu'il venait de faire - les gens malintentionnés ou pas obligeants du tout n'étant point rares — un des merveilleux effets de la bénédiction épiscopale.

"Notre dupe m'approuvait de la tête, tout en glissant ses billets de banque dans le portefeuille.

" L’opération terminée, il prit fantaisie au compère de soupeser le talbin et de le mettre dans la poche du pardessus; mais, bien vite, il le rendait au Valencien, avec prière de l'enfermer dans la sacoche qui contenait les 40,000 francs.

" Le marchand écouta ce désir et plaça la sacoche ainsi lestée dans un meuble dont la clef fut confiée à l'Américain. On se quitta. Et quand, las de nous attendre au rendez-vous donné pour le paiement de deux montres en or achetées sur ses instances, le plaignant voulut se renseigner sur le trésor à lui confié, il ne trouva que des rouleaux de cinq centimes et un portefeuille ne contenant que des papiers sans valeur. Celui-lì n'était point béni. »)

Le condamné explique la sévérité de l'arrêt rendu contre lui par'l'hypothèse admise de ses relations étendues arec force escrocs ; sans compter que son identité n'a jamais paru établie d'une manière satisfaisante pour la justice " qui a le défaut d'être trop curieuse ").

C'est un malin! 
Taille $1 \mathrm{~m}$. 64. Envergure $1 \mathrm{~m}$. 71. Buste 0,86ə̈. Pied gauche 0,2:33. Tète : longueur 0,191 ; largeur 0,153 . Indice céphalique 81,15 .

Oreille droite : longueur 0,059 ; largeur 0,032. Indice auriculaire 54,23 .

Front : arcades moyennes; inclinaison intermédiaire; hauteur moyenne; largeur petite.

$\mathrm{Nez}$ : cavité (de la racine) moyenne; dos rectiligne; base relevée; hauteur, largeur et saillie moyennes.

Bouche : moyenue, à coins relevés ; ouverture intermédiaire.

Menton : bas, droit, rond.

Visage ovale. Iris impigmenté. Figure pleine de distinction.

Teint clair. Barbe, cheveux et sourcils châtain très clair. Tatoué d’une femme à moitié effacée.

Carrure moyenne. Santé délicate.

Il se conduit bien, mais refoulerait volontiers sur le turbin (flânerait avec joie). - Pipes. - Obs. 9.

\section{$6^{\circ}$ Au point de vue de la profession :}

129 professions agricoles; 57 ouvriers d'atelier's et de fabriques ; 46 ouvrier's du bâtiment et du mobilier; 31 employés; 31 sans profession; 28 professions alimentaires.

Un garçon boucher, né à Cette le 11 mars 1874, célibataire, sachant lire, bien noté, a été condamné par le tribunal de Montpellier, le 18 juin 1895, à 15 mois de prison.

Au mois d'avril, tantôt seul, tantôt de concert avec un camarade, il avait commis une série de vols de pièces d'argent, bijoux, armes, livres, effets mobiliers, au préjudice de nombreux habitants de la localité.

Taille 1 m. 63. Envergure 1 m. 68. Buste 0,873. Pied gauche 0,2:333. Tète : longueur 0.183 ; largeur 0,1508 . Indice céphalique 86,33 .

Oreille droite: longueur 0,062 ; largeur 0,034 . Indice auriculaire $\ddot{3} 4,83$.

Iront : arcales moyennes; inclinaison verlicale; hauteur et largeur moyennes. 
Nez : cavité (de la racine) petite; dos concave; base horizontale; hauteur, largeur et saillie moyennes.

Bouche : grande, à coins relevés; ouverture intermédiaire.

Menton : droit, rond, à houppe et à fossette; hauteur intermédiaire. Visage en losange. Iris pigmenté de chàtain. Expression du regard banale.

Teint clair. Barbe, cheveux et sourcils châtain clair. Carrure moyenne. Santé forte.

Excellent détenu. - Cordonnerie. - Obs. 10.

25 nomades; 13 commercants et fabricants ; 1 rentier.

Mais quel rentier ! né à Glasgow le 24 avril 1836 et domicilié à Nice où il n'exerçait aucune profession, cet Anglais, marié, sachant lire et écrire, à la seconde peine, a été condamné par arrêt de la cour d'appel d'Aix, en date du 20 juin 1893, à 5 ans d'emprisonnement, pour " complicité de vol et infraction à un arrêté d'expulsion ).

Dans le courant du mois de février, à Nice, il avait attiré sur le trottoir, devant la vitrine du magasin, une marchande de bijoux, et l'y avait retenue quelques instants, sous prétexte de lui demander le prix de diverses pièces à l'étalage. Pendant ce temps, un complice se glissait furtivement jusqu'au comptoir et commettait un vol de caisse de 1.600 francs.

Taille $1 \mathrm{~m}$. 66.3. Envergure $1 \mathrm{~m}$. 70. Buste 0,863. Pied gauche 0,247 . Tète : longueur 0,203 ; largeur 0,152 . Indice céphalique 74,14.

Oreille droite: longueur 0,073 ; largeur 0,039 . Indice auriculaire 53,42 .

Front: arcades moyennes; inclinaison fuyante; hauteur et largeur moyennes.

Nez: cavité (de la racine) grande; dos concave; base horizontảle; largeur grande; hauteur et saillie moyennes.

Bouche : moyenne, à coins abaissés ; ouverture intermédiaire.

Menton : large, droit, à houppe; hauteur intermédiaire.

Visage large. Iris impigmenté. 
Teint brun. Barbe et cheveux chàtain grisonnant; sourcils noirs.

Carrure grande. Santé bonne. Obésité légère, presbytie. Extérieur doux.

Son seul désir est de passer inaperçu. -- Empaillage. Obs. 11.

$7^{\circ}$ Au point de vue de la population:

224 urbains; 137 muraux.

\section{$8^{\circ}$ Au point de vue du domicile :}

201 avec domicile; 160 sans domicile.

\section{9' Au point de vue du nombre des condamnations :}

95 sans antécédents judiciaires.

Un Ardéchois, âgé de trente-six ans, marié, illettré, cultivateur, rural, bien noté, a été condamné par la cour d'assises de son département, le 13 novembre 1895, à 15 mois d'emprisonnement, pour « vol ).

Ayant découvert, dans le galetas d'une maison dont il avait la garde, une somme de 30,000 francs, en or, cachée dans deux malles, sous des vêtements et des vieux livres, il s'en était emparé et en avait employé près des deux tiers à des dépenses diverses.

Taille $1 \mathrm{~m}$. 58. Envergure $1 \mathrm{~m}$. 66. Buste 0,86: Pied gauche 0,24:5.

Tète : longueur 0,183 ; largeur 0,157 . Indice céphalique 83.79 .

Oreille droite: longueur $0,05.5$; largeur 0,034 . Indice anriculaire $6 !, 81$.

Front : arcades petites; inclinaison intermédiaire; hauteur moyenne; largeur petite.

Nez : cavité (de la racine) très petite; dos rectiligne, sinueux ; base horizontale; hanteur, largeur et saillie inoyennes. 
Bouche : moyenne, rectiligne, pincée.

Menton : Saillant, large, plat; hauteur intermédiaire.

Visage large. Iris pigmenté de jaune.

Teint clair. Barbe, cheveux et sourcils châtain clair.

Carrure moyenne. Santé bonne. Air prévenant.

Il travaille et cherche à " s'affranchir ». - Service général. - Obs. 12.

56 condamnés 1 fois; 48, 2 fois; 42, 3 fois; 31, 4 fois; 25, 5 fois; 47 , de 5 ì 10 fois; 14 , de 10 ì 20 fois; 3,20 fois et plus.

L’un d'eux est frappé, à jamais, d'interdiction de séjour ; il compte 61 condamnations, prononcées pour vols, vagabondage, mendicité, rupture de ban, faux livret, faux passeport, et (une) pour viol.

Ces 61 condamnations représentent un total de 419 mois, soit 35 ans de prison. Elles ont valu à ce vagabond, célibataire, né à Paris le 4 juillet 1825 et possédant une instruction primaire complète, le titre de doyen des condamnés.

Le tribunal de Nìmes lui a infligè, par jugement en date du 18 juin 1895, 1 an et 1 jour de prison, pour " vol ".

Il avait pénétré, le 26 mai de la même année, sous prétexte de demander la charité, dans le domicile d'un conseiller à la cour d'appel et lui avait dérobé une montre en or avec la chaîne.

La prison a cloîtré sa jeunesse; il veut y finir ses jours!

Taille $1 \mathrm{~m}$. 53. Envergure $1 \mathrm{~m}$. 5̋̈. Buste 0,784. Pied gauche 0,233. Tête : longueur 0,187 ; largeur 0,1000 . Indice céphalique 80,21 .

Oreille droite: longueur 0,062 ; largeur 0,031 . Indice auriculaire 50,00. Écartement postérieur.

Front: areades moyennes; inclinaison intermédiaire; hauteur $\mathrm{e}^{t}$ largeur petites. 
Nez : cavité (de la racine) movenne; dos rectiligne ; base horizontale ; hauteur et saillie grandes; largeur moyenne.

Bouche : moyenne, rectiligne; ouverture intermédiaire.

Menton: rond, droit; hauteur intermédiaire.

Visage ovale. Iris pigmenté d'orange.

Teint mat. Barbe, cheveux et sourcils châtains. Tatouage informe sur l'avant-bras gauche.

Carrure moyenne. Santé bonne. Athérome artériel. Physionomie de renard.

Ce tireur de pied de biche est réputé homme sage. - Quartier des vieillards. - Obs. 13.

$10^{\circ} \mathrm{Au}$ point de vue de l'oisivetè :

283 oisifs.

$11^{\circ}$ Au point de vue de l'ivrognerie :

109 adonnés à l'ivrognerie.

12. Au point de vue du libertinage et de la débauche :

125 libertins et débauchés.

13. Au point de vue du concubinage :

33 vivant en concubinage.

$14^{\circ}$ Au point de vue de la note de la commune :

9 bien notés, c'est-à-dir'e sans antécédents judiciaires et considérés comme travailleurs, sobres, etc., jusqu'au jour de la première faute. 


\section{$15^{\circ}$ Au point de vue de la taille :}

Dans la catégorie de 16 à 20 ans : taille au-dessous de $1 \mathrm{~m} .60$. 13 individus; de $1 \mathrm{~m} .60$ à $1 \mathrm{~m} .70$, 23: de $1 \mathrm{~m}$. 70 et plus, $\%$.

Soit, moyenne de la taille $1 \mathrm{~m} .62 \%$.

De 20 a 25 ans : taille au-dessous de $1 \mathrm{~m} .60,18$ individus : de $1 \mathrm{~m} .60$ à $1 \mathrm{~m}$. 70, 45 ; de $1 \mathrm{~m}$. 70 et au-dessus, 14 .

Soit, moyenne de la taille $1 \mathrm{~m} .639$.

De 25 à 30 ans : taille au-dessous de $1 \mathrm{~m} .60,22$ individus : de $1 \mathrm{~m} .60$ à $1 \mathrm{~m} .70,4 \%$; de $1 \mathrm{~m}$. 70 et au-dessus, 18 .

Soit, moyenne de la taille $1 \mathrm{~m} .639$.

De 30 à 40 ans : taille au-dessous de $1 \mathrm{~m} .60,26$ individus : de $1 \mathrm{~m} .60$ à $1 \mathrm{~m} .70,55$; de $1 \mathrm{~m} .70$ et au-dessus, 20.

Soit, moyenne de la taille $1 \mathrm{~m} .643$.

De 40 à 50 ans : taille au-dessous de $1 \mathrm{~m} .60,6$ individus: de $1 \mathrm{~m} .60$ à $1 \mathrm{~m} .70,21$; de $1 \mathrm{~m}$. $\% 0$ et au-dessus, $\%$

Soit, moyenne de la taille 1 m. 655 .

De 50 ans et plus : taille au-dessous de $1 \mathrm{~m} .60,5$ individus ; de $1 \mathrm{~m} .60$ à $1 \mathrm{~m} .70,9$; de $1 \mathrm{~m}$. 70 et au-dessus, 5 .

Soit, moyenne de la taille $1 \mathrm{~m} .643$.

En résumé: taille au-dessous de $1 \mathrm{~m} .60,90$ individus; (le $1 \mathrm{~m} .60$ à $1 \mathrm{~m} .70,200$; de $1 \mathrm{~m}$. 70 et au-dessus, 71.

Soit, moyenne de la taille $1 \mathrm{~m} .640$. 


\section{$16^{\circ}$ Au point de vue de l'envergure :}

Dans la catégorie de 16 à 20 ans : envergure inférieure à la taille, de 0 à 8 cent., 8 individus; égale à la taille, 2 ; supérieure à la taille, de 0 à 4 cent., 15 ; de 4 à 8 cent., 12 ; de 8 à 16 cent. 6 .

Soit, moyenne de l'envergure $1 \mathrm{~m} .660$.

De 20 à 25 ans : envergure inférieure à la taille, de 0 à 8 cent., 15 individus; égale à la taille, 1 ; supérieure à la taille, de 0 à 4 cent., $2 S$; de 4 à $S$ cent., 21 ; de $S$ à 16 cent., 11 . Infirme non mensuré, 1.

Soit, moyenne de l'envergure $1 \mathrm{~m} .671$.

De 25 à 30 ans : envergure inférieure à la taille, de 0 à 8 cent., 7 individus; égale à la taille, 3 ; supérieure à la taille, de 0 à 4 cent., 24 ; de 4 à 8 cent., 35 ; de 8 à 16 cent., 18 .

Soit, moyenne de l'envergure $1 \mathrm{~m} .686$.

De 30 à 40 ans : envergure inférieure à la taille, de 0 à 8 cent., 10 individus; égale à la taille, 2 ; supérieure à la taille, de 0 à 4 cent., 29 ; de 4 à 8 cent., 40 ; de 8 à 16 cent., 20 .

Soit, moyenne de l'envergure $1 \mathrm{~m} .689$.

De 40 à 50 ans : envergure inférieure à la taille, de 0 à 8 cent., 2 individus; égale à la taille, 2 ; supérieure à la taille, de 0 à 4 cent., 4 ; de 4 à 8 cent., 18 ; de 8 à 16 cent., 8 .

Soit, moyenne de l'envergure $1 \mathrm{~m} .708$.

De 50 ans et au-dessus : envergure inférieure à la taille, de 0 à 8 cent., 1 individu; égale à la taille, 2 ; supérieure à la taille, de 0 à 4 cent., $\%$; de 4 à 8 cent., 4 ; de 8 à 16 cent., 5 .

Soit, moyenne de l'envergure $1 \mathrm{~m} .684$. 
En résumé : envergure inférieure à la taille, de 0 à 8 cent., 43 individus; égale à la taille, 12 ; supẹ́rieure à la taille, de 0 à 4 cent., 107 ; de 4 à $S$ cent., 130 ; de 8 à 16 cent., 68. Infirme non mensuré, 1.

Soit, moyenne de l'envergure $1 \mathrm{~m} .682$.

\section{Au point de vue du buste :}

Dans la catégorie de 16 à 20 ans : buste supérieur à la moitié de la taille, de 0 à 5 cent., 6 individus; de 5 à 10 cent., 34 ; de 10 à 18 cent., 3 .

Soit, moyenne du buste 0,881 .

De 20 à 25 ans: buste supérieur à la moitié de la taille, de 0 à 5 cent., 21 individus; de 5 à 10 cent., 51 ; de 10 à 18 cent., 5 .

Soit, moyenne du buste 0,882.

De 25 à 30 ans : buste inférieur à la moitié de la taille, 1 individu; supérieur à la moitié de la taille, de 0 à 5 cent., 24 ; de 5 à 10 cent. , 57; de 10 à 18 cent., 5 .

Soit, moyenne du buste 0,879 .

De 30 à 40 ans : buste inférieur à la moitié de la taille, 1 individu ; supérieur à la moitié de la taille, de 0 à 5 cent., 25 ; de 5 à 10 cent,, 70 ; de 10 à 18 cent., 5 .

Soit, moyenne du buste 0,883 .

De 40 à 50 ans : buste supérieur à la moitié de la taille, de 0 à 5 cent., 9 individus; de 5 à 10 cent., 25 .

Soit, moyenne du buste 0,888 .

De 50 ans et au-dessus: buste égal à la moitié de la taille, 1 individu; supérieur à la moitié de la taille, de 0 à 5 cent., 8 ; de 5 à 10 cent., 9 ; de 10 à 18 cent., 1 .

Soit, moyenne du buste 0,871 . 
En résumé : buste inférieur à la moitié de la taille, 2 individus; égal à la moitié de la taille, 1 ; supérieur à la moitié de la taille, de 0 à 5 cent., 93 ; de 5 à 10 cent., 246 ; de 10 à 18 cent., 19.

Soit, moyenne du buste 0,881 .

\section{$18^{\circ}$ Au point de vue du pied :}

Dans la catégorie de 16 à 20 ans: pied de 22 à 24 cent., 3 individus; de 24 à 26 cent., 25 ; de 26 à 28 cent., 13 ; de 28 à 30 cent., 2 .

Soit, moyenne du pied 0,256.

De $20 \dot{a} 25$ ans : pied de 22 à 24 cent., 5 individus; de 24 à 26 cent., 51 ; de 26 à 28 cent., 20 ; de 28 à 30 cent., 1 .

Soit, moyenne du pied 0,254.

De 25 à 30 ans : pied de 22 à 24 cent., 12 individus; de 24 à 26 cent., 42 ; de 26 à 28 cent., 31 ; de 28 à 30 cent., 2 .

Soit, moyenne du pied, 0,254.

De 30 à 40 ans : pied de 22 à 24 cent., 6 individus; de 24 à 26 cent., 48 ; de 26 à 28 cent., 45 ; de 28 à 30 cent., 2.

Soit, moyenne du pied 0,25\%.

De 40 à 50 ans : pied de 22 à 24 cent., 3 individus; de 24 à 26 cent., 15 ; de 26 à 28 cent., 16.

Soit, moyenne du pied 0,259.

De 50 ans et au-dessus : pied de 22 à 24 cent., 1 individu ; de 24 à 26 cent., 8 ; de 26 à 28 cent., 10.

Soit, moyenne du pied $0,25 \%$.

En résumé : pied de 22 à 24 cent., 30 individus ; de 24 à 26 cent., 189; de 26 à 28 cent., 135 ; de 28 à 30 cent., 7.

Soit, moyenne du pied 0,256. 
$19^{\circ}$ Au point de vue de la tête :

10 dolichocéphales vrais ; 32 sous-dolichocéphales; 63 mésaticéphales; 97 sous-brachycéphales; 159 brachycéphales vrais.

D'autre part, les calculs donnent :

Longueur moyenne de la tête 0,1876 ; largeur moyenne de la tête 0,1552 .

D'où : Indice céphalique 82,72.

\section{$20^{\circ}$ Au point de vue de l'oreille :}

Indice auriculaire: au-dessous de 52, 32 individus; de 52 à 56 .

112; de 56 à 60, 124 ; de 60 à 65,83 : de 65 et au-dessus, 10 .

D'autre part, les calculs donnent :

Longueur moyenne de l'oreille 0,0620; largeur moyenne de l'oreille 0,0353 .

D'où : Indice auriculaire 56,93.

$$
\text { *** }
$$

21. Au point de vue du visage :

En tronc de pyramide 4, en losange 24, rond 33, large ou carré 50, ovale 237, allongé 11 , en toupie 2. 
$22^{\circ} \mathrm{Au}$ point de vue du front:

Arcades : grandes 70, petites 36 , moyennes 255.

Inclinaison : verticale 54, fuyante 74, intermédiaire 233.

Hauteur : grande 40, petite 34 , moyenne 287.

Largeur : grande 23, petite 64, moyenne 274 .

$23^{\circ}$ Au point de vue du nez:

Cavité (dela racine) : grande 29, petite 84, moyenne 248.

Dos : rectiligne 217 , concave 75 , convexe 69 .

Base : horizontale 21\%, relevée 120, abaissée 24 .

Hauteur : grande 40, petite 35, movenne 286 .

Scillie : grande 42 , petite 25 , moyenne 294.

Largeur : grande 46, petite 11, moyenne 304 .

\section{$24^{\circ}$ Au point de vue de la bouche :}

Dimension : grande 38 , petite 47 , moyenne 276 .

Inclinaison des angles : rectiligne 246, à coins abaissés 53, à coins relevés 62 .

Degré habituel d'ouverture: bẻe 49, pincée 43, intermédiaire 269.

\section{$25^{\circ}$ Au point de vue du menton :}

Inclinaison générale : menton saillant 61, fuyant 53, droit 247.

Avec et sans houppe: plat ou sans houppe 61, a houppe 55, intermédiaire 245 .

Hauteur : haut 59, bas 106. intermédiaire 196.

For'me : large 64 , rond 267 , pointu 30 . 
$26^{\circ}$ Au point de vue de l'œil :

Iris : impigmenté 34, pigmenté de jaune 72, pigmenté d'orange 163, pigmenté de châtain 66, pigmenté de marron 25 , aveugle 1.

27. Au point de vue du teint :

Brun 247, mat 7, basané 1, mulâtre 1, clair 92, blond 13.

$$
\text { *** }
$$

28 Au point de vue de la carrure :

Grande 66, moyenne 275, petite 20.

29. Au point de vue de la constitution et de l'état général à l'arrivée :

Très bons 32, bons 217, passables 66, mauvais 40, très mauvais 6 .

$30^{\circ} \mathrm{Au}$ point de vue des maladies et infirmités à l'arrivée :

147 maladies et infirmités, à répartir entre 115 individus (82 Français, dont 13 Corses; 16 Italiens, 3 Espagnols, 3 Arabes, 11 divers). Soit :

Bronchite bacillaire 17, insuffisance valvulaire 13, hypertrophie du cœur 2, dégénérescence graisseuse 2 , adhérences 
péricardiques 1, artérite chronique avec dégénérescence athée romateuse prononcée 11 , accidents syphilitiques 4 , uréthritaiguë 4, scrofule 4 , déviation de la colonne vertébrale 4 , boiteux 1, manchot 1, estropié (pied) 1, tumeur blanche (genou) 1 , hernie inguinale droite 8 , gauche 10 , double 2 , pointe de hernie 1, hernie ombilicale 1 , éventrement 1 , obésité 2 , goître 1 , varices 5 , varicocèle 1 , bec-de-lièvre 1 , aveugle 1 , borgnes 4 , cataracte 1 , astigmatisme 1 , strabisme 6 , myopie 4 , presbytie 13 , faiblesse de la vue 2 , surdité légère 3 , surdité prononcée 2 , épilepsie 3 , déséquilibration mentale 1 , bégaiement 2, gynécomastie 5 .

Un épileptique (Provençal, âgé de vingt et un ans, cẻlibataire, sachant lire, écrire et calculer, maçon, urbain, ayant un domicile, à la $6^{\mathrm{e}}$ peine, adonné à l'ivrognerie) a été condamné à 2 ans de prison, par la cour d'appel d'Aix, pour " vols ". Antécédents héréditaires : père absinthique; grand'mère paternelle ainsi que deux sœurs de son père épileptiques.

Première attaque, à huit ans, à la suite d'une émotion.

Taille $1 \mathrm{~m} .675$. Envergure $1 \mathrm{~m}$. 71. Buste 0,895. Pied gauche 0,266. Tète : longueur 0,183 ; largeur 0,147 . Indice céphalique 79,4.5.

Oreille droite: longueur 0,066 ; largeur 0,038 . Indice auriculaire 57,57 .

Front : arcades moyennes; inclinaison fuyante; hauteur et largeur moyennes.

$\mathrm{Nez}$ : cavité (de la racine) moyenne; dos convexe; base horizoutale; hauteur; largeur et saillie moyennes.

Bouche : petite, rectiligne; ouverture intermédiaire.

Menton : droit, rond, à fossette; hauteur intermédiaire.

Visage ovale. Iris pigmenté de marrou.

Teint brun. Barbe, cheveux et sourcils châtain foncé (sourcils réunis). Tatoué.

Carrure moyenne. Santé délabrée. Stralisme. Mine niaise.

Il a de mauvaises mour's; c'est le questeur du Sénat (prévôt des vieillards). - Obs. 14. 
Le déséquilibré (Italien, âgé de trente-trois ans, célibataire, illettré, cultivateur, à la $3^{\mathrm{e}}$ peine, rural, ayant un domicile, adonné à l'ivrognerie) subit la peine de 1 an et 1 jour, prononcée par le tribunal de Marseille, pour " tentative de vol et infraction à un arrêté d'expulsion »).

Des araignées tissent constamment devant ses yeux et il craint qu'on n'assassine son " grand " frère. Derrière la toile, il voit un poignard : "Té ! vé-le. Oụais ! "

Taille $1 \mathrm{~m}$. 49. Envergure $1 \mathrm{~m}$. 52. Buste 0,812. Pied gauche 0,230. Tète : longueur 0,184 ; largeur 0,153 . Indice céphalique 83,15 .

Oreille droite : longueur 0,029 ; largeur 0,036 . lndice auriculaire 61,01 . Front : arcades moyennes; inclinaison intermédiaire; hauteur et largeur petites.

Nez : cavité (de la racine) moyenne; dos concave, sinueux ; base horizontale ; hauteur, largeur et saillie moyennes.

Bouche : moyenne, à coins relevés; ouverture intermédiaire.

Menton : droit, rond, à houppe ; hauteur intermédiaire.

Visage ovale. Iris pigmenté de châtain. Des yeux éteints.

Teint brun. Barbe, cheveux et sourcils châtain moyen (sourcils réunis).

Carrure moyenne. Santé faible.

Monomane (point dangereux) en villégiature au Sénat: quartier des vieillards. - A expulser. - Obs. 15.

Parmi les gynécomastes se trouve un Arabe, âgé de 22 ans, célibataire, illettré, garçon de café, urbain, sans domicile, à la $3^{\mathrm{e}}$ peine, se livrant au libertinage et à la débauche, condamné, par la cour d'appel d'Aix, à 2 ans de prison, pour " vol ).

Il a les seins d'une fillette. Le mamelon et l'aréole ont une teinte rosée. A la palpation, on sent une sorte de tissu rénitent. La peau est fine.

Taille $1 \mathrm{~m} .71$. Envergure $1 \mathrm{~m}$. 73. Buste 0,922. Pied gauche 0,252. Tète : longueur 0,180 ; largeur 0,141 . Indice céphalique 78,33. 
Oreille droite : longueur 0,061 ; largeur 0,034 . Indice auricuIaire $3 \ddot{3}, 73$.

Front : arcades moyennes; inclinaison verticale; hauteur et largeur moyennes.

Nez : cavité (de la racine) moyenne ; dos convexe ; base horizontale; hauteur, largeur et saillie moyennes.

Bouche : moyenne, rectiligne, bée.

Menton : droit, rond, bas.

Visage ovale. Iris pigmenté d'orange. Regard langoureux.

Teint mat. Cheveux et sourcils chàtain moyen. Imberbe. Tatoue.

Carrure grande. Des hanches de femme. Organes génitaux bien conformés. Santé parfaite.

C'est un galoubé, très maniẻré et beau garcon. Il fait sa tâche en dormant et s'en acquitte tout de travers. - Sprerterie. - Obs. 16.

$$
\text { 米 }{ }^{*}
$$

31. Au point de vue du lieu du crime :

Lieu de naissance : 68 individus, dont 4 urbains sans domicile. Département du lieu de naissance : 59 individus, dont 21 sans domicile (14 urbains et 7 ruraux).

Autre département : 234 individus, dont 135 sans domicile ( 88 urbains et 47 ruraux).

\section{Au point de vue de la date du crime :}

37 en janvier, 38 en février, 17 en mars, 35 en avril, 33 en mai, 27 en juin, 22 en juillet, 22 en août, 31 en septembre, 34 en octobre, 20 en novembre, 28 en décembre, 17 pendant l'année. 
Soit: Hiver (décembre, janvier, février). . . 103 Printemps (mars, avril, mai). . . . 85 Été (juin, juillet, août) . . . . . . . 71 A utomne(septembre, octobre, novembre) 85 Pendant l'année. . . . . . . . 17

361

$$
\text { *** }
$$

\section{$33^{\circ}$ Au point de vue de la juridiction :}

Condamnés par tribunaux correctionnels. . . . . 301

$\begin{array}{llll}\text { - } & \text { cours d'assises . . . . . . . . . . . . } & 57 \\ \text { - } & \text { conseil de guerre . . . . . . . . } & 2 \\ \text { — } & \text { tribunal supérieur de Monaco . . } & 1\end{array}$

Les 2 individus condamnés, le 25 février 1896, par le conseil de guerre permanent de la $15^{\mathrm{e}}$ région de corps d'armée, sont d'origine italienne.

Reconnus coupables de complicité (par aide et assistance) de vol de 30 kilos de café, commis, par un soldat, au préjudice des ordinaires du $23^{\text {e }}$ bataillon de chasseurs à pied, ils ont à subir : l'un, 4 ans d'emprisonnement; l'autre, 5 ans. Tous les deux sont maçons, mariés et âgés d'une trentaine d'années ; ils savent lire et écrire et appartiennent à la population rurale. On leur connaît un domicile. Le plus jeune en est à la seconde peine. L'expulsion les attend.

Nous relevons chez le premier :

Taille $1 \mathrm{~m}$. 60. Envergure $1 \mathrm{~m}$. 64. Buste 0,87: Pied gauche 0,242. Tète : longueur 0,173 ; largeur 0,160 . Indice céphalique 92,48 . Oreille droite: longueur 0,061 ; largeur 0,033. Indice auriculaire 54,09. Front : arcades moyennes; inclinaison intermédiaire ; largeur grande; hauteur moyenne.

Nez : cavité (de la racine) moyenne; dos rectiligne; base horizontale; largeur grande; saillie et hauteur moyennes, 
Bouche : grande, rectiligne ; ouverture intermédiaire; lèvres épaisses. Menton : bas, droit, rond.

Visage ovale. Iris pigmenté de châtain. Figure de cafard.

Teint brun. Barbe, cheveux et sourcils châtain foncé. Tatoué.

Carrure moyenne. Santé bonne. Paresse et inconduite.

C'est une soupière (Monsieur, par devant; Madame, par derrière). - Empaillage. - Obs.17.

On note chez le second :

Taille $1 \mathrm{~m} .63$. Envergure $1 \mathrm{~m}$. 64. Buste 0,872. Pied gauche 0,247.

Tête : longueur 0,192 ; largeur 0,161 . Indice céphalique 83,83 .

Oreille droite : longueur 0,062 ; largeur 0,03 . Indice auriculaire $56,4.5$.

Écartement total.

Front : arcades grandes; inclinaison intermédiaire ; hauteur et largeur moyennes.

$\mathrm{Nez}$ : cavité (de la racine) moyenne; dos concave ; base horizontale; largeur grande; hauteur et saillie movennes.

Bouche: moyenne, à coins relevés; ouverture intermédiaire.

Menton: droit, rond, bas, à fossette.

Visage ovale. Iris pigmenté d'orange, truité.

Teint brun. Barbe, cheveux et sourcils chàtain grisonnant. Carrure grande. Santé bonne. Mine réjouie.

Gynécomaste; velu comme un ours. Excellent détenu. Ébénisterie. - Obs. 18.

Quant au malandrin, condamné à 18 mois de prison, par jugegement du tribunal supérieur de Monaco (1), en date du

(1) La Principauté de Monaco n'a pas de prison. Son tribunal ressortit à la cour d'appel de Paris et les peines prononceies sont subies en France.

Aux termes de l'article 21 de la convention conclue, le 9 novembre 186.3, entre la France el la Principauté, les frais de transfirenent, d'entretien et de rapatriement des détenus sont supportés par le gouvernement de Monaco.

Un élat nominatif des individus condanıés par le tribunal monégasque est dressé à la fin de chaque année et fait connaitre le nombre des journées de présence et le montant des frais de détention d'ajrès le prix payí à l'entreprise ou le coùt des services en régie, suivant le cas. 
4 avril 1895, c'est un Français, âgé de trente-sept ans, divorcé, sachant lire et écrire, garçon de café, urbain, ayant un domicile et comptant à son actif 10 condamnations, dont plusieurs pour tenue de jeux de hasard.

Il charmait les loisirs de sa vie oisive, soit par le « vol à la tire " dans les salons du casino de Monte-Carlo, soit par le libertinage et la débauche.

Taille $1 \mathrm{~m}$. 66. Envergure $\mid \mathrm{m}$. 73. Buste 0,890. Pied gauche 0,20̈7. Tète: longueur 0,189 ; largeur $0,15 \%$. Indice céphalique 82,01 .

Oreille droite: longueur $0,05 \%$; largeur 0,033 . Indice auriculaire 60,00 . Écartement total.

Front: arcades grandes; inclinaison intermédiaire; hauteur et largeur movennes.

Nez: cavité (de la racine) moyenne; dos convexe; base horizontale; largeur grande; hauteur et saillie moyennes.

Bouche: grande, rectiligne; ouverture intermédiaire.

Menton: droit, rond, bas.

Visage ovale. Iris pigmenté de marron.

Teint brun. Barbe, cheveux et sourcils chàtain foncé; sourcils écartés.

Carrure moyenne. Santé bonne. Physionomie douce.

C'est un ennuyeux qui tranche du personnage et que la fainéantise tient. - Filoches. - Obs. 19.

$34^{\circ} \mathrm{Au}$ point de vue de la durèe de la peine:

37 condamnés d̀ 1 an et 1 jour ; 55, à 13 mois ; 50, de 15 à 18 mois; 14 , de 18 mois à 2 ans; 80 , de $2 \dot{a} 3$ ans; 49 , de $3 \dot{a} 4$ ans; 23, de 4 à 5 ans; 42 , ̀̀ 5 ans; 9 , de $5 \dot{a}$ 10 ans; 2 , à 10 ans.

Les deux derniers (repris de justice dangereux) sont frappés de dix ans d'interdiction de séjour.

L'un (célibataire, journalier, rural, ayant un domicile, à la 7o peine, adonné à l'ivrognerie) est âgé de trente-quatre 
ans. Il sait lire et écrire et a été condamné, le 5 juillet 1895 , par le tribunal de Corté, jugeant en police correctionnelle, pour " vols, violences volontaires et menaces verbales de mort avec ordre et sous condition "), commis en 1894 .

Le 14 avril, il pénétra dans une maison de campagne et $\mathrm{y}$ déroba un costume en velours marron et un fusil à deux coups, légèrement détérioré, qu'un de ses compatriotes fut forcé d'accepter en échange du sien en meilleur état.

Avec ce fusil, il mit en joue une personne qui se rendait à la justice de paix de Vezzani déposer dans l'instance instruite contre un de ses amis.

Après l'avoir menacée de mort, si elle continuait son chemin, il obligea cette personne à rester avec lui pendant plusieurs heures et la reconduisit à son domicile, tenant les canons de son fusil armé dirigés sur son dos.

Taille $1 \mathrm{~m}$. 560. Envergure $1 \mathrm{~m} .560$. Buste 0,853 . Pied gauche $0,244$. Tète : longueur 0,182 ; largeur $0,1: 50$. Indice céphalique 82,41 .

Oreille droite : longueur 0,039 ; largeur 0,034 . Indice auriculaire 57,62 . Front : arcades moyennnes; inclinaison intermédiaire; largeur petite; hauteur moyenne.

Nez : cavité (de la racine) grande; dos rectiligne; base relevée; saillie petite; hauteur et largeur moyennes.

Bouche: petite, rectiligne, pincée.

Yenton: fuyant, rond; hauteur intermédiaire.

Visage ovale, rébarbatif. Iris pigmenté d'orange.

Teint brun. Barbe, cheveux et sourcils chàtain clair.

Carrure moyenne. Constitution et état général mauvais. Scrofules.

Amère pégre; presque toujours en cellule. - Pipes. Obs. 20.

L'autre (célibataire, scieur de long, rural, ayant un domicile) est âgé de trente-huit ans. Il sait lire, écrire et calculer et vivait en concubinage, dans son pays natal, avec une "fille ", 
condamnée, en 1886, à 12 années de travaux forcés, pour assassinat. Sa réputation est détestable.

On lui compte cinq condamnations antérieures.

Le tribunal de Sartène, par jugement, en date du 30 mars 1887. confirmé par arrêt de la cour d'appel de Bastia, le 4 mai de la même année, l'a envoyé dans l'établissement de Nîmes, pour " vols ).

Dans la nuit du 13 au 14 septembre 1886, il s'introduisit, à l'aide d'escalade et d'effraction, dans la chambre d'une débitante dont il savait le mari absent. S'étant emparé des clefs du magasin et du comptoir, il déroba une somme de 110 à 120 francs en numéraire.

Désigné par la rumeur publique comme étant l'auteur de ce vol et d'une foule d'autres restés impunis, il gagna le maquis.

La capture de ce malfaiteur ne s'est pas opérée sans danger pour les agents de la force publique.

Taille $1 \mathrm{~m} .612$. Envergure $1 \mathrm{~m}$. 640. Buste 0,837 . Pied gauche 0,236 . Tète : longueur 0,179 ; largeur 0,149 . Indice céphalique 83,24 .

Oreille droite : longueur 0,039 ; largeur 0,034 . Indice auriculaire 57,62 .

Front: arcades moyennes; inclinaison fuyante; hauteur et largeur petites

Nez : cavité (de la racine) grande; dos rectiligne ; base abaissée ; largeur, hauteur et saillie moyennes.

Bouche : moyenne, rectiligne ; ouverture intermédiaire.

Menton: droit, rond, bas, plat.

Visage ovale. Iris pigmenté d'orange.

Teint brun. Barbe, cheveux et sourcils châtains. Tatoné.

Carrure movenne. Santé chancelante. Surdité légère. Méchante mine.

C'est un gonze à la redresse (débrouillard) et un chicn hargneux. - Filoches. - Obs. 21. 
$35^{\circ}$ Au point de vue de l'interdiction de sẻjour :

47 individus, dont 11 frappés de cette mesure de rigueur par une condamnation antérieure.

$$
\text { *** }
$$

36 Au point de vue du travail en prison :

Bons ouvrier's 207, passables 91, maucais 63 .

37. Au point de vue de la conduite en prison :

Bonne 152, passable 116, mauvaise 93.

$$
\text { *** } *
$$

$38^{\circ}$ Au point de vue de l'expulsion :

97 étrangers sur 116. 
VOL QUALIFIÉ - COMPligitÉ - TENTATIVE - RECEI.

138 individus

$1^{\circ}$ Au point de vue de la naissance :

133 enfants légitimes, 5 enfants naturels.

On rencontre, parmi les enfants naturels, un Marseillais. âgé de vingtetunans, célibataire, sachant lire et écrire, ouvrier boulanger, sans domicile fixe, vivant de vol et d'expédients, adonné à l'ivrognerie, 4 fois condamné.

Il subit la peine de 3 ans d'emprisonnement, prononcée, le 16 février 1895, par la cour d'assises du Gard, pour avoir pris part, dans la nuit du 5 au 6 octobre 1894, avec une bande de malfaiteurs, à la mise à sac d'un magasin de bijouterie, situé à Nîmes, boulevard Victor-Hugo.

Taille $1 \mathrm{~m}$. 320̈. Envergure $1 \mathrm{~m}$. 590. Buste 0,80 . Pied gauche 0,244 . Tète : longueur 0,184 ; largeur 0,152 . Indice céphalique 82,60 .

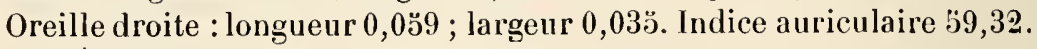
Écartement total.

Front : arcades moyennes; inclinaison intermédiaire; hauteur et largeur moyennes.

Nez : cavité (de la racine) moyenne ; dos concave; base relevée; hauteur, saillie et largeur moyennes.

Bouche : moyenne, rectiligne; ouverture intermédiaire.

Menton: droit, large; hauteur intermédiaire.

Visage ovale. Iris pigmenté de chàtain. Figure sombre. 
Teint brun. Barbe, chevemx et sourcils chàtains (sourcils réunis). Tatoué.

Carrure moyenne. Constitution et état général bons.

Il s'est habitué au durillon (travail) et sa conduite n'est point mauvaise. - Cordonnerie. - Obs. 22.

\section{$2^{\circ}$ Au point de vue de la nationalité :}

\section{Franç̧ais (dont 4 Corses), 27 Étrangers (18 Italiens, 5 Espagnols, 1 Arabe, 3 divers).}

L'Arabe, natif de Bel-Abbès, âgé de vingt-neuf ans, célibataire, illettré, portefaix, à la $3^{\mathrm{e}}$ peine, vivant en concubinage, a été condamné par la cour d'assises de la Corse, le 23 novembre 1895, à 5 ans de prison et à 5 ans d'interdiction de séjour, pour " vol qualifié »).

Il s'était introduit, pendant la nuit du 9 au 10 juillet, à l'aide d'escalade et d'effraction, dans une maison de campagne et $\mathrm{y}$ avait soustrait de nombreux objets mobiliers.

Taille $1 \mathrm{~m}$. 66. Envergure $1 \mathrm{~m}$. 68. Buste 0,882. Pied gauche 0,20̈4.

Tète : longueur 0,194 ; largeur 0,147 . Indice céphalique 75,77.

Oreille droite : longueur 0,067 ; largeur 0,040 . Indice auriculaire 59,70 . Écartement inférieur.

Front: arcades moyennes ; inclinaison intermédiaire; largeur grande; hauteur moyenne.

Nez : cavité (de la racine) petite; dos rectiligne; base horizontale; largeur grande ; hauteur et saillie moyennes.

Bouche: moyenne, rectiligne; ouverture intermédiaire ; lèvres épaisses.

Nenton : fuyant, rond ; hauteur intermédiaire.

Visage ovale (pommettes saillantes). Iris pigmenté de marron.

Teint brun. Barbe, cheveux et sourcils noirs. Tatoué.

Carrure moyenne. Constitution robuste. Bonne physionomie.

Il travaille et se conduit assez convenablement. - Pipes. Obs. 23. 
L'un d'entre eux, né en 1874 et domicilié à Clermont-Ferrand, possède une instruction primaire complète. C'est un ouvrier serrurier, libertin débauché, 2 fois condamné pour vol, " chef » déclaré d'une bande de mauvais sujets de son âge.

La cour d’assises du Puy-de-Dôme lui a appliqué, le 11 février 1892, 5 ans de prison, pour ( 11 vols qualifiés ).

Muni de fausses clefs, il pénétrait dans les appartements, pendant que les maîtres étaient absents, et faisait main basse sur l'argent, les comestibles et les objets mobiliers de toute sorte qui se trouvaient à sa portée, forçant au besoin les meubles et les coffres-forts.

Taille $1 \mathrm{~m}$. 602. Envergure $1 \mathrm{~m}$. $61 \%$. Buste 0,8\%. Pied gauche 0,24\%. Tète : longueur 0,189 ; largeur 0,153 . Indice céphalique $80,9 \ddot{\text { o }}$.

Oreille droite : longueur 0,054 ; largeur 0,033 . Indice auriculaire 61,11 . Front : arcades moyennes ; inclinaison intermédiaire; hauteur et largeur movennes.

Nez : cavité (de la racine) moyenne ; dos rectiligne ; base horizontale; hauteur, saillie et largeur moyennes.

Bouche : en cœur (petite, à coins relevés; lèvre supérieure retroussée). Menton : saillant, rond, haut, à houppe.

Visage ovale. Iris pigmenté de jaune.

Teint mat. Barbe, cheveux et sourcils chàtain clair. Tatoué d'un point sur le poignet.

Carrure petite. Santé bonne. Air doux et riant.

Sa conduite a souvent fait endiabler les gaffes. Actuellement, on est content de lui. - Service de l'infirmerie. - Obs. 24.

36 de $20 \dot{a} 25$ ans, 33 de $25 \dot{a} 30$ ans, 28 de $30 \dot{a} 40$ ans, 6 de 40 à 50 ans, 4 de 50 ans au moins.

Citons un malfaiteur audacieux, enfant de la Loire, âgé de 
vingt-huit ans. célibataire, sachant lire et écrire, journalier, urbain, demeurant à Marseille, débauché, à la $4^{\mathrm{e}}$ peine.

Par arrêt du 25 juillet 1895, la cour d'assises du Várlui a infligé 4 ans de prison et 10 ans d'interdiction de séjour, pour (" vol qualifié ).

En décembre 1894, aidé de plusieurs camarades, il avait réussi à soustraire 4,000 francs à un habitant de la Cadière.

La victime fut ( saisie en plein jour, bàillonnée, traînée dans sa demeure et menacée de mort si elle n'indiquait pas l'endroit où se trouvait son argent $)$.

Taille $1 \mathrm{~m}$. 70. Envergure $1 \mathrm{~m}$. 77. Buste 0,880. Pied gauche 0,263̈.

Tète : longueur 0,173 ; largeur 0,134 . Indice céphalique 89,01 .

Oreille droite : longueur 0,067 ; largeur 0,037 . Indice auriculaire 55 , 22 .

Front: arcades moyennes; inclinaison intermédiaire; hauteur et largeur moyennes.

Nez : cavité (de la racine) moyenne; dos rectiligne ; base horizontale; hauteur, largeur et saillie moyennes.

Bouche : moyenne, à coins abaissés ; ouverture intermédiaire.

Menton : droit, large, à fossette ; hauteur intermédiaire.

Visage ovale. Iris pigmenté de jaune.

Teint clair. Barbe, cheveux et sourcils chàtains. Tatoué.

Carrure moyenne. Constitution et état général bons. Figure courante.

Excellent détenu. - Pantoufles. - Obs. 25.

\section{$4^{\circ}$ Au point de vue de l'état civil :}

114 célibataires.

$\mathrm{Au}$ nombre desquels figure H..., l'ex-amant de cœur de la belle Paulette et l'ancien compagnon de débauche du faux marquis d'Alba, escroc italien qui ne frayait qu'avec la Haute et qui fut son maître jusqu'au jour où une discussion dans une salle de jeu, à propos de femme, les brouilla.

Cet individu (né dans les Alpes-Maritimes, âgé de 28 ans, possédant une instruction primaire complète, urbain, sans 
profession, sans domicile. sans moyens d'existence, à la $5^{\text {e }}$ peine) a été reconnu pour l'indicateur de nombreux vols qualifiés, commis, à Nice, dans la première quinzaine du mois de février 1895 .

Toutefois, comme il n'avait pas pris part à tous les crimes relevés par l'accusation, la cour d'assises des Alpes-Maritimes ne l'a condamné (19 juillet 1895) qu'à 4 ans d'emprisonnement, malgré les renseignements recueillis sur son compte qui le signalent comme dangereux.

Il a étudiè l'anatomie et écrit techniquement et très orthographiquement toutes les expressions médicales. Il sait rédiger un rapport, faire les opérations chirurgicales simples, soigner un malade et panser un blessé.

Quoique n'étant pas chirurgien dentiste, il a quelques notions pour arracher les dents. Et si, parmi les membres de l'administration, il en est qui « enflent ) des cors aux pieds, il se fait fort de guérir infailliblement et radicalement les cors les plus vieux et les mieux enracinés. (Extrait d'une lettre où il brigue la place d'infirmier-panseur.)

Taille $1 \mathrm{~m}$. 71. Envergure $1 \mathrm{~m}$. 72. Buste 0,930. Pied gauche 0,249.

Tète : longueur 0,203 ; largeur 0,158 . Indice céphalique 77,83 .

Oreille droite : longueur 0,063 ; largeur 0,038 . Indice auriculaire 60,31 . Front : arcades moyennes; inclinaison fuyante; hauteur et largeur moyennes.

Nez : cavité (de la racine) moyenne; dos rectiligne; base horizontale; hauteur et saillie grandes; largeur moyenne.

Bouche : moyenne, à coins relevés, bée.

Neuton : saillant, rond; hauteur intermédiaire.

Visage ovale. Iris pigmenté de jaune. Une fausse douceur.

Teint clair. Barbe et cheveux châtain clair. Sourcils châtain foncé, réunis.

Carrure moyenne. Faible santé. Épilepsie.

Cet homme-là est un batteur (habitué de la visite médicale) et une truffe non clessalée (imbécile). Quand il est ennuyé de faire des espadrilles, il joue la comédie du suicide. Obs. 26. 
23 mariés.

On distingue un Marseillais, àgé de trente-trois ans, sachant lire, écrire et calculer, maçon, soupçonné d'avoir aidé à provoquer l'arrestation du capitaine Romani et signalé comme " anarchiste militant et dangereux ".

Jusqu'à douze ans, il fut envoyé à l'école. A partir de cet áge, il dut apprendre un métier. Son père, qui était un excellent ouvrier plâtrier, le prit comme aide.

Tous ses loisirs, il les consacrait à la lecture des ouvrages de Proudhon, Benoît Malon, Karl Marx, etc. Mais son esprit, sans pondération ni mesure, mal préparé d'ailleurs au choc des idées, ne s'ouvrit volontiers qu'à la violence et au paradoxe.

Il prêcha la grève générale dans les assemblées publiques et se livra à la fabrication clandestine (il fait de la chimie le point de départ d'une organisation nouvelle).

Ce qui a le plus contribué à lui rendre la société odieuse, ce sont les mauvais traitements qu'il endura aux compagnies de discipline.

Durant 44 mois, la crapaudine, le silo, la cellule furent son partage. "Que de larmes versées! Que de nuits d'insomnie ! On dit que la réflexion assagit. Allons donc! elle rend méchant. ")

Sans compter que la faim, cette mauvaise conseillère, s'est dressée continuellement devant lui et l'a obligé à faire de ses idées subversives un commerce, une condition d'existence.

Cet homme, ancien président de plusieurs corporations, ancien candidat révolutionnaire aux élections municipales, deux fois incarcéré (pendant quinze jours) : la première, pour escroquerie; la deuxième, pour violences à un agent dans une réunion publique, a été condamné, par la cour d'assises des Bouches-du-Rhône, malgré ses dénégations, le 13 février 1895, à 5 ans d'emprisonnement et à 5 ans d'interdiction de séjour, pour " vols qualifiès ). 
Il s'était introduit, pendant la nuit du 17 au 18 novembre 1894, dans le magasin de deux négociants en huiles, à Marseille, et s'était emparé d'une panoplie d'armes anciennes ou historiques d'une valeur de 4,500 francs.

Taille $1 \mathrm{~m}$. 58. Envergure $1 \mathrm{~m}$. 64. Buste 0,884. Pied gauche 0,2588.

Tête : longueur 0,188 ; largeur 0,160 . Indice céphalique 83,10 .

Oreille droite : longueur 0,061 ; largeur 0,036 . Indice auriculaire 59,01 .

Écartement postérieur.

Front : areades moyennes; inclinaison fuyante; hauteur et largeur moyennes.

Nez : cavité (de la racine) mnoyenne; dos rectiligne; base horizontale; Saillie et hauteur moyennes; largeur grande.

Bouche : moyenne, rectiligne; ouverture intermédiaire.

Menton : large, bas, droit.

Visage ovale. Iris pigmenté de marron. OEil grand et vif.

Teint mat. Barbe, cheveux et sourcils chàtain foncé. Tatoné. Carrure moyenne.

Solide et bon ouvrier, dont la physionomie expressive n'a pourtant rien d'un méchant homme. Nerveux et sanguin. Empaillage. - Obs. 2\%.

Le $138^{\mathrm{e}}$ (Ardéchois, âgé de quarante-deux ans, illettré, manœuvre, urbain, ayant un domicile, à la 2 condamnation, très mal noté dans sa commune) est veuf.

Il fait 2 ans de prison (arrêt de la cour d'assises de son département, en date du 5 aout 1895) pour avoir, dans le courant de l'année 1895 , soit comme auteur, soit comme co-auteur ou complice, soustrait frauduleusement divers effets, une horloge, des ustensiles de ménage, des outils et des bijoux, au préjudice de deux personnes différentes.

Taille $1 \mathrm{~m}$. 69. Envergure $1 \mathrm{~m}$. 77. Buste 0,900. Pied gauche 0,271. Tète : longueur 0,188 ; largeur 0,14 . Indice céphalique 77,12 . Oreille droite: longueur 0,037 ; largeur 0.036 . Indice auriculaire 63,15 . Forme triangulaire. 
Front : arcades moyennes; inclinaison fuyante; hauteur et largeur moyennes.

$\mathrm{Nez}$ : cavité (de la racine) petite; dos rectiligne; base horizontale; hauteur, largeur et saillie moyennes.

Bouche : moyenne, rectiligne, pincée.

Menton : droit, rond, à fossette; hauteur intermédiaire.

Visage ovale. Iris pigmenté de jaune.

Teint clair. Barbe, cheveux et sourcils ehâtains (sourcils réunis).

Carrure moyenne. Extérieur honnète.

Individu vigoureux et bon drille. Il travaille assidûment et a de la conduite. - Service général. - Obs. 28.

\section{$5^{\circ} \mathrm{Au}$ point de vue de l'instruction :}

Un seul a reçu une instruction supérieure.

Ii est négociant en eaux minérales, marié, âgé de quaranteneuf ans, urbain, originaire du département de la Loire.

Le jury l'ayant reconnu coupable, malgré ses dénégations, de vol d'une somme d'argent (40,648 francs), la nuit (9 au 10 janvier 1892), avec effraction intérieure dans un édifice (maison de banque), il a été condamné par arrêt de la cour d'assises du Puy-de-Dôme, en date du 20 novembre 1892, à 5 ans de travaux forcés, peine commuée, après rejet du pourvoi en cassation, en 5 ans de prison, par le président de la République.

La faiblesse de caractère, une tendance à se laisser entraîner aux plaisirs faciles par des amis peu scrupuleux vivant $\dot{a}$ ses dépens, telles paraissent être les principales causes des écarts de conduite de cet homme qui avait tout ce qu'il faut pour réussir dans la vie.

Taille $1 \mathrm{~m} .660$. Envergure $1 \mathrm{~m}$. 70. Buste 0,902 . Pied gauche 0,258 . Tète : longueur 0,189 ; largeur 0,168 . Indice céphalique 88,88 .

Oreille droite : longueur 0,064 ; largeur 0,033 . Indice auriculaire $\$ 1,56$. 
Front: arcades proéminentes; inclinaison intermédiaire ; hauteur grande ; largeur moyenne.

Nez: cavité (de la racine) petite; dos rectiligue; base horizontale; saillie petite; hauteur et largeur moyennes. Dévié à droite (chute de cheval).

Bouche : moyenne, pincée, à coins abaissés.

Menton : saillant, large ; hauteur intermédiaire.

Visage large. Iris pigmenté de châtain. Figure agréable et pleine de vivacité.

Teint clair. Barbe, cheveux et sourcils chàtain grisonnant.

Carrure grande. Santé robuste. Obésité légère.

Travail soutenu; conduite et moralité excellentes. - Service de l'infirmerie. - Obs. 29.

92 savent lire et écrire; 20 savent lire, écrire et calculer.

Un Gascon, âgé de dix-neuf ans, sachant lire, écrire et calculer, domestique, urbain, ayant un domicile, 2 fois condamné, subit la peine de 2 ans de prison, prononcée, le 13 janvier 1896 , par la cour d'assises du Gers, pour 3 vols commis, en novembre 1895, à l'aide d'escalade et d'effraction, dans diverses maisons d'habitation, et un dîner à la cour'se mis sur table et mangé dans un petit café restaurant: ( A bon vin point d'enseigne ).

Jusqu'à quinze ans, il a toujours ignoré la gravité des délits commis. La misère n'est point la cause de son malheur. Les mauvais exemples seuls l'ont perdu.

Taille $1 \mathrm{~m} .61$. Envergure $1 \mathrm{~m}$. 70. Buste 0,874. Pied gauche 0,256. Tète : longueur 0,183 ; largeur 0,159 . Indice céphalique 86,88 .

Oreille droite : longueur $0,0 \leftrightarrows 6$; largeur 0,033 . Indice auricuculaire 58,92 .

Front: arcades petites; inclinaison verticale; hauteur et largeur moyennes.

Nez : cavité (de la racine) moyenne; dos rectiligne, sinueux; base relevée; hauteur, largeur et saillie moyennes.

Bonche : moyenne, rectiligne, bée.

Menton : saillant, rond, bas, plat. 
Visage ovale. Iris impigmenté. Yeux saillants. Regard timide. Teint brun. Barbe, cheveux et sourcils noirs. Sourcils réunis. Carrure moyenne. Constitution et état général passables. Humeur obséquieuse.

Un poupin qui ne fuit aucun travail. - Espadrilles. Obs. 30 .

\section{2 sont illettrés.}

Ici prend place un Espagnol, âgé de vingt-neuf ans, marié, charretier, rural, ayant un domicile, sans antécédents judiciaires, adonné à l'ivrognerie, condamné, le 29 octobre 1894, par la cour d'assises des Pyrénées-Orientales, à 5 ans de prison et à 5 ans d'interdiction de séjour, pour " tentative de vol qualifié ).

Dans la nuit du 4 août 1894, de concert avec un autre malfaiteur, il avait arrêté un voiturier pour le voler.

Tandis que son complice prenait la lanterne et projetait la lumière sur les yeux de la victime, il saisissait celle-ci par le cou et lui demandait " la bourse ou la vie », le poignard à la main.

L'arrivée de deux voitures leur avait fait prendre la fuite.

Taille $1 \mathrm{~m}$ : 745. Envergure $1 \mathrm{~m}$. 83. Buste 0,914. Piel gauche 0,270 Tète : longueur 0,197 ; largeur 0,146 . Indice céphalique 74,11 .

Oreille droite : longueur 0,066 ; largeur 0,032. Indice auriculaire 48,48. Écartement supérieur. Forme allongée.

Front : arcades moyenne ; inclinaison intermédiaire; hauteur et largeur moyennes.

Nez : cavité (de la racine) grande ; dos concave ; base horizontale ; saillie grande; hauteur et largeur moyennes.

Bouche: grande, rectiligne; ouverture intermédiaire.

Menton : droit, rond, haut, i fossette.

Visage allongé, rébarbatif. Iris pigmenté de chàtain.

Teint brun. Barbe, cheveux et sourcils noirs.

Carrure moyenne. Santé parfaite. A expulser. 
Il a souvent besoin d'être relevé du péché de paresse. C'est un sattoneur (batailleur) qui aime à se bouchonner. - Atelier d'ébénisterie. - Obs. 31.

S savent lire; 5 possèdent une instruction primaire complète.

Un enfant de l'Isère, âgé de trente-trois ans, célibataire, ayant reçu une instruction primaire complète, portefaix (souteneur), rural, domiciliéà Marseille, à la $S^{e}$ peine, a été condamné, par la cour d'assises du département de la Drôme, le 5 avril 1895, à 4 années d'emprisonnement, pour " vol qualifié »).

Le 26 novembre 1894, ce récidiviste et un de ses camarades (agissant d'après les instructions d'un indicateur) étaient entrés dans une maison de campagne, à Montélimar, et, après avoir ligotté le mari et la femme, s'étaient emparés d'une somme de 135 francs et de quelques bijoux cachés dans une armoire.

Taille $1 \mathrm{~m} .697$. Envergure $1 \mathrm{~m}$. 770. Buste 0,873. Pied gaviche 0,270. Tête : longueur 0,181 ; largeur 0,156 . Indice céphalique 86,18.

Oreille droite : longueur 0,055 ; largeur 0,036 . Indice auriculaire $65,4.5$.

Front: arcades moyennes; inclinaison intermédiaire; hauteur et largeur moyennes.

$\mathrm{Nez}$ : cavité (de la raciue) moyenne ; dos rectiligne; base horizontale; hauteur et saillie grandes; largeur moyenne.

Bouche : moyenne, rectiligne; ouverture intermédiaire. Menton : droit, rond, à fossette ; hauteur intermédiaire.

Visage ovale (figure plate; maxillaires écartés). Iris impigmenté. Olil enfoncé.

Teint brun. Barbe, cheveux et sourcils chàtains (sourcils épais et arqués). Tatoué.

Carrure grande. Froide mine.

Individu très vigoureux; bien noté, - Chaises. 
"Fouillez ma vie et signalez-moi la cause de mes fautes, je désire, dit-il, faire retour à l'honnêteté. ”

Eh bien ! il faut fuir les fréquentations mauvaises, les femmes surtout, et sacrifier au travail. "Le travail et la bonne conduite ne manquent jamais de trouver leur récompense. ) (Saint-Just.) - Obs. 32.

\section{$6^{\circ}$ Au point de vue de la profession :}

72 professions agricoles, 19 ouvriers du batiment et du mobilier, 18 ouvriers d'atelier's et de fabriques, 14 professions alimentaires, 9 employés, 4 nomades, 2 commerçants.

Un maquignon, âgé de trente-neuf ans, célibataire, sachant lire et écrire, sans domicile, 6 fois condamné, subit la peine de 5 ans d'emprisonnement, prononcée, par la cour d'assises du Gard, le 14 novembre 1892, pour " vol qualifié ).

11 s'était introduit, le 9 mars, entre midi et 2 heures, dans le magasin d'un épicier de la ville de Nîmes et y avait dẻrobẻ 3,104 francs enfermés dans un coffre-fort.

Taille $1 \mathrm{~m}$. 678. Envergure $1 \mathrm{~m}$. 678. Buste 0,910. Pied gauche 0,262. Tète: longueur 0,185; largeur 0,153. Indice céphalique 82,70.

Oreille droite: longueur 0,068 ; largeur 0,035 . Indice auriculaire 51,47 . Écartement supérieur.

Front: arcades moyennes; inclinaison fuyante; hauteur petite; largeur moyenne.

Nez : cavité (de la racine) petite; dos busqué; base abaissée; hauteur et saillie grandes; largeur petite.

Bouche : grande, rectiligne; ouverture intermédiaire.

Venton: droit, rond, bas.

Visage orale (màchoires écartées). Iris impigmenté.

Teint lırun: Barbe, cheveux et sourcils chàtains (sourcils réunis). Tatoué.

Carrure moyenne. Santé forte. Physionomie expressive, originale.

Il rentre dans la catégorie de ceux qui font leur temps, cahincaha, sans s'attirer ni éloges, ni reproches. - Chaises. 
Voici, par le menu, les grandes étapes de sa vie :

"Je suis né, dit-il, dans une sous-préfecture de la Provence, mon père, un saltimbanque, ayant bien voulu me mettre au monde.

« Je fus élevé un peu à la diable et passai par tant de mains qu'à dix ans j'étais déjà un assez mauvais garnement.

"Enfin, une sœur de ma mère me recueillit. C'ètait une vieille fille à son aise, très confite en dévotion. D'humeur acariâtre, elle me reprochait, soir et matin, le pain qu'elle me donnait.

"Vint la foire du pays; je partis avec un charlatan. Pendant le jour, juché sur les hautes banquettes de sa voiture, je battais de la grosse caisse. A la nuit tombante, j'allais chanter dans les cafés avec une petite fille plus jeune que moi. Le patron et sa femme nous attendaient à la porte pour nous prendre la recette.

"Ce qu'ils nous rossaient quand ça ne marchait pas!

"Un soir que mes bourreaux étaient étendus dans la roulotte, plus saouls que d'ordinaire, je me vengeai en coupant les moustaches au barnum et filai sur Marseille.

"On couchait où on pouvait, le plus souvent dans les tonneaux défoncés, étalés sur le port. Il me souvient d'avoir laissé aux douelles de l'un d'eux, qui avait contenu du goudron, le fond de ma culotte. ")

Franc-tireur pendant la campagne de 1870, il partit, la paix signée, guerroyer, en Espagne, sous l'étendard de don Carlos, contre les troupes d'Amédée.

Fait prisonnier, l'intervention d'un officier français le sauva.

De retour chez nous, il fut condamné, comme insoumis à la loi de recrutement, à quelques jours de prison.

Peu de temps après, il déserte l'armée et se réfugie en Suisse.

Le spleen le ramène à la frontière. Il est arrêté. On le transfère à Bône. Il s'échappe et revient à la côte d'Espagne oủ il fait un an de prévention, comme inculpé de vol. 
Le voici, à Marseille, croupier dans un cercle. Les affaires vont bon train. Malheureusement, un joueur décavé le dénonce. On lui inflige 5 ans de travaux publics.

Il s'évade. Des Arabes s'emparent de lui, le lient sur un âne et le remettent aux autorités militaires.

Pour la troisième fois, il se donne de l'air. Il troque ses effets contre ceux d'un mannequin servant d'épouvantail aux oiseaux, vient à Philippeville et se glisse dans la cale d'un bateau en partance.

Sur le quai du débarcadère, la police marseillaise le saisit au collet.

En 1889, il est rendu à la vie libre, gracié.

" Je me demande, dit-il, comment ma mâ̂tresse a pu avoir connaissance du vol que j’ai commis à Nîmes. C'est, pourtant, sur ses indications que j'ai èté arrêté! Elle a mon pardon; mais, je jure bien qu'on ne m'y reprendra plus à vivre avec des filles de cet acabit. Ci-gît mon dernier chameau! " et il fait le signe de la croix.

Très solide; nerveux ; rit rarement; parle peu, mais s'exprime bien.

Un courage à toute épreuve. N'a eu peur qu'une fois en sa vie, le jour où, à la place d'un cochon gras sur lequel il avait jeté son dévolu, il trouva dans l'écurie un ours remisé là par un bateleur, le cochon ayant été vendu dans la journée.

Il le prit pour le diable en personne! - Obs. 33.

Parmi les nomades, on remarque un cordonnier ambulant, âgé de cinquante-sept ans, célibataire, sachant lire et écrire, rural, sans domicile fixe, à la $9^{\mathrm{e}}$ condamnation.

2 ans de prison et 10 ans d'interdiction de séjour lui ont été infligés par arrêt de la cour d'assises de l'Aude, en date du 6 août 1895, pour "vol qualifié ".

Le 23 avril, de passage à Axat, il était entré dans l'église 
paroissiale et avait fracturé, avec un ciseau à froid. "le tronc des offrandes aux âmes du purgatoire ».

On le trouva nanti d'une somme de 9 francs 30 centimes (4 francs 80 centimes en monnaie de billon), et il ne put en indiquer la provenance.

Taille $1 \mathrm{~m}$. 60. Envergure $1 \mathrm{~m}$. 61. Buste 0,86̈. Pied gauche 0,242. Tète : longueur 0,200 ; largeur 0,171 . Indice céphalique $85 . ; 0$.

Oreille droite: longueur 0,066 ; largeur 0,037 . Indice auriculaire 56,06 .

Front: arcades moyennes; inclinaison verticale; hauteur et largeur moyennes.

Nez : cavité (de la racine) moyenne; dos rectiligne; base horizontale; largeur grande ; hauteur et saillie moyennes.

Boucle: grande, rectiligne; ouverture intermédiaire.

Menton: droit, large, bas.

Visage ovale. Iris pigmenté d'orange.

Teint brun. Barbe et cheveux gris; sourcils chàtains.

Carrure moyenne. Santé boune.

" Toujours triste quand il ne fait rien et plus triste encore quand il a quelque chose à faire "): Un vrai fourneau. Atelier de clouage. - Obs. 34.

$7^{\circ} \mathrm{Au}$ point de vue de la population:

86 urbains, 52 ruraux.

$8^{\circ}$ Au point de vue du domicile:

38 sans domicile: 100 avec domicile.

$9^{\circ}$ Au point de vue du nombre des condamnations:

37, sans condamnation antérieure; 74 , condamnés de 1 ì 5 fois; 25 , de 5 ì 10 fois; 2,10 fois et plus. 
Un Marseillais, âgé de 18 ans, célibataire, sachant lire, écrire et calculer, domestique, sans domicile fice, à la $11^{\circ}$ peine, débauché, réputé par la facilité avec laquelle il change de nom (renseignements fournis par les tribunaux de Gap, d'Embrun et la cour d'appel de Dijon), a été condamné par la cour d'assises du Gard, le 14 mai 1895, à 3 ans de prison, pour s'être emparé, à Alais, dans la nuit du 2 au 3 mars, d'une somme de 250 francs, de bijoux, d'effets d'habillement et de lingerie, et d'une valise déposés dans une voiture remisée au domicile de son maître.

Taille $1 \mathrm{~m}$. 78. Envergure $1 \mathrm{~m}$. 71. Buste 0,930. Pied gauche 0,277.

Tète : longueur 0,184 ; largeur 0,162 . Indice céphalique 88,04 .

Oreille droite: longueur 0,061 ; largeur 0,033 . Indice auricu. laire 54,09 .

Front: arcades moyennes; inclinaison intermédiaire; hauteur et largeur moyenues.

Nez: cavité (de la racine) moyenne; dos concave; base relevée; hauteur petite; largeur et saillie moyennes.

Bouche : moyenne, rectiligne; ouverture intermédiaire.

Menton : droit, rond, bas.

Visage arrondi. Iris pigmenté d'orange. Expression du regard banale.

Teint clair. Barbe, cheveux et sourcils châtain clair. Tatoné.

Carrure moyenne. Excellente santé.

Il craint la peine et la fatigue et ne fait rien de bien. Cordonnerie. - Obs. 35.

$10^{\circ}$ Au point de vue de l'oisiveté :

99 oisifs.

$11^{\circ} \mathrm{Au}$ point de vue de l'ivrognerie :

42 adonnés à l'iorognerie. 
12. A point de vue du libertinage et de la débauche : 48 libertins et débauchés.

13. Au point de vue du concubinage :

18 vivant en concubinage.

$14^{\circ}$ Au point de vue de la note de la commune :

3 bien notés.

$$
\text { ** }
$$

$15^{\circ}$ Au point de vue de la taille :

Dans la catégorie de 16 à 20 ans : taille au-dessous de $1 \mathrm{~m} .60$, 4 individus; de $1 \mathrm{~m} .60$ à $1 \mathrm{~m}$. 70,24 ; de $1 \mathrm{~m}$. 70 et audessus, 3.

Soit, moyenne de la taille $1 \mathrm{~m} .638$.

De 20 a 25 ans : taille au-dessous de $1 \mathrm{~m}$. 60, 10 individus; de $1 \mathrm{~m}$. 60 à $1 \mathrm{~m}$. 70, 24; de $1 \mathrm{~m}$. 70 et au-dessus, 2 .

Soit, moyenne de la taille $1 \mathrm{~m} .625$.

De 25 a 30 ans : taille au-dessous de $1 \mathrm{~m}$. 60, 7 individus; de $1 \mathrm{~m} .60$ à $1 \mathrm{~m}$. 70, 15 ; de $1 \mathrm{~m}$. 70 et au-dessus, 11 . Soit, moyenne de la taille $1 \mathrm{~m} .659$.

De 30 à 40 ans : taille-au-dessous de $1 \mathrm{~m} .60,5$ individus; de $1 \mathrm{~m} .60$ a $1 \mathrm{~m} .70,1 \%$; de $1 \mathrm{~m}$. 70 et au-dessus, 6 .

Soit, moyenne de la taille $1 \mathrm{~m} .661$. 
De 40 à 50 ans : taille au-dessous de $1 \mathrm{~m}$. 60, 2 individus; de $1 \mathrm{~m} .60$ à $1 \mathrm{~m}$. 70, 3; de $1 \mathrm{~m}$. 70 et au-dessus, 1 .

Soit, moyenne de la taille $1 \mathrm{~m} .639$.

De 50 ans et au-dessus : taille de $1 \mathrm{~m} .60$ à $1 \mathrm{~m} .70,4$ individus.

Soit, moyenne de la taille $1 \mathrm{~m} .658$.

En résumé: taille au-dessous de $1 \mathrm{~m}$. 60, 28 individus; de $1 \mathrm{~m} .60$ à $1 \mathrm{~m}$. 70, 87; de $1 \mathrm{~m}$. 70 et au-dessus, 23 .

Soit, moyenne de la taille $1 \mathrm{~m} .645$.

\section{$16^{\circ}$ Au point de vue de l'envergure :}

Dans la catégorie de 16 à 20 ans: Envergure inférieure à la taille, de 0 à 8 cent., 1 individu; égale à la taille, 2 ; supérieure à la taille, de 0 à 4 cent., 12; de 4 à 8 cent., 9 ; de 8 à 16 cent., 7 .

Soit, moyenne de l'envergure $1 \mathrm{~m} .680$.

De 20 à 25 ans : envergure inférieure à la taille, de 0 à 8 cent., 3 individus; égale à la taille, 1 ; supérieure à la taille, de 0 à 4 cent., 10 ; de 4 à 8 cent., 15 ; de 8 à 16 cent., 7.

Soit, moyenne de l'envergure $1 \mathrm{~m} .670$.

De 25 à 30 ans : envergure inférieure à la taille, de 0 à 8 cent., 3 individus; supérieure à la taille, de 0 à 4 cent., 8 ; de 4 à 8 cent., 15 ; de 8 à 16 cent., $\%$.

Soit, moyenne de l'envergure $1 \mathrm{~m}$. $70 \%$.

De 30 à 40 ans : envergure inférieure à la taille, de 0 à $\mathrm{S}$ cent., 2 individus; égale à la taille, 1 ; supérieure à la taille, de 0 à 4 cent., 4 ; de 4 à 8 cent., 14 ; de 8 à 16 cent., $\%$.

Soit, moyenne de l'envergure $1 \mathrm{~m} .715$. Ch. Perrier. 
De 40 à 50 ans : envergure inférieure à la taille, de 0 à 8 cent.. 1 individu ; supérieure à la taille, de 4 à 8 cent., 3 ; de 8 a 16 cent., 2 .

Soit, moyenne de l'envergure $1 \mathrm{~m} .700$.

De 50 ans et au-dessus : envergure inférieure à la taille, de 0 à 8 cent., 1 individu ; supérieure à la taille, de 0 à 4 cent., 1 ; de 4 ì 8 cent., 2 .

Soit, moyenne de l'envergure 1,680.

En résımé : envergure inférieure à la taille, de 0 à 8 cent., 11 individus; égale à la taille, 4 ; supérieure à la taille, de 0 à 4 cent., 35 ; de 4 à 8 cent., 58 ; de 8 à 16 cent., 30 . Soit, moyenne de l'envergure 1,692.

\section{$17^{\circ}$ Au point de vue du buste :}

Dans la catégorie de 16 à 20 ans: buste supérieur à la moitié de la taille, de 0 à 5 cent., 12 individus; de 5 à 10 cent., 19 . Soit, moyenne du buste 0.873 .

De 20 à 25 ans : buste supérieur à la moitié de la taille, de 0 à 5 cent., 10 individus: de 5 à 10 cent., 25 ; de 10 à 18 cent., 1.

Soit, moyenne du buste 0,872 .

De 25 à 30 ans : buste supérieur à la moitié de la taille, de 0 à 5 cent., 12 individus; de 5 à 10 cent., 20 ; de 10 à 18 cent., 1.

Soit, moyenne du buste 0,886 .

De 30 à 40 ans: buste supérieur à la moitié de la taille, de 0 à 5 cent., 12 individus; de 5 à 10 cent., 14 ; de 10 à 18 cent., 2.

Soit, moyenne du buste 0,884 . 
De 40 à 50 ans : buste inférieur à la moitié de la taille, 1 individu; buste supérieur à la moitié de la taille, de 5 à 10 cent., 4 ; de 10 à 18 cent., 1 .

Soit, moyenne du buste 0,882 .

De 50 ans et au-dessus : buste supérieur à la moitié de la taille, de 0 à 5 cent., 2 individus; de 5 à 10 cent., 2 .

Soit, moyenne du buste 0,887 .

En résumé : buste inférieur à la moitié de la taille, 1 individu; supérieur à la moitié de la taille, de 0 à 5 cent., 48; de 5 à 10 cent., 84 ; de 10 à 18 cent., 5 .

Soit, moyenne du buste 0,879 .

\section{$18^{\circ}$ Au point de vue du pied :}

Dans la catégorie de 16 à 20 ans : pied de 24 à 26 cent., 16 individus; de 26 à 28 cent., 14 ; de 28 à 30 cent., 1.

Soit, moyenne du pied 0,259.

De 20 à 25 ans : pied de 22 à 24 cent., 1 individu; de 24 a 26 cent , 20 ; de 26 à 28 cent., 14 ; de 28 à 30 cent., 1 .

Soit, moyenne du pied 0,258.

De $25 \dot{a} 30$ ans : pied de $22 \dot{a} 24$ cent., 3 individus; de 24 à 26 cent., 16 ; de 26 à 28 cent, 12 ; de 28 à 30 cent., 2 .

Soit, moyenne du pied 0,260 .

De 30 à 10 ans: pied de 22 à 24 cent., 1 individu; de 24 à 26 cent., 14 ; de 26 à 28 cent., 13.

Soit, moyenne du pied 0,259.

De 40 à 50 ans : pied de 24 à 26 cent., 1 individus ; de 26 à 28 cent., 2.

Soit, moyenne du pied 0,258 . 
De 50 ans et au-dessus : pied de 24 à 26 cent., 2 individus ; de 26 à 28 cent. , 2.

Soit, moyenne du pied 0,258.

En résumé: pied de 22 à 24 cent., 5 individus; de 24 à 26 cent., 72 ; de 26 à 28 cent. , 57 ; de 28 à 30 cent., 4 .

Soit, moyenne du pied 0,259.

$19^{\circ}$ Au point de vue de la tête :

5 Dolichocéphales vrais; 6 sous-dolichocéphales; 18 mésaticéphales; 36 sous-brachycéphales; 73 brachycéphales vrais.

D'autre part, les calculs donnent :

Longueur moyenne de la tête 0,1859 ; largeur moyenne de la tête 0,1556 .

D'où : indice céphalique 83,70 .

$20^{\circ}$ Au point de vue de l'oreille:

Indice auriculaire : Au-dessous de 52,13 individus; de 52 à 56 , 39 : de 56 à 60,52 ; de 60 à 65,29 ; de 65 et au-dessus, 5 .

D'autre part, les calculs donnent :

Longueur moyenne de l'oreille 0,0610; largeur moyenne de l'oreille $0,034 \%$.

D'où : Indice auriculaire 56,88. 


\section{$21^{\circ}$ Au point de vue du visage :}

En tronc de pyramide 1, en losange 9, rond 10, large ou carré 16 , ovale 96 , allongé 4 , en toupie 2.

$22^{\circ} \mathrm{Au}$ point de vue du front:

Arcades : grandes 21, petites 16, moyennes 101.

Inclinaison: verticale 17 , fuyante 26 , intermédiaire 95 .

Hauteur : grande 18 , petite 6 , moyenne 114 .

Largeur: grande 14, petite 13, moyenne 111.

23 $^{\circ}$ Au point de vue du nez:

Cavité (de la racine) : grande 7 , petite 43 , moyenne 88 .

Dos : rectiligne 90 , concave 36 , convexe 12.

Base : horizontale 93, relevée 39 , abaissée 6 .

Hauteur : grande 13, petite 11, moyenne 114.

Saillie: grande 21, petite 8, moyenne 109 .

Largeur : grande 16 , petite 5 , moyenne $11 \%$.

$24^{\circ}$ Au point de vue de la bouche :

Dimension : grande 17, petite 16, moyennè 105.

Inclinaison des angles : rectiligne 103, a coins abaissės 12, a coins relevés 23 .

Degré habituel d'ouverture: bẻe 12, pincée 17, intermédiaire 109. 
$25^{\circ}$ Au point de vue du menton :

Inclinaison générale : menton saillant 26, fuyant 23 , droit 89. Avec et sans houppe: plat 17, a houppe 16, intermédiaire 105. Hauteur: haut 23 , bas 31 , intermédiaire 84 .

Forme: large 27 , rond 105 , pointu 6 .

26. Au point de vue de l'œil:

Iris : impigmenté 11 , pigmenté de jaune 38 , d'orange 55 , de châtain 19, de marron 15 .

$27^{\circ}$ Au point de vue du teint:

Brun 95, mat 4, clair 33, blond 4, pâle 2 .

$$
\text { ** } *
$$

$28^{\circ} \mathrm{Au}$ point de vue de la carrure:

Grande 32, moyenne 103, petite 3.

$29^{\circ}$ Au point de vue de la constitution et de l'état général à l'arrivèe:

Très bons 12, bons 87, passables 19 , mauvais 20 .

$30^{\circ}$ Au point de vue des maladies et infirmités à l'arrivée:

37 maladies et infirmités, à répartir entre 32 individus (25 França is, dont 1 Corse; 3 Italiens; 3 Espagnols; 1 divers). Soit : 
Bronchite bacillaire 6 , artérite chronique avec dégénérescence athéromateuse prononcée 1 , asthme 1 , accidents syphilitiques 2 , uréthrite aiguë 2 , scrofule 4 , déviation de la colonne vertébrale 1 , hernie inguinale droite 4 , gauche 1 , double 1 , pointe de hernie 1 , obésité 1 , varices 2 , varicocèle 1 , borgne 1 , strabisme 1, atrophie du nerf optique 1 , faiblesse de la vue 1 , conjonctivite chronique 1, surdité légère 2 , épilepsie 1(obs. 26), imbécillité 1.

L'individu atteint d'imbécillité (Corse,âgé de trente et un ans, célibataire, sachant lire et écrire, cultivateur, rural, ayant un domicile, à la $1^{\text {re }}$ peine, adonné à l'ivrognerie) a été condamné à 5 ans de prison, par le tribunal de Bastia, pour " vols qualifiés ".

Taille $1 \mathrm{~m}$. 66. Envergure $1 \mathrm{~m}$. 71. Buste 0,868. Pied gauche 0,256.

Tète: longueur 0,183 ; largeur 0,145 . Indice céphalique 79,23.

Oreille droite : longueur $0,0 \not 9$; largeur 0,035 . Indice auriculaire 59,32 .

Front: arcades moyennes; inclinaison intermédiaire; hauteur et largeur moyennes.

$\mathrm{Nez}$ : cavité (de la racine) moyenne ; dos rectiligue; base horizontale; hauteur, largeur et saillie moyennes.

Bouche : grande, rectiligne; ouverture intermédiaire.

Menton : rond, droit, à fossette; hanteur intermédiaire.

Visage ovale. Iris pigmenté d'orange.

Teint brun. Barbe, cheveux et sourcils chàtain clair.

Carrure grande. Santé précaire. Nine renfrognée.

Il est fainéant, menteur et poltron. - Empaillage. Obs. 36.

\section{$31^{\circ}$ Au point de vue du lieu du crime:}

Lieu de naissance: 34 individus avant domicile (29 urbains et 5 ruraux?.

Département du lieu de naissance: 33 individus, dont 8 sans domicile ( 5 urbains et 3 ruraux).

Autre département: 71 individus, dont 30 sans domicile (18 urbains et 12 ruraux: 
$32^{\circ}$ Au point de vue de la date du crime:

7 en janvier, 9 en février, 13 en mars, $\$$ en avril, 9 en mai, 6 en juin, 11 en juillet, 14 en août, $S$ en septembre, 12 en octobre, 19 en novembre, 18 en décembre, 4 pendant l'année.

$$
\begin{aligned}
& \text { Soit:Hiver . . . . . . . . . . } 34 \\
& \text { Printemps . . . . . . . . } 30 \\
& \text { Été. . . . . . . . . . . } 31 \\
& \text { Automne. . . . . . . . } 39 \\
& \text { Pendant l'année . . . . . . } 4 \\
& 138 \\
& \text { *** }
\end{aligned}
$$

$33^{\circ} \mathrm{Au}$ point de vue de la juridiction :

Condamnés par tribunaux correctionnels. . . . . 3

$\begin{array}{llr}\text { - } & \text { cours d'assises . . . . . . . . . . . . . } 134 \\ \text { — } & \text { tribunal de Monaco. . . . . . . . } & 1\end{array}$

L’individu condamné par le tribunal monégasque (Italien, àgé de vingt-huit ans, marié, domestique, rural, ayant un domicile) sait lire et écrire.

6 condamnations figurent à son dossier.

Par jugement, rendu le 15 janvier 1896, on lui a infligé 2 ans de prison, pour " vol qualifié ".

Il mettait les villas au pillage.

Taille $1 \mathrm{~m}$. 64. Envergure $1 \mathrm{~m}$. 68. Buste 0,89.̈. Pied gauche 0,256. Tète : longueur 0,193 ; largeur 0,163 . Indice céphalique 85,49 . Oreille droite: longueur 0,059 ; largeur 0,032 . Indice auriculaire 54,23. Écartement total. 
Front: arcades moyennes; inclinaison intermédiaire; largeur grande; hauteur moyenne.

Nez : cavité (de la racine) moyenne; dos rectiligne; base relcvée; hauteur, saillie et largeur moyennes.

Bouche : moyenne, à coins relevés; ouverture intermédiaire.

Menton : droit, rond, plat; hauteur intermédiaire.

Visage ovale. Iris pigmenté d'orange. Figure agréable.

Teint blond. Barbe, cheveux et sourcils blonds.

Carrure moyenne. Santé vigoureuse. A expulser.

Un pénard: individu se conduisant bien par calcul. Filoches. - Obs. 37.

$34^{\circ}$ Au point de vue de la durée de la peine:

Un seul subit la peine de 15 mois de prison. Il n'avait jamais eu maille à partir avec la justice.

Les autres font :

2, 18 mois; 29, 2 ¿̀ 3 ans; 33, 3 à 4 ans ; 23, 4 ì 5 ans; 50, 5 ans et plus.

Un Marseillais, âgé de vingt-deux ans, célibataire, sachant lire et écrire, carrier, sans domicile fixe, à la 4 e peine, intrépide buveur, a été condamné à 5 ans d'emprisonnement, par la cour d'assises de Vaucluse (arrêt en date du 30 janvier 1896).

Ayant appris qu'il existait, à Avignon, un bureau de tabac dans lequel on laissait la recette pendant toute la semaine, il s'adjoignit trois camarades besogneux et opéra, pendant la nuit du 27 octobre 1895, le magasin en question, ainsi que le comptoir d'une brasserie voisine : 600 francs environ furent dérobés.

Taille $1 \mathrm{~m}$. 69. Envergure $1 \mathrm{~m}$. 72. Buste 0,923. Pied gauche, $0,263$.

Tète : longueur 0,188 ; largeur 0,153 . Indice céphalique 81,38 .

Oreille droite: longueur 0,068 ; largeur 0,037 . Indice auriculaire $34,4.1$. Écartement total.

Front: arcades movennes; inclinaison intermédiaire; hauteur et largeur moyennes. 
Nez : cavité (de la racine) moyenne; dos reetiligne; base horizontale; saillie grande; hauteur et largeur moyennes.

Bouehe : moyenne, rectiligne; ouverture intermédiaire.

Menton: fuyant, rond, à fossette; hauteur intermédiaire.

Visage ovale. Iris pigmenté de ehàtain. Physionomie ouverte.

Teint elair. Barbe, cheveux et sourcils chàtains.

Carrure moyenne. Santé bonne. Hernie inguinale gauche.

Il a débuté comme marchand d'allumettes de contrebande à quinze ans. C'est l'aiguillon de la faim qui l'a poussé au mal.

Dans l'établissement, on ne peut que lui faire compliment de sa conduite et de son travail. - Cordonnerie. - Obs. 38.

35 Au point de vue de l'interdiction de séjour:

34 sont frappés d'interdiction de séjour, parmi lesquels, 2, par une condamnation antérieure.

$$
\text { *** }
$$

$36^{\circ}$ Au point de vue du travail en prison:

Bons ouvriers 85 ; passables 36 ; mauvais 17.

$37^{\circ}$ Au point de vue de la conduite en prison :

Bonne 48 ; passable 41 ; mauvaise 49.

$$
\text { *** }
$$

$38^{\circ} \mathrm{Au}$ point de vue de l'expulsion :

24 étrangers sur 27. 


$$
\begin{gathered}
\text { III } \\
\text { VOL - VAGABONDAGE - MENDICITÉ } \\
20 \text { individus }
\end{gathered}
$$

$1^{\circ}$ Au point de vue de la naissance :

16 enfants légitimes, 4 enfants naturels.

$2^{\circ}$ Au point de vue de la nationalité :

13 Français, 7 étranger's (3 Italiens, 2 Espagnols, 2 divers).

\section{$3^{\circ}$ Au point de vue de l'âge:}

8 de 20 à 30 ans, 5 de 30 ì 40 ans, 4 de 40 ans et plus, 3 de 16 à 20 ans.

A citer, un Niçois, âgé de dix-huit ans, sachant lire et écrire, sans profession, à la $3^{\circ}$ peine, dans une mauvaise réputation de conduite et de moralité.

Le tribunal de Nice lui a infligé, le 20 juin 1895, 13 mois de prison, pour " vol, tentative de vol et vagabondage ".

On raconte qu'un propriétaire de magasin avait pendu à sa porte un poids qui devait l'avertir si on pénètrait chez lui.

Dans la nuit du 13 au 14 mai 1895, le marchand fut éveillé par la chute de ce poids. Revolver en main, il sortit immédia- 
CH. PERRIKR

tement et rencontra deux individus qui s'enfuirent à son approche. Il les salua de deux balles.

Notre pensionnaire était un de ces deux individus.

Taille $1 \mathrm{~m}$. 39 . Envergure $1 \mathrm{~m}$. 56. Buste 0,842. Pied gauche 0,245.

Tète : longueur 0,196 ; largeur 0,156 . Indice céphalique 79,59.

Oreille droite: longueur 0,062 ; largeur 0,038 . Indice auriculaire 61,29 .

Front: arcades moyennes; inclinaison fuyante; hauteur et largeur moyennes.

Nez : cavité (de la racine) petite; dos rectiligne ; base relevée; hauteur, largeur et saillie moyennes.

Bouche: moyenne, rectiligne; ouverture intermédiaire.

Menton: saillant, large, haut, plat.

Visage ovale. Iris pigmenté de jaune.

Teint brun. Barbe châtain ; cheveux et sourcils châtain foncé. Tatouć. Carrure petite. Constitution et état général médiocres. Extérieur doux.

Dans son ardeur, il se couche, etc. - Atelier de cordonnerie. - Obs. 39.

\section{$4^{\circ}$ Au point de vue de l'ètat civil :}

17 célibataires, 3 mariés.

Au nombre des mariés se trouve un Espagnol, enfant naturel, âgé de trente-neuf ans, possédant quelques notions de grammaire, marchand ambulant, rural, récidiviste. adonné à l'ivrognerie, condamné, le 22 mai 1895, par le tribunal d'Avignon, et sur appel, le 13 juin, par la cour de Nîmes, à 15 mois d'emprisonnement et à 50 francs d'amende, pour " mendicité en réunion, violences et voies de fait, et infraction à un arrêté d'expulsion "), commis en mai de la même année.

Il faisait habituellement mendier ses trois jeunes enfants et deux petits garçons, âgés de moins de seize ans, d'origine espagnole, ainsi qu'une femme naine et difforme qu'il avait enlevée de force et qu'il maltraitait. 
Taille $1 \mathrm{~m}$. 53. Envergure $1 \mathrm{~m}$. 57. Buste 0,824. Pied gauche 0,243. Tête : longueur 0,181 ; largeur 0,1303 . Indice céphalique 85,63 .

Oreille droite : longueur 0,058 ; largeur 0,03 ö. Indice auriculaire 60,3 Ł. Front : arcades moyennes; inclinaison intermédiaire ; hauteur et largeur moyennes.

$\mathrm{Nez}$ : cavité (de la racine) noyenne ; dos rectiligne ; base horizontale ; hauteur, largeur et saillie moyennes.

Bouche : moyenne, à coins abaissés ; ouverture intermédiaire.

Menton : bas, droit, rond.

Visage ovale. Iris pigmenté d'orange, truité.

Teint brun. Barbe et cheveux châtain foncé; sourcils châtain moyen. Carrure moyenne. Santé bonne. Air bourru.

Il sait ne pas attirer l'attention sur lui. - Empaillage. Obs. 40 .

\section{$5^{\prime}$ Au point de vue de l'instruction :}

16 savent lire et écrire; un seul (c'est un vieil alcoolique) sait lire, écrire et calculer. Les 3 autres n'ont recu aucune instruction; mais, ils sont (" à l'œil ).

Un Italien, âgé de trente-neuf ans, célibataire, illettré, sans autres moyens d'existence que le vol ( $\dot{a}$ la tire ), subit la peine de deux ans de prison, prononcée, le 20 février 1896, par le tribunal correctionnel d'Aix, pour (( vagaboudage ).

Arrêté, le 13 février 1896, cet ancien mineur, - condamné deux fois sous un faux nom et se disant né à Trieste (1), -

(1) C'est le lieu d'origine que se donnent les malfaiteurs qui ont intérêtà cacher leur identité.

Les magistrats de cette ville sont la discrétion même. Toute demande à eux adesséepar voie de justice va se perdre dans un silence éternel.

Et, comme l'affaire est généralement de celles que l'exemple commun autorise à mener rondement, les procureurs et juges d'instruction (casier central consulté) se désintéressent vite des inculpés qui avouent leur délit.

Ils coupent dans le pont, suivant l'expression consacrée. Voilà pourquoi, sur la notice de deux de nos pensionnaires, l'un à la $14^{\mathrm{e}}$, l'autre à la $17^{\circ}$ peine, on lit, sous la rubrique " nombre des condamnations " : Néant. 
n'arait pu indiquer la provenance d'une somme de 360 francs, trouvée en sa possession.

Taille I m. 60. Envergure $1 \mathrm{~m}$. 69. Buste 0,848. Pied gauche 0,254.

Tète : longueur 0,183 ; largeur 0,163 . Indice céphalique 89,07 .

Oreille droite : longueur 0,064 ; largeur 0,036 . Indice auriculaire 56,25 .

Écartement total.

Front : arcades moyennes; inclinaison verticale; hauteur et largeur moyennes.

Nez: cavité (de la racine) petite; dos rectiligne; base abaissée; hauteur grande, largeur et saillie moyennes.

Bouche : grande, rectiligne; ouverture intermédiaire ; lèvres minces. Menton: droit, rond, bas, a fossette.

Visage ovale (màchoires écartées). Iris pigmenté de jaune. Vilaine figure.

Teint brun. Barbe, cheveux et sourcils chàtains (sourcils réunis).

Carrure moyenne. Santé bonne. A expulser.

Un débrouillard a l'harnache: qui roule son patron. Talons. - Obs. 41.

\section{$6^{\circ} \mathrm{Au}$ point de vue de la profession :}

9 ouvriers d'ateliers et de fabriques, 5 professions agricoles, 2 professions alimentaires, 1 nomade, 1 sans profession, 1 ancien employé, 1 menuisier.

Le menuisier, né à Cannes, âgé de vingt-sept ans, célibataire, sachant lire et écrire, vieille connaissance de la justice et pilier de caboulots, a été condamné à 1 an et 1 jour de prison, le 26 juillet 1895, par le tribunal de Castres, pour " vagabondage, mendicité, vol et outrages aux agents de la force publique »).

Mis en arrestation, dans la journée du 11 avril 1895, en même temps que trois de ses camarades sur lesquels planaient de graves présomptions de vol, il avait pris une attitude menaçante et jeté dans les eaux du Thoré un sac contenant " trois couverts en ruolz, une cuiller en fer et un couteau de table ». 
Tous ces objets, " ainsi qu'une paire de bottes neuves et un canard ") trouvés en sa possession, provenaient de vols commis au préjudice de divers habitants du pays.

Taille $1 \mathrm{~m}$. 66. Envergure $1 \mathrm{~m}$. 71. Buste 0,852. Pied gauche 0,20ั5. Tète : Iongueur $0.19 \ddot{3}$; largeur 0,160 . Indice céphalique 82,03 .

Oreille droite: longueur 0,066 ; largeur 0,036 . Indice auricu-

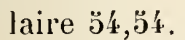

Front : arcades grandes; inclinaison fuyante; hauteur et largeur petites.

Nez: cavité (de la racine) petite; dos convexe, sinueux; base horizontale; largeur grande; hauteur et saillie moyennes.

Bouche : moyenne, à coins abaissés; ouverture intermédiaire.

Veuton : fuyant, rond, à houppe ; hauteur intermédiaire.

Visage arrondi. Iris pigmenté d'orange.

Teint clair. Barbe, cheveux et sourcils chàtains.

Carrure movgenne Santé bonne. Humeur inégale.

Épaulant (jamais satisfait) et barbotteur. - Atelier d'ébénisterie. - Obs. 42.

$7^{\circ}$ Au point de vue de la population :

17 urbains, 3 ruraux.

$8^{\circ}$ Au point de vue du domicile :

Tous sans domicile.

9. Au point de vue du nombre des condamnations :

5 à la première condamnation, 15 récidivistes.

Notons un Malouin, âgé de trente ans, célibataire, sachant lire et écrire, journalier, à la treizième peine, adonnè à l'ivrognerie, sans autres moyens d'existence que la vente d'articles divers (papier à lettres, crayons, etc.) et la chine, genre de 
mendicité qui consiste à simuler une infirmité ou un manque de travail pour soutirer une aumône.

En bon chineur, il a pu entretenir femme et chien, et avoir un lot de marchandises de choix. La femme faisait le tour des cafés et procédait à la vente. Quelquefois même, elle avait l'art de tout rapporter avec une bonne recette gagnée dans une position horizontale. Madame avait sobriquet : "Bandalaise ".

La cour de Riom a condamné cet individu à 15 mois de prison (18 décembre 1895), sur l'appel, interjeté par le ministère public, d'un jug'ement rendu, à Moulins, lui infligeant la peine de 3 mois pour (" mendicité en réunion », délit commis le 16 novembre 1895 .

Taille $1 \mathrm{~m} .60$. Envergure $1 \mathrm{~m}$. 61. Buste 0,881 . Pied gauche 0 ,2:3̈. Tète: longueur 0,201; largeur 0,162. Indice céphalique 80,59. En besace.

Oreille droite: Iongueur 0,038 ; largeur 0,034 . Indice auriculaire 58,62. Écartement supérieur.

Front: arcades grandes; inclinaison fuyante; hauteur grande; largeur moyenne.

Nez : cavité (de la racine) moyenne; dos rectiligne; base horizontale; saillie et largeur moyennes; hauteur grande.

Bouche : en cœur (petite, à coins relevés; lèvre supérieure retroussée).

Menton : droit, rond, à houppe,à fossette; hauteur intermédiaire.

Visage ovale. Iris impigmenté.

Teint brun. Barbe, cheveux et sourcils châtains; sourcils drus et longs.

Carrure moyenne. Excellente santé. Bonne physionomie.

Il s'honore du nom de fainéant et pisse du blaire (pleure) à la moindre réprimande. - Empaillage. - Obs. 43.

$10^{\circ}$ Au point de vue de l'oisiveté :

18 oisifs. 
$11^{\circ}$ Au point de vue de l'ivrognerie :

18 adonnés à l'ivrognerie.

$12^{\circ}$ Au point de vue du libertinage et de la dèbauche .

12 libertins et débauchés.

$13^{\circ}$ Au point de vue du concubinage :

1 vivant en concubinage.

$14^{\circ}$ Au point de vue de la note de la commune :

Aucun bien noté.

$$
\text { ** }
$$

$15^{\circ}$ Au point de vue de la taille :

Dans la catégorie de 16 à 20 ans : taille au-dessous de $1 \mathrm{~m} .60$, 1 individu; de $1 \mathrm{~m} .60$ à $1 \mathrm{~m}$. $70,2$.

Soit, moyenne de la taille $1 \mathrm{~m} .606$.

De 20 à 25 ans : taille au-dessous de $1 \mathrm{~m} .60,1$ individu : de $1 \mathrm{~m} .60$ à $1 \mathrm{~m} .70,3$.

Soit, moyenne de la taille $1 \mathrm{~m} .624$.

De 25 à 30 ans : taille de $1 \mathrm{~m} .60$ à $1 \mathrm{~m}$. \%0, 4 individus.

Soit, moyenne de la taille $1 \mathrm{~m} .654$.

Ch. Perrier. 
De 30 à 40 ans: taille au-dessous de $1 \mathrm{~m} .60,2$ individus: de $1 \mathrm{~m} .60$ à $1 \mathrm{~m} .70,3$.

Soit, moyenne de la taille $1 \mathrm{~m} .578$.

De 40 a 50 ans : taille au-dessous de $1 \mathrm{~m} .60,1$ individu; de $1 \mathrm{~m} .60$ a $1 \mathrm{~m} .70,1$.

Soit, moyenne de la taille $1 \mathrm{~m} .640$.

De 50 ans et au-dessus: taille au-dessous de $1 \mathrm{~m} .60,2$ individus.

Soit, moyenne de la taille $1 \mathrm{~m} .571$.

En r'ésumé : taille au-dessous de $1 \mathrm{~m} .60,7$ individus; de $1 \mathrm{~m} .60$ à $1 \mathrm{~m} .70,13$.

Soit, moyenne de la taille $1 \mathrm{~m} .612$.

$16^{\circ} \mathrm{Au}$ point de vue de l'envergure :

Dans la catégorie de 16 à 20 ans : envergure inférieure à la taille, de 0 à 8 cent., 1 individu; supérieure à la taille, de 8 à 16 cent., 2 .

Soit, moyenne de l'envergure $1 \mathrm{~m} .660$.

De 20 à 25 ans : envergure supérieure à la taille, de 0 à 4 cent., 1 individu; de 4 à 8 cent., 2 ; de $S$ à 16 cent., 1 .

Soit, moyenne de l'envergure $1 \mathrm{~m} .680$.

De 25 à 30 ans : envergure supérieure à la taille, de 0 à 4 cent., 1 individu; de 4 à 8 cent., 1 ; de 8 à 16 cent., 2 .

Soit, moyenne de l'envergure $1 \mathrm{~m} .722$.

De 30 à 40 ans : envergure supérieure à la taille, de 0 à 4 cent., 2 individus; de 4 à 8 cent., 1 ; de 8 à 16 cent., 2 .

Soit, moyenne de l'envergure $1 \mathrm{~m} .626$. 
De 40 à 50 ans : envergure supérieure à la taille, de 0 à 4 cent., 1 individu ; de 4 à 8 cent., 1 .

Soit, moyenne de l'envergure $1 \mathrm{~m} .670$.

De 50 ans et au-dessus : envergure supérieure à la taille, de 0 à 4 cent., 1 individu; de 4 à 8 cent., 1 .

Soit, moyenne de l'envergure $1 \mathrm{~m} .605$.

En résumé : envergure inférieure à la taille, de 0 à 8 cent., 1 individu ; supérieure à la taille, de 0 à 4 cent., 6 ; de 4 à 8 cent., 6 ; de 8 à 16 cent., 7 .

Soit, moyenne de l'envergure $1 \mathrm{~m} .663$.

\section{Au point de vue du buste :}

Dans la catégorie de 16 à 20 ans : buste supérieur à la moitié de la taille, de 0 à 5 cent., 2 individus ; de 5 à 10 cent., 1. Soit, moyenne du buste 0,853 .

De 20 à 25 ans: buste supérieur à la moitié de la taille, de 0 à 5 cent., 1 individu; de 5 à 10 cent., 3 .

Soit, moyenne du buste 0,850 .

De 25 à 30 ans: buste supérieur à la moitié de la taille, de 0 à 5 cent., 4 individus.

Soit, moyenne du buste 0,861 .

De 30 à 40 ans: buste supérieur à la moitié de la taille, de 0 à 5 cent., 1 individu; de 5 à 10 cent., 3 ; de 10 à 18 cent., 1.

Soit, moyenne du buste 0,864 .

De 40 à 50 ans : buste supérieur à la moitié de la taille, de 5 à 10 cent., 2 individus.

Soit, moyenne du buste 0,889. 
De 50 ans et au-dessus: buste supérieur à la moitié de la taille, de 5 à 10 cent., 2 individus.

Soit, moyenne du buste 0,839 .

En résumé: buste supérieur à la moitié de la taille, de 0 à 5 cent., 8 individus; de 5 à 10 cent., 11 ; de 10 à 18 cent., 1.

Soit, moyenne du buste 0,859 .

18 ${ }^{\circ}$ Au point de vue du pied:

Dans la catégorie de 16 à 20 ans: pied de 24 à 26 cent., 3 individus.

Soit, moyenne du pied 0,252.

De 20 à 25 ans : pied de 24 à 26 cent., 2 individus; de 26 à 28 cent., 2.

Soit, moyenne du pied 0,258.

De 25 a 30 ans : pied de 24 à 26 cent., 4 inclividus.

Soit, moyenne du pied, 0,250.

De 30 à 40 ans: pied de 22 à 24 cent., 1 individu; de 24 à 26 cent., 3 ; de 26 à 28 cent., 1 .

Soit, moyenne du pied 0,248.

De 40 à 50 ans : pied de 24 à 26 cent., 1 individu; de 26 à 28 cent., 1.

Soit, moyenne du pied 0,251 .

De. 50 ans et au-dessus : pied de 24 à 26 cent., 2 individus. Soit, moyenne du pied 0,24\%.

En résumé: pied de 22 à 24 cent., 1 individu; de 24 à 26 cent. 15 ; de 26 à $2 S$ cent., 4.

Soit, moyenne du pied 0,251. 
$19^{\circ}$ Au point de vue de la tête :

1 mésaticéphale; 5 sous-brachycéphales; 14 brachycéphales vrais.

D'autre part, les calculs donnent :

Longueur moyenne de la tête 0,1847 ; largeur moyenne de la tête 0,1565 .

D'où : Indice céphalique 84,73 .

$20^{\circ} \mathrm{Au}$ point de vue de l'oreille :

Indice auriculaire: de 52 à 56,6 individus; de 56 à 60,7 ; de 60 à $65,7$.

D'autre part, les calculs donnent :

Longueur moyenne de l'oreille 0,0620; largeur moyenne de l'oreille 0,0359 .

D'où: Indice auriculaire 57,90 .

$$
\text { *** }
$$

$21^{\circ}$ Au point de vue du visage :

En losange 1, rond 4, ovale 12, en toupie 3.

$22^{\circ}$ Au point de vue du front:

Arcades : grandes 4, petites 1, moyennes 15 .

Inclinaison : verticale 3 , fuyante 5 , intermédiaire 12 . 
Hauteur: grande 1, petite 5, moyenne 14.

Largeur : grande 7 , petite 1 , moyenne 12.

$2^{\circ}$ Au point de vue du nez:

Cavité (de la racine) : grande 2 , petite 11, moyenne 7 .

Dos : rectiligne 13, concave 2 , convexe 5.

Base : horizontale 14, relevée 5, abaissée 1.

Hauteur : grande 6, petite 1, moyenne 13 .

Saillie : grande 2, petite 2 , moyenne 16 .

Largeur : grande 1, moyenne 19.

24. Au point de vue de la bouche :

Dimension : grande 1, petite 1, moyenne 18 .

Inclinaison des angles : rectiligne 15, à coins abaissés 2, à coins relevés 3 .

Degré llabituel d'ouverture: bée 4, pincée 3, intermédiaire 13.

$25^{\circ}$ Au point de vue du menton :

Inclinaison générale : menton saillant 3, fuyant 1 , droit 16 . Avec et sans houppe: plat 4, à houppe 3, intermédiaire 13. Hauteur: haut 5 , bas 7 , intermédiaire 8 .

Forme : large 3 , rond 15 , pointu 2.

$26^{\circ}$ Au point de vue de l'œil :

Iris : impigmenté 3 , pigmenté de jaune 6 , d'orange 6 , de châtain 4 , de marron 1 .

$27^{\circ}$ Au point de vue du teint :

Brun 14, clair 6. 


$$
\text { *** }
$$

28 Au point de vue de la carrure:

Moyenne 16 , petite 4.

29. Au point de vue de la constitution et de l'état général à l'arrivée :

Très bons 2 , bons 10, passables 6, mauvais 2.

$30^{\circ}$ Au point de vue des maladies et infirmités à l'arrivẻe :

9 maladies et infirmités, à répartir entre 6 individus (5 Français et 1 Italien).

Soit: hypertrophie du cœur 1, artérite chronique avec dégénérescence athéromateuse prononcée 3 , accidents syphilitiques 1, boiteux 1, estropié (pied) 1, hernie inguinalo droite 1, imbécillitẻ 1 .

L'individu atteint d'imbécillité (Italien, âgé de trente-trois ans, célibataire, sachant lire et écrire, fondeur, urbain, sans antécéden ts judiciaires, adonné à l'ivrognerie, répu té très dangereux) subit la peine de trois ans de prison, prononcée, par le tribunal de Marseille, pour "vol et vagabondage ».

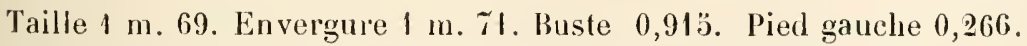
Tète : longueur 0,181 ; largeur 0,160 . Indice céphalique 86,93 .

Oreille droite: longueur $0,0.39$; largeur 0,037 . Indice auriculaire 62,71 . 
Front: arcades grandes; inclinaison intermédiaire; hauteur et largeur moyennes.

Nez : cavité (de la racine) moyenne; dos eonvexe; base horizontale; largeur, hauteur et saillie moyennes.

Bouche : movenne, à coins relevés; ouverture intermédiaire.

Menton : bas, rond, droit.

Visage arrondi. Iris pigmenté de jaune. Regard incertain.

Teint clair. Barbe chàtain clair ; cheveux et sourcils châtain moyen. Carrure moyenne. Santé faible. A expulser.

Sa conduite est sage: Tout en faisant des filoches, " il cherche le mouvement perpétuel ». - Obs. 44 .

$$
\text { *** }
$$

31 Au point de vue du lieu du crime:

Département du lieu de naissance : 2 individus (urbains ) Autre département : 18 , dont 3 ruraux.

$32^{\circ}$ Au point de vue de la date du crime :

1 en janvier, 2 en février, 2 en mars, 2 en avril, 2 en mai, 2 en juin, 2 en juillet, 2 en septembre, 1 en octobre, 2 en novembre, 2 en décembre.

Soit:Hiver . . . . . . . . . . . . . . . 5

Printemps . . . . . . . . . . . . . . 6

Été . . . . . . . . . . . 4

Automne. . . . . . . . . . . . 5 


$$
\text { *** } * \text { * }
$$

$33^{\circ}$ Au point de vue de la juridiction :

20 tribunaux correctionnels.

\section{$34^{\circ} \mathrm{Au}$ point de vue de la durée de la peine:}

6, condamnés $\dot{a} 1$ an et 1 jour ; 1 , $\dot{\alpha} 13$ mois; 6 , de 15 à 18 mois; 1 , de 18 mois $\dot{a} 2$ ans; 2 , de $2 \dot{\alpha} 3$ ans; 2 , de $3 \dot{a}$ 4 ans; $2, \dot{a} 5$ ans.

Un Espagnol, âgé de vingt-huit ans, marié, sachant lire et écrire, ex-ouvrier imprimeur, urbain, sans domicile, récidiviste, faisant partie d'une association de voleurs " à la tire ). a été condamné, à 5 ans de prison et à 5 ans d'interdiction de séjour, par la cour d'appel d'Aix (arrêt du 12 mai 1893, confirmant le jugement rendu, à Nice, le 24 mars de la même année), pour " vol, tentative de vol et vagabondage ).

On l'avait surpris, le 4 janvier, à la gare, volant la montre d'un voyageur.

Dans la matinée du même jour, il avait soulevé, à Cannes, un porte-monnaie contenant 50 francs et un coupon d'obligation.

De plus, en allant au poste de police, il avait frappé et mordu le commissaire du quartier.

Taille $1 \mathrm{~m}$. 676. Envergure $1 \mathrm{~m}$. 710. Buste 0,882. Pied gauche 0,232. Tête: longueur 0,182 ; largeur 0,147 . Indice céphalique 80,76 .

Oreille droite : longueur $0,0 \not 8$; largeur 0,036. Indice auriculaire 62,06 . Écartement supérieur. 
Front : arcades moyennes; inclinaison intermédiaire; hauteur et largeur moyennes.

$\mathrm{Nez}$ : cavité (de la racine) petite; dos rectiligne; base relevée; saillie petite ; hauteur et largeur mojennes.

Bouche : movenne, rectiligne ; ouverture intermédiaire.

Menton : droit, rond; hauteur intermédiaire.

Visage ovale. Iris pigmenté de châtain. Des yeux fins.

Teint clair. Barbe, cheveux et sourcils châtains.

Carrure movenne. Très bonne santé. A expulser.

C'est un costeau (batailleur) qui ne peut s'accoutumer au travail. - Espadrilles. - Obs. 45.

$35^{\circ}$ Au point de vue de l'interdiction de sejour :

7 sont frappés d'interdiction de séjour, parmi lesquels, 3 , par une condamnation antérieure.

36 ${ }^{\circ}$ Au point de vue du travail en prison :

Bons travailleurs 11, passables 4, maucais 5.

37. Au point de vue de la conduite en prison:

Bonne 8, passable 5, maucaise $\%$.

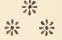

$38^{\circ}$ Au point de vue de l'expulsion :

7 étrangers sur $\%$. 


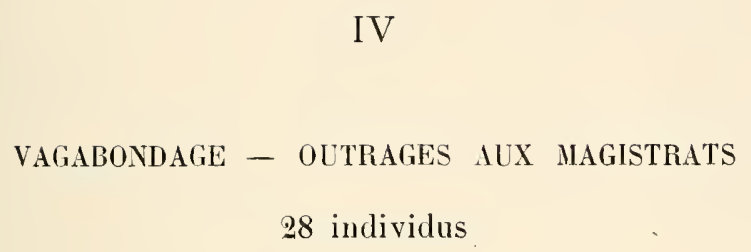

$1^{\circ}$ Au point de vue de la naissance :

26 enfants légitimes, 2 enfants nuturels.

\section{$2^{\circ}$ Au point de vue de la nationalité :}

25 Français (dont 1 Corse), 3 Étrangers (dont 1 Italien et 1 Espagnol).

Un Annonéen, âgé de vingt-cinq ans, sachant lire, écrire et calculer, artiste musicien, 9 fois condamné sous un faux nom, adonné à l'ivrognerie, subit la peine de 2 ans d'emprisonnement, prononcée, le 28 janvier 1895, par le tribunal correctionnel de Montpellier.

A la suite d'une condamnation, à 1 mois de prison, pour vagabondage et mendicité avec infirmitẻ simulée, cet homme avait adressé au procureur de la République une lettre des plus outrageantes. Il y traitait les magistrats de " lâches, canailles, imposteurs, scélérats, ânes, etc. ” (16 janvier 1895). 
Taille $1 \mathrm{~m}$. 622. Envergure $1 \mathrm{~m}$. 710. Buste 0,877. Pied gauche 0,260. Tète : longueur 0,186 ; largeur 0,161 . Indice céphalique 86,303 .

Oreille droite : longueur 0,065 ; largeur 0,038 . Indice auriculaire $58,46$. Front: arcades moyennes; inclinaison verticale; largeur petite; hauteur moyenne.

Nez : cavité (de la racine) petite; dos rectiligne; base relevée; saillie, hauteur et largeur moyennes.

Bouche : petite, bée, rectiligne.

Menton: droit, rond, bas.

Visage arrondi. Iris pigmenté de jaune.

Teint brun. Barbe, cheveux et sourcils chàtains (sourcils réunis). Carrure moyenne. Santé forte. Nine fière.

Un feignant. - Atelier de cordonnerie. - Obs. 46.

\section{$3^{\circ} \mathrm{Au}$ point de vue de l'âge :}

1 de $16 \dot{a} 20$ ans, 11 de $20 \dot{a} 30$ ans, 7 de $30 \dot{a} 40$ ans, 8 de 40 à 50 ans.

Le $28^{\mathrm{e}}$ a 60 ans.

C'est une " hirondelle " de prison. Connaissant tous les établissements qui possèdent un bon páturin (1), il y revient, périodiquement, avec le froid, et y travaille de bon gré lui, dont les poches ne renferment, à l'arrivée, que quelques bouts de cigare - pour gagner de quoi faire un peu la fête, le jour de la libération.

Il n'a pratiqué le vol que dans les grandes extrémités.

D'ailleurs, sa façon d'opérer manque absolument d'adresse. Pour se vêtir ou se mettre un morceau de pain sous la dent, il lui est arrivé de briser, à tout hasard, avec une pince prise dans un chantier, la porte de tel ou tel cabanon.

En revanche, il sientend au maniement des trucs à la c... : il sait descendre un bec de gaz, mettre les pattes en l'air à un agent de ville et diner à la paire, quand il veut être conduit au violon.

(1) Entrepreneur qui ne gagne pas trop sur les vivres réglementaires. 
La cour d'appel de Riom l'a condamné, le 28 janvier 1891, a 5 ans d'emprisonnement, sans confusion avec la peine de 4 mois, prononcée, par le tribunal de Montluçon, pour "vagabondage ").

Cet individu, natif du département de la Somme, sachant lire et écrire, journalier, urbain, 36 fois condamné, adonné à l'ivrognerie, avait outragé les magistrats, en tenant le propos suivant :

" Eh bien! voulez-vous que je vous le dise? vous êtes tous des salauds! ”

Taille $1 \mathrm{~m}$.66ว. Envergure $1 \mathrm{~m} .613$. Buste 0,923. Pied gauche 0,251. Tète : longueur 0,199 ; largeur 0,150 . Indice céphalique $7 \breve{3}, 37$.

Oreille droite : longueur 0,067 ; largeur 0,042 . Indice auriculaire 62,68 . Front: arcades moyennes ; inclinaison fuyante; hauteur moyenne; largeur petite.

Nez : cavité (de la racine) moyenue ; dos rectiligne ; base relevée ; saillie grande; hauteur et largeur moyennes.

Bouche: grande, rectiligne; ouverture intermédiaire.

Nenton : fuyant, rond; hauteur intermédiaire.

Visage ovale. Iris pigmenté d'orange. Truité.

Teint brun. Barbe, cheveux et sourcils châtains grisonnants. Tatoué. Carrure petite. Santé délabrée. Caractère sournois.

Conduite régulière. - Service général. - Obs. 47.

\section{$4^{\circ}$ Au point de vue de l'état civil :}

Tous sont célibataires.

Deux d'entre eux ont participé à l'insurrection de la Commune de Paris.

Ils comptent, chacun, 17 condamnations et rentrent dans la catégorie des bidonneur's.

L'un (ancien serrurier) appartient à la population rurale et a appris à lire dans le Pas-de-Calais, où il est né, le 19 avril 1848. 
Il subit la peine de 3 ans de prison, prononcée, le 5 juillet 1894, par le tribunal de Perpignan.

En s'entendant infliger 3 mois d'emprisonnement, pour vagabondage et mendicité, il s'était écrié que le tribunal n'ètait composé que de "Jésuites ».

Invité à s'expliquer, il avait répété ce qu'il avait dit, en ajoutant: " Le gouvernement de la République devrait bien vous épurer ».

Taille 1 m. 36 . Envergure $1 \mathrm{~m}$. 67. Buste 0,846. Pied gauche 0,20̈4. Tète : longueur 0,230 ; largeur 0,157 . Indice céphalique 68,26 . Oreille droite : longueur 0,067; largeur 0,036. Indice auriculaire 33,73 . Front : arcades grandes; inclinaison intermédiaire; hauteur grande ; largeur moyenne.

$\mathrm{Nez}$ : cavité (de la racine) moyenne; dos concave; base horizontale; largeur grande; hauteur et saillie moyennes.

Bouche : grande, rectiligne; ouverture intermédiaire.

Menton : fuyant, rond; hauteur intermédiaire.

Visage ovale. Iris pigmenté d'orange.

Teint brun. Barbe, cheveux et sourcils chàtains. Carrure grande. Santé bonne. Borgne.

Travailleur ; esprit remuant. - Filoches. - Obs. 48.

L'autre (tailleur d'habits, sachant lire, originaire du département de Seine-et-Oise, rural, ancien déporté à la NouvelleCalédonie) est âgé de 42 ans.

Le 15 juillet 1894, à 1 heure du soir, il se présentait dans un des postes de police de Pau, pour y recevoir un secours.

Comme il paraissait être en état de vagabondage, le commissaire l'interrogea et, après avoir reconnu que cette inculpation était fondée, l'arrêta.

Condamné, pour ce fait, par le tribunal, il fit appel et la cour confirma le jugement prononcé.

A la lecture de l'arrêt, cet homme essaya de se jeter sur les magistrats en s'écriant : "Vous ne valez pas mieux que les autres; vous êtes, tous, des canailles. ") 
On lui a infligé, le 10 août 1894, pour ce délit d'outrages, 3 ans de prison et 5 ans d'interdiction de séjour.

Taille $1 \mathrm{~m}$. 500. Envergure $1 \mathrm{~m}$. 520. Buste 0,763̈. Pied gauche 0,236 . Tète : longueur 0,170 ; largeur 0,140 . Indice céphaluiqe 82,3 . En pain de sucre.

Oreille droite : longueur 0,064 ; largeur 0,039 . Indice auriculaire 60,93 . Écartement total.

Front: arcades moyennes; inclinaison fuyante; hauteur moyenne; largeur petite.

Nez : cavité (de la racine) petite; dos convexe ; base horizontale; hauteur et saillie grandes; largeur moyenne.

Bouche: grande, rectiligne, pincée.

Menton: droit, rond, bas.

Visage en tronc de pyramide. Iris pigmenté d'orange, truité.

Teint mat. Barbe, cheveux et sourcils noirs (sourcils réunis). Tatoné. Carrure petite. Santé médiocre.

Bossu, variqueux et fourré de malice : mais, à l'abri de tout reproche. - Sacristain. - Obs. 49.

\section{$5^{\circ}$ Au point de vue de l'instruction :}

6 savent lire; 14 savent lire et écrire ; r savent lire, écrire et calculer ; 1 a reçu une instruction primaire complète.

Ce dernier (rural, sans profession, deux fois condamné, adonné à l'ivrognerie) est né, le 20 avril 1845, dans le Puy-deDôme.

Appelé à comparaître devant le tribunal de Mauriac, comme inculpé de vagabondage, outrages et rébellion, il se présenta, à l'audience, la tête couverte de son béret.

Sur l'invitation du président d'avoir à se découvrir, il s'écria : "Je n'ai pas de leçons de politesse à recevoir de vous, vous en avez plus besoin que moi »; puis, s'adressant à tous les magistrats : "Vous êtes des fabricants de misère!" 
Interrogé sur ses nom et qualités, il répondit encore : “Cela ne vous regarde pas. )

Cinq ans lui ont été infligés, pour " outrages »,le 25 mai 1894.

Taille $1 \mathrm{~m}$. 47. Envergure $1 \mathrm{~m}$. 53. Buste 0,820. Pied gauche 0,226. Tète : longueur 0,183 ; largeur 0,152 . Indice céphalique 83,06 .

Oreille droite : longueur 0,061 ; largeur 0,036 . Indice auriculaire $\ddot{3} 9,01$. Forme triangulaire

Front : arcades moyennes; inclinaison intermédiaire; hauteur et largeur moyennes.

Nez : cavité (de la racine) petite; dos convexe ; base horizontale; saillie grande; hauteur et largeur moyennes.

Bouche : moyenne, rectiligne; ouverture intermédiaire.

Nenton : droit, large, bas, plat.

Visage ovale. Iris pigmenté d'orange.

Teint brun. Barbe, cheveux et sourcils châtain foncé.

Carrure moyenne. Santé médiocre.

Boiteux (fracture de la cuisse droite, à dix ans) et faible d'esprit : il s'épuise à trouver des pensées ingénieuses et piquantes, en cassant des amandes, au Sénat. - Obs. 50.

\section{$6^{\circ}$ Au point de vue de la profession :}

9 rentrent dans la catégorie des ouvriers d'ateliers et de fabriques; 8 peuvent être classés parmi les professions agricoles, 4 dans les sans profession, 3 parmi les ouvriers du bâtiment et du mobilier, 2 parmi les nomades, 1 parmi les professions alimentaires, 1 parmi les employés.

L'employé (ancien comptable) est originaire d'une petite commune du département des Vosges et âgé de quarante ans. Il sait lire, écrire et calculer. La notice le signale comme étant à la $34^{\mathrm{e}}$ peine et comme ayant un caractère violent, arrogant et insolent envers toutes les autorités. On prétend qu'il lisait assidûment les feuilles " très avancées ») et qu'il a l'esprit imbu des "théories révolutionnaires ». 
A lui, le mot de la dive bouteille.

Le 27 septembre 1895, il se battit avec cinq gendarmes qui, l'ayant rencontré, à l'état de vagabondage, voulaient le conduire au parquet. Il résista avec une violence inouie - cherchant à les frapper à coups de pied, à coups de poing - et mordit l'un d'eux.

En même temps, il les insultait avec la dernière grossièreté, attitude qu'il conserva, vis-à-vis du procureur de la République, lors de son interrogatoire.

Le tribunal de Lombez l'a condamné, le 13 octobre 1895, à 13 mois de prison, et la cour d'appel d'Agen a confirmé ce jugement, par arrêt du 6 novembre 1895 .

Taille $1 \mathrm{~m}$. 62. Envergure $1 \mathrm{~m}$. 63̈. Buste 0,890. Pied gauche 0,25̈6. Tète : longueur 0,181 ; largeur 0,163 . Indice céphalique $90,03 ̈$.

Oreille droite : longueur 0,065 ; largeur 0,038 . Indice auriculaire 58,46 .

Front: arcades moyennes; inclinaison intermédiaire; hauteur et largeur moyennes.

Nez: cavité (de la racine) moyenne; dos rectiligne; base relevée; hauteur, largeur et saillie moyennes.

Bouche : moyenne, rectiligne, pincée.

Ienton: droit, large, plat; hauteur iutermédiaire.

Visage ovale. Iris impigmenté. OEil vif.

Teint clair. Barbe, cheveux et sourcils chàtains.

Carrure moyenne. Constitution et état général bons.

Il fait du ressaut (se plaint sans cesse) et se passe volontiers un coup de torchon. - Atelier de sparterie. - Obs. 51.

\section{$7^{\circ}$ Au point de vue de la population :}

19 urbains, 9 ruraux.

$8^{\circ} \mathrm{Au}$ point de vue du domicile :

4, arce domicile; 24, sans domicile. 


\section{9' Au point de vue du nombre des condamnations:}

4 sont sans antécédents judiciaires; 24 on tété condamnés 2 et plus de 20 fois.

Un Auvergnat, âgé de trente-cinq ans, sachant lire et écrire, journalier, rural, à la $27^{\circ}$ peine, antérieurement frappé d'interdiction de séjour, a été condamné, le 18 avril 1894, par la cour de Riom, à cinq ans d'emprisonnement, sur appel d'un jugement lui infligeant 4 mois pour vagabondage.

Il avait répondu à la question du président : " Pourquoi avez-vous fait appel? - C'est pour voir si vous êtes aussi sauvages et aussi canailles que les juges du tribunal de Gannat. „ Aujourd'hui, il ose, " comme ami », nous dire en confidence: " Ces messieurs ont un caractère raide.

" Nombre de trimards leur enverraient, de bon cœur, un sabot à la tête, n'était la précaution prise, depuis longtemps, d'enfermer les appelants, sous l'œil de trois ou quatre gendarmes, dans une sorte de volière solidement grillagée. »)

Taille $1 \mathrm{~m}$. 720̆. Envergure $1 \mathrm{~m}$. 800. Buste 0,927. Pied gauche 0,268. Tète: longueur 0,191; largeur 0,158 . Indice céphalique 82,72.

Oreille droite: longueur 0,067 ; largeur 0,034 . Indice auriculaire 50,74 .

Front: arcades grandes; inclinaison fuyante; hauteur et largeur moyennes.

Nez : cavité (de la racine) moyenne; dos rectiligne; base horizontale; largeur grande; hauteur et saillie moyennes.

Bouche : moyenne, à coins abaissés; ouverture intermédiaire. Menton: droit, large, a fossette; hauteur intermédiaire. Visage large. Iris pigmenté d'orange. Physionomie expressive. Teint brun. Barbe, chevenx et sourcils chàtain foncé (sourcils réunis). Carrure moyenne. Santé bonne.

Au demeurant, un drôle bien découplé et grand travailleur ; mais, sans conduite. - Ébénisterie. - Obs. 52. 
$10^{\circ}$ Au point de vue de l'oisiveté :

25 oisifs.

$11^{\circ} \mathrm{Au}$ point de vue de l'ivrognerie :

19 adonnés à l'ivrognerie.

12. A u point de vue du libertinage et de la débauche:

13 libertins et débauchés.

13 Au point de vue du concubinage :

2 vivant en concubinage.

$14^{\circ}$ Au point de vue de la note de la commune:

Aucun bien noté.

$$
\text { *** }
$$

$15^{\circ} \mathrm{Au}$ point de vue de la taille :

Dans la catégorie de 16 à 20 ans : taille de $1 \mathrm{~m} .60$ à $1 \mathrm{~m} .70$, 1 individu.

Soit, taille $1 \mathrm{~m} .640$.

De 20 à 25 ans : taille au-dessous de $1 \mathrm{~m}$. 60, 2 individus; de $1 \mathrm{~m} .60$ à $1 \mathrm{~m}$. 70,4 .

Soit, moyenne de la taille $1 \mathrm{~m} .606$. 
De 25 i 30 ans : taille au-dessous de $1 \mathrm{~m}$. 60, 1 individu: de $1 \mathrm{~m}$. 60 à $1 \mathrm{~m}$. $\% 0,4$.

Soit, moyenne de la taille $1 \mathrm{~m}$. 614 .

De 30 a 40 ans : taille au-dessous de $1 \mathrm{~m}$. 60, 1 individu: de $1 \mathrm{~m}$. 60 à $1 \mathrm{~m}$. 70, 4 ; de $1 \mathrm{~m}$. 70 et au-dessus, 2 .

Soit, moyenne de la taille $1 \mathrm{~m} .660$.

De 40 à 50 ans: taille au-dessous de $1 \mathrm{~m}$. 60, 4 individus: de $1 \mathrm{~m} .60$ à $1 \mathrm{~m} .70,4$.

Soit, moyenne de la taille $1 \mathrm{~m} .576$.

De 50 ans et au-dessus : taille de $1 \mathrm{~m} .60$ à $1 \mathrm{~m}$. 70, 1 individu.

Soit, taille $1 \mathrm{~m} .665$.

En résumé: taille au-dessous de $1 \mathrm{~m}$. 60, 8 individus; de $1 \mathrm{~m} .60$ à $1 \mathrm{~m}$. \%0, 18; de $1 \mathrm{~m}$. 70 et au-dessus, 2 .

Soit, moyenne de la taille $1 \mathrm{~m} .615$.

\section{$16^{\circ} \mathrm{Au}$ point de vue de l'envergure :}

Dans la catégorie de 16 à 20 ans : Envergure supérieure à la taille, de $S$ à 16 cent., 1 individu.

Soit, envergure $1 \mathrm{~m}$. 720 .

De 20 à 25 ans : envergure inférieure à la taille, de 0 à 8 cent.,

1 individu; supérieure à la taille, de 0 à 4 cent., 2 ; de 4 à 8 cent, 1 ; de 8 à 16 cent., 2.

Soit, moyenne de l'envergure $1 \mathrm{~m} .64 \%$.

De 25 à 30 ans : envergure supérieure à la taille, de 0 à 4 cent.,

2 individus; de 4 à 8 cent., 1 ; de 8 à 16 cent., 2 .

Soit, moyenne de l'envergure $1 \mathrm{~m} .670$.

De 30 à 40 ans : envergure inférieure à la taille, de 0 à $\mathrm{S}$ cent.,

1 individu; supérieure à la taille, de 0 à 4 cent., 2 ; de 4 à 8 cent., 4 .

Soit, moyenne de l'envergure $1 \mathrm{~m} .694$. 
De $40 \dot{\alpha} 50$ ans : envergure inférieure à la taille, de 0 à $\delta$ cent., 2 individus; supérieure à la taille, de 0 à 4 cent., 3 ; de 4 à 8 cent., 1 ; de 8 à 16 cent., 2 .

Soit, moyenne de l'envergure $1 \mathrm{~m} .61 \%$.

De 50 ans et au-dessus : envergure inférieure à la taille, de 0 à 8 cent., 1 individu.

Soit, envergure $1 \mathrm{~m} .615$.

En résumé : envergure inférieure à la taille, de 0 à 8 cent., 5 individus; supérieure à la taille, de 0 à 4 cent., 9 ; de 4 a 8 cent., 7 ; de 8 à 16 cent., 7.

Soit, moyenne de l'envergure $1 \mathrm{~m} .656$.

\section{7॰ Au point de vue du buste :}

Dans la catégorie de 16 à 20 ans: buste supérieur à la moitié de la taille, de 5 à 10 cent., 1 individu.

Soit, hauteur du buste $0,8 \% 2$.

De 20 a 25 ans : buste supérieur à la moitié de la taille, de 0 à 5 cent., 1 individu; de 5 à 10 cent., 5 .

Soit, moyenne du buste 0,886.

De 25 a 30 ans : buste supérieur à la moitié de la taille, de 0 à 5 cent., 1 individu; de 5 à 10 cent., 3 ; de 10 à 18 cent., 1.

Soit, moyenne du buste 0,859 .

De 30 à 10 ans : buste supérieur à la moitié de la taille, de 0 à 5 cent., 1 individu; de 5 à 10 cent., 6 .

Soit, moyenne du buste 0,889 .

De 40 a 50 ans: buste supérieur à la moitié de la taille, de 0 à 5 cent., 2 individus; de 5 à 10 cent. 6 .

Soit, moyenne du buste 0,849 . 
De 50 ans et au-dessus : buste supérieur à la moitié de la taille, de 5 a 10 cent., 1 individu.

Soit, hauteur du buste 0.923 .

En résumé: buste supérieur à la moitié de la taille, de 0 à 5 cent., 5 individus; de 5 a 10 cent., 22 ; de 10 à 18 cent., 1.

Soit, moyenne du buste 0,872 .

$18^{\circ} \mathrm{Au}$ point de vue du pied :

Dans la catégorie de 16 à 20 ans:pied de 26 à 28 cent., 1 individu.

Soit, longueur du pied 0,262.

De 20 à 25 ans : pied de 22 à 24 cent., 1 individu; de 24 à 26 cent., 3 ; de 26 à 28 cent., 2.

Soit, moyenne du pied 0,254.

De $25 \dot{a} 30$ ans : pied de 22 à 24 cent., 1 individu; de 24 à 26 cent., 1 ; de 26 à 28 cent., 3.

Soit, moyenne du pied 0,255.

De 30 à 40 ans: pied de 22 à 24 cent., 1 individu; de 24 à 26 cent., 2 ; de 26 a 28 cent., 4.

Soit, moyenne du pied 0,256.

De 10 a 50 ans : pied de 22 à 24 cent., 4 individus; de 24 à 26 cent., 3 ; de 26 à 28 cent , 1 .

Soit, moyenne du pied 0,243 .

De 50 ans et au-dessus : pied de 24 à 26 cent., 1 individu.

Soit, longueur du pied 0,251.

En résumé: pied de 22 à 24 cent., 7 individus; de 24 à 26 cent., 10 ; de 26 à 28 cent., 11 .

Soit, moyenne du pied 0,252. 
$19^{\circ} \mathrm{Au}$ point de vue de la tête :

1 dolichocéphale trai, 3 sous-dolichocéphales, 3 mésaticéphales, 10 sous-brachycéphales, 11 brachycéphales vrais.

D'autre part, les calculs donnent :

Longueur moyenne de la tête 0,1893 ; largeur moyenne de la tête $0,155 \%$.

D’où : Indice céphalique 82,25 .

$20^{\circ} \mathrm{Au}$ point de vue de l'oreille :

Indice auriculaire : Au-dessous de 52, 4 individus ; de 52 à 56, 10 ; de 56 à 60,10 ; de 60 à 65,4 .

D'autre part, les calculs donnent :

Longueur moyenne de l'oreille 0,0631; largeur moyenne de l'oreille $0,035 \%$.

D'où : Indice auriculaire 56,5\%.

$$
\text { *** }
$$

$21^{\circ} \mathrm{Au}$ point de vue du visage :

En tronc de pyramide 1, rond 4, large ou carré 3,ovale 20.

$22^{\circ} \mathrm{Au}$ point de vue du front:

Arcades: grandes 5 , petites 2 , moyennes 21 .

Inclinaison: verticale 4, fuyante 6 , intermédiaire 18 .

IIauteur : grande 3 , petite 4 , moyenne 21 .

Largeur : grande 6, petite 7, moyenne 15. 
$23^{\circ}$ Au point de vue du nez:

Cavité (de la racine) : grande 1 , petite 7 , moyenne 20.

Dos : rectiligne 19, concave 4 , convexe 5.

Base : horizontale 19, relevée 9 .

Hauteur: grande 4, petite 1, moyenne 23.

Saillie: grande 3, petite 2 , moyenne 23.

Largeur: grande 3, moyenne 25 .

$24^{\circ} \mathrm{Au}$ point de vue de la bouche:

Dimension : grande 7, petite 1 , moyenne 20.

Inclinaison des angles : rectiligne 21, à coins abaissés 3, à coins relevés 4 .

Degré habituel d'ouverture: bée 3 , pincée 3 , intermédiaire 22.

25 Au point de vue du menton:

Inclinaison générale : saillant 3 , fuyant 7 , droit 18 .

A vec et sans houppe: plat 5 , a houppe 3 , intermédiaire 20 Hauteur: haut 4, bas 10, intermédiaire 14 .

Forme: large 8, rond 19, pointu 1.

26. Au point de vue de l'œil :

Iris : impigmenté 3 , pigmenté de jaune 7 , d'orange 13 , de châtain 3 , de marron 2 .

$27^{\circ}$ Au point de vue du teint:

Brun 14, mat 3, basané 1, clair 10. 


$$
\text { *** }
$$

$28^{\circ} \mathrm{Au}$ point de vue de la carrure:

Grande 3, moyenne 21, petite 4 .

$29^{\circ} \mathrm{Au}$ point de vue de la constitution et de l'état général à l'arrivèe:

Très bons 5, bons 14, passables 3, mauvais 5, tries mauvais 1.

30. Au point de vue des maladies et infirmités à l'arrivèe :

11 maladies et infirmités, à répartir entre 7 individus (6 Français, dont 1 Corse; 1 Italien).

Soit : bronchite bacillaire 1, ataxie 1, déviation de la colonne vertébrale 1 , boiteux 1 . hernie inguinale droite 1 , varicocèle 2 , borgne 1, atrophie du nerf optique 1, surdité légère 1, imbécillité 1 .

$$
\text { *** }
$$

$31^{\circ}$ Au point de vue du lieu du crime:

Lieu de naissance: 1 individu (urbain ayant un domicile). Département du lieu de naissance: 2 individus (urbains, dont 1 sans domicile).

Autre département: 25 individus, dont 23 sans domicile (16 urbains et 7 ruraux). 
32. Au point de vue de la date du crime:

6 en janvier, 4 en mars, 4 en avril, 2 en mai, 1 en juin, 3 en juillet, 1 en août, 2 en septembre, 1 en octobre, 1 en novembre, 3 en décembre.

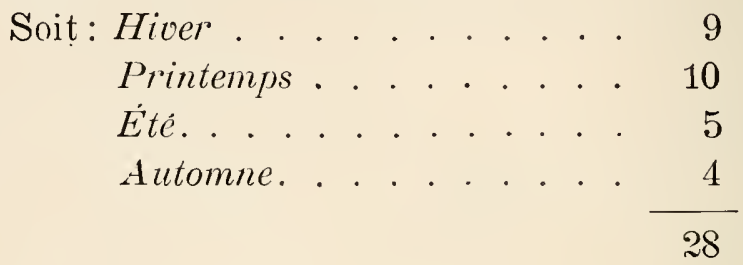

$33^{\circ}$ Au point de vue de la juridiction :

On ne compte que des tribunaux.

$34^{\circ} \mathrm{Au}$ point de vue de la durée de la peine:

1, condamné à 1 an et 1 jour; 2 , à 13 mois; 9 , à 2 et moins de 3 ans; $6, \dot{a} 3$ et moins de 4 ans; $10, \dot{a} 5$ ans et plus.

Signalons un ancien jardinier, né le 5 janvier 1854, sachant lire écrire et calculer, à la $24^{\mathrm{e}}$ condamnation.

Le tribunal de Cusset lui ayant infligé 2 mois d'emprisonnement pour mendicité, il fit appel à Riom où la peine fut élevée à 6 mois, par arrêt de la cour, en date du 13 septembre 1894.

"C'était plus que le comble! Je me mis alors en frais d'éloquence et je leur dis : "Messieurs, il est bien regrettable que des gens comme vous, ça mange du pain, tandis qu'il y a de la 
si belle avoine qui se perd. ") Le président m'ayant demandé si je maintenais mes paroles, je lui répondis: "Tout ce que je puis faire, c'est de vous offrir, à vous, Monsieur le président, un hectolitre d'avoine, et à ces Messieurs, vos collègues, une botte de foin."

Ces paroles obligeantes lui valurent 5 ans d'emprisonnement.

Depuis lors, il ne demande qu'i revoir son cher petit pays tant regretté... Saint-Ouen! et à boire un coup, car rien ne lui paraît plus beau que de se trouver " entre deux vins ").

A quatre ans, il était orphelin de sa mère. L'année suivante, son père se remariait. On ne peut se faire une idée dess dégoûts et tracasseries qui l'attendaient.

Il lack ha les siens et vint, à Paris, se faire cueillir, endormi, sur un bane des Champs-Elysées. Le commissaire du quartier le jeta dans le panier à salade, à destination de la Tour pointue (préfecture de police). Le lendemain, un Cipal le conduisait devant la $11^{\mathrm{e}}$ chambre. Le vagabondage est un délit.

Taille $1 \mathrm{~m}$. 68. Envergure $1 \mathrm{~m}$. 82. Buste 0,873. Pied gauche 0,274.

Tète : longueur 0,192 ; largeur 0,158 . Indice céphalique 82,29 .

Oreille droite: longueur 0,071 ; largeur 0,039 . Indice auriculaire ö4,92. Écartement total.

Front: arcades moyennes; inclinaison intermédiaire; hauteur et largeur moyennes.

Nez: cavité (de la racine) moyenne; dos rectiligne; base relevée; largeur, hauteur et saillie moyennes.

Bouche : moyenne, rectiligne, pincée.

Mentun : saillant, large, haut.

Visage large. Iris pigmenté d'orange. Regard voilé.

Teint brun. Barbe, cheveux et sourcils chàtains.

Carrure moyenne. Santé chancelante.

Misanthrope frondeur et empailleur de chaises. - Obs. 53. 
$35^{\circ} \mathrm{Au}$ point de vue de l'interdiction de séjour :

4 sont frappés d'interdiction de séjour, parmi lesquels, 1, par une condamnation antérieure.

$$
\text { *** }
$$

36 Au point de vue du travail en prison:

Bons travailleurs 16, passables 10, mauvais 2.

$$
\text { *** }
$$

37. Au point de vue de la conduite en prison :

Bonne 11, passable 10, manvaise $\%$

$38^{\circ} \mathrm{Au}$ point de vue de l'expulsion:

2 étrangers sur 3. 
VIOLENGES - COUPS ET BLESSURES - RERELLLION

90 individus
\end{abstract}

1. Au point de vue de la naissance:

S6 enfants légitimes, 4 enfants naturels.

$2^{\circ}$ Au point de vue de la nationalité:

70 Francais (dont 27 Corses), 20 étrangers (18 Italiens et 2 divers).

Un Suisse, né à Bâle, âgé de vingt-deux ans, célibataire, sachant lire et écrire, typographe, sans domicile, à la $1^{\text {re }}$ peine, adonné à l'ivrognerie, a été condamné, par arrêt de la cour d'appel de Grenoble, en date du 25 octobre 1895, à deux ans de prison (jugement du tribunal de Vienne confirmé), pour " coups et blessures ".

Le 3 septembre 1895 , vers 8 heures $1 / 2$ du soir, en compagnie d'un malfaiteur de sa trempe, il s'était approché d'une maison habitée, près de la route nationale, à Saint-Maurice-de-l'Exil, et, sur le refus de leur donner un gîte, de l'argent et du pain, il avait porté au propriétaire deux coups de couteau, pendant 
que son compagnon saisissait, par les cheveux, la sœur accourue au secours, la terrassait et la frappait de la même façon.

Il fallut l'arrivée des voisins, armés de fusils, pour que les deux agresseurs prissent la fuite.

L'expulsion suivra la peine.

Taille 1 m. 6ว̈. Envergure $1 \mathrm{~m}$. 71. Buste 0,877 . Pied gauche 0,278 .

Tète : longueur 0,190 ; largeur 0,137 . Indice céphalique 82,63 .

Oreille droite: longueur 0,071 ; largeur 0,038 . Indice auriculaire 53,202 .

Front: arcades moyennes; inclinaison intermédiaire; hauteur et largeur grandes.

Nez: cavité (de la racine) moyenne; dos concave; base horizontale; hauteur, saillie et largeur moyennes.

Bouche : moyenne, à coins abaissés; ouverture intermédiaire.

Menton : droit, rond, bas.

Visage ovale. Iris pigmenté de jaune. Expression du regard banale.

Teint clair. Barbe, cheveux et sourcils chàtain clair. Tatoné.

Carrure grande. Santé excellente.

Bon détenu. - Pantouftes. - Obs. 54.

\section{$3^{\circ}$ Au point de vue de l'âge :}

13 de 16 à 20 ans.

On distingue un Corse, âgé de dix-neuf ans, sachant lire et écrire, journalier (souteneur), urbain, domicilié à Marseille, adonné à l'ivrognerie, 6 fois condamné.

La cour d'Aix, par arrêt du 16 mai 1895, sur l'appel du ministère public, a élevé à 3 ans la peine de 13 mois de prison, prononcée contre lui, par le tribunal de Marseille, le 2 avril 1895, pour "violences, voies de fait aux agents et port d'arme prohibée ".

Cet individu a ici les mêmes principes que dehors. Depuis un an, il se paie des douceurs avec le produit de la prostitution 
de deux gamins, sur le dos desquels les coups pleuvent, dru comme grêle, quand il y a chômage.

Une chose digne de remarque et constamment notée par ses pareils, c'est que l'attachement d'une fille - gigolette ou giron - pour son " ami », varie en raison inverse de l'affection de ce dernier : Un homme trop bon est bientôt plaqué. Le brutal au contraire est craint, ménagé et obéi.

Le teint doucement animé, ce triste personnage raconte ses premiers pas dans le monde des petits requins.

"A Après avoir volé, à mon capitaine qui commandait le navire à voile: l'Événement, une somme de 250 francs, j'achetai un " costume de nervi (1).) et je partis, à Toulon, avec trois camarades qui « s'y entendaient pour les femmes ». J'étais le plus jeune de trois, âgé de dix-sept ans. Arrivé au "ChapeauRouge ", ces clames m'invitèrent à danser. A leur vue, j'éprouvai quelque honte, surtout de ne pas savoir. Une d'entre elles insista tout particulièrement; c'était une charmante blonde, à la fleur de l'âge, en religion: "Augustine ». Je lui fis part de mes regrets et de mon ignorance. Mais, ce qu'une femme veut, Dieu le veut. Elle était amoureuse; on le sentait. Quelques petits verres me donnèrent du toupet. Nom d'un chien! Tout à coup, je saisis Titine par le cou et par la taille et je me mis à sauter avec elle.

"L'ardeur de ses baisers coulait au fond de mon âme. J'étais en forme. C'est alors qu'elle me proposa de nous mettre ensemble. Rien ne devait me manquer.

" Le pacte fut conclu. Pendant quinze jours, on vécut d'un bonheur sans mélange. Elle me nourrissait et me donnait quatre ou cinq sous de tabac par jour. Après ce laps de temps, il y eut de la froideur entre nous. Ma moitié en pinçait pour se faire morfiller et, moi, je ne savais pas ce que c'était que frotter sa langue sur une petite sœur.

(1) Pantalon de velours noir, a la hussarde; veston bleu marine, vulgairement appelé : " cotte "; gilet á fleurs ou de fantaisie; chemise de couleur, très échancrée, en satinette; ceinture de flanelle, tris voyante; souliers jaunes, il bout pointu; foulard en soie, à ramages; chapeau de feutre noir, a la Buffalo. 
" Je fus mis au rancart. Dès lors, je changeai souvent de gon:esse. Enfin je revins à Marseille, où je perforai l'hymen à une Parisienne que je conduisis, le soir du même jour, chez un vieil asticot à persiennes, de mes amies.

" Tiens, Berthe, lui dis-je, voici un début que je t'amène: elle m'appartient. Attention!'si elle cache l'argent, je le saurai et tu le paieras cher."

Et voilà comment me revient l'honneur d'avoir fait de Mélie une putain des plus débrouillardes, entretenue, en ce moment. par un richard qui habite à la Corniche. ")

Conserver sa devise; elle est chère à son cœur.

Les motsen sont sacrés : point d'amour, point d'houneur.

Et si on recherche la cause de tant d'avilissement, on la trouve, peut-être, dans ce fait que l'école, à laquelle il fut envoyé, enfant, était située dans un quartier qu'on appelle : "Pentagone ", où il existe des filles soumises. "Tous les jours, en passant, dit-il, nous regardions comment elles faisaient leurs affaires d'amour. ")

Taille $1 \mathrm{~m}$. 6ว̈. Envergure $1 \mathrm{~m}$. 64. Buste 0,893. Pied gauche 0, 258 .

Tète: longueur 0,188 ; largeur $0,1 \%$. Indice céphalique 81,91 .

Oreille droite : longueur 0,061 ; largeur 0,034 . Indice auriculaire 55,73. Tubercule darwinien sur le bord postérieur.

Front : arcades moyennes; inclinaison verticale; hauteur et largeur moyennes.

Nez : cavité (de la racine) moyenne; dos rectiligne; base relevée; hauteur, largeur et saillie moyennes.

Bouche : moyenne, à coins abaissés, bée ; lèvres épaisses.

Menton: large, fuyant, haut.

Visage ovale. Iris pigmenté d'orange. Traits durs.

Teint brun. Barbe, cheveux et sourcils châtain clair. Tatoué. Carrure moyenne. Santé forte.

Un rossard : Il est venu au monde fatigué, et se gausse de toutes les remontrances qu'on lui fait. - Chaises. Obs. 55 . 
36 de 20 à 30 ans, 22 de 30 ¿̀ 40 ans, 16 de 40 à 50 ans, 3 de 50 ans et plus.

Le plus vieux a soixante-neuf ans. Sa réputation est mauvaise. C'est à boire qu'il lui faut; ainsi en témoignent deux condamnations, prononcées jadis, contre lui, par le Conseil de guerre de Paris - lune, pour bris d'un fusil; l'autre, pour outrages envers un supérieur.

Il est originaire de l'Aveyron, veuf, sans instruction, coloriste, urbain, et fait 2 ans de prison, pour " coups et blessures volontaires, et violences sur un magistrat de l'ordre administratif » (jugement du tribunal de Millau, en date du 11 juillet 1895).

Prompt et colère, il avait pénétré, le 26 mai 1895, entre 9 et 10 heures du matin, dans la chambre d'une voisine, où se trouvait sa fille, et avait blessé l'amie, en faisant feu sur elle avec un revolver.

Pour le désarmer, il fallut engager une véritable lutte, pendant laquelle le commissaire de police reçut un coup de couteau à la main droite.

Taille $1 \mathrm{~m}$. 59. Envergure $1 \mathrm{~m}$. 63. Buste 0,834. Pied gauche 0,248. Tête : longueur 0,194 ; largeur 0,1337 . Indice céphalique 80,92 .

Oreille droite : longueur 0,06 ; ; largeur 0,042 . Indice auriculaire 64,61. Front : arcades moyennes; inclinaison fuyante; hauteur et largeur moyennes.

Nez : cavité (de la racine) moyeune; dos rectiligne; base horizontale; hauteur, largeur et saillie moyennes.

Bouche: moyenne, rectiligne ; ouverture intermédiaire.

Menton: droit, rond, plat; hauteur intermédiaire.

Visage arrondi. Iris pigmenté de jaune. Physionomie insignifiante.

Teint brun. Barbe blanche; cheveux et sourcils châtains.

Sourcils écartés. Tatoué.

Carrure moyenne. Santé médiocre. Presbytie.

Il aime le travail et tient une bonne conduite. - Filoches. - Obs. 56. 
$4^{\circ} \mathrm{Au}$ point de vue de l'ètat civil :

68 célibataires, 15 mariés, 7 veufs.

L'un des veufs (Corse, âgé de cinquante-sept ans, illettré, cultivateur, rural, à la $3^{\mathrm{e}}$ peine), a été condamné, par la cour d'assises de son département, le 27 juin 1893, à 5 ans de prison.

Le 26 septembre 1892, cet homme et 45 habitants de Guagno* - parmi lesquels, 33 armés de fusils - s'étaient rendus à Soccia, pour imposer aux membres du bureau central, réunis dans ce chef-lieu de canton, la proclamation de leur candidat comme conseiller d'arrondissement. Là, ils firent rébellion à la gendarmerie lorsque, conformément à un arrêté pris par le maire, elle leur interdit d'entrer en armes dans le village, et ils donnèrent la mort aux gendarmes.

Le jury n'a retenu que la rébellion.

Taille $1 \mathrm{~m}$. 683. Envergure $1 \mathrm{~m}$. 630. Buste 0,872 . Pied gauche 0,25̈2. Tète : longueur 0,200 ; largeur 0,158 . Indice céphalique 79,00.

Oreille droite: longueur 0,068 ; largeur 0,042 . Indice auriculaire 61,76 .

Front: arcades moyennes; inclinaison intermédiaire; hauteur et largeur moyennes.

Nez : cavité (de la racine) moyenne; dos busqué; base abaissée; hauteur, largeur et saillie moyennes.

Bouche : moyenne, rectiligne ; ouverture intermédiaire.

Menton : fuyant, rond; hauteur intermédiaire.

Visage ovale. Iris pigmenté de châtain. Figure ouverte.

Teint brun. Barbe, cheveux et sourcils chàtains.

Carrure petite. Santé bonne.

Sa conduite vaut mieux que son travail. - Scrvice général, - Obs. $5 \%$. 


\section{5" Au point de vue de l'instruction :}

17 sont illettrés; 11 savent lire.

Parmi ceux qui savent lire, figure un Corse, âgé de quarantehuit ans, veuf, journalier, rural, à la $4^{\mathrm{e}}$ peine.

Le tribunal de Bastia lui a infligé (29 juillet 1895), 2 ans de prison, pour " coups et blessures volontaires ".

Le 11 juillet 1895, après boire, il chercha dispute à un de ses compatriotes qu'il traita de "cornard».

Une femme ayant voulu lui faire peser tout le fiel contenu dans une si sotte injure, il s'arma d'un couteau et poursuivit cette femme jusque dans sa maison, où il n'osa pas pénėtrer devant son attitude menaçante (elle tenait une hache à la main). Ayant alors rellcontré, sur son chemin, la mère, âgée de soixante-sept ans et presque infirme, sans mot dire, il se rua sur elle et lui porta deux coups de couteau à la gorge.

Taille $1 \mathrm{~m}$. 5̆. Envergure $1 \mathrm{~m}$. 59. Buste 0,842. Pied gauche 0 ,248.

Tète : longueur 0,187 ; largeur 0,148 . Indice céphalique 79,14 .

Oreille droite : longueur 0,063 ; largeur 0,040 . Indice auriculaire 63,49 . Front : arcades grandes; inclinaison fuyante; hauteur grande; largeur moyenne.

Nez : cavité (de la racine) moyenne; dos rectiligne ; base horizontale; hauteur, largeur et saillie moyennes.

Bouche : moyenne, rectiligne, pincée.

Menton : fuyant, rond; hauteur intermédiaire.

Visage ovale. Iris pigmenté de marrou.

Teint brun. Barbe, cheveux et sourcils châtains.

Carrure moyenne. Santé bonne. Humeur inégale.

Paresseux, souvent au tourniquet (salle de discipline). Atelier de sparterie. - Obs. 58 : 
56 sacent lire et écrire ; 6 savent lire, écrire et calculer.

Un Italien, âgé de vingt et un ans, célibataire. sachant lire, écrire et calculer, chaudronnier, urbain, à la $1^{\text {re }}$ peine, a été condamné, par la cour d'assises de l'Aveyron, le 27 juin 1894, à 5 années d'emprisonnement, pour " coups et blessures volontaires sur son père $)$.

Le père avait cru devoir adresser, plusieurs fois, des reproches a son fils, parce qu'il rentrait souvent fort tard et qu'il dépensait trop d'argent pour ses plaisirs. D'un autre côté, le fils s'était permis de faire des reproches au père, pour les mêmes motifs.

Il faut dire pourtant que, d'une manière habituelle, le père et le fils, surtout ce dernier, se conduisaient bien.

Le tort principal du père était d'avoir une maîtresse (notice individuelle).

Dans la soirée du 27 mai 1894, la mère, voulant s'assurer si son mari la trompait, se rendit au domicile de la concubine et l'y trouva.

Elle lui fit de violents reproches qu'il accueillit très mal.

Sur ces entrefaites, le fils arriva. Les invectives recommencèrent; puis, tous trois rentrèrent chez eux, non sans s'injurier, en route, réciproquement. Sur le seuil de la porte, le père aurait menacé son fils de lui faire son compte. Alors celui-ci, tirant de sa poche un grand couteau de table pointu, le plongea dans la poitrine de son père qui mourut sur le coup.

Taille $1 \mathrm{~m}$. 69. Envergure $1 \mathrm{~m}$. 79. Buste 0,920. Pied gauche 0,266. Tète : longueur 0,187 ; largeur 0,161 . Indice céphalique 86,09 .

Oreille droite: longueur 0,059; largeur 0,037. Indice auriculaire 62,71. Forme triangulaire.

Front: arcades moyennes; inclinaison intermédiaire; hauteur et largeur moyennes.

Nez: cavité (de la racine) moyenne ; dos convexe; base horizontale; hauteur, largeur et saillie moyennes. Dévié à gauche.

Bouche : petite, rectiligne; ouverture intermédiaire.

Jenton: droit, rond, haut. 
Visage ovale. Iris pigmenté d'orange. Physionomie douce.

Teint brun. Barbe, cheveux et sourcils chàtain 'moyen.

Carrure moyenne. Constitution robuste.

Travailleur, mais sans conduite. - Lits en fer. - Obs. 59.

\section{$6^{\circ}$ Au point de vue de la profession :}

4 nomades, 2 propriétaires et rentiers, 2 employés.

Un Corse, âgé de trente-six ans, sachant lire et ėcrire, employé de commerce, urbain, sans antécédents judiciaires, subit la peine de 18 mois de prison, prononcée, le 19 novembre 1895, par la cour d'assises des Bouches-du-Rhône, pour " coups et blessures".

Le 15 juillet 1895, il fit feu avec un revolver sur l'amant de sa femme, et lui porta, dans la région du coeur, deux coups de poignard mortels.

Taille $1 \mathrm{~m}$. 770. Envergure $1 \mathrm{~m}$. 83. Buste 0,935. Pied gauche 0,258. Tète : longueur 0,194; largeur 0,147. Indice céphalique 75,77.

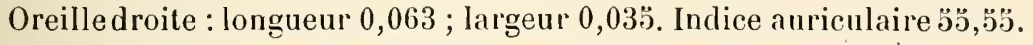
Front : arcades moyennes; inclinaison verticale; hauteur et largeur moyennes.

Nez: cavité (de la racine) moyenne; dos rectiligne, sinueux; base horizontale; saillie, hauteur et Iargeur moyennes.

Bouche: moyenne, à coins abaissés ; ouverture intermédiaire ; lèvres épaisses.

Menton : saillant, rond, à fossette; hauteur intermédiaire.

Visage ovale. Iris pigmenté de marron.

Teint brun. Barbe, cheveux et sourcils chàtains; sourcils sinueux et écartés. Tatoué.

Carrure grande. Santé vigoureuse. Bonne mine.

Ouvrier habile et tranquille. - Pipes. - Obs. 60. 
47 professions agricoles, 19 ouvrier's d'ateliers et de fabriques, 8 outriers du bâtiment et du mobilier, S professions alimentaires.

Un boulanger (Agenois, âgé de vingt-sept ans, célibataire, sachant lire et écrire, récidiviste, adonné à l'ivrognerie, dans l'habitude de battre ses parents), a été condamné, le 20 juin 1893, par la cour d'assises du Tarn-et-Garonne, à 5 ans de prison, pour " coups et blessures volontaires à ses père et mère ».

Dans les premiers jours du mois de mai 1893, sa mère lui ayant refusé de l'argent, il l'avait frappée à coups de pied et à coups de poing.

Pour le même motif, le 15 mai, il donnait, sur la tête, plusieurs coups de parapluie, à son père, vieillard paralytique, qu'il fouilla.

Taille $1 \mathrm{~m}$. 704. Envergure $1 \mathrm{~m}$. 780. Buste 0,887. Pied gauche 0,262. Tète : Iongueur 0,183 ; largeur 0,156 . Indice céphalique 85,24 .

Oreille droite: longueur 0,059 ; largeur 0,034 . Indice auriculaire 57,62 . Écartement inférieur.

Front: arcalles moyennes; inclinaison fuyante; hauteur moyenne; largeur petite.

$\mathrm{Nez}$ : cavité (de la racine) moyenne; dos concave; base horizontale; saillie grande; hauteur et largeur moyennes.

Bouche: moyenne, à coins abaissés; ouverture intermédiaire.

Menton: droit, rond, plat; hauteur intermédiaire.

Visage ovale. Iris pigmenté de marron. Regard dur.

Teint brun. Barbe, cheveux et sourcils noirs. Tatoué.

Carrure moyenne. Santé forte.

Il est clairon et a du souffle pour sonner à la soupe et au repos. Quand vient l'heure du travail, il ronchonne. - Espadrilles. - Obs. 61.

$\boldsymbol{\gamma}^{\circ} \mathrm{Au}$ point de vue de la population:

46 urbains, 44 r'uraux. 
$8^{\circ}$ Au point de vue du domicile :

74 , avec domicile; 16, sans domicile.

\section{$9^{\circ}$ Au point de vue du nombre des condamnations :}

30 n'ont jamais eu maille ì partir avec la justice.

Fintre autres, un cultivateur, né le 30 janvier 1875 , dans une petite commune de la Seine-Inférieure, célibataire, sachant lire et écrire, bien notė.

Le tribunal correctionnel d'Yssingeaux lui a infligé, pour " coups et blessures volontaires ", 15 mois de prison et cent francs d'amende (jugement confirmé, le 26 décembre 1895 , par la cour d'appel de Riom).

A la date du 15 septembre 1895, sans provocation aucune, il avait porté plusieurs coups de couteau à quatre personnes qui voulaient l'empêcher de jeter des pierres à leurs femmes et à leurs enfants.

Taille $1 \mathrm{~m}$. 56. Envergure $1 \mathrm{~m}$. 62. Buste 0,833 . Pied gauche 0 ,242.

Tète : longueur 0,185 ; largeur 0,160 . Indice céphalique 86,48 .

Oreille droite: longueur 0,061; largeur 0,034. Indice, auriculaire 53,73 . Ecartement supérieur.

Front: arcades moyennes; inclinaison intermédiaire; hauteur et largeur moyennes.

Nez: cavité (de la racine) petite; dos rectiligne, sinueux; base relevée; saillie, hauteur et largeur moyennes.

Bouche : moyenne, rectiligne; ouverture intermédiaire.

Menton: droit, rond, bas.

Visage arrondi. Iris pigmenté de jaune.

Teint clair. Barbe, cheveux et sourcils châtain clair.

Carrure moyenne. Constitution et état général bons. Air prévenant.

Force compliments pour le travail et la conduite. - Esprdrilles. - Obs. 62. 
45 ont subi jusqu'à 4 peines; 15 ont été condamnés 5 fois et plus.

Un enfant du Gard, àgé de quarante-six ans, veuf, sachant lire et écrire, mineur (braconnier et contrebandier audacieux), urbain, ayant un domicile, très violent de caractère, adonné à l'ivrognerie, 12 fois condamné, subit la peine de 2 ans de prison, prononcée, le 8 août 1895, pour « coups et blessures volontaires "), par la cour d'assises de son département.

Le 15 avril 1895, il avait cherché dispute à un de ses camarades et l'avait frappé si violemment, à coups de talon de botte, que celui-ci était mort sur place.

Taille $1 \mathrm{~m}$. 62. Envergure $1 \mathrm{~m}$. 66. Buste 0,837. Pied gauche 0,2วั8. Tète : longueur 0,195 ; largeur 0,158 . Indice céphalique 81,02 .

Oreille droite: longueur 0,069 ; largeur 0,038 . Indice auricu-

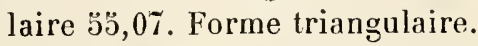

Front: arcades moyennes; inclinaison intermédiaire; hauteur et largeur moyennes.

Nez: cavité (de la racine) petite; dos concave; base horizontale; hauteur, saillie et largeur grandes. Dévié à droite.

Bouche : moyenne, rectiligne, pincée.

Menton : droit, rond, à fossette; hauteur intermédiaire.

Visage ovale. Iris pigmenté de jaune. OEil vif.

Teint brun. Barbe, cheveux et sourcils chàtain clair; sourcils réunis.

Carrure moyenne. Bonne santé.

Il manque d'assiduité au travail, mais est d'une moralité reconnue. - Cordonnerie. - Obs. 63 .

$10^{\circ} \mathrm{Au}$ point de vue de l'oisiveté :

41 oisifs. 
$11^{\circ} \mathrm{Au}$ point de vue de l'ivrognerie :

47 adonnés à l'ivrogneric.

$12^{\circ}$ Au point de vue du libertinage et de la débauche:

22 libertins et débauchés.

$13^{\circ} \mathrm{Au}$ point de vue du concubinage :

8 vivant en concubinage.

14. Au point de vue de la note de la commune:

5 bien notés.

15 ${ }^{\circ}$ Au point de vue de la taille :

Dans la catégorie de 16 à 20 ans: taille au-dessous de $1 \mathrm{~m} .60,5$ individus; de $1 \mathrm{~m} .60$ à $1 \mathrm{~m}$. 70, 6 ; de $1 \mathrm{~m} .70$ et au-dessus, 2 .

Soit, moyenne de la taille $1 \mathrm{~m} .61 \%$.

De 20 à 25 ans : taille au-dessous de $1 \mathrm{~m}$. 60, 5 individus; de $1 \mathrm{~m} .60$ à $1 \mathrm{~m}$. 70, 15 ; de $1 \mathrm{~m}$. 70 et au-dessus, 2.

Soit, moyenne de la taille $1 \mathrm{~m} .638$.

De 25 i 30 ans: taille au-dessous de $1 \mathrm{~m} .60,2$ individus; de $1 \mathrm{~m} .60$ à $1 \mathrm{~m}$. 70, 8 ; de $1 \mathrm{~m}$. 70 et au-dessus, 4 .

Soit, moyenne de la taille $1 \mathrm{~m} .659$. 
De 30 à 40 ans: taille au-dessous de $1 \mathrm{~m} .60,6$ individus; de $1 \mathrm{~m} .60$ à $1 \mathrm{~m} .70,12$; de $1 \mathrm{~m}$. 70 et au-dessus, 4 .

Soit, moyenne de la taille $1 \mathrm{~m} .639$.

De 40 à 50 ans : taille au-dessous de $1 \mathrm{~m} .60,7$ individus; de $1 \mathrm{~m} .60$ à $1 \mathrm{~m}$. 70, 6 ; de $1 \mathrm{~m}$. 70 et au-dessus, 3 .

Soit, moyenne de la taille $1 \mathrm{~m} .628$.

De 50 ans et au-dessus : taille au-dessous de $1 \mathrm{~m} .60,1$ individu; de $1 \mathrm{~m} .60$ à $1 \mathrm{~m} .70,2$.

Soit, moyenne de la taille $1 \mathrm{~m} .641$.

En résumé: taille au-dessous de $1 \mathrm{~m}$. 60, 26 individus; de $1 \mathrm{~m} .60$ à $1 \mathrm{~m}$. 70, 49 ; de $1 \mathrm{~m}$. 70 et au-dessus, 15 .

Soit, moyenne de la taille $1 \mathrm{~m} .637$.

\section{6 ${ }^{\circ}$ Au point de vue de l'envergure :}

Dans la catégorie de 16 à 20 ans : envergure inférieure à la taille, de 0 à 8 cent., 1 individu; supérieure à la taille, de 0 à 4 cent., 2 ; de 4 à 8 cent., 5 ; de 8 à 16 cent., 5 .

Soit, moyenne de l'envergure $1 \mathrm{~m}$. 674 .

De 20 à 25 ans : envergure supérieure à la taille de 0 à 4 cent., 6 individus; de 4 à 8 cent., 8 ; de 8 à 16 cent., 8 .

Soit, moyenne de l'envergure $1 \mathrm{~m} .695$.

De 25 à 30 ans : envergure inférieure à la taille de 0 à 8 cent.,

2 individus; égale à la taille, 1 ; supérieure à la taille, de 0 à 4 cent., 3 ; de 4 à 8 cent., 5 , de 8 à 16 cent., 3 .

Soit, moyenne de l'envergure $1 \mathrm{~m} .706$.

De 30 à 40 ans: envergure inférieure à la taille, de 0 à 8 cent., 1 individu; supérieure à la taille, de 0 à 4 cent., 10 : de 4 à 8 cent., 7 ; de 8 à 16 cent., 3 ; infirme. 1.

Soit, moyenne de l'envergure $1 \mathrm{~m} .670$. 
De 40 à 50 ans : envergure inférieure à la taille, de 0 à 8 cent., 1 individu; supérieure à la taille, de 0 à 4 cent., 5 ; de 4 à 8 cent., 9 ; de 8 à 16 cent., 1.

Soit, moyenne de l'envergure $1 \mathrm{~m} .668$.

De 50 ans et au-dessıs : envergure inférieure à la taille, de 0 à 8 cent., 2 individus; supérieure à la taille, de $4 \dot{a}$ 8 cent., 1.

Soit, movenne de l'envergure $1 \mathrm{~m} .633$.

En résumé: envergure inférieure à la taille, de 0 à $S$ cent., 7 individus; égale à la taille, 1 ; supérieure à la taille, de 0 à 4 cent., 26 ; de 4 à 8 cent., 35 ; de 8 à 16 cent., 20 ; infirme, 1.

Soit, moyenne de l'envergure $1 \mathrm{~m} .681$.

\section{7' Au point de vue du buste :}

Dans la catégorie de 16 à 20 ans : buste supérieur à la moitié de la taille, de 0 à 5 cent., 3 individus; de 5 à 10 cent., 8 ; de 10 à 18 cent., 2 .

Soit, moyenne du buste 0,879 .

De 20 à 25 ans: buste supérieur à la moitié de la taille, de 0 a 5 cent., 3 individus; de 5 à 10 cent., 19 .

Soit, moyenne du buste 0,886 .

De 25 à 30 ans : buste supérieur à la moitié de la taille, de 0 à 5 cent., 3 individus; de 5 à 10 cent., 10 ; de 10 à 18 cent., 1.

Soit, moyenne du buste 0,893.

De 30 it 10 ans: buste inférieur à la moitié de la taille, 1 individu; supérieur à la moitié de la taille, de 0 à 5 cent., 1 ; de 5 à 10 cent., 19 ; de 10 à 18 cent. 1 .

Soit, moyenne du buste 0,884 . 
De 40 à 50 ans: buste supérieur à la moitié de la taille, de 0 à 5 cent., 5 individus; de 5 à 10 cent., 11 .

Soit, moyenne du buste 0,870 .

De 50 ans et au-dessus: buste supérieur à la moitié de la taille, de 0 à 5 cent., 1 individu; de 5 à 10 cent., 2 .

Soit, moyenne du buste $0,87 \%$.

En résumé: buste inférieur à la moitiè de la taille, 1 individu; supérieur à la moitié de la taille, de 0 à 5 cent., 16 ; de 5 à 10 cent., 69 ; de 10 à 18 cent., 4 .

Soit, moyenne du buste 0,882 .

18 Au point de vue du pied :

Dans la catégorie de 16 à 20 ans: pied de 22 à 24 cent., 2 individus ; de 24 à 26 cent., 5 ; de 26 à 28 cent., 6 .

Soit, moyenne du pied 0,253.

De 20 à 25 ans : pied de 22 à 24 cent., 1 individu; de $24 \dot{a}$ 26 cent., 11 ; de 26 à 28 cent., 10.

Soit, moyenne du pied 0,258.

De 25 à 30 ans: pied de 24 à 26 cent., 9 individus; de 26 à 28 cent., 4 ; de 28 à 30 cent., 1.

Soit, moyenne du pied 0,260.

De $30 \dot{a} 40$ ans: pied de 22 à 24 cent., 3 individus; de 24 à 26 cent., 12 ; de 26 à 28 cent., 6 ; de 28 à 30 cent., 1 .

Soit, moyenne du pied 0,253.

De 40 à 50 ans : pied de 22 à 24 cent., 1 individu; de 24 à 26 cent., 11 ; de 26 à 28 cent., 3 ; de 28 à 30 cent., 1.

Soit, moyenne du pied 0,255.

De 50 ans et au-dessus: pied de 24 à 26 cent., 3 individus. Soit, moyenne du pied 0,250. 
En résumé : pied de 22 à 24 cent., 7 individus; de 24 à 26 cent., 51 ; de 26 à 28 cent., 29 ; de 28 à 30 cent., 3.

Soit, moyenne du pied 0,255.

$19^{\circ}$ Au point de vue de la tête:

7 dolichocéphales vrais, 14 sous-dolichocéphales, 8 mésaticéphales, 19 sous-brachycéphales, 42 brachycéphales vrais.

D'autre part, les calculs donnent:

Longueur moyenne de la tête 0,1888; largeur moyenne de la tête 0,1549 .

D’où : Indice céphalique 82,04 .

20 Au point de vue de l'oreille:

Indice anriculaire: au-dessous de 52, 5 individus; de 52 à 56 , 29 ; de 56 à 60.38 ; de 60 à 65,17 ; de 65 et audessus, 1.

D'autre part, les calculs donnent :

Longueur moyenne de l'oreille 0,0614; largeur moyenne de l'oreille 0,0349 .

D'où : Indice auriculaire 56,84 .

$21^{\circ}$ Au point de vue du visage :

En tronc de pyramide 1, en losange 9, rond 10, large ou carré 8, ovale 59, allongé 1 , en toupie 2. 
$22^{\circ}$ Au point de vue du front :

Arcades : grandes 15, petites 10, moyennes 65 .

Inclinaison : verticale 15 , fuyante 17 , intermédiaire 58.

Hauteur : grande 12, petite 5, moyenne 73.

Largeur : grande 4, petite 17, moyenne 69.

$23^{\circ}$ Au point de vue du nez:

Cavité (de la racine): grande 8 , petite 29, moyenne 53 .

Dos : rectiligne 63 , concave 19 , couvexe 8 .

Base : horizontale 61 , relevée 24 , abaissée 5 .

Hauteur : grande 5, petite 9 , moyenne 76 .

Saillie : grande 9 , petite 11 , moyenne 70.

Largeur : grande 9, petite 1, moyenne 80 .

$24^{\circ}$ Au point de vue de la bouche :

Dimension : grande 12, petite 9, moyenne 69 .

Inclinaison des angles : rectiligne 56, à coins abaissés 21, a coins relevés 13 .

Degré habituel d'ouverture : bée 5 , pincée 7 , intermédiaire 78.

$25^{\circ}$ Au point de vue du menton:

Inclinaison générale : menton saillant 17, fuyant 18, droit 55 . Avec et sans houppe: plat 17, à houppe 11, intermédiaire 62. Hauteur : haut 16, bas 17 , intermédiaire $5 \%$.

Forme: large 15, rond 69, pointu 6. 
$26^{\circ}$ Au point de vue de l'œil :

Iris : impigmenté 8 , pigmenté de jaune 21 , d'orange 43 , de châtain 15 , de marron 3 .

$27^{\circ}$ Au point de vue du teint:

Brun 61, mat 2, clair 25, blond 2.

$$
*^{* *}
$$

$28^{\circ} \mathrm{Au}$ point de vue de la carrure:

Grande 15, moyenne 72, petite 3 .

$29^{\circ} \mathrm{Au}$ point de vue de la constitution et de l'état général à l'arrivée :

Très bons 19, bons 49, passables 10, mauvais 12 .

$30^{\circ}$ Au point de vue des infirmités et maladies à l'arrivée :

25 maladies et infirmités à répartir entre 22 individus (19 Français, dont 10 Corses; 3 Italiens).

Soit :

Bronchite bacillaire 1, insuffisance valvulaire 2, hypertrophie du cour 1 , atrophie du cour 1 , palpitations 1 , accidents syphilitiques 1 , scrofule 2 , déviation de la colonne vertébrale 2, boiteux 1, manchot 1, atrophie de la jambe 1 , atrophie du bras 1, hernie inguinale droite 3 , double 1 , 
presbytie 1, faiblesse de la vue 1, conjonctivite chronique 1 , épilepsie 1, hystéro-épilepsie 1, déséquilibration mentale 1.

L'épileptique (Aveyronnais, âgé de trente ans, célibataire, sachant lire et écrire, cultivateur, rural, ayant un domicile, 2 fois condamné, adonné à l'ivrognerie) subit la peine de 3 ans de prison, prononcée, par la cour d'appel de Montpellier, pour " coups et blessures à son père ".

Grand'mère paternelle épileptique.

Il est des périodes pendant lesquelles il tombe deux et trois fois par jour.

Prodromes : un sentiment de peur - première attaque à la suite d'une brûlure (étant enfant).

Taille $1 \mathrm{~m}$. 60. Envergure $1 \mathrm{~m}$. 62. Buste 0,888. Pied ganche 0,249. Tète : longueur 0,183 ; largeur 0,161 . Indice céphalique 87,97 .

Oreille droite: longueur 0,062 ; largeur 0,03 . Indice auriculaire $36,4 \ddot{3}$.

Front: arcades moyennes; inclinaison intermédiaire; hauteur et largeur moyennes.

Nez : cavité (de la racine) moyenne; dos rectiligne; base horizontale; hauteur, largeur et saillie moyennes.

Bouche: moyenne, rectiligne; ouverture intermédiaire.

Menton : plat, large, droit; hauteur intermédiaire.

Visage ovale. Iris pigmenté d'orange, truité. Pupilles très dilatées.

Teint brun. Barbe, cheveux et sourcils chàtain foncé.

Carrure moyenne. Santé délicate; affaiblissement des facultés mentales et propension marquée de l'esprit aux pensées tristes.

Quartier des vieillards.-Obs. 64.

L'hystéro-épileptique (Italien, âgé de trente-cinq ans, célibataire, sachant lire et écrire, cuisinier, urbain, sans domicile, à la $3^{\ominus}$ peine, adonné à l'ivrognerie) fait 2 ans de prison (arrêt de la cour d'appel d'Aix). pour "coups et blessures ") L'expulsion suivra la peine. 
Taille $1 \mathrm{~m}$. 60. Envergure $1 \mathrm{~m}$. 68. Buste 0,862. Pied gauche 0,245. Tète : longueur 0,187 ; largenr 0,158 . Indice céphalique 84,49.

Oreille droite: longuenr 0,064; largeu 0,035. Indice auriculaire 54,68 .

Front: arcades moyennes; inclinaison intermédiaire; hauteur et largeur moyennes.

$\mathrm{Nez}$ : cavité (de la racine) petite; dos rectiligne; base horizontale; hauteur et largeur moyennes; saillie petite.

Bouche : moyenne, rectiligne, pincée.

Menton : saillant, rond; lauteur intermédiaire.

Visage ovale. Iris impigmenté.

Teint brun. Barbe, chevenx et sourcils châtain foncé.

Carrure moyenne. Santé délabrée.

Il a des crises qui durent douze heures environ, à la suite desquelles il perd toute connaissance.

Fn dehors des accès, fièvre hystérique rémittente. - Infirmerie. - Obs. 65 .

Le déséquilibré (Nîmois, âgé de vingt-quatre ans, célibataire, sachant lire et écrire, portefaix, sans domicile fixe, à la $10^{\mathrm{e}}$ peine) a été condamné, à 2 ans de prison, par la cour d'assises des Bouches-du-Rhône, pour " violences, coups et blessures, rèbellion ).

Taille $1 \mathrm{~m}$ 59. Envergure $4 \mathrm{~m}$. 63. Buste 0,864. Pied gauche 0,243. Tète: longueur 0,176 ; largeur 0,13 . Indice céphalique $8 \ddot{3,79}$.

Oreille droite: longueur 0,059 ; largeur 0,034 . Indice auriculaire 57,62 .

Front: arcades grandes; inclinaison fuyante; hauteur et largeur moyennes.

Nez: cavité (de la racine) petite; dos rectiligne; base horizontale; hauteur, largeur et saillie moyennes.

Bouche : moyenne, à coins abaissés ; ouverture intermédiaire.

Menton : large, fuyant; hanteur intermédiaire.

Visage ovale. Iris pigmenté de chàtain.

T'eint clair. Barbe, cheveux et sourcils chàtain clair.

Carrure moyenne. Dégénérescence mentile.

Сh. Perrier. 
Il a été reconnu inapte au service militaire, " bien que pouvant faire un général », et a failli être "assassiné » à Montdevergues, pendant qu'il y était interné.

Ce malheureux jeune homme passe son temps à des riens. - Balayeur. - Obs. 66.

\section{Au point de vue du lieu du crime:}

Lieu de naissance: 41 individus (17 ruraux et 24 urbains, dont 1 sans domicile).

Département du lieu de naissance : 14 individus (1 urbain et 13 ruraux, dont 2 sans domicile).

Autre département : 35 individus, dont 13 sans domicile ( 8 urbains et 5 ruraux).

\section{2 ${ }^{\circ}$ A point de vue de la date du crime :}

2 en janvier, 5 en février, 2 en mars, 9 en avril, 6 en mai, 15 en juin, 10 en juillet, 7 en août, 8 en septembre, 11 en octobre, 5 en novembre, 8 en décembre, 2 pendant l'année.

$$
\begin{array}{rlll}
\text { Soit : Hiver. . . . . . . . . . . } & 15 \\
\text { Printemps . . . . . . . . . } & 17 \\
& \text { Eté . . . . . . . . . . . } & 32 \\
\text { Automne. . . . . . . . . . . } & 24 \\
\text { Pendant l'année . . . . } & \frac{2}{90}
\end{array}
$$




\section{$*^{* *}$}

33 ${ }^{\circ}$ A point de vue de la juridiction :

Condamnés par tribunaux correctionnels. . . . 68

- cours d'assises . . . . . . . . 21

- conseil de guerre . . . . . . . 1

Ce dernier est né, à Milan, le 26 mars 1861; il sait lire, écrire et calculer, et achève la peine de 2 ans de prison, prononcée, le 5 avril 1888, par le conseil de guerre de la division d'Oran, pour refus d'obéissance à un ordre relatif au service (2e régiment ètrangers).

S'il est ici, c'est qu'il a été exclu des rangs de l'armée par une condamnation à cinq ans de réclusion, infligée, pour vols qualifiés, après son évasion du pénitencier militaire de Birkadem.

Taille $1 \mathrm{~m}$. 67. Envergure $1 \mathrm{~m}$. 68. Buste 0,893 . Pied gauche 0,261 . Tète : longueur 0,194 ; largeur 0,160 . Indice céphalique 82,47 .

Oreille droite: longueur 0,063 ; largeur 0,034. Indice auricu laire 53,96 .

Front: inclinaison intermédiaire; arcades, hauteur et largeur moyennes.

Nez : cavité (de la racine) moyenne; dos rectiligne; base relevée; saillie, hauteur et largeur moyennes.

Bouche : petite, rectiligne; ouverture intermédiaire.

Menton : droit, rond, plat ; hauteur intermédiaire.

Visage ovale. Iris impigmenté. Physionomie banale.

Teint brun. Barbe, cheveux et sourcils chàtains. Sourcils réunis.

Tatoué.

Carrure moyenne. Santé parfaite.

Il est d'un orgueil insupportable et se plaint constamment d'avoir trop d'ouvrage. - Cordonnerie. - Obs. 67. 
34 Au point de vue de la durée de la peine:

11, condamnés ì 1 an et un jour ; 4, a 13 mois; 10 , de 15 à 18 mois; 7 , de 18 mois $\dot{a} 2$ ans; 30 , de 2 a 3 ans; 16 , de 3 à 4 ans; 5 , de 4 à 5 ans; 7 , à 5 ans.

Un forgeron, né dans le département de l'Aude, âgé de vingt et un ans, célibataire, illettré, sans domicile fixe, rural, à la $6^{\mathrm{e}}$ peine, adonné à l'ivrognerie, a èté condamné, à Montpellier (arrêt en date du 24 janvier 1895), sur appel d'un jugement rendu par le tribunal de Narbonne, le 31 décembre 1894, pour " coups et blessures, avec préméditation », à 5 ans de prison.

Dans la nuit du 14 au 15 décembre, en compagnie d'un camarade, il avait attaqué dans un endroit désert, et blessé à la nuque d'un coup de couteau, afin de le dévaliser, un homme rencontré, au café, en train de compter de l'argent.

Taille $1 \mathrm{~m}$. 60. Envergure $1 \mathrm{~m}$. 70. Buste 0,88̈. Pied gauche 0,2506. Tète : longueur 0,180 ; largeur 0,1303 . Indice céphalique 83,78.

Oreille droite: longueur 0,063 ; largeur 0,036 . Indice auriculaire $5 \pi, 14$.

Front: arcades moyennes; inclinaison fuyante; hauteur et largeur moyennes.

Nez: cavité (de la racine) petite; dos rectiligne; base relevée; saillie, hauteur et largeur moyennes.

Bouche: moyenne, rectiligne; ouverture intermédiaire.

Menton: saillant, rond, bas.

Visage arrondi. Iris pigmenté d'orange. Mine réjouie.

Teint brun. Barbe, cheveux et sourcils châtain foncé; sourcils réunis.

Carrure moyenne. Santé bonne.

C'est une teigne; " il est né le 14 juillet : ce jour-là, on ne travaille pas. $)$ - Pipes. - Obs. 68. 
$35^{\circ}$ Au point de vue de l'interdiction de séjour :

10 sont frappés d'interdiction de séjour, parmi lesquels, 4, par une condamnation antérieure.

$36^{\circ}$ Au point de vue du travail en prison :

Bons travailleurs 48, passables 24, mauvais 18.

$37^{\circ} \mathrm{Au}$ point de vue de la conduite en prison :

Bonne 50, passable 17, mauvaise 23.

$38^{\circ} \mathrm{Au}$ point de vue de l'expulsion :

17 étranger's sur 20. 


\section{VI \\ COLPS ET BLESSURES AYANT OCCASIONNÉ LA MORT SANS INTENTION DE LA DONNER}

17 individus

\section{$1^{\circ}$ Au point de vue de la naissance :}

13 enfants légitimes, 4 enfants naturels.

Parmi les enfants naturels, se trouve: un Marseillais, âgé de vingt ans, sachant lire et écrire, typographe, sans antécédents judiciaires, qui subit la peine de 4 ans de prison, infligée, par la cour d'assises des Bouches-du-Rhône, le 16 décembre 1895, pour " coups et blessures ayant occasionné la mort, sans intention de la donner 1 .

$\mathrm{Au}$ cours d'une discussion et dans un violent mouvement de colère, il porta à sa mère quatre coups de couteau terribles. La victime mourut quelques instants après (21 août 1895).

Taille $1 \mathrm{~m}$. 76. Envergure $1 \mathrm{~m}$. 78. Buste 0,937. Pied gauche 0,272.

Tète : longueur 0,181 ; largeur 0,164 . Indice céphalique 90,60 .

Oreille droite : longueur 0,061 ; largeur 0,034 . Indice auriculaire 33,73 . Écartement total.

Front : arcades petites; inclinaison verticale; largeur grande; hauteur moyenne.

Nez : cavité (de la racine) moyenne; dos rectiligne; base horizontale; hauteur, saillie et largeur moyennes.

Bouche : moyenne, à coins relevés; ouverture intermédiaire. 
Menton : droit, rond, à fossette ; hauteur intermédiaire.

Visage ovale. Iris pigmenté de chàtain.

Teint clair. Barbe, cheveux et sourcils châtains (sourcils réunis).

Carrure moyenne. Extérieur doux.

Individu sain et robuste. Comme travail et comme conduite, il a droit à des éloges. - Pipes. - Obs. 69.

\section{$2^{\circ}$ Au point de vue de la nationalité :}

14 Français, 3 Italiens.

Un Piémontais, âgé de trente-deux ans, enfant naturel, célibataire, sachant lire et écrire, terrassier, urbain, à la première peine a été condamné, le 3 novembre 1893, par la cour d'assises des Alpes-Maritimes, à 5 ans de prison et à 5 ans d'interdiction de séjour, pour " coups et blessures ayant occasionné la mort, sans intention de la donner ".

Le 2 juillet 1893, à la suite d'une dispute, après boire, il avait porté un coup de couteau mortel à un de ses concitoyens; puis, tranquillement, il était rentré se coucher.

Taille $1 \mathrm{~m}$. 638. Envergure $1 \mathrm{~m}$. 67. Buste 0,884. Pied gauche 0,235 . Tète : longueur 0,182 ; largeur 0,134 . Indice céphalique 84,61 .

Oreille droite : longueur 0,063 ; largeur 0,033 . Indice auriculaire 5๊2,38. Écartement supérieur.

Front : arcades moyennes; inclinaison intermédiaire; hauteur et largeur moyennes.

Nez: cavité (de la racine) petite; dos convexe, sinnenx; base horizontale ; hauteur grande ; saillie et largeur moyennes.

Bouche : moyenne, rectiligne; ouverture intermédiaire ; lèvre inférieure épaisse.

Menton : fuyant, rond ; hauteur intermédiaire.

Visage ovale. Iris pigmenté d'orange. Figure commune.

Teint brun. Barbe, cheveux et sourcils chàtain foncé.

Carrure moyenue. Santé vigoureuse. A expulser.

Bon détenu. - Filoches. - Obs. 70. 
$3^{\circ}$ Au point de vue de l'âge :

2 de $16 \dot{a} 20$ ans, 7 de $20 \dot{a} 25$ ans, 2 de $25 \dot{a} 30$ ans, 3 de 30 à 50 ans, 3 de 50 ans et plus.

Un Aveyronnais, né le 8 février 1842, marié, sachant lire et écrire, cultivateur, rural, sans condamnation antérieure, fait 2 ans de prison, peine prononcée, le 12 décembre 1895, par la cour d'assises de son département, pour " coups et blessures ayant occasionné la mort, sans intention de la donner $)$.

Le 25 août 1895, vers 8 heures du soir, il avait frappé, de deux coups de couteau, un de ses compatriotes qui mourut, le lendemain, des suites de ses blessures.

Des questions d'intérêt divisaient, depuis longtemps, la victime et le meurtrier.

Taille $1 \mathrm{~m} .61$. Envergure $1 \mathrm{~m}$. 79. Buste 0,896. Pied gauche 0,270.

Tête : longueur 0,203 ; largeur 0,158 . Indice céphalique 77,83.

Oreille droite : longueur 0,068 ; largeur 0,039 . Indice auriculaire 57,33 .

Front : arcades moyennes; inclinaison intermédiaire; hauteur petite; largeur moyenne.

Nez : cavité (de la racine) moyenne ; dos convexe, sinueux ; base abaissée ; hauteur grande ; saillie et largeur moyennes.

Bouche : moyenne, rectiligne ; ouverture intermédiaire.

Menton : fuyant, rond; hauteur intermédiaire.

Visage ovale. Iris pigmenté de marron.

Teint brun. Barbe el cheveux grisonnants ; sourcils arqués.

Carrure moyenne. Santé bonne. Huneur sanguine.

Il soigne son travail et ne craint pas qu'on épluche sa conduite. - Empaillage. - Obs. 71.

$4^{\circ} \mathrm{Au}$ point de vue de l'état civil :

12 célibataires, 4 mariés, 1 ceuf'. 


\section{$5^{\circ}$ Au point de vue de l'instruction:}

3 sont illettrés ; 1 sait lire; 11 savent lire et écrire; 2 savent lire, écrire et calculer.

L'un des deux derniers (Nìmois, âgé de cinquante-quatre ans, a la première peine) exerçait la profession de relieur.

De tous les dons du ciel, le vin est pour lui le plus cher.

Par arrêt de la cour d'assises du Gard, en date du 16 novembre....., il a été condamné, à 2 ans d'emprisonnement, pour " coups et blessures ayant occasionné la mort, sans intention de la donner $)$.

Le 23 juillet...., vers dix heures et demie du matin, cet individu, qui vivait séparé de sa femme, se trouvait assis devant un café, lorsque celle-ci vint à passer. Il l'aborda pour lui réclamer son linge, ses outils, etc., et sur son refus, il lui plongea dans le sein gauche un couteau, aiguisé de frais, qu'il sortit d'une poche de sa veste. Le crime commis, il alla se constituer prisonnier.

Taille $1 \mathrm{~m}$. 69. Envergure $1 \mathrm{~m}$. 76. Buste 0,867. Pied gauche 0,264.

Tète : longueur 0,188 ; largeur 0,149 . Indice céphalique 79 , 25.

Oreille droite : longueur 0,066 ; largeur 0,039 . Indice auriculaire 20,09 . Front : arcades moyennes; inclinaison intermédiaire; hauteur et largeur moyennes.

Nez: cavité (de la racine) moyenne; dos rectiligne; base relevée; largeur grande; hauteur et saillie moyennes.

Bouche : grande, à coins abaissés ; ouverture intermédiaire.

Menton : droit, rond, bas; mâchoires écartées.

Visage ovale. Iris pigmenté de jaune.

Teint brun. Barbe, cheveux et sourcils châtains grisonuants ; sourcils en brosse. Tatoué.

Carrure moyenne. Santé bonne. Caractère timide.

Ouvrier habile et rassis. - Service général. - Obs. 72. 


\section{Au point de vue de la profession :}

4 ouvriers d'ateliers et de fabriques, 4 ouvriers du batiment et du mobilier, 9 professions agricoles.

Un enfant de la Haute-Loire, âgé de quarante et un ans, marié, illettré, cultivateur, rural, 1 fois condamné, fait 2 ans. de prison (arrêt de la cour d'assises de son département, en date du 2 décembre 1895), pour " coups et blessures ayant entraîné la mort, sans intention de la donner ».

Sa fille avait fait paitre des moutons dans la propriété d'un voisin, âgé de quatre-vingts ans. Mis au courant des reproches à elle adressés, il alla (15 août 1895) - le cerveau troublé par les fumées du vin — demander des explications au vieillard. Une vive discussion s'ensuivit, au cours de laquelle il étendit l'octogénaire, d'un coup de barre sur le crâne.

Taille $1 \mathrm{~m}$. 37. Envergure $1 \mathrm{~m}$. 63. Buste 0,948. Pied gauche 0,20̈1. Tète : longueur 0,179 ; largeur 0,163 . Indice céphalique $92,17$.

Oreille droite : longueur 0,057 ; largeur 0,030. Indice auriculaire 52,63. Front: arcades moyennes; inclinaison intermédiaire; largeur grande ; hauteur moyenne.

Nez: cavité (de la racine) moyenne; dos convexe, sinueux; base horizontale; saillie, hauteur et largeur moyennes. Dévié à droite. Bouche: moyenne, rectiligne; ouverture intermédiaire.

Menton: droit, rond, haut, a fossette.

Visage en losange. Iris pigmenté d'orange. Expression du regard banale.

Teint brun. Barbe, cheveux et sourcils châtains grisonnants. Carrure moyenne. Naturel fort et robuste.

Il n'y a rien à redire à sa conduite; c'est un travailleur. Cordonnerie. - Obs. 73. 
$7^{\circ}$ Au point de vue de la population :

8 appartiennent $\dot{a}$ la population urbaine, $9 \dot{\alpha}$ la population rurale.

8" Au point de vue du domicile :

Un seul n'a pas de domicile.

\section{$9^{\circ}$ Au point de vue du nombre des condamnations :}

11 à la première condamnation; 6 récidivistes (5 condamnẻs 1 fois et un 7 fois).

L'individu sept fois condamné est né le 25 aoùt 1874.

Il ne possède aucune instruction et appartient à la population rurale. On le dit cultivateur.

Le parquet le signale comme ne vivant que de mendicité et de vol.

Le 4 septembre 1894, à huit heures du soir, au café de la Paix, à...., il provoqua un camarade, sous le plus futile des prétextes, et se battit avec lui. Rentré en son logis, il aiguisa un couteau et repartit tout aussitôt dans la direction du même établissement. Une nouvelle rixe se produisit, au cours de laquelle il fit à son adversaire une blessure mortelle au flanc droit.

3 ans de prison lui ont été infligés, le 22 novembre 1894, par la cour d'assises de l'Hérault, “ pour coups et blessures volontaires ayant entraîné la mort, sans intention de la donner »).

Taille I II. 64. Envergure 1 m. 6ว. Buste 0,99̈. Pied gauche 0,24:5. Tète : longueur 0,170 ; largeur $0,10 ̈ 0$. Indice céphalique 88,23 . Oreille droite : longueur 0,062 ; largeur 0,034 . Indice auriculaire $3 \ddot{4}, 83$. Écartement inférieur. 
Front: arcades moyennes; inclinaison intermédiaire; largeur grande ; hauteur moyenne. .

Nez : cavité (de la racine) grande; dos rectiligne; base horizontale; largeur grande; saillie et hauteur moyennes.

Bouche : moyenne, rectiligne ; ouverture intermédiaire.

Menton : saillant, large, haut.

Visage large. Iris pigmenté d'orange.

Teint brun. Barbe, cheveux et sourcils châtains. Tatoué.

Carrure moyenne. État général et constitution bons. Nature abrutie.

Il craint les réprimandes et paraît aimer le travail plus que toutes choses. - Pantoufles. - Obs. 74.

$10^{\circ}$ Au point de vue de l'oisiveté :

2oisifs.

$11^{\circ} \mathrm{Au}$ point de vue de l'ivrognerie :

9 adonnés à l'ivrogneric.

$12^{\circ} \mathrm{Au}$ point de vue du libertinage et de la débauche:

4 libertins et débauchés.

$13^{\circ} \mathrm{Au}$ point de vue du concubinage :

2 vicant en concubinage.

$14^{\circ} \mathrm{Au}$ point de vue de la note de la commune:

4 bien notés. 
$15^{\circ}$ Au point de vue de la taille :

Dans la catégorie de 16 à 20 ans : taille au-dessous de $1 \mathrm{~m} .60$, 1 individu; de $1 \mathrm{~m} .60$ à $1 \mathrm{~m}$. 70,1 .

Soit, moyenne de la taille $1 \mathrm{~m}$. 620 .

De 20 à 25 ans : taille au-dessous de $1 \mathrm{~m} .60,1$ individu; de $1 \mathrm{~m} .60$ à $1 \mathrm{~m}$. 70, 4 ; de $1 \mathrm{~m}$. 70 et au-dessus, 2 .

Soit, moyenne de la taille $1 \mathrm{~m} .664$.

De 25 à 30 ans : taille de $1 \mathrm{~m} .60$ à $1 \mathrm{~m} .70,1$ individu; de $1 \mathrm{~m}$. 70 et au-dessus, 1 .

Soit, moyenne de la taille $1 \mathrm{~m} .665$.

De 30 à 40 ans : taille de $1 \mathrm{~m} .60$ à $1 \mathrm{~m} .70,1$ individu.

Soit, taille $1 \mathrm{~m} .638$.

De 40 à 50 ans : taille au-dessous de $1 \mathrm{~m} .60,1$ individu; de $1 \mathrm{~m} .60$ à $1 \mathrm{~m} .70,1$.

Soit, moyenne de la taille $1 \mathrm{~m} .595$.

De 50 ans et au-dessus: taille au-dessous de $1 \mathrm{~m} .60,1$ individu; de $1 \mathrm{~m} .60$ à $1 \mathrm{~m}$. \%0, 2 .

Soit, moyenne de la taille $1 \mathrm{~m} .616$.

En résumé: taille inférieure à $1 \mathrm{~m}$. 60, 4 individus; de $1 \mathrm{~m} .60$ à $1 \mathrm{~m}$. 70, 10 ; de $1 \mathrm{~m}$. 70 et au-dessus, 3 .

Soit, moyenne de la taille $1 \mathrm{~m} .641$. 


\section{$16^{\circ}$ Au point de vue de l'envergure :}

Dans la catégorie de 16 d 20 ans: envergure supérieure à la taille, de 0 à 4 cent., 1 individu; de 8 à 16 cent., 1 .

Soit, moyenne de l'envergure $1 \mathrm{~m} .680$.

De $20 \grave{a} 25$ ans : envergure inférieure à la taille, de 8 à 16 cent., 1 individu; supérieure à la taille de 0 à 4 cent., 2 ; de 4 à 8 cent., 3 ; de 8 à 16,1 .

Soit, moyenne de l'envergure $1 \mathrm{~m} .70 \%$.

De 25 à 30 ans : envergure supérieure à la taille, de 4 à 8 cent., 1 individu; de 8 à 16 cent., 1 .

Soit, moyenne de l'envergure $1 \mathrm{~m}$. 765;

De $30 \dot{a} 40$ ans : envergure supérieure à la taille, de 0 à 4 cent., 1 individu.

Soit, envergure $1 \mathrm{~m} .670$.

De 40 à 50 ans : envergure supérieureà la taille, de 4 à 8 cent., 2 individus.

Soit, moyenne de l'envergure $1 \mathrm{~m} .650$.

De 50 ans et au-dessus: envergure supérieure à la taille, de 4 à 8 cent., 1 individu; de 8 à 16 cent., 2 .

Soit, moyenne de l'envergure $1 \mathrm{~m}$. 723.

En résumé : envergure inférieure à la taille, de 0 à 8 cent., 1 individu ; supérieure à la taille, de 0 à 4 cent., 4 ; de $4 \dot{a}$ 8 cent., 7 ; de 8 à 16 cent., 5 .

Soit, moyenne de l'envergure $1 \mathrm{~m}$. 704. 
$17^{\circ}$ Au point de vue du buste :

Dans la catégorie de 16 à 20 ans: buste supérieur à la moitié de la taille, de 0 à 5 cent., 1 individu; de 5 à 10 cent., 1.

Soit, moyenne du buste 0,872 .

De 20 à 25 ans: buste supérieur à la moitié de la taille, de 5 à 10 cent., 6 individus; de 10 à 18 cent., 1 .

Soit, moyenne du buste 0,912.

De 25 à 30 ans: buste supérieur à la moitié de la taille, de 0 à 5 cent., 1 individu; de 5 à 10 cent., 1 .

Soit, moyenne du buste 0,891 .

De 30 à 40 ans: buste supérieur à la moitié de la taille, de 5 à 10 cent., 1 individu.

Soit, hauteur du buste 0,884 .

De 40 à 50 ans: buste supérieur à la moitié de la taille, de 5 à 10 cent., 1 individu; de 10 à 18 cent., 1.

Soit, moyenne du buste 0,905 .

De 50 ans et au-dessus: buste supérieur à la moitié de la taille, de 0 à 5 cent., 2 individus; de 5 à 10 cent., 1 .

Soit, moyenne du buste 0,842 .

En résumé : buste supérieur à la moitié de la taille, de 0 à 5 cent., 4 individus; de 5 à 10 cent., 11 ; de 10 à 18 cent., 2.

Soit, moyenne du buste, 0,890 .

$18^{\circ}$ Au point de vue du pied :

Dans la catégorie de 16 à 20 ans: pied de 24 à 26 cent., 1 individu; de 28 à 30 cent., 1.

Soit, moyenne du pied 0,263. 
De 20 à 25 ans: pied de 24 à 26 cent., 4 individus; de 26 a 28 cent., 2 ; de 28 à 30 cent., 1.

Soit, moyenne du pied 0,258.

De 25 à 30 ans : pied de 24 à 26 cent. 1 individu ; de 26 à 28 cent., 1.

Soit, moyenne du pied 0,259.

De 30 à 40 ans: pied de 22 à 24 cent., 1 individu.

Soit, longueur du pied 0,235 .

De 40 a 50 ans : pied de 24 à 26 cent., 2 individus.

Soit, moyenne du pied 0,254.

De 50 ans et au-dessus : pied de 24 a 26 cent., 1 individu ; de 26 à $2 S$ cent., 2.

Soit, moyenne du pied 0,258.

En résumé: pied de 22 à 24 cent., 1 individu; de 24 à 26 cent., 9 ; de 26 à 28 cent., 5 ; de 28 à 30 cent., 2.

Soit, moyenne du pied $0,25 \%$.

$19^{\circ}$ Au point de vue de la tête:

1 sous-dolichocéphale, 4 mésaticéphales, 1 sous-brachycéphale, 11 brachycéphales vrais.

D'autre part, les calculs donnent :

Longueur moyenne de la tête 0,1860 ; largeur moyenne de la tête 0,1554 .

D’où : Indice céphalique 83,54 .

$20^{\circ}$ Au point de vue de l'oreille:

Indice auriculaire: au-dessous de 52, 2 individus; de 52 a 56,9 ; de 56 à 60,4 ; de 60 à $65,2$. 
D'autre part, les calculs donnent :

Longueur moyenne de l'oreille 0,0631; largeur movenne de l'oreille 0,0350 .

D'où : Indice auriculaire 55,46.

$*^{* * *}$

$21^{\circ}$ Au point de vue du visage :

En losange 6, large ou carré 2 , ovale 8, allongé 1.

$22^{\circ}$ A u point de vue du front :

Arcades : grandes 3 , petites 1 , moyennes 13 .

Inclinaison : verticale 3 , fuyante 2 , intermédiaire 12.

Hauteur : grande 3, petite 2, moyenne 12.

Largeur : grande 5, petite 2, moyenne 10.

$23^{\circ} \mathrm{Au}$ point de vue du nez :

Cavité (de la racine) : grande 2 , petite 6 , moyenne 9.

Dos : rectiligne 9 , concave 1 , convexe 7.

Base : horizontale 12, relevée 3, abaissée 2.

Hauteur : grande 4, petite 2, moyenne 11.

Saillie : grande 1, petite 1 , moyenne 15.

Largeur : grande 6, moyenne 11 .

$24^{\circ}$ Au point de vue de la bouche :

Dimension : grande 2, petite 2, moyenne 13 .

Inclinaison des angles : rectiligne 11, à coins abaissés 3 , à coins relevés 3 .

Degré habituel d'ouverture : bée 3, pincée 1 , intermédiaire 13.

Gii. Peraleir. 
$25^{\circ}$ Au point de vue du menton :

Inclinaison générale : menton saillant 1 , fuyant 5, droit 11. Avec et sans houppe : plat 1, à houppe 2, intermédiaire 14. Hauteur : haut 3, bas 3 , intermédiaire 11. Forme : large 3 , rond 13 , pointu 1 .

$26^{\circ}$ Au point de vue de l'œil :

Iris : pigmentẻ de jaune 5 , d'orange 8 , de châtain 3 , de marron 1.

$27^{\circ}$ A u point de vue du teint :

Brun 14, clair 3.

$$
\text { ** } *
$$

$28^{\circ}$ Au point de vue de la carrure :

Grande 2, moyenne 14, petite 1.

$29^{\circ}$ Au point de vue de la constitution et de l'état général, à l'arrivée :

Très bons 2, bons 12, mauvais 3 . 
$30^{\circ}$ A u point de vue des maladies et infirmités, à l'arrivée:

11 maladies et infrrmités, à répartir entre 4 individus 3 Francais et 1 Italien).

Soit : Artérite chronique avec dégénérescence athéromateuse 5, uréthrite aiguë 1, atrophie de la jambe 1, strabisme 1, surdité légère 1 , gynécomastie 2.

Rentre dans la catégorie des gynécomastes un Italien, âgé de vingt-six ans, célibataire, sachant lire et écrire, maçon, à la $2^{\text {e }}$ peine, urbain, fils de marchands ambulants.

La cour d'assises des Bouches-du-Rhône l'a condamné à 3 ans de prison, pour " coups et blessures ayant occasionné la mort, sans intention de la donner, et infraction à un arrêté d'expulsion ".

Taille $1 \mathrm{~m} .66$. Envergure $1 \mathrm{~m} .70$. Buste 0,898. Pied gauche 0,20̈5. Tète : longueur 0,174 ; largeur 0,157 . Indice céphalique 90,22 .

Oreille droite: longueur 0,035 ; largeur 0,030 . Indice auriculaire 54,54 .

Front : arcades moyennes; inclinaison intermédiaire; hauteur et largeur grandes.

Nez : cavité (de la racine) moyenne; dos concave; base relevée; largeur grande; hauteur et saillie moyenues.

Bouche : moyenne, rectiligne, bée.

Menton : rond, haut, droit ; mâchoires écartées.

Visage ovale. Iris pigmenté d'orange. Physionomie expressive.

Teint clair. Barbe, cheveux et sourcils châtain clair.

Carrure moyenne. Bonne santé.

Seins de dimension anormale, musculeux; mamelons de couleur foncée, gros comme un pois chiche. Organes génitaux très bien conformés. Poitrine velue.

Dans l'établissement, il jouit d'une bonne réputation. Service général. - Obs. 75 . 
31. Au point de vue du lieu du crime :

Lieu de naissance : 6 individus (5 urbains et 1 rural). Département du lieu de naissance : 3 individus (ruraux). Autre departement : 8 individus (3 urbains et 5 ruraux, dont 1 sans domicile'.

$32^{\circ}$ Au point de vue de la date du crime :

1 en mars, 3 en mai, 2 en juillet, 6 en août, 2 en septembre, 1 en octobre, 2 en décembre.

$$
\begin{aligned}
& \text { Soit : Hiver . . . . . . . . . . . . . . } 2 \\
& \text { Printemps .. . . . . . . . . . } 4 \\
& \text { Été . . . . . . . . . . . } 8 \\
& \text { Automne. . . . . . . . . . . . . } 3 \\
& 17 \\
& \text { *** }
\end{aligned}
$$

$3^{\circ}$ Au point de vue de la Juridiction :

Ces 17 individus sont passés aux assises.

$34^{\circ}$ Au point de vue de la durée de la peine :

Ils ont été condamnés : 10 , de 2 à 3 ans ; 3 , de 3 à 4 ans ; 4 , $\dot{a} 4$ ans et plus. 
Au nombre des condamnés à 4 ans, on rencontre un enfant du Var, né le 8 octobre 1843 , célibataire, sachant lire, bouchonnier, rural, adonné à l'ivrognerie, sans antécédents judiciaires.

Cette peine lui a été infligée, le 23 décembre 1893, par la cour d'assises des Bouches-du-Rhône, pour avoir blesséà mort, d'un coup de couteau à l'épaule(18 septembre 1893), un aubergiste de Marseille qui lui réclamait, d'une façon un peu vive, le payement de quelques gueuletons.

Taille $1 \mathrm{~m}$. 53. Envergure $1 \mathrm{~m}$. 69. Buste 0,823. Pied gauche 0,242.

Tète : longueur 0,185 ; largeur 0,149 . Indice céphalique 80,34 .

Oreille droite: longueur 0,061 ; largeur 0,033 . Indice auriculaire

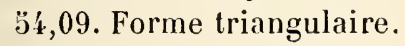

Front : arcades moyennes; inclinaison intermédiaire; hauteur et largeur moyennes.

Nez : cavité (de la racine) grande; dos rectiligne; base relevée; hauteur petite; largeur grande; saillie moyenne.

Bouche : grande, à coins relevés; ouverture intermédiaire.

Menton : droit, large, has, à fossette.

Visage large. Iris pigmenté de jaune. Air bète.

Teint brun. Barbe, cheveux et sourcils châtains. Tatoué.

Carrure moyenne. Santé délabrée. Atrophie de la jambe gauche, consécutive à une chute survenue pendant l'enfance.

Toujours sa rate fume; néanmoins, il exécute la tåche. Empaillage. - Obs. 76 .

$35^{\circ}$ Au point de vue de l'interdiction de sejour :

2 sont frappés d'interdiction de séjour. 


$$
\text { *** }
$$

$36^{\circ}$ A u point de vue du travail en prison :

Bons travailleurs 13, passables 2 , mauvais 2.

$37^{\circ}$ Au point de vue de la conduite en prison :

Bonne 11, passable 4, mauvaise 2.

$$
\text { **** }
$$

$38^{\circ}$ Au point de vue de l'expulsion :

2 étranger's expulsés sur 3. 


\section{VII}

MENACES DE MORT - SUPPRESSION D'E.VFANT

TENTATIVE D'EMPOISONNEMENT - TENTATIVE D'HOMICIDE

ASSASSINAT - TENTATIVE D'ASSASSINAT

9 individus

$1^{n}$ Au point de vue de la naissance :

9 enfants légitimes.

$2^{\circ} \mathrm{Au}$ point de vue de la nationalité :

7 Français (dont 5 Corses), 2 Italiens.

Un Corse, âgé de 43 ans, célibataire, sachant lire, écrire et calculer, cultivateur, rural, à la $6^{\mathrm{e}}$ peine, adonné à l'ivrognerie, signalé comme " extrêmement dangereux"), subit la peine de 3 ans de prison, prononcée, le.... 1892, par la cour d'appel de Bastia, pour " menaces de mort, avec ordre et sous conditions".

$\mathrm{Au}$ cours d'une discussion avec un de ses compatriotes, il sortit un pistolet de sa poche et dit: " $\mathrm{Si}$ tu bouges, je te brûle la cervelle. »)

Dans la même journée, il se promenait avec une canne à épée et il agitait, à tout moment, l'arme dans le fourreau, en s'écriant : "Voilà pour l'adjoint au maire!" 
Sur le tard, il menaçait verbalement de mort son frère et sa sœur.

Arrêtẻ par les agents de la force publique, il traita les gendarmes, de "voleurs, canailles et assassins".

Taille $1 \mathrm{~m}$. 66. Envergure $1 \mathrm{~m}$. 70. Buste 0,898. Pied gauche $0,20 \mathrm{l}$. Tète : longueur 0.203 ; largeur 0.151 . Indice céphalique 74,38.

Oreille droite: longueur 0,067 ; largeur 0,033 . Indice auriculaire 322,23 .

Front: arcades moyeunes; inclinaison verticale; largeur petite; hauteur moyenne.

Nez : cavité (de la racine) petite ; dos large, rectiligne ; base horizontale ; saillie, hauteur et largeur moyennes.

Bouche : moyenne, à coins abaissés; ouverture intermédiaire.

Menton : fuyant, rond ; hauteur intermédiaire.

Visage ovale. Iris pigmenté d'orange; oeil gauche peu ouvert ; regard farouche.

Teint brun. Barbe, cheveux et sourcils châtain foncé.

Carrure mosenne. Petite santé.

Mauvais détenu. - Pantoufles. - Obs. 77.

\section{3c Au point de vue de l'âge:}

3, de 20 à 25 ans ; 4, de 30 à 50 ans; 2 , plus de 50 ans.

\section{Au point de vue de l'état civil :}

5 célibatares, 3 mariés, 1 divorcé.

Au nombre des mariés, figure un Italien, âgé de quarante ans, sachant lire et écrire, carrier, à la $3^{\mathrm{e}}$ peine, rural, condamné, à 5 ans de prison, par la cour d'assises de l'Hérault, le 24 mai 1892, pour "suppression d'enfant".

Dans le courant du mois de février 1892, sa femme, ayant 
sans doute surpris le secret des relations incestueuses qui existaient entre son mari et l'aînée de ses filles, quitta le domicile conjugal.

Le 2 mars, la fille accouchait d'un garçon dans la cave de la maison où elle s'était enfermée avec son père.

De concert avec elle, celui-ci fit disparaître l'enfant, né à terme et viable.

Taille $1 \mathrm{~m}$. 663. Envergure $1 \mathrm{~m}$. 73 Buste 0,886. Pied gauche 0,266. Tète : longueur 0,196 ; largeur 0,13 ö. Indice céphalique 79,08 .

Oreille droite : longueur 0,061 ; largeur 0,032 . Indice auriculaire $52.4: 3$.

Front : arcades proéminentes; inclinaison verticale ; largeur grande ; hauteur moyenne.

Nez : cavité (de la racine) moyenne; dos rectiligne sinueux; bașe abaissée ; largeur grande ; hauteur et saillie moyennes.

Bouche : moyenne, à coins abaissés ; ouverture intermédiaire.

Menton : saillant, large, haut, à houppe et à fossette.

Visage large. Iris pigmenté d'orange. Figure courante.

Teiut brun. Barbe, cheveux et sourcils chàtain foncé, grisonnants.

Carrure moyenne. Santé inédiocre. A expulser.

Conduite satisfaisante; travail soutenu. - Pipes. - Obs. 78.

\section{$5^{\circ} \mathrm{Au}$ point de vue de l'instruction :}

3 sont illettrés ; 4 savent lire et écrire; 1 sait lire, écrire et calculer; 1 a reçu une instruction primaire complète.

Ce dernier est âgé de quarante-neuf ans. Il appartient à la population urbaine et exercait la profession de limonadier. On ne lui connait aucune condamnation antérieure. En revanche, sa réputation est mauvaise.

Il lui a été infligé, le.... 1895, par la cour d'assises du...., 2 ans de prison et cent francs d'amende, pour avoir "occasionnè une maladie ou incapacité de travail personnel à 
sa femme, en lui administrant, volontairement, dans une boisson, des substances (une décoction d'allumettes) qui, sans être de nature à donner la mort, sont nuisibles à la santé ".

La tentative d'empoisonnement a été écartée par le jury, comme chef d'accusation.

Taille $1 \mathrm{~m}$. 60. Envergure $1 \mathrm{~m}$. 60. Busle 0,865. Pied gauche 0,234. Tète : longueur 0,197 ; largeur 0,165 . Indice céphalique 83,75.

Oreille droite : longueur 0,064 ; largeur 0,040 . Indice auriculaire 62,50 .

Forme triangulaire; écartement postérieur.

Front : arcades proéminentes ; inclinaison intermédiaire ; hauteur et largeur moyennes. Plat.

Nez : cavité (de la racine), saillie, hauteur et largeur moyennes; dos rectiligne; base horizontale.

Bouche : grande, à coins abaissés; ouverture intermédiaire. Menton : droit, large, haut, à fossette.

Visage large et plat. Iris pigmenté de jaune. Traits altérés. Teint brun. Barbe, cheveux et sourcils châtain foncé.

Carrure grande. Bonne santé ; presbytie. Contenance avilie.

Il porte des bas noirs, cravatés de faveurs bleues.

Cependant c'est un chaisier qui travaille d'une manière consciencieuse. - Obs. 79.

\section{$6^{\circ} \mathrm{Au}$ point de vue de la profession :}

4 cultivateurs, journaliers, domestiques ; 2 ouvriers du bâtiment et du mobilier ; 1 ouvrier d'atelier ; 1 commerçant; 1 garçon de café.

Le garcon de café, âgẻ de vingt-quatre ans, célibataire, sachant lire et écrire, rural, ayant un domicile, sans antécédents judiciaires, adonné à l'ivrognerie, alla à Narbonne voir une femme qui l'avait quitté pour entrer dans une maison de tolérance. Son wil affectueux, humide de tendresse, implorait un baiser. Elle le lui donna. Dans le moment même, il résolut de 
la tuer et de se suicider ensuite. Six coups de revolver s'enten dirent, remplissant le claque d'effroi.

La mort les épargna l'un et l'autre.

Par arrêt du 13 février 1894, la cour d'assises de l'Aude l'a condamné, pour " tentative d'homicide volontaire ", à $\mathbf{5}$ ans de travaux forcés, peine commuée en 5 années d'emprisonnement.

Taille $1 \mathrm{~m}$. 635. Envergure $1 \mathrm{~m}$. 72. Buste 0.860. Pied gauche 0,265. Tète : longueur 0,188 ; largeur 0,161 . Indice céphalique 85,63 .

Oreille droite : longueur 0,030 ; largeur 0,034 . Indice auriculaire 60,71 . Front : arcades proémineutes ; inclinaison verticale ; hauteur grande ; largeur moyenne.

Nez : cavité (de la racine) moyenne; dos concave; base horizontale ; hauteur, largeur et saillie moyennes.

Bouche: moyenne, à coins relevés; ouverture intermédiaire.

Menton : rond, droil ; hauteur intermédiaire.

Visage ovale. Iris pigmenté d'orange.

Teint brun. Barbe, cheveux et sourcils châtain clair. Tatoué.

Carrure moyenne. Santé bonne. Manières franches.

Bien noté. - Cordonnerie. - Obs. 80.

$7^{\circ}$ Au point de vue de la population :

8 ruraux, 1 urbain.

$8^{\circ} \mathrm{Au}$ point de vue du domicile :

Tous avaient un domicile.

$9^{\circ}$ Au point de vue du nombre des condamnations :

4 sans antécédents judiciaires et 5 récidivistes.

Un Corse, âgẻ de cinquante-deux ans, marié, illettré, journalier, rural, adonné à l'ivrognerie, vivant aux crochets de sa 
femme, fait 5 ans de prison, peine prononcée (avec 10 ans d'interdiction de séjour) le 29 novembre 1894, par la cour d'assises de son département, pour " tentative d'assassinat provoqué $)$.

Il frappa, sournoisement, d'un coup de couteau (21 août 1894), un boulanger qui lui avait refusé la petite somme de 60 centimes.

Taille $1 \mathrm{~m}$. 72. Envergure $1 \mathrm{~m}$. 72. Buste 0,873. Pied gauche 0,263. Tète : longueur 0,198; largeur 0,140. Indice céphalique 70,70.

Oreille droite: longueur 0,$064 ;$ largeur 0,038 . Indice auriculaire 59,37 .

Front : arcades moyennes; inclinaison intermédiaire; hauteur et largeur moyennes.

Nez : cavité (de la racine) moyenne; dos rectiligne; base horizontale; hauteur, saillie et largeur moyennes.

Bouche: moyenne, à coins relevés; ouverture intermédiaire.

Nenton : rond, droit; hauteur intermédiaire.

Visage ovale. Iris pigmenté de chàtain. Méchante mine.

Teint brun. Barbe, cheveux et sourcils chàtains grisonnants; sourcils écartés.

Carrure moyenne. Mauvais état général. Artérite chronique avec dégénérescence athéronateuse; hernie inguinale droite.

Il travaille de son mieux et se conduit convenablement. Service général. - Obs. 81.

\section{$10^{\circ} \mathrm{Au}$ point de vue de l'oisiveté :}

2 oisifs.

\section{$11^{\circ}$ Au point de vue de l'ivrognerie :}

6 adonnés à l'iorognerie.

$12^{\circ}$ Au point de vue du libertinage et de la débauche : 2 libertins et débauchés. 
$13^{\circ}$ Au point de vue du concubinage :

Aucun ne vivait en concubinage.

$14^{\circ}$ Au point de vue de la note de la commune :

Pas un seul bien noté.

$15^{\circ} \mathrm{Au}$ point de vue de la taille :

Dans la catégorie de 20 à 25 ans : taille de $1 \mathrm{~m} .60$ à $1 \mathrm{~m} .70$, 2 individus; de $1 \mathrm{~m}$. 70 et au-dessus, 1.

Soit, moyenne de la taille $1 \mathrm{~m} .679$.

De 30 a 40 ans : taille de $1 \mathrm{~m}$. 70 et au-dessus, 1 individu. Soit, taille $1 \mathrm{~m} .71$.

De 40 à 50 ans : taille de $1 \mathrm{~m} .60$ à $1 \mathrm{~m} .70,3$ individus.

Soit, moyenne de la taille $1 \mathrm{~m} .641$.

De 50 ans et au-dessus: taille de $1 \mathrm{~m} .60$ à $1 \mathrm{~m} .70,1$ individu; de $1 \mathrm{~m}$. 70 et au-dessus, 1.

Soit, moyenne de la taille $1 \mathrm{~m} .660$.

En résumé : taille de $1 \mathrm{~m} .60$ à $1 \mathrm{~m}$. 70, 6 individus; de $1 \mathrm{~m}$. 70 et au-dessus, 3.

Soit, moyenne de la taille $1 \mathrm{~m} .665$. 
16. Au point de vue de l'envergure:

Dans la catégorie de 20 à 25 ans : envergure supérieure à la taille, de 4 à 8 cent., 2 individus; de 8 à 16 cent., 1 .

Soit, moyenne de l'envergure $1 \mathrm{~m}$. 760 .

De 30 à 40 ans : envergure supérieure à la taille, de 4 à 8 cent., 1 individu.

Soit, envergure $1 \mathrm{~m} .750$.

De 40 à 50 ans : envergure égale à la taille, 1 individu ; supérieure à la taille, de 4 à $S$ cent., 2 .

Soit, moyenne de l'envergure $1 \mathrm{~m} .676$.

De 50 ans et au-dessus: envergure égale à la taille, 1 individu ; supérieure à la taille, de 8 à 16 cent., 1 .

Soit, moyenne de l'envergure $1 \mathrm{~m}$. 710.

En résumé : envergure égale à la taille, 2 individus ; supérieure à la taille, de 4 à 8 cent., 5 ; de 8 à 16 cent., 2 . Soit, moyenne de l'envergure $1 \mathrm{~m} .713$.

\section{Au point de vue du buste :}

Dans la catégorie de 20 à 25 ans : buste supérieur à la moitié de la taille, de 0 à 5 cent., 3 individus.

Soit, moyenne du buste 0,883 .

De 30 à 40 ans : buste supérieur à la moitié de la taille, de 5 à 10 cent., 1 individu.

Soit, hauteur du buste 0,918 .

De 40 à 50 ans: buste supérieur à la moitié de la taille, de 5 à 10 cent., 3 individus.

Soit, moyenne du buste 0,883 . 
De 50 ans et au-dessus : buste supérieur à la moitié de la taille, de 0 à 5 cent., 2 individus.

Soit, moyenne du buste 0,850 .

En résumé: buste supérieur à la moitié de la taille, de 0 à 5 cent., 5 individus; de 5 à 10 cent., 4 .

Soit, moyenne du buste 0,875 .

\section{$18^{\circ}$ Au point de vue du pied :}

Dans la catégorie de 20 à 25 ans: pied de 26 à 28 cent., 3 individus.

Soit, moyenne du pied 0,263.

De $30 \dot{a} 40$ ans : pied de 24 à 26 cent., 1 individu.

Soit, longueur du pied 0,260.

De 40 à 50 ans : pied de 22 à 24 cent., 1 individu; de 24 à 26 cent., 1; de 26 à 28 cent., 1 .

Soit, moyenne du pied 0,250.

De 50 ans et au-dessus : pied de 24 à 26 cent., 1 individu ; de 26 à 28 cent., 1 .

Soit, moyenne du pied 0,259.

En résumé: pied de 22 à 24 cent., 1 individu ; de 24 à 26 cent., 3 ; de 26 à 28 cent., 5 .

Soit, moyenne du pied 0,254.

$19^{\circ}$ Au point de vue de la tête :

3 dolichocéphales vrais, 2 mésaticéphales, 1 sous-brachycéphale, 3 brachycéphales vrais. 
D'autre part, les calculs donnent :

Longueur moyenne de la tête 0,1936 ; largeur moyenne de la tête 0,1536 .

D'où : Indice céphalique 79,33 .

$20^{\circ}$ Au point de vue de l'oreille :

Indice auriculaire: au-dessous de 52, 1 individu; de 52 à 56,3 ; de 56 à 60,3 ; de 60 à 65,2 .

D'autre part, les calculs donnent :

Longueur moyenne de l'oreille 0,062; largeur moyenne de l'oreille 0,035 .

D'où : Indice auriculaire $5 \%, 74$.

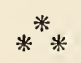

21. Au point de vue du visage :

Large ou carré 2, ovale 6, allongé 1.

$22^{\circ}$ Au point de vue du front:

Arcades : grandes 4, moyennes 5 .

Inclinaison : verticale 3 , fuyante 2 , intermédiaire 4 .

Hauteur : grande 1, moyenne 8 .

Largeur : grande 1, petite 1 , moyenne $\%$. 
$23^{\circ} \mathrm{Au}$ point de vue du nez:

Cavité (de la racine) : petite 3 , moyenne 6 .

Dos : rectiligne 6 , concave 1 , convere 2.

Base : horizontale 8, abaissẻe 1.

Hauteur : grande 1, moyenne 8 .

Saillie : grande 3, moyenne 6.

Largeur : grande 1, moyenne 8.

$24^{\circ}$ Au point de vue de la bouche :

Dimension: grande 1 , petite 1 , moyenne $\%$

Inclinaison des angles : rectiligne 3 , à coins abaissės 3 , à coins relevés 3 .

Degré habituel d'ouverture: bée 1, pincée 1, intermédiaire 7.

25. Au point de vue du menton :

Inclinaison générale : menton saillant 1 , fuyant 3 , droit 5 . Avec et sans houppe: à houppe 1, intermédiaire 8.

Hauteur : haut 3, bas 2, intermédiaire 4.

Forme : large 2 , rond $\%$.

26॰ Au point de vue de l'œil :

Iris: pigmenté de jaune 2 , d'orange 4 , de châtain 3 .

27' Au point de vue du teint :

Brun 9.

Cir. Perrien. 
$28^{\circ}$ Au point de vue de la carrure :

Grande 1, moyenne 8.

$29^{\circ}$ Au point de vue de la constitution et de l'ètat génèral, à l'arrivẻe :

Très bons 1, bons 5, passables 2 , mauvais 1 .

$30^{\circ}$ Au point de vue des maladies et infirmités, à l'arrivèe :

5 maladies et infirmités, à répartir entre 3 individus (dont 1 étranger).

Soit: presbytie 1, surdité légère 1 , artérite clıronique avec dégénérescence athéromateuse prononcée 1 , hernie inguinale droite 2.

31 ${ }^{\circ}$ Au point de vue du lieu du crime :

Lieu de naissance : 3 individus (ruraux).

Département du lieu de naissance : 3 individus (ruraux). Autre département : 3 individus (dont 1 urbain). 
$32^{\circ}$ Au point de vue de la date du crime:

2 en janvier, 2 en mar's, 1 en juin. 2 en août, 1 en septembre, 1 pendant l'année.

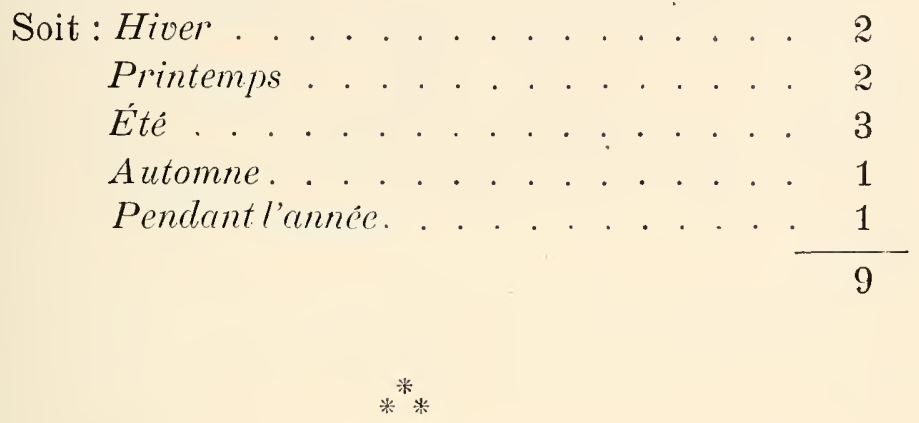

$33^{\circ}$ Au point de vue de la juridiction :

2 tribunaux (menaces de mort), 7 cour's d'assises.

$34^{\circ}$ Au point de vue de la durée de la peine :

2. de $2 \dot{a} 3$ ans; $1, \dot{a} 3$ ans; 6 , ì 5 ans.

Un berger (Corse, âgé de 20 ans, célibataire, illettré, rural, à la $3^{\text {e }}$ peine) a été condamné, le 31 mai 1893, par la cour d'assises de son département, ¿̇ 5 ans de prison et à 10 ans d'interdiction de séjour, pour " assassinat provoqué ".

Dans les premiers jours de janvier 1893, il fut surpris volant des lacets et des merles. Le propriétaire lui ayant reproché son action, d'une façon très vive, il alla se poster dans le maquis et, lorsque son compatriote vint à passer, il le blessa mortellement d'un coup de feu. 
Taille $1 \mathrm{~m}$. 732. Envergure $1 \mathrm{~m}$. 79. Buste 0,910. Pied gauche 0,262. Tète: longueur 0,199 ; largeur 0,147 . Indice céphalique 73,86 .

Oreille droite : longueur 0,068; largeur 0,035. Indice auriculaire 51,47. Écartement tolal.

Front : arcades moyennes; inclinaison fuyante; hauteur el largeur moyennes.

Nez: cavité (de la racine) moyenne; dos convexe; base horizontale ; saillie grande; hauteur et largeur moyennes.

Bouche : moyenne, rectiligne, bée.

Menton : fuyant, rond, baut, à fossette.

Visage allongé. Iris pigmenté de châtain .

Teint brun. Barbe, cheveux et sourcils chàtain moyen.

Carrure moyenne. Santé passable. Humeur sombre.

Le travail et la conduite ne laissent point à désirer. Sparterie. - Obs. 82.

$35^{\circ}$ Au point de vue de l'interdiction de séjour :

2 sont frappés d'interdiction de séjour.

$36^{\circ}$ Au point de vue du travail en prison :

Bons ouvriers 6, passables 2, mautais 1.

37. Au point de vue de la conduite en prison:

Bonne 5, passable 1, mauvaise 3.

$$
\text { *** }
$$

$38^{\circ}$ Au point de vue de l'expulsion :

2 étranger's sur 2. 


\section{VIII \\ MEURTRE. - TENTATIVE. - COMPLIGITÉ \\ 36 individus}

\section{$1^{\circ}$ Au point de vue de la naissance :}

1 enfant naturel.

Cet homme, âgé de vingt-cinq ans, né et domicilié en Corse, célibataire, sachant lire et écrire, cultivateur, rural, adonné à l'ivrognerie, condamné jadis à 1 an et 1 jour de prison par le conseil de guerre d'Oran (refus d'obéissance à un ordre relatif au service), subit la peine de 5 ans d'emprisonnement, prononcée (y compris 10 ans d'interdiction de séjour), le 20 décembre 1894, par la cour d'assises de son département, pour " meurtre provoqué »).

Dans la nuit du 23 au 24 juillet 1894, après avoir introduit ses bestiaux dans un enclos couvert de gerbes de blé, il étendit sur le carreau, d'un coup de revolver, le fermier qui lui adressait des observations.

Taille 1 m. 68:. Envergure 1 m. 72. Buste 0,89̈. Pied gauche 0,2:53. Tète : longueur 0,189 ; largeur 0,146 . Indice céphalique 77,24 .

Oreille droite: longueur 0,060 ; largeur 0,032. Indice auriculaire 53,33 . Écartement supérieur.

Front: arcades moyennes; inclinaison intermédiaire; largeur et hauteur moyennes. Bombé. 
Nez : cavité (de la racine) moyenne; dos rectiligne; base horizontale; saillie, largeur et hauteur moyennes.

Bouche : moyenne, à coins relevés; ouverture internédiaire.

Menton : droit, rond, haut.

Visage ovale. Iris pigmenté de marron. Regard froid et sombre.

Teint brun. Barbe, cheveux et sourcils chàtains.

Carrure grande. Santé forte.

C'est un paresseux, toujours de mauvaise humeur. Sparterie, - Obs. 83 .

\section{$2^{\circ}$ Au point de vue de la nationalité :}

\section{Français (dont 28 Corses), 3 Italiens.}

Un Piémontais, âgé de trente ans, célibataire, illettré, journalier, rural, sans an técédents judiciaires, adonné à l'ivrognerie, a été condamné, le 6 novembre 1893, par la cour d'assises des Alpes-Maritimes, à 5 ans de prison, pour (" meurtre provoqué ).

Le 20 aout 1893 , au cours d'une rixe, il porta plusieurs coups de couteau (dont deux devaient entraîner la mort) à son meilleur ami. Celui-ci avait brisé la porte d'entrée d'une chambre, par eux habitée en commun, et se refusait à payer les dégâts s'élevant à la somme de trois francs.

I'expulsion suivra la peine.

Taille $1 \mathrm{~m}$. 66. Envergure $1 \mathrm{~m}$. 78. Buste 0,878. Pied gauche 0,260.

Tète : longueur 0,183 ; largeur 0,1500 . Indice céphalique 81,08 .

Oreille droite : longueur 0,063 ; largeur 0,033 . Indice a uriculaire 52,38 . Front: arcades moyenues; inclinaison intermédiaire; hauteur et largeur petites.

Nez: cavité (de la racine) petite; dos concave; base horizontale; hauteur moyenne; saillie petite ; largeur grande.

Bouche : moyenne, rectiligne ; ouverture intermédiaire.

Menton : droit, rond; hauteur intermédiaire. 
Visage ovale. Iris pigmenté d'orange, truité. Physionomie sauvage.

Teint brun. Barbe, cheveux et sourcils chàtains.

Carrure moyenne. Santé bonne. Hernie inguinale gauche.

Un rageur peu porté au travail. - Filoches. - Obs. 84 .

\section{$3^{\circ}$ Au point de vue de l'âge :}

7 de 16 à 20 ans.

Entre autres, un Marseillais, âgé de dix-neuf ans, sachant lire et écrire, journalier, 4 fois condamné, adonné à l'ivrognerie, à qui la cour d'assises des Bouches-du-Rhône a infligé, le 14 février 1896, 2 ans d'emprisonnement, pour " complicité de meurtre après provocation $)$.

Il avait passé à un camarade le couteau avec lequel fut frappé son rival, l'amant d'une fille publique, pendant une querelle survenue dans la soirée du 25 juillet 1895.

Taille $1 \mathrm{~m} .6 \dot{4}$. Envergure $1 \mathrm{~m}$. 66. Buste 0,893. Pied gauche 0,24. Tète : longueur 0,187 ; largeur 0,161 . Indice céphalique 86,09 .

Oreille droite: longueur $0,0 \not 39$; largeur 0,033 . Indice auriculaire 30,93 .

Écartement total.

Front: arcades moyennes; inclinaison intermédiaire; hauteur et largeur movenines.

Nez : cavité (de la racine) petite ; dos concave ; base horizontale ; hauteur, largeur et saillie moyennes.

Bouche: moyenne, rectiligne, pincée.

Ilenton : bas, saillant, rond, plat.

Visage ovale. Iris pigmenté d'orange.

Teint clair. Barbe, cheveux et sourcils châtains. Tatoué.

Carrure moyenne. Santé bonne. Caractère difficile, bizarre, quiuteux.

Conduite déplorable et travail médiocre. - Cordonnerie. Obs. 85. 
9 de $20 \dot{a} 30$ ans, 8 de 30 à 40 ans, 6 de 40 à 50 ans, 6 de 50 ans et plus.

A signaler : un Italien, âgé de cinquante-deux ans, célibataire, sachant lire, journalier, rural, à la $3^{\mathrm{e}}$ peine.

Par arrêt, en date du 23 juillet 1894, la cour d'assises de la Corse l'a condamné, à 5 ans de prison et à 10 ans d'interdiction de séjour, pour "meurtre provoqué ».

Il était pris de boisson et sur le point de se coucher, lorsque son associé dans l'exploitation d'une propriété rurale vint le trouver (13 mai 1894), pour s'entendre avec lui au sujet des travaux à faire le lendemain. Furieux d'être dérangé, il le tua raide, d'un coup de pistolet en pleine poitrine.

Taille $1 \mathrm{~m}$. 60. Envergure $1 \mathrm{~m}$. 65. Buste 0,83̈. Pied gauche 0,240. Tète : longueur 0,190 ; largeur 0,146 . Indice céphalique 76,84.

Oreille droite : longueur 0,064 ; largeur 0,032. Indice auriculaire $\ddot{0} 0,00$.

Front: arcades moyennes; inclinaison intermédiaire; hauteur et largeur petites.

Nez : cavité (de la racine) moyenne; dos convexe; base relevée; largeur et hauteur petites; saillie moyenne. Dévié à droite.

Bouche : petite, rectiligne, pincée.

Menton: fuyant, rond ; hauteur intermédiaire.

Visage ovale, sans physionomie. Iris impigmenté.

Teint pâle. Barbe, cheveux et sourcils chàtain clair.

Carrure moyenne. Santé et eonstitution médiocres. A expulser.

Il passe tranquillement ses jours au quartier des vieillards. - Obs. 86.

\section{Au point de vue de l'état civil :}

18 célibataires, 16 mariés, 2 veufs.

L'un des veufs, âgé de vingt-six ans, cultivateur, sans antécédents judiciaires, naquit dans une petite commune de la Corse. 
Il ne possède aucune instruction.

La cour d'assises de son département lui a infligé, par arrêt du 27 février 1894, 5 ans de prison et 10 ans d'interdiction de séjour, pour "meurtre provoqué ".

Aussitôt après la mort de sa femme, il eut des difficultẻs avec son beau-père, au sujet de minimes questions d'intérêt.

Pour terminer toute discussion, il le blessa mortellement d'un coup de feu (25 octobre 1893).

Taille $1 \mathrm{~m}$. 6\%. Envergure $1 \mathrm{~m}$. 65. Buste 0,885. Pied gauche 0,234. Tète : Iongueur 0,193 ; largeur 0,152 . Indice céphalique 77,94.

Oreille droite : longueur 0,060 ; largeur 0,032 . Indice auriculaire 53,33 . Front: arcades moyenues; inclinaison intermédiaire; hauteur et largeur moyennes.

Nez: cavité (de la racine) moyenne; dos rectiligne ; base relevée; saillie, hauteur et largeur moyennes.

Bouche: moyenne, pincée, à coins relevés.

Menton : rond, droit; hauteur intermédiaire.

Visage ovale. Iris pigmenté de marron. Des yeux vifs.

Teint brun. Barbe, cheveux et sourcils chàtain foncé.

Carrure moyenne. Santé vigoureuse.

Tout en faisant du chabannais, il remplit sa tâche. Cordonnerie. - Obs. 87.

\section{$5^{\circ} \mathrm{Au}$ point de vue de l'instruction :}

9 sont illettrés.

Un Corse, âgé de quarante ans, mariè, cultivateur, sans condamnation antérieure, urbain, subit la peine de 4 ans de prison, prononcèe, le 12 décembre 1894, par la cour d'assises de son département, pour "meurtre provoquė ».

Le 22 juillet 1894, à la suite d'une dispute, il avait échangé, du haut de sa fenêtre, des coups de fusil avec plusieurs personnes d'une même famille qui se trouvaient dans la rue, et en avait tué une. 
Taille 1 m. 67. Envergure $1 \mathrm{~m}$. 74. Buste 0,92'. Pied gauche 0,2ว̈3. Tète : longueur 0,191 ; largeur $0,15 \%$. Indice céphalique 82,19.

Oreille droite: longueur $0,06 . \ddot{5}$; largeur 0,03 . Indice auriculaire 52,30. Forme triangulaire ; écartement total.

Front: arcades grandes; inclinaison verticale; hauteur et largeur moyennes.

Nez : cavité (de la racine) moyenne ; dos concave; base horizontale; hauteur, saillie et largeur moyennes. Narines fermées.

Bouche : moyenne, rectiligne, bée.

Menton : saillant, large, haut, plat.

Visage ovale. Iris pigmenté de châtain.

Teint brun. Barbe, cheveux et sourcils châtain foncé.

Carrure moyenne. Santé parfaite. Nature abrutie.

Il se conduit mieux qu'il ne travaille. - Empaillage. Obs. 88.

3 savent lire; 21 savent lire et écrire ; 3 savent lire, écrire et calculer.

Rentre dans la dernière catẻgorie : un jeune homme, âgẻ de vingt-quatre ans, célibataire, cultivateur, rural; adonné à l'ivrognerie, condamné, par la cour d'assises de la Corse (son pays natal), le.27 février 1893, à 5 ans de prison, pour " tentative de meurtre provoqué ".

Irrité contre un cultivateur dont la déposition devant le tribunal de Bastia lui avait fait infliger 6 mois d'emprisonnement (coups et blessures), il déclara, dès sa rentrée chez lui, que le témoin n'avait qu'à se tenir sur ses gardes.

Le lendemain (11 novembre 1892), vers 6 heures du matin, il lui plongeait, par derrière, un poignard dans le dos.

Taille $1 \mathrm{~m} .66$. Envergure $1 \mathrm{~m} .63$ Buste 0,912. Pied gauche 0,257. Tète : longueur 0,193 ; largeur 0,147 . Indice céphalique 76,16. Oreille droite : longueur 0,063 ; largeur 0,033 . Indice auriculaire 53,84 . Éeartement postérieur.

Front: fuyant, haut, étroit; areades moỵennes. 
Nez : cavité (de la racine) moyenne ; base horizontale ; dos concave ; hauteur, saillie et largeur moyennes.

Bouche : moyenne, rectiligne, pincée.

Menton : droit, large, à fossette ; hauteur intermédiaire.

Visage ovale. Iris pigmenté d'orange. Air faux.

Teint blond. Barbe, cheveux et sourcils chàtain clair.

Carrure grande. Santé bonne. Hernie inguinale gauche.

C'est un bon à nib (paresseux) et une rousselette (méchant). - Isolement. - Obs. 89.

\section{$6^{\circ}$ Au point de vue de la profession :}

2 propriétaires, 1 employé, 2 commerçants, 2 ouvriers d'ateliers et de fabriques, 2 ouvriers du bâtiment et du mobilier, 2 sans profession, 25 journaliers, cultivateur's, domestiques.

Un Italien, domestique, âgé de cinquante et un ans, célibataire, rural, illettré, adonné à l'ivrognerie, vivant en concubinage, 3 fois condamné, subit la peine de 5 ans de prison, prononcée (y compris 10 ans d'interdiction de séjour), le 21 mai 1894, par la cour d'assises de la Corse, pour « meurtre provoqué ".

Vers une heure du matin, dans la nuit du 25 au 26 mars 1894, à Bastia, une dispute ayant éclaté dans l'auberge que tenait sa maîtresse, il s'arma d'un grand couteau de cuisine et tua raide un boulanger.

Taille $1 \mathrm{~m}$. 7366. Envergure $1 \mathrm{~m}$. 78. Buste 0,979. Pied gauche 0,264. Tète: longueur 0,189 ; largeur 0,147 . Indice céphalique 77,77.

Oreille droite: longueur 0,062 ; largeur 0,036 . Indice auriculaire 58,06. Écartement total.

Front: arcades moyennes; inclinaison intermédiaire; hauteur et largeur moyennes. 
Nez: cavité (de la racine)grande ; largeur moyenne; hauteur et saillie grandes ; dos rectiligne ; base abaissée. Dévié à gauche.

Bouche : moyenne, à coins relevés; ouverture intermédiaire.

Menton: droit, pointu, haut.

Visage allongé. Iris pigmenté d'orange. Physionomie mauvaise.

Teinl brun. Barbe, cheveux et sourcils chàtain foncé.

Carrure grande. Santé délabrée. Hypertrophie du cœur.

A expulser. - Infirmerie. - Obs. 90.

$7^{\circ} \mathrm{Au}$ point de vue de la population :

9 appartiennent $\dot{a}$ la population urbaine ; $27, \dot{a}$ la population rurale.

$8^{\circ}$ Au point de vue du domicile :

Tous avaient un domicile.

9. Au point de vue du nombre des condamnations :

20, sans antécédents judiciaires; 10, condamnés 1 fois ; 6, plusieurs fois.

Un Corse, âgé de trente-six ans, marié, sachant lire, écrire et calculer, cultivateur, à la $\gamma^{\mathrm{e}}$ peine, urbain, aimant à lever le coude, a étẻ condamné, par arrêt de la cour d'assises de son département, en date du 5 mars 1892, à 5 ans de prison, pour " tentalive de meurtre provoqué ".

Ne pouvant souffrir dans son village la présence d'un concitoyen qui s'était livré à des voies de fait sur sa personne, il intima à son ancien adversaire l'ordre de partir, sous peine de mort. Celui-ci n'ayant pas obtempéré à ses sommations, il le guetta dans la journée du 12 août et lui tira, d'une fenêtre, un coup de fusil qui eut des conséquences graves. 
Taille 1 m. 634. Envergure 1 m. 690. Buste 0,875. Pied gauche 0, 239 . Tète : longueur 0,197 ; largeur $0,13 \%$. Indice céphalique 78,17.

Oreille droite: longueur $0,06 \ddot{3}$; largeur 0,039 . Indice auriculaire 60,00. Forme triangulaire ; écartement inférieur.

Front: arcades grandes; inclinaison intermédiaire; hauteur et largeur moyennes.

Nez: cavité (de la racine) petite; dos rectiligne; base horizontale ; hauteur et saillie moyennes ; largeur petite.

Bouche : moyenne, rectiligne, pincée.

Menton : droit, rond, haut.

Visage ovale. Iris pigmenté de châtain. Mine hypocrite.

Teint brun. Barbe, cheveux et sourcils chatain foncé.

Carrure moyenne. Santé boune. Surdité légère.

Il travaille et se conduit bien. - Ébénisterie. — Obs 91.

$10^{\circ}$ Au point de vue de l'oisiveté :

9 vivaient dans l'oisiveté.

11. Au point de vue de l'ivrognerie :

22 s'adonnaient à l'ivrognerie.

$12^{\circ} \mathrm{Au}$ point de vue du libertinage et de la débauche :

10 se livraient au libertinage et à la débauche.

13. Au point de vue du concubinage :

3 vivaient en concubinage.

$14^{\circ}$ Au point de vue de la note de la commune :

9 étaient bien notés. 
$15^{\circ} \mathrm{Au}$ point de vue de la taille :

Dans la catégorie de 16 à 20 ans: taille de $1 \mathrm{~m} .60$ à $1 \mathrm{~m}$. 70, 6 individus ; de $1 \mathrm{~m} .70$ et au-dessus, 1.

Soit, moyenne de la taille $1 \mathrm{~m} .659$.

De 20 à 25 ans : taille de $1 \mathrm{~m} .60$ à $1 \mathrm{~m} .70,1$ individu.

Soit, taille $1 \mathrm{~m} .660$.

De 25 à 30 ans: taille $1 \mathrm{~m} .60$ à $1 \mathrm{~m} .70,7$ individus; de $1 \mathrm{~m}$. 70 et au-dessus, 1.

Soit, moyenne de la taille $1 \mathrm{~m} .665$.

De 30 à 40 ans : taille de $1 \mathrm{~m} .60$ à $1 \mathrm{~m} .70,8$ individus. Soit, moyenne de la taille $1 \mathrm{~m} .653$.

De 40 à 50 ans: taille au-dessous de $1 \mathrm{~m}$. 60, 2 individus; de $1 \mathrm{~m}$. 60 à $1 \mathrm{~m} .70,3$; de $1 \mathrm{~m}$. 70 et au-dessus, 1 .

Soit, moyenne de la taille $1 \mathrm{~m} .633$.

De 50 ans et au-dessus : taille de $1 \mathrm{~m} .60$ à $1 \mathrm{~m} .70,4$ individus ; de $1 \mathrm{~m} .70$ et au-dessus, 2.

Soit, moyenne de la taille $1 \mathrm{~m} .680$.

En résumé: taille au-dessous de $1 \mathrm{~m}$. 60, 2 individus; de $1 \mathrm{~m} .60$ à $1 \mathrm{~m}$. 70, 29; de $1 \mathrm{~m}$. 70 et au-dessus, 5 .

Soit, moyenne de la taille $1 \mathrm{~m} .658$. 


\section{Au point de vue de l'envergure :}

Dans la catégorie de 16 à 20 ans: envergure inférieure à la taille, de 0 à 8 cent., 3 individus; supérieure à la taille de 0 à 4 cent., 2 ; de 4 à 8 cent., 1 ; de 8 à 16 cent., 1 .

Soit, moyenne de l'envergure 1.665 .

De 20 à 25 ans : envergure inférieure à la taille, de 0 à 8 cent., 1 individu.

Soit, envergure $1 \mathrm{~m} .630$.

De 25 à 30 ans : envergure inférieure à la taille, de 0 à 8 cent.,

3 individus; égale à la taille, 1 ; supérieure à la taille, de 0 à 4 cent., 1 ; de 4 à 8 cent., 3 .

Soit, moyenne de l'envergure $1 \mathrm{~m} .682$.

De 30 à 40 ans : envergure égale à la taille, 1 individu ; supérieure à la taille, de 0 à 4 cent., 4 ; de 4 à 8 cent., 2 ; de 8 à 16 cent., 1 .

Soit, moyenne de l'envergure $1 \mathrm{~m} .694$.

De 40 à 50 ans : envergure inférieure à la taille, de 0 à 8 cent., 2 individus; supérieure à la taille, de 0 à 4 cent., 2 ; de 4 à 8 cent., 2 .

Soit, moyenne de l'envergure $1 \mathrm{~m} .660$.

De 50 ans et au-dessus : envergure inférieure à la taille, de 0 à 8 cent., 1 individu; supérieure à la taille, de 0 à 4 cent., 2 ; de 4 à 8 cent., 2 ; de 8 à 16 cent., 1 .

Soit, moyenne de l'envergure $1 \mathrm{~m}$. 729.

En résumé : envergure inférieure à la taille, de 0 à 8 cent., 10 individus; égale à la taille, 2 ; supérieure à la taille, de 0 à 4 cent., 11 ; de 4 à 8 cent., 10 ; de 8 à 16 cent., 3.

Soit, moyenne de l'envergure $1 \mathrm{~m} .684$. 


\section{$17^{\circ}$ Au point de vue du buste :}

Dans la catégorie de 16 à 20 ans: buste supérieur à la moitié de la taille, de 0 à 5 cent., 4 individus; de 5 à 10 cent., 3 . Soit, moyenne du buste 0,883 .

De 20 à 25 ans : buste supérieur à la moitié de la taille, de 5 à 10 cent., 1 individu.

Soit, hauteur du buste 0,912.

De 25 à 30 ans : buste supérieur à la moitié de la taille, de 0 à 5 cent., 3 individus; de 5 à 10 cent., 5 .

Soit, moyenne du buste 0,888 .

De 30 à 40 ans : buste supérieur à la moitié de la taille, de 0 à 5 cent., 2 individus; de 5 à 10 cent., 6 .

Soit, moyenne du buste 0,892 .

De 40 à 50 ans: buste supérieur à la moitié de la taille, de 5 à 10 cent., 6 individus .

Soit, moyenne du buste 0,895 .

De 50 ans et au-dessus: buste égal à la moitié de la taille, 1 individu; supérieur à la moitié de la taille, de 5 à 10 cent., 4 ; de 10 à 18 cent., 1 .

Soit, moyenne du buste 0,898 .

En résumé: buste égal à la moitié de la taille, 1 individu ; supérieur à la moitié de la taille, de 0 à 5 cent., 9 ; de 5 à 10 cent., 25 ; de 10 à 18 cent., 1 .

Soit, moyenne du buste 0,891 . 
$18^{\circ} \mathrm{Au}$ point de vue du pied :

Dans la catégorie de 16 à 20 ans:pied de 24 à 26 cent., 6 individus; de 26 à 28 cent., 1.

Soit, moyenne du pied 0,253.

De 20 à 25 ans : pied de 24 à 26 cent., 1 individu.

Soit, longueur du pied 0,257.

De $25 \dot{a} 30$ ans : pied de $22 \dot{a} 24$ cent., 1 individu; de 24 à 26 cent., 4 ; de 26 à 28 cent., 3.

Soit, moyenne du pied 0,254 .

De 30 a 40 ans: pied de 22 à 24 cent., 1 individu; de 24 à 26 cent., 5 ; de 26 à 28 cent., 2.

Soit, moyenne du pied 0,250.

De 40 à 50 ans : pied de 22 à 24 cent., 1 individu ; de 24 à 26 cent., 5 .

Soit, moyenne du pied 0,248.

Dc 50 ans et au-dessus : pied de 24 à 26 cent., 3 individus ; de 26 à 28 cent., 3.

Soit, moyenne du pied 0,256.

En résumé: pied de 22 à 24 cent., 3 individus; de 24 à 26 cent., 24 ; de 26 à 28 cent., 9 .

Soit, moyenne du pied 0,252.

\section{$19^{\circ}$ Au point de vue de la tête :}

9 dolichocéphales vrais, 8 sous-dolichocéphales, 11 mésaticéphales, 6 sous-brachycéphales, 2 brachycéphales vrais.

D'autre part, les calculs donnent :

Longueur moyenne de la tête 0,1930 ; largeur moyenne de la tête 0,1502 .

D'où : Indice céplıalique $7 \%, 82$

Cil Perrier. 
$20^{\circ}$ Au point de vue de l'oreille:

Indice auriculaire : Au-dessous de 52, 4 individus; de 52 à 56 ,

12 ; de 56 à 60,8 ; de 60 à 65,12 .

D'autre part, les calculs donnent :

Longueur moyenne de l'oreille 0,0617 ; largeur moyenne de l'oreille 0,0349 .

D’où : Indice auriculaire 56,56.

$$
\text { *** }
$$

$21^{\circ}$ Au point de vue du visage:

En losange 1, rond 3, large ou carré 3, ovale 25, allongé 4 .

$22^{\circ} \mathrm{Au}$ point de vue du front:

Arcades: grandes 7 , petites 2 , moyennes 27.

Inclinaison: verticale 4 , fuyante 5 , intermédiaire 27.

Hauteur : grande 3 , petite 3 , moyenne 30 .

Largeur : grande 5, petite 8, moyenne 23.

\section{$23^{\circ}$ Au point de vue du nez:}

Cavité (de la racine) : grande 5, petite 12, moyenne 19.

Dos : rectiligne 22, concave 6, convexe 8 .

Base : horizontale 22 , relevée 11 , abaissée 3 .

Hauteur: grande 4, petite 1, moyenne 31 .

Saillie: grande 6 , petite 4 , moyenne 26 .

Lasgeur: grande 5 , petite 4 , moyenne 27. 
$24^{\circ}$ Au point de vue de la bouche :

Dimension : grande 4, petite 5, moyennè 27.

Inclinaison des angles : rectiligne 27, à coins abaissés 3, à coins relevés 6 .

Degré habituel d'ouverture: bée 4, pincée 6, intermédiaire 26.

$25^{\circ}$ Au point de vue du menton :

Inclinaison générale : menton saillant 9, fuyant 5, droit 22. A vec et sans houppe: plat 10, a houppe 7, intermédiaire 19. Hauteur: haut 11 , bas 10 , intermédiaire 15.

Forme: large 10, rond 24, pointu 2.

\section{Au point de vue de l'œil :}

Ir is : impigmenté 2, pigmenté de jaune 5, d'orange 20 , de châtain $\%$, de marron 2 .

27. Au point de vue du teint:

Brun 26, clair \%, blond 1, pâle 2.

$$
\text { *** }
$$

$28^{\circ}$ Au point de vue de la carrure:

Grande 6, moyenne 30. 
$29^{\circ} \mathrm{Au}$ point de vue de la constitution et de l'état gẻnéral, à l'arrivée:

Très bons 3 , bons 17, passables 10 , mauvais 5 ,très mauvais 1.

\section{$30^{\circ} \mathrm{Au}$ point de vue des maladies et infirmités, à l'arrivée:}

23 maladies et infirmités, ¿ répartir entre 17 individus (15 Français, dont 13 Corses; 2 Italiens).

Soit : bronchite bacillaire 3 , insuffisance valvulaire 4 , hypertrophie du cœur 1 , artérite avec dégénérescence athéromateuse prononcée 3 , hernie inguinale droite 1 , gauche 2 , goître 1 , varices 1 , varicocèle 1 , borgne 1 , myopie 1 , surdité légère 2 , surdi-mutité 1 , imbécillité 1 .

Le sourd-muet (Corse, âgé de cinquante-huit ans, célibataire, illettré, cordonnier, à la première peine, rural), a été condamné, à 5 ans de prison, par la cour d'assises de son département, pour " meurtre excusable ".

Irrité contre son frère pour un motif futile, il lui cassa la tête d'un coup de pistolet (29 août 1895).

Taille $1 \mathrm{~m}$. 63. Envergure $1 \mathrm{~m}$. 64. Buste 0,876. Pied gauche 0,253. Tète : longueur 0,194 ; largeur 0,151 . Indice céphalique 77.83.

Oreille droite: longueur 0,065 ; largeur 0,040 . Indice auriculaire 61,53 .

Front: areades petites; inclinaison intermédiaire; hauteur moyenne; largeur grande.

Nez: cavité (de la racine) grande; dos rectiligne; base abaissée; largeur grande; hauteur et saillie moyennes.

Bouche : moyenne, à coins abaissés; ouverture intermédiaire. Menton : rond, droit, à houppe; hauteur intermédiaire. 
Visage ovale. Iris pigmenté de chàtain. Physionomie sauvage.

Teint clair. Barbe, cheveux et sourcils chàtains.

Carrure moyenne. Santé bonne.

Détenu bien noté. - Cordonnerte. - Obs. 92.

L'individu frappé d'imbécillité (Corse, âgé de vingt-sept ans, célibataire, sachant lire et écrire, armurier, sans antécédents judiciaires, rural) a été condamné, par la cour d'assises de son département, à 5 ans de prison, pour " tentative de meurtre ".

Après avoir bu tout son soûl, il se prit de querelle avec un camarade et lui creva l'œil gauche d'un coup de revolver (17 mars 1893).

Taille $1 \mathrm{~m}$. 63. Envergure $1 \mathrm{~m}$. 399. Buste 0.840 . Pied gauche 0,245 . Tète : longueur 0,191 ; largeur 0,130 . Indice eéphalique 78,33.

Oreille droite: longueur 0,058 ; largeur 0,036 . Indice auriculaire 62,06 .

Front : arcades moyennes; inclinaison intermédiaire; hauteur et Jargeur moyennes.

Nez : cavité (de la racine) moyenne; base horizontale; dos convexe ; saillie grande; hauteur et largeur moyennes.

llenton : droit, rond ; hauteur intermédiaire.

Bouche : moyenne, rectiligne; ouverture intermédiaire.

Visage ovale. Iris pigmenté d'orange.

Teint brun. Barbe, cheveux et soureils châtains.

Carrure moyenne. Santé bonne. Nature veule.

Partout où il va, il donne la comédie. - Filoches. Obs. 93.

$$
\text { *** }
$$

$31^{\circ}$ Au point de vue du lieu du crime:

Lieu de naissance: 25 individus (9 urbains et 16 ruraux). Département du lieu de naissance: 7 individus (ruraux). Autre departement: 4 individus (ruraux). 


\section{$32^{\circ} \mathrm{Au}$ point de vue de la date du crime:}

1 en janvier, 7 en mars, 4 en avril, 2 en mai, 3 en juin, 4 en juillet, 8 en août, 3 en octobre, 4 en novembre.

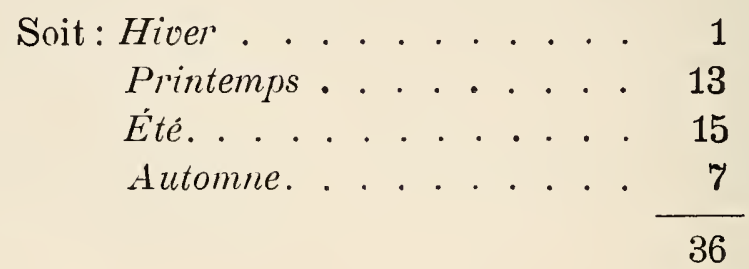

$33^{\circ} \mathrm{Au}$ point de vue de la juridiction :

36 Cour's d'assises.

$34^{\circ}$ Au point de vue de la durée de la peine:

2, condamnés de $2 \dot{a} 3$ ans; 1 , de $3 \dot{a} 4$ ans; 1 , de $4 \dot{\alpha} 5$ ans; 29, $\dot{a} 5$ ans; 3 , à plus de 5 ans.

Un journalier (Corse, âgé de quarante et un ans, marié, sachant lire et écrire, urbain, à la $10^{\mathrm{e}}$ condamnation, adonné a l'ivrognerie) fait huit ans, peine prononcée, par la cour d'assises de son département, le 3 juin 1893, pour " tentative de meurtre provoqué »).

Dans la nuit du 3 au 4 mars, à Ajaccio, il en vint aux mains, dans une buvette, avec deux marins de l'escadre. Chassé de l'ètablissement, il lia conversation, dans la rue, avec d'autres matelots auxquels il offrit sa chambre. Sur leur refus, il porta à l'un d'eux un coup de couteau dans le flanc gauche. 
Taille $1 \mathrm{~m}$. 574. Envergure $1 \mathrm{~m}$. 3̆4. Bıste 0,870. Pied gauche 0,233.

Tète : longueur 0,193 ; largeur 0,151 . Indice céphalique 77,43 .

Oreille droite: longueur 0,062 ; largeur 0,037. Indice auriculaire ว9,67. Écartement inférieur.

Front: arcades moyennes; inclinaison intermédiaire; largeur moyenne; hauteur grande.

$\mathrm{Nez}$ : cavité (de la racine) petite; dos rectiligne; base horizontale; largeur grande; hauteur et saillie moyennes. Écrasé.

Bouche : grande, rectiligne; ouverture intermédiaire.

Menton : saillant, linge, a fossette; hauteur intermédiaire.

Visage ovale. Iris pigmenté de châtain. Physionomie banale.

Teint brun. Barbe, cheveux et sourcils noirs. Tatoné.

Carrure moyenne. Santé bonne. Hernie inguinale droite.

Il pèche un peu par la conduite. - Cordonnerie. - Obs. 94.

$35^{\circ}$ Au point de vue de l'interdiction de séjour :

21 sont frappés d'interdiction de séjour.

$$
\text { **** }
$$

$36^{\circ}$ Au point de vue du travail en prison :

Bons ouvriers 22, passables 10, mauvais 4.

$$
\text { *** }
$$

$37^{\circ}$ Au point de vue de la conduite en prison :

Bonne 20, passable 10, mauvaise 6.

$3^{\circ} \mathrm{Au}$ point de vue de l'expulsion :

3 étrangers sur 3. 


\section{ATTENTATS ET OUTRAGES A LA PUDEUR}

63 individus

1. Au point de vue de la naissance:

60 enfants légitimes, 3 enfants naturels.

\section{$2^{\circ}$ Au point de vue de la nationalité :}

53 Français (dont 4 Corses), 10 Étrangers (dont 8 Italiens).

Deux Italiens - l'un, charbonnier ; l'autre, cultivateur attirent l'attention.

Le charbonnier, àgé de dix-sept ans, illettré, urbain, domicilié à Marseille, sans antécédents judiciaires, libertin, débauché, a été condamné, le 7 février 1896, par la cour d'assises des Bouches-du-Rhône, à 5 ans de prison, pour " attentat à la pudeur, avec violences ", commis, le 12 octobre 1895, sur un enfant de 5 ans $1 / 2$.

Il le pédéra dans une remise où il l'avait attiré.

Taille $1 \mathrm{~m}$. ə̈8. Envergure $1 \mathrm{~m}$. 64. Buste 0,83̈. Pied gauche 0,263. Tète : longueur 0,186 ; largeur 0,142 . Indice céphalique 76,34 . Oreille droite: longueur 0,064 ; largeur 0,040 . Indice auriculaire 70,31 . 
Front: arcades grandes; inclinaison fuyante; hauteur et largeur movennes.

Nez : cavité (de la racine) moyenne; dos rectiligne; base relevée; largeur grande; hauteur et saillie moyennes.

Bouche : moyenne, à coins relevés; ouverture intermédiaire; lèvres épaisses.

Menton : droit, rond, bas.

Visage ovale. Iris pigmenté de châtain.

Teint brun. Barbe, cheveux et sourcils noirs. Sourcils réunis. Tatoué. Carrure moyenne. Santé délicate. Strabisme; hernie inguinale gauche. A expulser.

C'est un petit mauvais sujet qui n'aime pas à se fatiguer. Cordonnerie. - Obs. 95.

Son compatriote, âgé de quarante-trois ans, veuf, sachant lire et écrire, urbain, demeurant à Beaucaire, 2 fois condamné pour port d'armes prohibées, subit la peine de 4 ans de prison, prononcée - y compris la déchéance de la puissance paternelle - par arrêt de la cour d'assises du Gard, en date du 3 mars 1893, pour « attentat à la pudeur sur sa fille légitime, mineure, non émancipée par le mariage ", devenue enceinte de ses œuvres.

Il partageait son lit, sous prétexte qu'il n'en avait pas pour lui-même.

L'économie n'est pas toujours une vertu !

Tailte $1 \mathrm{~m}$. 60. Envergure $1 \mathrm{~m}$. 66. Buste 0,836. Pied gauche 0,25้2. Tète : longueur 0,183 ; largeur 0,166 . Indice céphalique 89,72.

Oreille droite: longueur 0,062 ; largeur 0,036 . Indice auriculaire 58,06 . Front : arcades moyennes; inclinaison intermédiaire; hauteur et largeur moyennes.

Nez: cavité (de la racine) moyenne; dos convexe; base horizontale ; hauteur grande; largeur et saillie moyennes.

Bouche: grande, rectiligne; ouverture intermédiaire.

Henton : droit, rond, haut. 
Visage ovale. Iris pigmenté de chàtain. Expression du regard, courante.

Teint brun. Barbe, cheveux et sourcils chàtain clair.

Carrure moyenne. Santé forte. A expulser.

Bon détenu. - Service général. - Obs. 96.

\section{$3^{\circ}$ Au point de vue de l'âge :}

5, de 16 à 20 ans; 8 , de 20 à 30 ans; 14, de 30 à 40 ans; 20 , de 40 à 50 ans; 16, de 50 ans et plus.

Le plus jeune (deux fois condamné pour vagabondage et mendicité) est né, à Nîmes, le 20 mars 1879. Il sait lire et écrire. On ne lui connait pas de domicile fixe.

Par arrêt, en date du 9 août 1895, la cour d'assises de l'Hérault lui a infligé 2 ans d'emprisonnement.

Le $1^{\text {er }}$ juillet 1895, à deux heures du matin, à Cette, ce petit vaurien, qui exerçait par intermittence la profession de journalier, avait, en compagnie de quelques camarades (contrebandiers qui volaient des liqueurs sur les quais), commis un " attentat à la pudeur " sur un gamin couché dans un vagon de marchandises: " Nous l'éveillâmes et l'un de nous lui dit de poser le grimpant (pantalon), qu'on allait le sacrer " chevalier de la Lune et du Brouillard ". Comme le garçonnet se dérobait à l'inévitable consécration, on le déculotta de force et chacun à son tour lui conféra les ordres, en bonne forme. "

Taille $1 \mathrm{~m}$. 68. Envergure $1 \mathrm{~m}$. 72. Buste 0,880. Pied gauche 0,261. Tète: longueur 0,189 ; largeur 0,162 . Indice céphálique 85,71 .

Oreille droite: longueur 0,064 ; largeur 0,036 . Indice auriculaire 56,25 . Front: arcades moyennes; inclinaison intermédiaire; hauteur moyenne; largeur petite.

Nez : cavité (de la racine) moyenne; dos rectiligne ; base horizontale;

largeur, saillie et hanteur moyennes. Dévié à droite.

Bouche: moyenne, rectiligne, pincée. 
Menton : droit, rond, à houppe ; hauteur intermédiaire.

Visage ovale. Iris impigmenté. OEil doux. Figure agréable et point banale.

Teint brun. Barbe, cheveux et sourcils chàtains. Tatoué.

Carrure petite. Constitution et état général médiocres. Épilepsie.

Il avait à peine 4 ans à la mort de sa mère. Son père se remaria. Or, ce qu'une marâtre aime le moins au monde, ce sont les enfants de son mari (La Bruyère). Il fut traité durement par elle.

Livré à lui-même, il ne tarda pas à faire le gandard.

L'hiver, il couchait dans les écuries du marché aux bestiaux ; l'été, sous les arbres de la Tour Magne ou dans les souterrains des Arènes.

Pendant le jour, il s'attachait aux pas des porteurs de pain et mettait leur corbeille à contribution.

A loccasion, il volait aux étalages.

Le soir, il vendait des contremarques devant le péristyle du théâtre ; et, à minuit, pour clore dignement la journée, notre jeune homme allait licher un verre et manger un morceau de charcuterie.

Sous les verrous, il est grand travailleur. — Empaillage. Obs. 97 .

- Dans la catégorie de vingt à trente ans, se trouve : un cultivateur de la Haute-Loire, âgé de vingt et un ans, célibataire, sachant lire, écrire et calculer, urbain, ayant un domicile, sans antécédents judiciaires, perdu de réputation.

Le tribunal d'Yssingeaux lui a infligé, le 6 février 1896, 15 mois de prison, pour " outrage public à la pudeur, vol et violences $)$.

A la date du 6 janvier 1896, il obligea, la nuit, sur le bord d'une route très passante, un vieillard à le masturber.

Puis, il se livra, sur sa victime, à des attouchements obscènes ; après quoi, il la dépouillait. 
Taille $1 \mathrm{~m}$. 62. Envergure $1 \mathrm{~m}$. 67. Buste 0,902. Pied gauche 0,200.

Tète: longueur 0,187; largeur 0,168. Indice céphalique 89,83.

Oreille droite : longueur 0,059 ; largeur 0,036 . Indice auriculaire 61,01 .

Front: arcades moyennes ; inclinaison intermédiaire ; largeur grande ; hauteur moyenne.

Nez : cavité (de la racine) moyenne; dos rectiligne, sinueux; base relevée; saillie et largeur grandes; hauteur moyenne.

Bouche : moyenne, à coins relevés; ouverture intermédiaire.

Menton: rond, droil, haut.

Visage en toupie. Iris pigmenté de marron. Traits durs.

Teint brun. Barbe et cheveux châtains. Sourcils chàtain foncé.

Carrure moyenne. Santé bonue.

Il soigne son travail et a de la conduite. - Espadrilles. Obs. 98 .

- Parmi les individus ayant dépassé la cinquantaine, figurent: un Montpelliérain et un Vauclusien.

Né en 1824, marié, sachant lire, écrire et calculer, facteur des postes en retraite, à la première peine, le Montpelliérain a été condamné, par la cour d'assises de l'Hérault, le 6 août 1895, à 15 mois de prison, pour " attentat á la pudeur ».

En mai 1895, il avait renversé sur son lit et couvert de caresses impudiques une fillette de neuf ans, attirée en son logis par de petits cadeaux. Ce faisant, il cherchait à abuser d'elle: mais, devant la résistance désespérée de l'enfant, il se contenta de se masturber.

Taille $1 \mathrm{~m}$. 64. Envergure $1 \mathrm{~m}$. 70. Buste 0,837. Pied gauche 0,254. Tète : longueur 0,230 ; largeur 0,144 . Indice céphalique 62,60 . Oreille droite : longueur 0,073 ; largeur 0,0 \& . Indice auriculaire $60,2 \pi$. Front: arcades grandes; inclinaison fuyante; hauteur et largeur moyennes.

Nez : cavité (de la racine) moyenne; dos rectiligne; base horizontale; largeur grande; hauteur et saillie moyennes. Dévié à gauche. Bouche : grande, à coins abaissés ; ouverture intermédiaire. Ilenton : fuyant, rond, à houppe el à fossette; hauteur intermédiaire. 
Visage ovale. Iris pigmenté de jaune. OEil terne.

Teint clair. Barbe blanche; chevenx et sourcils grisonnants; sourcils réunis. Tatoué.

Carrure movenne. Etat général mauvais. Alcoolisme chronique et fistules urinaires.

Au demeurant, pas appétissant du tout. Il ne lui reste plus de jouissance à goûter que celle de la sagesse. - Sénateur. Obs. 99.

- Le Vauclusien, âgé de cinquante et un ans, célibataire, illettré, carrier, rural, récidiviste, adonné à l'ivrognerie, fait 3 ans de prison, pour " attentat à la pudeur, sans violences )) (arrêt de la cour d'assises de Vaucluse, en date du 29 octobre 1895 .

Le 7 août, assis sur un banc, en face d'une maison habitée, il attira sur ses genoux la fille de son patron, âgée de sept ans. Sans crainte d'être vu, il passa la main sous les vêtements de la fillette et introduisit, par deux fois, le doigt dans ses parties sexuelles.

Taille $1 \mathrm{~m}$. 64. Envergure $1 \mathrm{~m}$. 71. Buste 0,882 . Pied ganuche 0,235 . Tète : longueur 0,191 ; largeur 0,147 . Indice céphalique 76,96 . Oreille droite : longueur 0,066 ; largeur 0,034 . Indice auriculaire 31,51 . Front : arcades moyennes; incliuaison intermédiaire ; hauteur petite ; largeur moyenne.

Nez : cavité (de la racine) moyenne; dos rectiligne; base relevée ; largeur, saillie et hauteur moyennes.

Bouche : moyenne, rectiligne, pincée.

Menton: droit, rond, à fossette; hauteur intermédiaire.

Visage en losange. Iris impigmenté. Physionomie insignifiante.

Teint brun. Barbe, cheveux et sourcils chàtains grisonnants. Carrure moyenne. Bonne santé.

Quoiqu'il ne s'éreinte pas, il est bien coté en haut lieu. Service général. - Obs. 100. 
$4^{\circ}$ Au point de vue de l'ètat civil :

36 célibataires, 16 mariés, 10 veufs, 1 divorré.

Ce dernier, âgé de quarante-deux ans, illettré, charpentier, urbain, sans condamnation antérieure, vivait en concubinage et aimait la dive bouteille.

Par arrêt du 15 novembre 1894, la cour dassises de la Gironde a prononcé contre lui la peine de 3 ans de prison, pour " attentat à la pudeur, sans violences "), commis, le $1^{\text {er }}$ septembre 1894, sur une petite fille, âgée de six ans, sa voisine.

Après l'avoir cajolée gentiment, il lui mit son membre viril au derrière et la ramena chez ses grands-parents en lui recommandant de ne rien dire.

Taille $1 \mathrm{~m}$. 67. Envergure $4 \mathrm{~m}$. 73. Buste 0,873. Pied gauche 0,259 . Tête : longueur 0,192 ; largeur 0,133 . Indice céphalique 79 , 68 .

Oreille droite: longueur 0,0 ö8; largeur 0,034 . Indice auriculaire $: 38,62$. Forme triangulaire.

Front: arcades grandes; inclinaison intermédiaire; hauteur et largeur moyennes.

Nez : cavité (de la racine) moyenne; dos rectiligne; base horizontale; hauteur, saillie et largeur moyennes.

Bouche : moyenne, rectiligne, pincée.

Menton : saillant, rond, a houppe ; hauteur intermédiaire.

Visage ovale. Iris pigmenté d'orange. Air niais.

Teinı brun. Barbe, cheveux el sourcils châtains.

Carrure moyenne. Santé médiocre. Insuffisance valvulaire.

Il cochonne son ouvrage et son temps. - Lits en fer. Obs. 101. 


\section{$5^{\circ}$ Au point de vue de l'instruction :}

18 sont illettrés.

Un Stéphanois, âgé de trente ans, célibataire, journalier, bon biberon, sans antécédents judiciaires, a été condamné, par la cour d'assises de la Haute-Loire, le 5 décembre 1894, à 4 ans de prison, pour " attentat à la pudeur, sans violences, sur une enfant de moins de treize ans 1 .

Le 22 octobre 1894, dans l’après-midi, il pénétrait dans le domicile de ses voisins, les époux X..., où il savait devoir ne rencontrer que leurs 3 fillettes, et il persuadait à l'aînée de coucher la plus jeune de ses sœurs et de conduire la cadette en classe.

Puis, il l'envoyait elle-même acheter de l'eau-de-vie et, à son retour, après avoir bu et fait boire l'enfant, il la plaçait sur ses genoux, lui cliatouillait les parties génitales, et, finalement, la portait sur son lit où il tâcha de la posséder.

Taille $1 \mathrm{~m}$. 36 . Envergure $1 \mathrm{~m}$. 61. Buste 0,840 . Pied gauche 0,234 . Tète : longueur 0,178 ; largeur 0,133 . Indice céphalique $8 \ddot{3}, 9 \ddot{\text {. }}$

Oreille droite : longueur 0,060 ; largeur 0,036 . Indice auriculaire 60 . Forme triangulaire.

Front: arcades moyennes; inclinaison. intermédiaire; hauteur et largeur petites.

Nez : cavité (de la racine) petite; largeur et saillie petites; hanteur moyenne ; dos convexe ; base relevée.

Bouche : moyenne, rectiligne; ouverture intermédiaire.

Menton : large, fuyant; hauteur intermédiaire.

Visage large. Iris impigmenté. Humeur sombre.

Teint brun. Barbe, cheveux et sourcils châtains. Tatoué.

Carrure moyenne. Santé faible. Hernie inguinale double, volumineuse.

Bien noté. - Empaillage. - Obs. 102. 
7 savent lire ; 32 sacent lire et écrire ; 5 sacent lire, écrire et calculer; 1 a reçu une instruction primaire complète. II zézaie en parlant.

C'est un Marseillais, âgé de vingt-sept ans, c élibataire, marchand verrier, signalé comme escroc et deux fois condamné à ce titre.

5 ans de prison lui ont été infligés, le 18 février 1895, par la cour d'assises des Bouches-du-Rhône, pour " attentat à la pudeur » sur une petite fille de six ans.

L'ayant attirée dans son magasin et renversée sur un escabeau, il lui lécha la vulve; après quoi, il se fit toucher le membre viril qu'il essaya, ensuite, d'introduire dans les parties sexuelles de l'enfant (3 novembre 1894).

Taille $1 \mathrm{~m} .59$. Envergure $1 \mathrm{~m}$. 60. Buste 0,876 . Pied gauche 0,245 .

Tète : longueur 0,188 ; largeur 0,162 . Indice céphalique 86,17.

Oreille droite: longueur 0,054 ; largeur 0,032. Indice auriculaire $59,2 \ddot{2}$. Écartement supérieur.

Front: arcades moyennes; inclinaison intermédiaire; hauteur et largeur moyennes.

Nez : cavité (de la racine) petite; dos rectiligne; base horizontale; hauteur, saillie et largeur moyennes.

Bouche : moyenne, pincée, à coins relevés.

Menton: large, droit, bas.

Visage arrondi. Iris pigmenté de châtain. Regard froid.

Teint brun. Barbe, cheveux et sourcils châtains.

Carrure moyenne. Bonne santé. Caractère énergique.

Travail etconduite excellents. - Service général. —Obs. 103.

\section{$6^{\circ}$ Au point de vue de la profession :}

1 rentier, 1 propriétrire.

Le propriétaire (Gascon, âgé de cinquante-six ans, marié, sachant lire et écrire, rural) compte à son actif 4 délits de 
chasse et subit la peine de 2 ans de prison, prononcée, le 16 janvier 1896, par la cour d'assises du Gers, pour " attentat a la pudeur $n$.

$\mathrm{Au}$ cours de l'année 1895, il avait possédè de force et défloré deux jeunes filles, âgées de moins de treize ans - deux sœurs, ses domestiques - et les avait contaminées.

Taille $1 \mathrm{~m}$. 63. Envergure 1 II. 70. Baste 0,893. Pied gauche 0, 2ä।.

Tète : longueur 0,187 ; largeur 0,169 . Indice céphalique 90,37 .

Oreille droite : Iongueur 0,067 ; largeur 0,037 . Indice auriculaire ว̈ว̈,22. Écartement total.

Front: arcades moyennes; inclinaison intermédiaire; hauteur et largeur moyennes.

Nez: cavité (de la racine) moyenne; dos rectiligne, sinueux; base horizontale ; largeur et saillie grandes; hauteur moyenne.

Bouche: moyenne, à coins abaissés ; onverture intermédiaire.

Menton: saillant, pointu; hauteur intermédiaire.

Visage ovale. Iris pigmenté d'orange. Plyysionomie ouverte.

Teint brun. Barbe, cheveux et sourcils noirs (sourcils en brosse, arqués).

Carrure moyenne. Bonne santé. Hernie inguinale droite.

C'est un travailleur; il se conduit bien. - Sparterie. -Obs. 104.

2 employés, 1 commerçant, 1 ancien fabricant de couteaux.

L'ex-fabricant de couteaux, né et domicilié à Thiers, âgé de cinquante-six ans, veuf, sachant lire, écrire et calculer, fort libertin, aisé, à la $1^{\mathrm{re}}$ peine, a été condamné, le 20 mai 1895 , par la cour d'assises du Puy-de-Dôme, à 2 ans de prison, pour " attentat à la pudeur sans violence ", commis, le

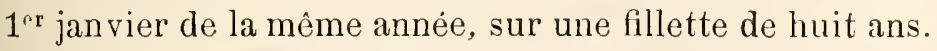

Il l'assit sur ses genoux, dans la salle a manger de son appartement, et lui chatouilla les parties génitales. L'enfant n'ayant pas voulu toucher son membre viril, mis à nu, il la congédia. en lui donnant 25 centimes.

Cii. Penrier. 
Taille $1 \mathrm{~m}$. 52. Envergure $1 \mathrm{~m}$. 60. Buste 0,79 . Pied gauche 0,23ว. Tête : longueur 0,183 ; largeur 0,163 . Indice céphalique 89,07 .

Oreille droite : longueur 0,061 ; largeur 0,032 . Indice auriculaire 52,45 . Front : arcades petites; inclinaison intermédiaire; hauteur et largeur moyennes.

Nez : cavité (de la racine) petite; dos rectiligne; base horizontale; hauteur, saillie et largeur moyennes.

Bouche: moyenne, à coins abaissés ; ouverture intermédiaire.

Menton: droit, rond, bas.

Visage ovale. Iris pigmenté de jaune.

Teint clair. Barbe, cheveux et sourcils châtains.

Carrure moyenne. Santé délicate.

Il a la mine paillarde et est malicieux comme un vieux singe. - Quartier des vieillards. -- Obs. 105.

3 professions alimentaires (2 cuisiniers et 1 pêcheur), 15 ouvrier's d'ateliers et de fabriques.

Parmi les ouvriers d'ateliers et de fabriques, on rencontre un puddleur, âgé de quarante-deux ans, né et domicilié dans un gros bourg du département de l'Aveyron, sachant lire et écrire, vivant du produit de son travail, sans antécédents judiciaires, séparé de sa femme qui est partie, en 1887, pour l'Amérique, avec ses enfants, après avoir confié aux soins de sa mère la plus jeune de ses trois fillettes, âgée de six ans.

Le 9 juillet 1890, il la retira de chez sa belle-mère et, à partir de ce moment, il ne cessa d'assouvir sur elle ses habitudes de lubricité, la prenant dans son lit, lui chatouillant les parties sexuelles et voulant la contraindre à toucher son membre viril.

Malgré la résistance de la gamine, il essaya, à maintes reprises, d'introduire sa verge dans les parties génitales de l'enfant.

$\mathrm{Ne}$ pouvant y parvenir, il éjaculait entre ses cuisses.

Il lui a été infligé, le 20 juin 1892, par la cour d'assises de 
l'Aveyron, 5 ans de prison, avec léchéance de la puissance paternelle, pour "attentat a la pudeur sans violence ", commis depuis moins de dix ans.

Taille $1 \mathrm{~m}$. 66. Envergure I m. 68. Buste 0,917. Pied gauche 0,263.

Tète: longueur 0,172 ; largeur 0,13 ə. Indice céphaliquue $88,3 \%$.

Oreille droite: longueur 0,062 ; largeur 0,037 . Indice auriculaire 59,67 . Écartement total.

Front: arcades moyennes; inclinaison intermédiaire; hauteur et largeur moyennes.

$\mathrm{Nez}$ : cavité (de la racine) petite; dos rectiligne; base relevée; hauteur, saillie et largeur moyennes.

Bouche : grande, rectiligne; ouverture intermédiaire.

Menton : droit, pointu, à fossette; hauteur intermédiaire.

Visage allongé. Iris pigmenté de jaune.

Teint brun. Barbe, cheveux et sourcils châtains. Tatoué.

Carrure moyenne. Esprit Jourd.

Individu solide; travailleur. -- Lits en fer. - Obs. 106.

1 nomade (marchand d'allumettes), 3 ouvriers du batiment et du mobilier (1 menuisier, 1 maçon, 1 charpentier), 31 professions agricoles.

Un berger, âgé de dix-huit ans, né en Corse et y demeurant, illettré, urbain, bien noté, subit la peine de 5 ans de prison, prononcée (y compris 5 ans d'interdiction de séjour), le 21 juillet 1894, par la Cour d'assises de son département, pour " attentat à la pudeur, consommé ou tenté, avec violence ".

Dans la matinée du 25 mai, vers 7 heures, après avoir saisi violemment, poussé dans l'intérieur d'une cabane et renversé par terre une jeune femme, il assouvit sur elle sa brutale passion.

Il sentait, dit-il, un grand besoin d'aimer! 
Taille $1 \mathrm{~m}$. 60. Envergure $\mid \mathrm{m}$. 63. Buste 0,880. Pied gauche 0,243. Tète : longueur 0,18 ; largeur 0,183 . Indice céphalique 100.

Oreille droite : longueur 0,057 ; largeur 0,031 . Indice auriculaire 54,38 .

Front : inclinaison verticale; arcades, hauteur et largeur moyennes. Nez: cavité (de la racine) moyenne; dos rectiligne; base horizontale; saillie petite; hauteur et largeur moyennes.

Bouche : moyenne, à coins abaissés ; ouverture intermédiaire.

Menton: rond, droit; hiuteur intermédiaire.

Visage ovale. Iris pigmenté de chàtain.

Teint clair. Barbe, cheveux et sourcils châtains; sourcils réunis. Carrure moyenne. Constitution et état général médiocres. Humeur joviale.

Travail soutenu, mais conduite équivoque. - Cordonnerie. - Obs. 107.

4 sans profession.

Un Aveyronnais, âgé de quarante-sept ans, célibataire, sachant lire et écrire, rural, sans domicile fixe, sans moyens d'existence connus, 14 fois condamné (délits divers), fait un an et un jour de prison, pour « outrage public à la pudeur et ivresse manifeste " (arrêt de la cour d'appel de Montpellier, en date du 4 juillet 1895, confirmant le jugement rendu, le 7 juin de la même année, par le tribunal de Rodez).

Le $1^{\text {er }}$ juin 1895 , se trouvant en état d'ivresse, il avait exhibé ses parties sexuelles, et s'était mis à déambuler, à travers les rues de la ville, le membre viril à la main.

Taille $1 \mathrm{~m}$. 399. Envergure $1 \mathrm{~m}$. 63. Buste 0,870. Pied gauche 0, 2.38 . Tète : longueur 0,171 ; largeur 0,157 . Indice céphalique 91,81 .

Oreille droite : longueur 0,052 ; largeur 0,031 . Indice auriculaire 59,61 .

Front : arcades petites; inclinaison intermédiaire ; largeur grande ; hauteur moyenne. 
Nez : cavité (de la racine) moyenne; dos rectiligne ; base horizontale; largeur grande; hauteur et saillie moyennes. Tordu a droite.

Bouche : moyenne, à coins abaissés; ouverture intermédiaire.

Menton : droit, rond; hauteurintermédiaire.

Visage ovale. Iris pigmenté d'orange.

Teint clair. Barbe, cheveux et sourcils chàtains.

Carrure moyenne. Santé robuste. Extérieur prévenant.

C'est un bon diable, assidu au travail. - Service général. - Obs. 108.

\section{$7^{\circ}$ Au point de vue de la population:}

28 appartiennent à la population urbaine; 35, à la population rurale.

\section{$8^{\circ} \mathrm{Au}$ point de vue du domicile :}

57 avaient un domicile; 6 n'en araient pas.

\section{$9^{n} \mathrm{Au}$ point de vue du nombre des condamnations :}

27 sont sans antécédents judiciaires; 13 ont été condammés 1 fois ; 12 , 2 et 3 fois ; 11 , plus de 3 fois .

Un Avignonnais, âgé de trente-sept ans, célibataire, sachant lire, écrire et calculer, journalier, 4 fois condamné pour vagabondage et mendicité, était dans l'habitude de se faire masturber par de jeunes enfants sur lesquels il se livrait parfois à des actes de pédérastie.

Le 7 juin 1895, après s'être fait masturber par l'un d'eux, il lui mit son membre viril dans la houche. 
La cour d'assises de l'Aude lui a infligé, le 7 août 1895, 5 ans de prison et 10 ans d'interdiction de séjour, pour « attentat à la pudeur ».

Taille $1 \mathrm{~m}$. 63. Envergure $1 \mathrm{~m}$. 66. Buste 0,896. Pied gauche 0,243. Tête : longueur 0,186 ; largeur 0,134 . Indice céphalique 82,79 .

Oreille droite: longueur 0,058 ; largeur 0,032 . Indice auriculaire 55,17 .

Front: arcades moyennes; inclinaison intermédiaire; hauteur et largeur moyennes.

Nez: cavité (de la racine) moyenne; dos rectiligne; base relevée; saillie, hauteur et largeur moyennes.

Bouche : moyemne, rectiligne, bée.

Menton : droit, rond, à houppe; bauteur intermédiaire.

Visage ovale. Iris impigmenté.

Teint clair. Barbe, cheveux et sourcils chàtain clair.

Carrure muyenne. Santé vigoureuse. Strabisme.

Il ne demande que paix et aise. - Filoches. ...- Obs. 109.

$10^{\circ} \mathrm{Au}$ point de vue de l'oisivetè :

22 oisifs.

$11^{\circ} \mathrm{Au}$ point de vue de l'ivrognerie :

33 adonnés à l'ivrognerie.

12. A point de vue du libertinage et de la débauche 39 libertins et débauchés.

$13^{\circ} \mathrm{Au}$ point de vue du concubinage : 10 vivant en concubinage.

$14^{\circ} \mathrm{Au}$ point de vue de la note de la commune: 4 bien notés. 
$15^{\circ}$ Au point de vue de la taille :

Dans la catégorie de 16 à 20 ans: taille au-dessous de $1 \mathrm{~m} .60,1$ individu; de $1 \mathrm{~m} .60$ à $1 \mathrm{~m}$. 70, 3 ; de $1 \mathrm{~m}$. 70 et au-dessus, 1.

Soit, moyenne de la taille $1 \mathrm{~m}$. 632.

De 20 à 25 ans : taille au-dessous de $1 \mathrm{~m} .60,1$ individu; de $1 \mathrm{~m}$. 60 à $1 \mathrm{~m}$. 70, 4 .

Soit, moyenne de la taille $1 \mathrm{~m} .615$.

De 25 a 30 ans: taille au-dessous de $1 \mathrm{~m}$. 60, 2 individus; de $1 \mathrm{~m} .60$ à $1 \mathrm{~m} .70,1$.

Soit, moyenne de la taille $1 \mathrm{~m} .604$.

De 30 à 40 ans: taille au-dessous de $1 \mathrm{~m} .60,2$ individus; de $1 \mathrm{~m} .60$ à $1 \mathrm{~m} .70,10$; de $1 \mathrm{~m}$. 70 et au-dessus, 2.

Soit, moyenne de la taille $1 \mathrm{~m} .645$.

De 40 a 50 ans : taille au-dessous de $1 \mathrm{~m} .60,5$ individus; de $1 \mathrm{~m} .60$ à $1 \mathrm{~m} .70,14$; de $1 \mathrm{~m}$. 70 et au-dessus, 1.

Soit, moyenne de la taille $1 \mathrm{~m} .638$.

De 50 ans et cur-dessus: taille au-dessous de $1 \mathrm{~m} .60,8$ individus; de $1 \mathrm{~m} .60$ à $1 \mathrm{~m}$. 70, 7 ; de $1 \mathrm{~m}$. 70 et au-dessus, 1. Soit, moyenne de la taille $1 \mathrm{~m} .60$.

En résumé: taille au-dessous de $1 \mathrm{~m} .60,19$ individus; de $1 \mathrm{~m} .60$ à 1 m. 70, 39 ; de $1 \mathrm{~m}$. 70 et au-dessus, 5 .

Soit, moyenne de la taille $1 \mathrm{~m} .626$. 


\section{6॰ Au point de vue de l'envergure :}

Dans la catégorie de 16 à 20 ans : envergure supérieure a la taille, de 0 à 4 cent., 1 individu; de 4 à 8 cent., 4 .

Soit. moyenne de l'envergure $1 \mathrm{~m}$. 682.

De 20 à 25 ans : envergure infẻrieure à la taille, de 0 à 8 cent., 1 individu; supérieure à la taille, de 0 à 4 cent., 1 ; de 4 à 8 cent., 2 ; de $S$ à 16 cent., 1 .

Soit, moyenne de l'envergure $1 \mathrm{~m}$. 662.

De 25 à 30 ans : envergure supérieure à la taille de 0 à 4 cent., 2 individus: de 8 à 16 cent., 1 .

Soit, moyenne de l'envergure $1 \mathrm{~m} .660$.

De.30 à 40 ans : envergure inférieure à la taille, de 0 à 8 cent., 2 individus; égale à la taille, 1 ; supérieure à la taille, de 0 à 4 cent. 2 ; de 4 à 8 cent., 7 ; de 8 à 16 cent., 2 .

Soit, moyenne de l'envergure $1 \mathrm{~m} .686$.

De 40 à 50 ans: envergure égale à la taille, 1 individu; supérieure à la taille, de 0 à 4 cent., 1 ; de 4 à 8 cent., 9; de 8 à 16 cent., 9 .

Soit, moyenne de l'envergure $1 \mathrm{~m} .706$.

De 50 ans et au-dessus : envergure inférieure à la taille, de 0 à $\&$ cent., 1 individu; égale à la taille, 1 ; supérieure à la taille, de 0 à 4 cent., 4 ; de 4 à 8 cent., 5 ; de 8 à 16 cent., 4 ; Infirme, 1.

Soit, moyenne de l'envergure $1 \mathrm{~m} .655$.

En résumé: envergure inférieure à la taille, de 0 à 8 cent., 4 individus; égale à la tailie, 3 ; supérieure à la taille, de 0 à 4 cent., 11 ; de 4 à $S$ cent., 27 ; de $S$ à 16 cent., 17. Infirme, 1.

Snit, moyenne de l'envergure $1 \mathrm{~m} .681$. 


\section{$17^{\circ}$ Au point de vue du buste :}

Dans la catégorie de 16 à 20 ans : buste supérieur à la moitié de la taille, de 0 à 5 cent., 1 individu; de 5 à 10 cent., 4 .

Soit, moyenne du buste 0,879 .

De 20 a 25 ans: buste supérieur à la moitié de la taille, de 5 à 10 cent., 3 individus; de 10 à 18 cent., 2 .

Soit, moyenne du buste 0,898 .

De 25 à 30 ans : buste supérieur à la moitié de la taille, de 0 à 5 cent., 1 individu; de 5 à 10 cent., 2 .

Soit, moyenne du buste 0,864 .

De 30 à 40 ans: buste supérieur à la moitié de la taille, de 0 à 5 cent., 3 individus; de 5 à 10 cent., 11.

Soit, moyenne du buste 0,887 .

De 40 à 50 ans: buste supérieur à la moitié de la taille, de 0 à 5 cent., 6 individus; de 5 à 10 cent., 14 .

Soit, moyenne du buste 0,873 .

De 50 ans et au-dessus : buste inférieur à la moitié de la taille, 1 individu; supérieur à la moitié de la taille, de 0 à 5 cent., 7 ; de 5 à 10 cent., 8 .

Soit, moyenne du buste 0,848 .

En résumé: buste inférieur à la moitié de la taille, 1 individu; supérieur à la moitié de la taille, de 0 à 5 cent., 18 ; de 5 à 10 cent., 42 : de 10 à 18 cent.. 2.

Soit, moyenne du buste 0,872 . 
18. Au point de vue du pied :

Dans la catégorie de 16 à 20 ans: pied de 22 à 24 cent., 1 individu ; de 24 à 26 cent., 1 ; de 26 à 28 cent., 2 ; de 28 à 30 cent., 1 .

Soit, moyenne du pied 0,260 .

De 20 à 25 ans: pied de 24 à 26 cent., 4 individus; de 26 à 28 cent., 1 .

Soit, moyenne du pied 0,252.

De 25 a 30 ans: pied de 24 à 26 cent., 3 individus.

Soit, moyenne du pied 0,248 .

De 30 à 40 ans: pied de 22 à 24 cent., 2 individus : de 24 à 26 cent., 7 ; de 26 à 28 cent., 5.

Soit, moyenne du pied 0,252.

De 40 à 50 ans : pied de 24 à 26 cent., 11 individus ; de 26 à 28 cent., 8 ; de 28 à 30 cent., 1 .

Soit, moyenne du pied 0,260.

De 50 ans et au-dessus : pied de 22 à 24 cent., 4 individus; de 24 à 26 cent., 9 ; de 26 à 28 cent., 3 .

Soit, moyenne du pied 0,250.

En résumé : pied de 22 à 24 cent., 7 individus; de 24 à 26 cent., 35 ; de 26 à 28 cent., 19; de 28 à 30 cent., 2 .

Soit, moyenne du pied 0,254 .

$19^{\circ}$ A u point de vue de la tête:

4 dolichocéphales vrais, 6 sous-dolichocéphales, 3 mésaticéphales, 13 sous-brachycéphales, 37 brachycéphales vrais. 
D'autre part, les calculs donnent:

Longueur moyenne de la tête 0,1869; largeur moyenne de la tête 0,1571 .

D’où : Indice céphalique 84,05 .

$20^{\circ} \mathrm{Au}$ point de vue de l'oreille:

Indice auriculaire: au-dessous de 52, 7 individus; de 52 à 56,20 ; de 56 à 60,23 ; de 60 à 65,9 ; de 65 et audessus, 4.

D'autre part, les calculs donnent :

Longueur moyenne de l'oreille 0,0631; largeur moyenne de l'oreille 0,0359 .

D'où : Indice auriculaire 56,89 .

21. Au point de vue du visage :

En losange 2, rond 7, larrge ou carré 7, ovale 43, allongé 3, en toupie 1.

$22^{\circ}$ Au point de vue du front :

Arcades : grandes 15 , petites 6 , moyennes 42.

Inclinaison : verticale 6 , fuyante 19 , intermédiaire 38 .

Hauteur: grande 2 , petite 7 , moyenne 54 .

Largeur : grande 6 , petite 9 , moyenne 48 . 
$23^{\circ}$ Au point de vue du nez:

Cavité (de la racine): grande 6 , petite 22, moyenne 35.

Dos : rectiligne 42 , convexe 14 , concave 7 .

Base: horizontale 36, relevée 23, abaissée 4.

Hauteur : grande 4, petite 1, moyenne 58.

Saillie : grande 5, petite 6, moyenne 52.

Largeur : grande 13, petite 6, moyenne 44.

$24^{\circ}$ Au point de vue de la bouche :

Dimension: grande 12, petite 1, moyenne 50 .

Inclinaison des angles : rectiligne 36, à coins abaissés 20, à coins relevés $\%$.

Degré habituel d'ouverture : bée 4, pincée 11, intermédiaire 48.

$25^{\circ} \mathrm{Au}$ point de vue du menton:

Inclinaison générale : menton saillant 11 , droit 44 , fuyant 8 . Avec et sans houppe: plat 10, à houppe 9, intermédiaire 44 . Hauteur : haut 12, bas 20, intermédiaire 31. Forme: large 23, rond 35, pointu 5 .

$26^{\circ}$ Au point de vue de l'œil :

Ir is : impigmenté $\%$, pigmenté de jaune 12 , d'orange 19 , de châtain 20, de marron 5 .

$27^{\circ}$ Au point de vue du teint :

Brun 47, mat 2, clair 14. 


\section{$\therefore$}

$28^{\circ}$ Au point de vue de la carrure:

Grande 9, petite 2, moyenne 52.

$29^{\circ} \mathrm{Au}$ point de vue de la constitution et de l'état général, à l'arrivée :

Bons 28, passables 15, mauvais 17, très mauvais 3 .

$30^{\circ}$ Au point de vue des maladies et infirmités, à l'arrivée : 51 maladies et infirmités, à répartir entre 32 individus (2S Français, dont 1 Corse ; 3 Italiens et 1 Arabe).

Soit: bronchite bacillaire 1 , insuffisance valvulaire 4 , a trophie du cœur 1 , dégénérescence graisseuse 1 , adhérences péricardiques 1, palpitations 1 , artérite chronique avec dégénérescence athéromateuse 4, asthme 1, hypertrophie du foie 1 , scrofule 3 , déviation de la colonne vertébrale 1 , boiteux 1 , ankylose du genou 1, ankylose du bras (coude) 1, hernie inguinale droite 2 , gauche 4 , double 2 , varices 1 , varicocèle 1 , fistules urinaires 1 , strabisme 3 , presbytie 1 , atrophie du nerf optique 1, conjonctivite chronique 1, blépharite chronique 1 , surdité légère 1, surdité prononcée 2, épilepsie 1 (obs. 97), imbécillité 2 (obs. 115), déséquilibration mentale 1 , bėgaiement 2 , zézaiement 1 , gynécomastie 1 .

Le déséquilibré (Hyérois, âgé de quarante et un ans, célibataire, sachant lire, écrire et calculer, sans profession, vivant d'une petite rente viagère, sans condamnation antérieure, mal famé, subit la peine de 3 ans de prison, prononcée, par la cour d'assises du Var, pour " attentat à la pudeur ». 
- Le 21 mars 1895, il conduisitun jeune enfant de dix ans dans un endroit écarté et, pardeux fois, il lui in troduisit son membre viril dans la bouche.

Taille 1 m. 6.̆. Envergure $1 \mathrm{~m}$. 70. Buste 0,88 . Pied gauche 0,276 . Tète : longueur 0,192 ; largeur 0,144 . Indice cóphalique 75,00 .

Oreille droite: Iongueur $0,07 \%$; largenr 0,038 . Indice auriculaire 50,66 . Forme ovale.

Front : arcades moyennes; inclinaison fuyante; hauteur et largeur moyennes.

Nez : cavité (de la racine) moyenne; dos rectiligne; base relevée; hauteur et saillie moyennes; largeur petite.

Bouche: grande, rectiligne; ouverture intermédiaire.

Menton : bas, droit, rond.

Visage ovale. Iris pigmenté de marron. Regard voilé.

Teint brun. Barbe, cheveux et sourcils chàtains.

Carrure moyenne. Santé médiocre. Hallucinations.

Détenu bien noté. - Quartier des vieillards. - Obs. 110.

Legynécomaste(Auvergnat,âgé decinquante et un ans, marié, illettré, cultivateur, sans antécédents judiciaires, rural, ayant un domicile, adonné à l'ivrognerie) a été condamné, par la cour d'assises du Puy-de-Dôme, à 3 ans de prison, pour " attentat à la pudeur" sur la fille de sa femme, issue d'un premier mariage.

Taille $1 \mathrm{~m}$. 5̆5. Envergure $1 \mathrm{~m} .67$. Buste 0,813 . Pied gauche 0,249 .

Tète : longueur 0,185 ; largeur 0,148 . Indice céphalique 80,00 .

Oreille droite : longueur 0,063 ; largeur 0,037 . Indice auriculaire 56,92.

Forme triangulaire.

Front: areades moyennes; inclinaison fuyante; hauteur et largeur moyennes.

Nez: cavité (de la racine) petite; dos rectiligne; base abaissée; hauteur, saillie et largeur moyennes.

Bouche : moyenne, à coins abaissés ; ouverture intermédiaire.

Menton : bas, droil, rond. 
Visage large. Iris pigmenté de jaune. Bonne physionomie.

Teint brun. Barbe, cheveux et sourcils chàtain foncé.

Carrure moyenne. Constitution et état général passables.

Dès sa première jeunesse, il exigeait des filles, avant de faire l'amour, qu'elles accablassent ses seins de caresses. Il a vieilli dans cette habitude.

Bon détenu. - Empaillage. - Obs. 111.

$$
\text { *** }
$$

$31^{\circ}$ Au point de vue du lieu du crime :

Lieu de naissance : 22 individus (12 urbains et 10 ruraux, tous avec domicile).

Département du lieu de naissance : 16 individus (5 urbains et 11 ruraux, dont 1 sans domicile).

Autre département : 25 individus (11 urbains et 14 ruraux, dont 4 urbains et 1 rural sans domicile!.

$32^{\circ}$ Au point de vue de la date du crime:

4 en janvier, 1 en février, 4 en mars, 5 en avril, 2 en mai, 11 en juin, 8 en juillet, 7 en août, 3 en septembre, 3 en octobre, 3 en novembre, 4 en décembre, 8 pendant l'année.

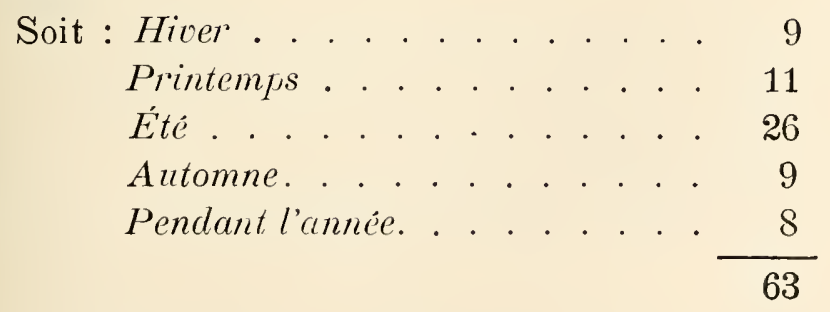




$$
\text { * * * }
$$

$33^{\circ} \mathrm{Au}$ point de vue de la jurid"ction :

Condamnés par tribunaux correctionnels . . . . . 10 cours d'assises . . . . . . . . . 53

$34^{\circ}$ Au point de vue de la durée de la peine:

3 individus subissent une peine de 1 an et 1 jour.

A la date du $1^{\text {er }}$ juillet 1895, l'un d'entre eux (Marseillais âgé de trente-sept ans, célibataire, garçon d'écurie, sachant lire et écrire, 3 fois condamné, vivant dans un libertinage continuel), avait pédéré un jeune enfant et pratiqué sur lui le coït buccal - affaire (outrages publics à la pudeur) jugée, par le tribunal de Marseille, le 23 juillet 1895.

Tailie $1 \mathrm{~m}$. 62. Envergure $1 \mathrm{~m}$. 68. Buste 0,863. Pied gauche 0,236 . Tète : longueur 0,183 ; largeur 0,165 . Indice céphalique 90,16 .

Oreille droite : longueur $0,06 \ddot{3}$; largeur 0,038 . Indice auriculaire 58,46 . Forme triangulaire.

Front : arcades moyennes; inclinaison intermédiaire ; hauteur grande; largeur moyenne.

Nez : cavité (de la racine) moyenne; dos rectiligne; base horizontale; hauteur et saillie moyennes; largeur grande.

Bouche : moyenne, à coins abaissés; ouverture intermédiaire. Menton : saillant, haut, large, plat, à fossette.

Visage arrondi. Iris pigmenté de chàtain.

Teint brun. Barbe, cheveux et sourcils châtain foncé. Carrure moyenne. Santé bonne. Strabisme.

Une Vermine. - Atelier d'empaillage. - Obs. 112. 
2 font 13 mois; 5,15 à 18 mois ; 4,18 mois à 2 ans; 16,2 à 3 ans.

Voici un fermier, originaire de l'Aveyron, âgé de trentetrois ans, marié, sachant lire et écrire, rural, ayant à son actif 4 condamnations et signalé comme ne fuyant jamais les occasions de débauches.

Le 25 février 1895, il rencontrait sur sa route, près d'Entraygues, une veuve qui revenait d'une foire. Ils lièrent conversation et cheminèrent ensemble: l'un, jouant la galanterie; l'autre,la pudeur. Arrivés devant un cours d'eau, sur lequel n'était établie aucune passerelle, notre homme s'offrit à porter la femme sur ses épaules.

L'ayant déposée sur le bord en face, il lui saisit vivement les fesses, pris d'un impérieux besoin d'aimer.

Comme la veuve se débattait, le fermier, dont les dėsirs grandissaient avec la résistance, l'empoigna par la taille, la jeta par terre et assouvit sa passion.

Proh pudor! "A cent mètres plus loin ", elle dut se résigner à subir un nouvel outrage.

Le tribunal d'Espalion a infligé au galant 2 ans de prison et 50 francs d'amende, par jugement du $1^{\text {er }}$ avril 1895.

Taille $1 \mathrm{~m}$. 66. Envergure $1 \mathrm{~m}$. 71. Buste 0,867. Pied gauche 0,2วั0. Tète: longueur 0,180 ; largeur 0,154 . Indice céphalique 85 ,ə̆5̆.

Oreille droite: longueur 0,064; largeur 0,033. Indice auricnlaire 51,56 . Écartement supérieur.

Front: arcades grandes; inclinaison intermédiaire; hauteur et largeur moyennes.

Nez : cavité (de la racine) moyenne; dos convexe; base horizontale; largeur petite; hauteur et saillie moyennes.

Bouche : moyenne, à coins relevés; ouverture intermédiaire.

Menton : droit, rond, à houppe; hauteur intermédiaire.

Visage ovale. Iris pigmenté d'orange (truité). Bonne mine.

Teint brun. Barbe, cheveux et sourcils chàtains.

Carrure moyenne. Santé parfaite.

Bon travail et bonne conduite. - Lits en fer. - Obs. 113. 
10 ont été condamnés de $3 \dot{a} 4$ ans; 10 , de 4 à 5 ans; ct 13 , $a$ 5 ans et plus.

2 cultivateurs, âgés de quarante ans, ruraux, sachant lire et écrire, ont eu, maintes fois, des affaires de vol à régler a vec la justice.

L'un est célibataire; l'autre, marié.

Le célibataire fait 5 ans de prison, peine prononcée, le 20 novembre 1895, par la cour d'assises de la Corse (son dejpartement), pour « attentat à la pudeur ".

Le 13 juin 1895, a la nuit tombante, prenant par la main une fille à moitié idiote, il la conduisit dans son jardin et, après l'avoir renversée par terre, il abusa d'elle.

A l'en croire, cet acte serait le résultat d'une vengeance.

Taille $1 \mathrm{~m}$. 38. Envergure $1 \mathrm{~m}$. 66. Buste 0,833. Pied gauche 0,245. Tète : longueur 0,192 ; largeur 0,137 . Indice céphalique 71,35 . Oreille d roite : longueur 0,057 ; largeur 0,037 . Indice auriculaire 64,91 . Front: arcades moyennes; inclinaison verticale; largeur petite; hauteur moyenne.

Nez: cavité (de la racine) grande; dos rectiligne; base relevée; saillio petite; hauteur et largeur moyennes.

Bouche : moyenne, rectiligne ; ouverture intermédiaire.

Menton : droit, large, plat; hauteur intermédiaire.

Visage ovale. Iris pigmenté d'orange (truité).

Teint brun. Barbe, cheveux et sourcils chàtain foncé.

Carrure petite. Sauté robusle.

Ses manières naïves et son air timide cachent beaucoup de ruse et d'habileté. Il est menteur comme une oraison funèbre.

Ouvrier médiocre. - Cordonnerie. - Obs. 114.

Quant au marié, J... (enfant de l'Hérault, adonné à l'ivrognerie), il a été condamné, à 5 ans de prison et déchu de la puissance paternelle, par la cour d'assises de son département, 
le 8 février 1893, pour «attentat à la pudeur », commis dans le courant des mois de mars à octobre 1892.

Un soir, au retour du travail, se trouvant seul avec ses deux petites filles, il exhiba son membre viril et le secoua vivement devant eiles.

Pendant la nuit, il se leva, se rendit près du lit où couchaient ses enfants et se livra à des attouchements obscènes sur sa fille aînée.

Un jour de mai 1892, il saisissait brusquement celle-ci, et, après l'avoir jetée sur le lit, il lui écartait de force les cuisses et lui introduisait dans le vagin un doigt de la main droite.

Taille: $1 \mathrm{~m} .634$. Envergure $1 \mathrm{~m}$. 72. Buste 0,867. Pied gauche 0,263. Tète: longueur 0,191; largeur $0,15 \%$. Indice céphalique 81,15 .

Oreille droite: longueur 0,062 ; largeur 0,036 . Indice auriculaire 58.06 .

Front: arcades proéminentes; inclinaison fuyante; largeur petite; hauteur moyenne.

Nez : cavité (de la racine) moyenne; dos rectiligne; base horizontale; saillic grande ; hauteur et largeur moyennes.

Bouche; moyenne, rectiligne, pincée.

Menton: droit, rond, à fossette; hauteur intermédiaire. Visage ovale. Iris pigmenté de châtain. Regard distrait. Teint brun. Barbe, cheveux et sourcils châtains. Carrure moyenne. Santé faible.

Impulsif ; poète crotté : Victor Hugo II, comme on l'appelle par dérision. Il ne parle de lui qu'avec enthousiasme. - Service général. - Obs. 115.

\section{$35^{\circ}$ Au point de vue de l'interdiction de séjour :}

5 ont été frappés d'inter liction de séjour', dont 1 par une condamnation antérieure. 


$$
\text { **** }
$$

$36^{\circ}$ Au point devue du travail en prison:

Bons travailleurs 28, passables 22, mauvais 13.

$37^{\circ}$ Au point de vue de la conduite en prison:

Bonne conduite 33, passable 20, mauvaise 10.

$$
\text { *** }
$$

$38^{\circ}$ Au point de vue de l'expulsion :

9 étranger's sur 10. 
VIOL

1 individu, marié, sachant lire, urbain, domicilièà Toulon, oủ il exerçait la profession de tailleur d'habits et avait la rẻputation d'un homme très violent.

Né en Italie, le 27 mai 1874 , il doit être expulsé à l'époque de sa libération.

On ne lui connaît aucune condamnation antérieure.

La peine de 4 ans, qu'il subit, a été prononcée, par la cour d'assises du Var, le 24 octobre 1895, pour " viol » sur. la personne de sa belle-sœur, crime commis le 31 juillet de la même année.

Le jury a admis les circonstances atténuantes.

Taille $1 \mathrm{~m}$. 65. Envergure $1 \mathrm{~m}$. 71. Buste 0,864. Pied gauche 0,268. Tète : longueur 0,190 ; largeur 0,157 . Indice céphalique 82,63 .

Oreille droite : longueur 0,059 ; largeur 0,036 . Indice auriculaire 61,01 .

Front : arcades moyennes ; inclinaison intermédiaire; hauteur et largeur moyennes. Plat.

Nez: cavité (de la racine) petite ; dos rectiligne; base horizontale; largeur grande ; saillie et hauteur moyennes.

Bouche : moyenne, à coins relevés ; uuverture intermédiaire.

Nenton : droit, rond, bas, plat. 
Visage ovale. Iris impigmenté. OLil vif.

Teint brun. Barbe, cheveux et sourcils chàtains. Tatoué.

Carrure moyenne. Constitution et état général bons.

Depuis qu'il a été écroué à la maison centrale de Nîmes (27 novembre 1895), il se montre soumis, respectueux, et son travail n'a donné lieu à aucune remarque défavorable. Ravaudage. - Obs. 116. 


\section{$\mathrm{XI}$}

DÉTOURNEMENT DE MINEURS, ENLĖVEMENT

3 individus

On compte 2 enfants légitimes et 1 enfant naturel.

Tous les 3 sont Français (dont 2 Corses). Ils ont un domicile.

Aucun n'est marié. Deux sont âgés de vingt et vingtdeux ans; le troisième a quarante-trois ans.

Ce dernier possède une instruction primaire complète.

Il vendait des chalands (était rabatteur) au casino de MonteCarlo, faisait chère lie et vivait en concubinage.

Perpignan est son pays natal.

Il avait déjà subi une condamnation, pour vol, lorsqu'il devint l'amant de la fille d'un libraire, qu'il enleva, le $1^{\text {er }}$ août 1893, après l'avoir rendue enceinte. Elle était âgée de quinze ans.

La cour d'assises des Bouches-du-Rhône lui a infligé 5 ans de prison, par arrêt du 14 mars 1894.

Taille $1 \mathrm{~m}$. วั̆̈. Envergure 1 m. 61. Buste 0,903. Pied gauche 0,249. Tète : longueur 0,194 ; largeur 0,138 . Indice céphalique 81 , 1.4.

Oreille droite: longueur 0,063 ; largeur 0,036 . Indice auriculaire 37,14 .

Front: arcades moyennes; inclinaison intermédiaire; largeur et hauteur moyennes.

Nez : cavité (de la racine) moyenne; dos reetiligne; base relevée; largeur, hauteur et saillie moyennes. 
Bouche : moyeune, rectiligne; ouverture intermédiaire.

Menton: bas, droit, rond, plat.

Visage ovale. Iris pigmenté de jaune. Mine hautaine.

Tcint blond. Barbe, cheveux et sourcils blonds.

Carrure moyenne. Constitution et étal général mauvais; hydrocèle des bourses; hernie inguinale gauche.

Mégalomane: Il se croit doué de tous les talents et se prétend issu de race illustre.

Travail passable; conduite bonne. - Service général. Obs. $11 \%$.

Les autres sont illettrés, cultivateurs et de population rurale.

L'un, franc buveur, antérieurement condamné, à 20 jours de prison, pour coups et blessures, fait 5 ans, peine prononcée, le 21 février 1895, par la cour d'assises de la Corse.

A la date du 2 novembre 1894, il avait enlevé de force une jeune fille qui ne voulait pas de lui et, avec l'aide de trois camarades, il l'avait conduite dans la maison de son oncle, où la pauvrette dut se résigner à partager la couche de son ravisseur.

Taille: $1 \mathrm{~m}$. 3̆ . Envergure $1 \mathrm{~m}$. 62. Bıste 0,865. Pied gauche 0,244. Tète : longueur 0,198 ; largeur 0,148. Indice céphalique 74,74.

Oreille droite : longueur 0,062; largeur 0,033. Indice auriculaire 53,22 . Écartement supérieur.

Front: arcades petites; inclinaison verticale; hauteur et largeur moyennes.

Nez : cavité (de la racine) moyenne; dos rectiligne; base relevée; hauteur et saillie petites; largeur moyenne.

Bouche : petite, rectiligne ; ouverture intermédiaire.

Menton : large, droit, à fosselle; hauteur intermédiaire.

Visage ovale. Iris pigmenté d'orange. 
Teint mat. Barbe, cheveux et sourcils châtain foncé (sourcils écartés). Tatoué.

Carrure petite. Constitution et état général passables.

Il a une humeur chagrine et se conduit mal. - Ébénisterie. - Obs. 118.

Le second (enfant naturel, à l'actif duquel figure un délit de pêche) a été condamné à 3 ans de prison, comme complice dans cet enlèvement.

Il se plaisait, lui aussi, à mettre pinte sur chopine.

Taille $1 \mathrm{~m} .46$. Envergure $1 \mathrm{~m}, 54$. Buste 0,782 . Pied gauche $0,22 \mathrm{~g}$.

Tète: longueur 0,186 ; largeur 0,145 . Indice céphalique 77,9:3.

Oreille droite: longueur 0,051 ; largeur 0,027 . Indice auriculaire 52,94.Écartement total.

Front : arcades moyennes; inclinaison intermédiaire; hauteur et largeur moyennes.

Nez: cavité (de la racine) petite; dos rectiligne; base relevée; hauteur, saillie et largeur moyennes.

Bouche: moyenne, à coins abaissés ; ouverture intermédiaire.

Menton: droit, haut, rond.

Visage ovale. Iris pigmenté d'orange. Yeux saillants.

Teint brun. Barbe, cheveux el sourcils châtains.

Carrure petite. Constitution et état général passables.

C'est un paresseux et un brutal. - Cordonnerie. -Obs. 119 . 


\section{XII}

ESCROQUERIE - ABUS DE CONFIANCE - BANQUEROUTE - FAUX, ETC.

7.3 individus

$1^{\circ}$ Au point de vue de la naissance :

73 enfants légitimes, 2 enfants naturels.

Dans le courant du mois de novembre 1891, l'un de ces 2 enfants naturels déposait, au bureau de poste de Bordeaux, une lettre portant la mention: "valeur déclarée, huit mille franes " et en faisait opérer le chargement, à l'adresse d'un Bitterois, son créancier.

A son arrivée, la lettre fut ouverte devant le facteur et un autre témoin. On constata qu'elle ne contenait que des formules de télégramme.

Informé du fait, il réclama, à l'administration des Postes, la somme de huit mille francs, qu'il prétendit avoir été habilement soustraite de l'enveloppe; mais, comme l'affaire prenait une mauvaise tournure, il jugea prudent de s'enfuir au loin.

Le tribunal de Bordeaux le condamna, par léfaut, pour " tentative d'escroquerie ", à trois ans d'emprisonnement, et, sur opposition, le 17 novembre 1892, à cinq ans de la même peine et à cent francs d'amende. 
Par arrêt du 14 décembre 1892, la cour d'appel a confirmé le jugement prononcé.

Cet homme, âgé de 46 ans, marié, employé de commerce, rural. ayant un domicile, possede une instruction primaire complète. 4 condamnations figurent à son dossier; on y lit : débauche et vol.

Taille $1 \mathrm{~m}$. 748. Envergure $1 \mathrm{~m}$. 81. Buste 0,937. Pied gauche 0,268. Tète : longueur 0,187 ; largeur 0,161 . Indice céphalique 86,09 .

Oreille droite : longueur 0,058 ; largeur 0,037 . Indice auriculaire 63,79 . Écartement supérieur.

Front: arcades moyennes; inclinaison intermédiaire; hauteur grande ; largeur moyenne.

Nez : cavité (de la racine) grande; dos rectiligne; base horizontale; hauteur et saillie moyennes; largeur grande.

Bouche : moyenne, rectiligne, pincée.

Menton : droit, rond, à fossette ; hauteur intermédiaire.

Visage large. Iris pigmenté de chàtain. Physionomie banale.

Teint brun. Barbe, cheveux et sourcils chàtain clair.

Carrure grande. Constitution et état général bons.

Il se tient pénard. - Atelier de filoches. - Obs. 120.

L'autre (scieur de long, àgé de quarante-huit ans, mariè, urbain, ayant un domicile) sait lire, écrire et calculer.

C'est un récidiviste.

On lui a infligé, à Castelsarrazin, 3 ans de prison (jugement confirmé, le 17 juillet 1895, par la cour d'appel de Toulouse). Il avait escroqué des sommes de 5,8 et $9,000 \mathrm{fr}$., en persuadant ses dupes de l'existence d'un trésor imaginaire.

Pour entiaîner la conviction, il exhibait des rouleaux de louis en carton doré; au besoin, il évoquait le témoignage de prétendues sorcières et faisait appel aux allégations intéresséesd'une maîtresse, sa complice.

De plus, il avait détourné une somme de 200 francs, à lui confiée à titre de mandataire. 
Taille $1 \mathrm{~m}$. 60. Envergure $1 \mathrm{~m}$. 73. Buste 0,85ว. Pied gauche 0,23 . Tète : longuear 0,182 ; largeur 0,1 ö. Indice céphalique 85,16 .

Oreille droite : longueur 0,063 ; largeur 0,038 . Indice auriculaire 58,46. Forme triangulaire.

Front : arcades moyennes ; inclinaison fuyante; hauteur et largeur moyennes.

$\mathrm{Nez}$ : cavité (de la racine) moyenne ; dos rectiligne; base horizontale; hauteur, largeur et saillie moyennes.

Bouche : moyenne, rectiligne; ouverture intermediaire.

Menton : droit, rond, à fossette; hauteur intermédiaire.

Visage ovale. Iris pigmenté d'orange. Figure commune.

Teint brun. Barbe, cheveux et sourcils chàtains grisonnants. Tatoué. Carrure moyenne. Constitution et état général bons.

Fainéant, bouffi d'orgueil. - Sparterie. — Obs. 121.

$2^{\circ}$ Au point de vue de la nationalité :

63 Français (dont 6 Corses), 12 Etrangers $(5$ Italiens et 7 divers).

Un malfaiteur cosmopolite, " dangereux », né à Rotterdam, le 12 février 1856, marié (séparé de sa femme), sachant lire et écrire, sans profession, sans moyens d'existence, sans domicile fixe, à la $1^{\text {re }}$ peine, a été condamné, le 26 juin 1895, par le tribunal de Lyon, à 18 mois de prison et à 50 francs d'amende, pour " escroquerie et complicité d'escroquerie" ".

Il avait engagé ou fait engager par sa maîtresse, au Montde-Piété de cette ville, pour une somme de 7,000 francs, de faux diamants, admirablements imitẻs.

Quand viendra l'heure de la libération, une voiture cellulaire le conduira au point de notre frontière le plus rapproché de son pays.

Taille $1 \mathrm{~m}$. 28 . Envergure $1 \mathrm{~m}$. 62. Buste 0,886 . Pied gauche 0,239 . Tète : longueur 0,190 ; largeur 0,130 . Indice céphalique 78,94. 
Oreille droite: longueur 0,064; largeur 0,039. Indice auricılaire 60,93 .

Front : arcades grandes; inclinaison fuyante; hauteur et largeur moyennes.

$\mathrm{Nez}$ : cavité (de la racine) moyenne; dos rectiligne ; base horizontale; hauteur, largeur et saillie moyennes.

Bouche : moyenne, rectiligne ; ouverture intermédiaire.

Menton : droit, rond, bas.

Visage ovale. Iris pigmenté de jaune. Bonne physionomie.

Teint clair. Barbe et sourcils chàtain clair. Cheveux châtains. Tatoué. Carrure moyenne. Santé bonne. Surdité légère. Presbytie.

( On ne peut être plus content de personne ) qu'il ne l'est de lui-même. - Atelier de filoches. - Obs. 122.

$3^{\circ}$ Au point de vue de l’âge :

5 de 16 à 25 ans, 11 de 25 à 30 ans, 26 de 30 à 40 ans, 33 de 10 ans et plus.

On remarque, parmi les individus ayant dépassé la quarantaine, un courtier de vin et un débitant forain de la plus infime catégorie.

$1^{\circ}$ Le courtier de vin, âgé de quarante-cinq ans, né dans un chef-lieu de canton de l'Hérault, marié, possédant une instruction primaire complète, récidiviste, subit la peine de 3 ans de prison, prononcée, par jugement du tribunal de Béziers, en date du 7 mai 1895, pour (( abus de confiance ).

Dans le commencement de l'année 1894, il avait réussi à capter la confiance d'un négociant bitterois et à se faire agréer par lui, comme voyageur.

Les marchandises étaient expédiées sous son nom.

Il en prenait livraison et les vendait pour son compte, tandis que les traites, tirées sur des clients imaginaires, revenaient impayées. 
Ainsi fut détournée, au préjudice du mandant, une somme de 3.740 francs

Taille 1 m. 6ว̈. Envergure 1 m. 69. Buste 0,887. Pied ganuche 0,230. Tìte : longueur 0,196 ; largeur 0,1008 . Indice céphalique 80,61 . Oreille droite : longueur 0,$060 ;$ largeur 0,036 . Indice auriculaire 60,00 . Front : arcades grandes; inclinaison fuyante; hauteur et largeur moyennes.

Nez : cavité (de la racine) moyenne ; dos rectiligne; base horizontale ; saillie grande; hauteur et largeur moyennes.

Bouche : grande, rectiligne; ouverture intermédiaire.

Menton : droit, rond, à houppe; hauteur intermédiaire.

Visage ovale. Iris pigmenté d'orange. Regard froid; air dédaigneux. Teint clair. Barbe, cheveux et sourcils chàtain clair.

Carrure moyenne. Santé délicate. Artérite chronique avec dégénérescence athéromateuse prononcée.

C'est un maître en trafics illicites. - Atelier de filoches.Obs. 123.

$2^{\circ}$ Le débitant forain, âgé de cinquante-six ans, marié, sachant lire et écrire, rural, récidiviste, a été condamné, à 2 ans de prison, le 2 juillet 1895, par le tribunal de Béziers, pour " escroquerie ).

Sa spécialité était d'exploiter les négociants en gros.

Il se servait habilement de son homony mie avec les personnes les plus avantageusement connues de la ville, où ilavait fixé sa résidence, pour inspirer à ses fournisseurs une confiance entière, absolue.

Grâce à ce stratagème, dans le courant des années 1894 et 1895, à sa sortie de prison, notre homme, après avoir loué, à Béziers, une petite remise, dans une rue oú est établi un commerçant très honorable, réussit à se faire envoyer quantité de marchandises et d'échantillons, ayant une valeur réelle, " par plus de cent négociants de France et de l'étranger ».

Taille $1 \mathrm{~m}$. 56. Envergure $1 \mathrm{~m}$. 60. Buste 0,880. Pied gauche 0,230 . Tète : longueur 0,168 ; largeur 0,153 . Indice céphalique 91,07 . 
Oreille droite: longueur 0,061 ; largeur 0,036 . Indice auriculaire $\check{5} 9,0$ I.

Front: arcades moyennes; inclinaison intermédiaire; hauteur et largeur moyennes.

Nez: cavité (de la racine) moyeune; dos convexe; base horizontale; largeur, hauteur et saillie noyemmes.

Bouche : moyeune, à coins abaissés; ouverture intermédiaire.

Menton : droit, rond, à fossette; hauteur intermédiaire.

Visage arrondi. Iris pigmenté de marron. Air prévenant.

Teint brun. Barbe, cheveux et sourcils chàtains, grisonnants. Sourcils écartés. Tatoué.

Carrure moyenne. Santé passable. Hernie inguinale double. Presbytie.

Bien noté. - Empaillage. - Obs. 124.

\section{$4^{\circ}$ Au point de vue de l'état civil :}

46 célibataires, 22 mariés, 5 veufs, 2 divorcès.

Au nombre des célibataires, est un Marseillais, âgé de vingtsept ans, sachant lire, écrire et calculer, employé de commerce, débauché, à la $3^{e}$ peine, condamné, par la cour d'assises des Bouches-du-Rhône, le 22 mars 1895, à 4 ans de prison et à cent francs d'amende, pour " faux et usage de pièces fausses ".

A la date du 25 juin 1894, l'agence du Crédit lyonnais, à Marseille, recevait de Gap une lettre, signée du nom d'un de ses déposants, demandant l'envoi d'une somme de 6,000 francs.

Cette somme venait d'être expédiée, quand, par hasard, le véritable déposant se présenta au Crédit lyonnais.

Avisé de l'envoi, celui-ci porta plainte.

On trouva, entre les mains du filou, un récépissé de lettre recommandée, adressée de Nîmes à la Société générale de Marseille, dans laquelle était demandé l'envoi de 4,500 francs,

- demande qui n'avait pas abouti.

De plus, il fut ètabli qu'à l'aide de lettres, faussement signées 
du nom d'un distillateur connu, il s'était fait adresser, à Cannes, en 1893 et 1894, des sommes dont le total s'élevait à 14,500 francs.

Taille $1 \mathrm{~m} .64$. Envergure $4 \mathrm{~m}$. 70. Buste 0,886. Pied gauche 0, 25ั5. Tète : longueur 0,175 ; largeur 0,1333 . Indice céphalique 87,42.

Oreille droite: longueur 0,061 ; largeur 0,036 . Indice auriculaire 59,01. Écartement total.

Front : arcades moyennes; inclinaison verticale; hauteur et largeur moyennes.

$\mathrm{Nez}$ : cavité (de la racine) moyenne; dos rectiligne; base horizontale ; saillie grande; hauteur et largeur moyennes.

Bouche : moyenne, rectiligne; ouverture intermédiaire.

Menton : droit, rond, bas.

Visage ovale. Iris pigmenté d'orange. Tète à l'évent.

Teint brun. Barbe, cheveux et sourcils chàtains. Sourcils réunis.

Carrure moyenne. État général et constitution bons.

Il ne se foule pas la rate. - Chaises. - Obs. 125.

Un des 2 divorcés a été jugé, à Nîmes, le 3 avril 1894 .

Admirons son audace :

Le 13 mars 1895, cet ancien commissaire de police révoqué, né, dans l'arrondissement de B..., en novembre 1852, sachant lire, écrire et calculer, rural, sans domicile fixe, 5 fois condamné, " se présentait à la mairie de Sommières et déclarait, à l'adjoint de cette commune, qu'il était nommé commissaire du canton et qu'il venait prendre possession de son poste »).

Sur l'observation qu'il ne pouvait être installé dans ses nouvelles fonctions sans avis officiel de cette nomination, " il demanda et obtint de se faire accompagner, par un agent de police, chez les autorités locales ").

Il se rendit, d'abord, chez le commandant de la brigade de gendarmerie.

Cette visite faite, il se présenta chez l'un des deux notaires de la ville et, à l'aide d'une prétendue commission rogatoire, il 
opérait une perquisition et procédait à la saisie d'une somme de 6,000 francs, sous prétexte que cet officier public était prévenu d'émission de fausse monnaie.

Condamné, pour " escroquerie et usurpation de fonctions "), à 3 ans de prison et à 50 francs d'amende, par le tribunal, il interjeta appel.

La cour, par arrêt du 26 avril 1894, confirma le jugement rendu.

Taille $1 \mathrm{~m} .663$. Envergure $1 \mathrm{~m}$. 690. Buste 0,886. Pied gauche 0,25\% Tèle : longueur 0,194 ; largeur 0,1 ö̈. Indice céphalique 79,89 .

Oreille droite : longueur $0,06 弓$; largeur 0,036 . Indice auriculaire 35,38 .

Forme triangulaire.

Front : arcades moyennes; inclinaison intermédiaire ; hauteur et largeur moyennes.

Nez : cavité (de la racine) moyenne; dos concave; base relevée ; hauteur, saillie et largeur moyennes.

Bouche : moyenne, à coins abaissés ; ouverture intermédiaire.

Menton : droit, rond, bas, plat.

Visage ovale. Iris pigmenté de châtain. Regard dur.

Teint brun. Barbe et cheveux châtain foncé. Sourcils chàtain clair.

Tatoué.

Carrure moyenne. Santé bonne.

Il le prend de haut avec ses codétenus. Au demeurant, bon ouvrier. - Empaillage. - Obs. 126.

\section{$5^{\circ}$ Au point de vue de l'instruction :}

32 savent lire et écrire; 15 savent lire, écrire et calculer; 11 savent lire; 3 sont illettrés.

Un Ardéchois, âgé de trente-sept ans, célibataire, illettré boucher, urbain, récidiviste, a été condamné, parle tribunal de Valence, et, sur appel, par la cour de Grenoble, le 30 mai 1895 , à 1 an et 1 jour de prison, pour " escroqueries ".

Ch. Perrier. 
Il avait été surpris, entraînant des paysans dans certains cafés borgnes, où l'on jouait aux cartes et où, après boire, ses associés vidaient labilement les poches des clients.

Taille $1 \mathrm{~m}$. 67. Envergure $1 \mathrm{~m}$. 72. Buste 0,880. Pied gauche 0,265. Tète : longueur 0,173 ; largeur 0,137 . Indice céphalique 90,73 . Oreille droite : longueur 0,063 ; largeur 0,036 . Indice auriculaire 37,14 . Front: arcades grandes; inclinaison fuyante; hauteur et largeur moyenne.

Nez: cavité (de la racine) moyenue; dos rectiligne sinueux; base horizontale ; hauteur, largeur et saillie moyennes.

Bouche : grande, à coins relevés; ouverture intermédiaire.

Menton: saillant, large, haut, plat.

Visage ovale. Iris pigmenté de jaune. Bonne mine.

Teint brun. Barbe et cheveux chàtains grisonnants; sourcils châtains. Carrure moyenne. Santé passable. Varices.

Travailleur et fêtard. - Filoches. - Obs. 127.

13 possèdent une instruction primaire complète.

La plupart se tiennent à une froide distance de leurs compagnons d'infortune.

Au premier rang, brille un aventurier des plus habiles, Palermitain, âgé de cinquante-trois ans, célibataire, à la $6^{\mathrm{e}}$ peine, sans domicile fixe, débauché, vivant en concubinage.

En 1892, il vint à Narbonne, où, se faisant passer pour employé de la Secrétairerie d'État du pape, il quêta pour l'œuvre des Nouvelles Églises de Rome. “ A plusieurs de ses dupes, il offrit de vendre et vendit des brevets de chevalier ou commandeur de Saint-Grégoire-le-Grand »).

Arrêté, le 19 décembre 1892, au moment où il essayait de placer un diplôme de chevalier de Saint-Grégoire, l'étrange quêteur, qui prétendit être le baron M... de H..., ancien colonel de hussards en Espagne, allégua, pour sa défense, que tous ses actes avaient été commandés par un Italien dont il était le commissionnaire. 
Son identité ne tarda pas à être établie; 26 faits d'escroquerie, commis dans les villes du Midi, furent relevés à sa charge.

Le tribunal de Narbonne lui a infligé, le 29 mai 1893, 5 ans d'emprisonnement et 50 francs d'amende.

Par arrêt du 29 juin 1893, la cour d'appel de Montpellier a confirmé le jugement ci-dessus énoncé.

L'expulsion suivra la peine.

Tailte $1 \mathrm{~m}$. 656. Envergure $1 \mathrm{~m}$. 670. Buste 0,907. Pied ga uche 0,257. Tète: longueur 0,198 ; Jargeur $0,13 ̈ 1$. Indics céphalique 76,26 .

Oreille droite : longueur 0,066 ; largeur 0,038 . Indice auriculaire 57,57 .

Front : arcades moyennes; inclinaison intermédiaire; hauteur grande; largeur petite.

Nez : cavité (de la racine) moyenne; dos rectiligne; base relevée; hauteur, largeur et sailtie moyennes.

Bouche : petite, rectiligne; ouverture intermédiaire.

Menton : droit, rond, à houppe, à fossette; hauteur intermédiaire.

Visage ovale. Iris pigmenté de jaune. Physionomie douce.

Teint clair. Barbe blanche; cheveux gris ; sourciis châtain clair.

Carrure moyenne. Santé délicate.

Bon détenu. - Filoches. - Obs. 128.

Le $75^{\mathrm{e}}$ a reçu, dit-on, une instruction supérieure.

Il n'y paraît pas.

Cet individu, employé de commerce, âgé de vingt-neuf ans, marié, urbain, originaire de la Loire, domicilié à Nice, 2 fois condamné, adonné á l'ivrognerie, subit la peine de 2 ans de prison, prononcée, le 18 juillet 1895, par la cour d'assises des Alpes-Maritimes, pour avoir commis, de concert avec un camarade, les crimes de " faux en écritures de commerce et usage de ces faux $)$.

Taille 1 m. 67. Envergure 1 m. 63. Busle 0,88:). Pied gauche 0,20̈3. Tète : longueur 0,186 ; largeur 0,167. Indice céphalique 89,78. 
Oreille droite : longueur 0,036 ; largeur 0,034 . Indice auriculaire 60,71 . Front: arcades, hauteur et largeur moyennes; inclinaison intermédiaire.

Nez: cavité (de la racine) moyenne; dos convexe; base horizontale; saillie, hauteur et largeur moyennes.

Bouche: moyenne, à coins relevés ; ouverture intermédiaire.

Menton: droit, rond, à houppe, à fossette; hauteur intermédiaire.

Visage ovale, sans physionomie. Iris pigmenté de jaune.

Teint brun. Barbe châtain clair ; cheveux et sourcils châtain foncé. Carrure moyenne. Constitution et état général bons.

Bien noté. - Cordonnerie. - Obs. 129.

\section{Au point de vue de la profession :}

4 rentrent dans la catégorie des propriétaires.

Entre autres, un Corse, âgé de trente-cinq ans, sachant lire et écrire, rural, à la $1^{\text {re }}$ peine, condamné, par la cour d'appel de Bastia, le 20 novembre 1895 , à 2 ans deprison et à 5 ans d'interdiction de séjour, pour " excitation de mineures à la débauche et chantage $)$.

Il avait dressé au racolage deux fillettes de douze à quatorze ans, dont une était la propre fille de sa maîtresse.

L'ignoble couple filait, adroitement, les clients que raccrochaient les petites et se montrait au moment psychologique, menaçant de révélations à la justice le racolé surpris et atterrè.

C'est ainsi que ce trist e sire obtint 1,200 francs, d'un sujet norvégien, 150 francs, d'une autre personne, et une somme dont le chiffre n'a pas été déterminé, d'un individu resté inconnu.

Taille $1 \mathrm{~m} .67$. Envergure $1 \mathrm{~m} .62$. Buste 0,915. Pied gauche 0,254. Tète : longneur 0,195 ; largeur 0,153 . Indice céphalique 79,48. Oreille droite: longueur 0,061 ; largeur 0.033 . Indice anriculaire $\ddot{3} 4,09$.

Front: arcarles moyenues; inclinaison intermédiaire; hauteur et largeur moyennes. 
Nez: cavité (de la racine) petite; dos rectiligne ; base horizontale; largeur grande; saillie et hauteur moyennes.

Bouche: moyenne, rectiligne; ouverture intermédiaire. Menton: droit, rond, à fossette; hauteur intermédiaire. Visage ovale. Iris impigmenté. Air faux. Teint blond. Barbe, cheveux et sourcils blonds. Carrure moyenne. Santé bonne.

Piètre ouvrier et insipide farceur. - Empaillage. Obs. 130.

17 figurent parmi les employés de banque et de commerce; 12 sont commerçants et fabricants.

Un négociant failli, âgé de quarante-six ans, divorcé, sachant lire, écrire et calculer, rural, 2 fois condamné, fait 4 ans de prison, peine prononcée, par la cour d'assises des HautesPyrénées, le 9 septembre 1893, pour " banqueroute frauduleuse ».

En novembre 1892, il rencontrait, dans la bonne ville de Toulouse, un ancien camarade de collège et décidait de fonder avec lui, à Vic-Bigorre, une maison de commerce: "les Docks Pyrénéens $)$.

L'argent manquait, mais l'ami connaissait " une sorte de banquier véreux "), qui promit de faire escompter les valeurs de la maison.

Les deux copains entrèrent alors en relations avec quelques négociants et se montèrent en marchandises. Les premières traites furent payées, ce qui inspira quelque confiance. Au mois de février, la gêne commença. Alors, "au moyen des manœuvres les plus déshonorantes ", ils se firent souscrire des billets de complaisance par des amis et par de petits boutiquiers, auxquels ils promettaient de la marchandise qu'ils n'envoyaient pas. 
Enfin, acculés à la faillite, "ils escroquèrent, à des entrepositaires, à Bordeaux, 18,000 franes de vin ") et dissipèrent cet argent.

Taille $1 \mathrm{~m}$. 707. Envergure $1 \mathrm{~m}$. 79. Buste 0,906. Pied gauche 0, 2038 . Tète : longueur 0,191 ; largeur 0,164 . Indice céphalique 800,86 .

Oreille droite: longneur $0,0 \ddot{39}$; largeur $0,03 \ddot{z}$. Indice auriculaire 89,32. Forme triangulaire.

Front: arcades moyennes; inclinaison fuyante; hateur et largeur moyennes.

Nez : cavité (de la racine) grande; dos rectiligne, sinueux; base horizontale; hauteur, saillie et largeur moyennes.

Bouche : moyeune, rectiligne; ouverture intermédiaire.

Menton : droit, rond, haut, i fossette.

Visage ovale. Iris impigmenté. Des yeux de viveur.

Teint brun. Barbe, cheveux et sourcils chàtains grisonnants.

Carrure moyenne. Constitution robuste.

Il se plaît au travail et se conduit bien. - Filoches. Obs. 131.

8 sont classés parmi les professions alimentaires; 9 , parmi les ouvriers d'ateliers et de fabriques; 8, parmi les nomades; 7, parmi les professions agricoles.

Un Italien, âgé de quarante-quatre ans, sachant lire, écrire et calculer, portefaix, urbain, ayant un domicile, 6 fois condamné, subit la peine de 2 ans de prison (arrêt de la cour d'assises de la Corse, en date du 20 juillet 1895), pour « faux en écriture publique ou authentique ").

En 1879, il abandonnait sa femme et allait s'ètablir, avec sa maîtresse, à Bastia, où il fit enregistrer, comme étant légitimes, a la Mairie et au Consulat, les trois enfants que celle-ci lui donna.

Taille $1 \mathrm{~m}$. 68. Lnvergure $1 \mathrm{~m}$. 72. Buste 0,933 . Pied ganche 0,261 . Tète : longueur 0,196 ; largeur 0,162 . Indice céphaliq̣ue $82,6.5$. 
Oreille droite: Iongueur 0,058 ; largeur 0,036 . Indice auriculaire 62,06 .

Front: arcades moyennes; inclinaison intermédiaire; hanteur et largeur moyennes.

Nez: cavité (de la racine) moyenne; dos rectiligue ; base relevée ; hauteur, saillie et largeur moyennes. Dévié à droite.

Bouche: moyenne, à coins relevés; ouverture intermédiaire.

Menton: droit, large; hauteur intermédiaire.

Visage large. Iris pigmenté de jaune. Physionomie insignifiante.

Teint brun. Barbe et cheveux chitains grisonnants. Sourcils chàtain moyen.

Carrure moyenne. Bonne santé. A expulser.

Excellent balayeur. - Obs. 132.

On compte 4 ouvrier's dubatiment et du mobilier et 6 individus sans profession.

En prenant la qualité de " Président d'une société de bienfaisance », un Bruxellois, âgé de quarante-quatre ans, célibataire, sachant lire, écrire et calculer, sans profession, poursuivi antérieurement pour banqueroute simple et connu pendant longtemps sous un faux nom, avait réussi à escroquer deux sommes de 50 francs (au consul d'Angleterre et au pasteur), à Nice.

Il avait, en outre, détourné le montant d'un effet de 1,000 francs, remis entre ses mains, a charge d'en rendre compte.

La cour d'appel d'Aix, par arrêt, en date du 20 décembre 1894, a confirmé le jugement rendu, par le tribunal de Nice, le 16 novembre 1894 , et lui infligeant 5 ans de prison et 50 francs d'amende, pour " escroquerie, abus de confiance, vagabondage et contravention à un arrêté d'expulsion »).

Taille 1 m.73. Envergure 1 m. 72. Buste 0,932. Pied gauche 0,278. Tète: longueur 0,194 ; largeur 0,161 . Indice céphalique 82,98 . 
Oreille droite: longueur 0,068 ; largeur 0,040 . Indice auriculaire 58,82 . Écartement tolal.

Front: fuyant, haut, étroit; arcades moyennes.

$\mathrm{Nez}$ : cavité (de la racine) moyenne; dos rectiligne, effilé ; base horizontale; largeur petite; hanteur et saillie grandes.

Bouche : moyenne, rectiligne, pincée.

Menton : droit, rond, bas.

Visage ovale. Iris impigmenté. Figure pleine de bonhomie.

Teint clair. Barbe, cheveux et sourcils châtain clair.

Carrure grande. Santé vigoureuse.

Très bavard, quand on chatouille sa vanité au bon endroit. Il a de la tenue. - Ébénisterie. - Obs. 133.

7० Au point de vue de la population :

40 ruraux et 35 urbains.

\section{$8^{\circ}$ Au point de vue du domicile}

55 avec domicile et 20 sans domicile.

Les sans domicile comprennent 11 urbains et 9 ruraux.

Un Pyrénéen, célibataire, âgé de vingt-quatre ans, urbain, sans domicile fixe, sans antécédents judiciaires, a été condamné. le 8 janvier 1895, par le tribunal de Nîmes, à 16 mois de prison, pour " escroquerie et filouterie d'aliments ".

En octobre et décembre 1894, il avait escroqué, à diverses maisons de commerce, plusieurs sommes d'argent, s'élevant au total de mille francs. En outre, il s'était fait servir, dans divers hôtels, des aliments qu'il avait consommés, sans en acquitter le montant.

Cet homme, qui a reçu une bonne instruction, se disait voyageur de commerce et transmettait aux maisons, dont il avait surpris la bonne foi. des commandes purement fictives. 
Taille: 1 m. 71. Envergure $1 \mathrm{~m}$. 82. Buste 0,900. Pied gauche 0,26ว̈. Tète: longueur 0,202 ; largeur 0,166 . Indice céphalique 82,17 .

Oreille droite: longueur 0,068 ; largenr 0,040 . Indice a uriculaire 58,82 .

Forme allongée.

Front: arcades grandes; inclinaison intermédiaire; hauteur et largeur petites.

Nez: cavité (de la racine) petite; dos concave; base horizontale ; hauteur grande; saillie et largeur moyennes. Dévié à droite.

Bouche: moyenne, rectiligne; ouverture intermédiaire; lèvres épaisses.

Menton: droit, rond, haut, à houppe et à fossette.

Visage ovale. Iris pigmenté de marron. Regard en dessous.

Teint brun. Barbe, cheveux et sourcils châtain foncé. Sourcils arqués.

Carrure grande. Bonne santé

Travailleur, mais vicieux. - Lits en fer. - Obs. 134.

Dans la catégorie des ruraux sans domicile, on distingue un enfant du Gard, âgé de trenté et un ans, célibataire, contrebandier, sachant lire et écrire, une fois condamné.

Il subit la peine de 3 ans de prison, prononcée (y compris 100 francs d'amende), le 15 avril 1893, par le tribunal de Reims, pour " extorsion de valeurs et tentative d'extorsion de fonds $)$.

Le 5 décembre 1892, il avait essayé de faire chanter un sieur D..., comme pédéraste.

Taille I m. 68. Envergure $1 \mathrm{~m}$. 73̈. Buste 0,890. Pied gauche 0,263.

Tète : Iongueur 0,190 ; Iargeur 0,1522 . Indice céphalique 80,00 .

Oreille droite : longueur 0,038 ; largeur 0,037 . Indice auricu-

laire 63,79. Forme triangulaire. Écartement inférieur.

Front: arcades moyennes; inclinaison fuyante; hauteur et largeur moyennes.

Nez: cavité (de la racine) petite; dos convexe; base horizontale; hauteur, largeur et saillie moyennes.

Bouche : grande, rectiligne; ouverture intermédiaire.

Ilenton : fuyant, rond; hauteur intermédiaire. 
Visage ovale. Iris impigmenté.

Teint brun. Barbe, cheveux et sourcils chàtains.

Carrure grande. Santé médiocre. Caractère sournois.

Mal noté. - Quartier des vieillards. - Obs. 135.

$9^{\circ}$ Au point de vue du nombre des condamnations :

36 ont été condamnés de 1 à 5 fois; 25 , de 5 à 20 fois; 14 sont à la première peine.

Un caissier-comptable, âgé de trente-trois ans, marié, possédant une instruction primaire complète, urbain, sans antécédents judiciaires, a été condamné, le 18 avril 1893, par la cour d'assises des Pyrénées-Orientales, à 5 ans de prison et à 100 francs d'amende, pour " abus de confiance et faux ".

Grâce à des altérations d'écritures, à des dissimulations de recettes et à des augmentations de dépenses, il avait pu cacher, aux yeux de son directeur et de la Société centrale de..., des détournements qui s'élevaient à 45,311 fr. 79.

Il avait falsifié, en outre, certaines pièces justificatives, adressées à Paris pour demander des fonds, et avait gratté et surchargé la feuille de paye du mois d'avril 1892, de manière a mettre le total de cette feuille de paye d'accord avec son livre de caisse, qui portait une somme supérieure.

C'est, dit-il, un coup de bourse qui fit ouvrir les yeux aux administrateurs sur les virements de fonds et les dépenses fictives de la fabrique.

( La Société sait pertinemment que je n'ai rien détourné à mon profit. Elle ne s'est pas portée partie civile dans l'affaire.

"Quant au faux de cinq cents francs, pour lequel je suis allé en cassation, l'expert ne me l'a pas attribué d'une façon formelle."

Et il ajoute avec malice: (Les plus forts font la loi. » 
Taille: I m. 67. Envergure 1 m. 61. Buste 0,888. Pied gauche 0, 252. Tète: longueur 0,197; largeur $0,122$. Indice céphalique 77,13 .

Oreille droite: longueur 0,068 ; largeur 0,038 . Indice auriculaire 55,88 .

Front: arcades moyennes; inclinaison intermédiaire; hauteur et largeur grandes.

Yez : cavité (de la racine) moyenne; dos rectiligne; base abaissée; hauteur, largeur et saillie moyennes.

Bouche : grande, rectiligne ; ouverture intermédiaire.

Menton: saillant, rond, à houppe; hauteur intermédiaire.

Visage rond. Iris pigmenté de marron. Air prévenant.

Teint brun. Barbe, cheveux et sourcils chàtains.

Carrure grande. Santé bonne. Obésité légère. Humeur toujours égale.

Conduite excellente, travail soutenu. - Service de l'infirmerie. - Obs. 136 .

10' Au point de vue de l'oisiveté :

47 oisifs.

11. A u point de vue de l'ivrognerie :

14 s'adonnaient à l'iorognerie.

12. Au point de vue du libertinage et de la débauche:

33 se livraient au liberlinage ct ì la débauche.

$13^{n}$ Au point de vue du concubinage :

16 vivaient en concubinage.

14. Au point de vue de la note de la commune:

4 bien notés. 
$15^{\circ}$ Au point de vue de la taille :

Dans la catégorie de 16 à 20 ans: taille de $1 \mathrm{~m} .60$ à $1 \mathrm{~m} .70$, 1 individu.

Soit, taille $1 \mathrm{~m} .650$.

De 20 à 25 ans : taille de $1 \mathrm{~m} .60$ à $1 \mathrm{~m} .70,2$ individus; de $1 \mathrm{~m} .70$ et au-dessus, 2.

Soit, moyenne de la taille $1 \mathrm{~m} .685$.

De 25 à 30 ans : taille au-dessous de $1 \mathrm{~m} .60,2$ individus; de $1 \mathrm{~m} .60$ à $1 \mathrm{~m} .70,7$; de $1 \mathrm{~m}$. 70 et au-dessus, 2 . Soit, moyenne de la taille $1 \mathrm{~m} .661$.

De 30 à 40 ans : taille au-dessous de $1 \mathrm{~m} .60,7$ individus; de $1 \mathrm{~m} .60$ à $1 \mathrm{~m} .70,15$; de $1 \mathrm{~m}$. 70 et au-dessus, 4 .

Soit, moyenne de la taille $1 \mathrm{~m} .638$.

De 40 à 50 ans : taille au-dessous de $1 \mathrm{~m} .60,1$ individu ; de $1 \mathrm{~m} .60$ à $1 \mathrm{~m}$. 70, 18 ; de $1 \mathrm{~m}$. 70 et au-dessus, 9 .

Soit, moyenne de la taille $1 \mathrm{~m} .676$.

De 50 ans et au-dessus : taille au-dessous de $1 \mathrm{~m} .60,1$ individu; de $1 \mathrm{~m} .60$ à $1 \mathrm{~m}$. 70, 3; de $1 \mathrm{~m}$. 70 et au-dessus, 1 . Soit, moyenne de la taille $1 \mathrm{~m} .640$.

En résumé: taille au-dessous de $1 \mathrm{~m} .60,11$ individus; de $1 \mathrm{~m} .60$ à $1 \mathrm{~m}$. 70, 46 ; de $1 \mathrm{~m}$. 70 et au-dessus, 18 .

Soit, moyenne de la taille $1 \mathrm{~m} .658$. 
$16^{\circ}$ Au point de vue de l'envergure :

Dans la catégorie de 16 à 20 ans: envergure supérieure à la taille, de 0 à 4 cent., 1 individu.

Soit, envergure $1 \mathrm{~m} .670$.

De 20 à 25 ans : envergure supérieure à la taille, de 0 à 4 cent. , 1 individu; de 4 à 8 cent., 1 ; de 8 à $16,2$.

Soit, moyenne de l'envergure $1 \mathrm{~m} .750$.

De 25 à 30 ans : envergure inférieure à la taille, de 0 à 8 cent., 3 individus; supérieure à la taille, de 0 à 4 cent., 1 ; de 4 à 8 cent., 6 ; de 8 à 16 cent., 1 .

Soit, moyenne de l'envergure $1 \mathrm{~m} .694$.

De 30 à 40 ans : envergure inférieure à la taille, de 0 à 8 cent., 3 individus; égale à la taille, 1 ; supérieure à la taille, de 0 à 4 cent., 7 ; de 4 à 8 cent., 9 ; de 8 à 16 cent., 6 .

Soit, moyenne de l'envergure $1 \mathrm{~m} .681$.

De 40 à 50 ans : envergure inférieure à la taille, de 0 à 8 cent., 2 individus ; égale à la taille, 1 ; supérieure à la taille, de 0 à 4 cent., 12 ; de 4 à 8 cent., 8 ; de 8 à 16 cent., 5 .

Soit, moyenne de l'envergure $1 \mathrm{~m}$. 718.

De 50 ans et au-dessus: envergure supérieure à la taille, de 0 à 4 cent., 2 individus; de 4 à 8 cent., 3 .

Soit, moyenne de l'envergure $1 \mathrm{~m} .672$.

En résumé : envergure inférieure à la taille, de 0 à 8 cent., 8 individus; égale à la taille, 2 ; supérieure à la taille, de 0 à 4 cent., 24 ; de 4 à 8 cent., 27 ; de 8 à 16 cent., 14 .

Soit, moyenne de l'envergure $1 \mathrm{~m} .699$. 


\section{$17^{\circ}$ Au point de vue du buste :}

Dans la catégorie de 16 à 20 ans: buste supérieur à la moitié de la taille, de 5 à 10 cent., 1 individu.

Soit, hauteur du buste 0,895 .

De 20 à 25 ans : buste supérieur à la moitié de la taille, de 0 à 5 cent., 3 individus; de 5 à 10 cent., 1.

Soit, moyenne du buste 0,886 .

De 25 à 30 ans: buste supérieur à la moitié de la taille, de 0 à 5 cent., 3 individus; de 5 à 10 cent., 7 ; de 10 à 18 cent., 1.

Soit, movenne du buste 0,889 .

De 30 à 40 ans: buste supérieur à la moitié de la taille, de 0 à 5 cent., 6 individus; de 5 à 10 cent., 20 .

Soit, moyenne du buste 0,880 .

De 40 à 50 ans: buste supérieur à la moitié de la taille, de 0 à 5 cent., 6 individus; de 5 à 10 cent., 22.

Soit, moyenne du buste 0,896 .

De 50 ans et au-dessus: buste inférieur à la moitié de la taille, de 0 à 8 cent., 1 individu ; supérieur à la moitié de la taille, de 5 à 10 cent., 3 ; de 10 à 18 cent., 1 .

Soit, moyenne du buste 0,870 .

En résumé : buste inférieur à la moitié de la taille, de 0 à 8 cent., 1 individu; supérieur à la moitié de la taille, de 0 à 5 cent., 18; de 5 à 10 cent., 54 ; de 10 à 18 cent., 2 .

Soit, moyenne du buste, $0,88 \%$. 
18. Au point de vue du pied :

Dans la catégorie de 16 à 20 ans: pied de 24 à 26 cent., 1 individu.

Soit, longueur du pied 0,251.

De 20 ¿̀ 25 ans : pied de 24 à 26 cent., 1 individu; de 26 à 28 cent., 3.

Soit, moyenne du pied 0,262.

De 25 i 30 ans : pied de 24 à 26 cent., 9 individus ; de 26 a 28 cent., 2.

Soit, moyenne du pied 0,255 .

De 30 à 40 ans : pied de 22 a 24 cent., 2 individus; de 24 à 26 cent., 16 ; de 26 à 28 cent., 7 ; de 28 à 30 cent., 1.

Soit, moyenne du pied 0,254 .

De 40 a 50 ans : pied de 24 à 26 cent., 14 individus : de 26 a 28 cent., 12 ; de 28 à 30 cent., 2.

Soit, moyenne du pied 0,261.

De 50 ans et au-dessus : pied de 22 à 24 cent., 1 individu; de 24 à 26 cent., 2 ; de 26 à 28 cent., 2 .

Soit, moyenne du pied 0,248 .

Én résumé : pied de 22 à 24 cent., 3 individus; de 24 a 26 cent., 43 ; de 26 à 28 cent., 26 ; de 28 à 30 cent., 3.

Soit, moyenne du pied 0,25\%.

19. Au point de vue de la tête:

2 dolichocéphales vrais, 6 sous-dolichocéphales, 14 mésaticéphales, 16 sous-brachycéphales, 37 brachycéphales orais. 
D'autre part, les calculs donnent :

Longueur moyenne de la tête 0,1886 ; largeur moyenne de la tête 0,1576 .

D’où : Indice céphalique 83,56 .

$20^{\circ} \mathrm{Au}$ point de vue de l'oreille :

Indice auriculaire: au-dessous de 52, 8 individus; de 52 à 56,20 ; de 56 à 60,26 ; de 60 à 65,18 ; de 65 et audessus, 3 .

D'autre part, les calculs donnent :

Longueur moyenne de l'oreille 0,0631; largeur moyenne de l'oreille 0,0362.

D'où : Indice auriculaire 57,36.

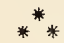

$21^{\circ}$ A u point de vue du visage :

En losange 1, rond 8, large ou carré 10, ovale 53, allongé 2, en toupie 1.

$22^{\circ}$ Au point de vue du front :

Arcades : grandes 15, petites 14, moyennes 46 .

Inclinaison : verticale 6, fuyante 18, intermédiaire 51.

Hauteur : grande 9, petite 6, moyenne 60.

Largeur : grande 5, petite 8, moyenne 62. 
$23^{\circ}$ Au point de vue du nez :

Cavité (de la racine) : grande 9, petite 19, moyenne 47.

Dos : rectiligne 45, concave 13 , convere 17.

Base : horizontale 55, relevée 14 , abaissée 6 .

Hauteur : grande 13, petite 2 , moyenne 60 .

Saillie : grande 15, petite 4, moyenne 56 .

Largeur : grande 11, petite 6, moyenne 58 .

\section{Au point de vue de la bouche :}

Dimension: grande 5, petite 7, moyenne 63 .

Inclinaison des angles : rectiligne 46, à coins abaissés 18, à coins relevés 11 .

Degré habituel d'ouverture : bée 5 , pincée 12, intermédiaire 58.

$25^{\circ}$ Au point de vue du menton :

Inclinaison générale : menton saillant 14, fuyant 8, droit 53. Avec et sans houppe : plat 13, à houppe 10, intermédiaire 52. Hauteur: haut 11, bas 19, intermédiaire 45.

Forme : large 16, rond 59.

$26^{\circ}$ Au point de vue de l'oil :

Iris : impigmenté 8 , pigmenté de jaune 25 , d'orange 19 , de châtain 18, de marron 5 .

$27^{\circ}$ Au point de vue du teint :

Brun 51, mat 1, clair 22, blond1. 


$$
\text { ** } *
$$

$28^{\circ}$ Au point de vue de la carrure :

Grande 20, moyenne 50, petite 5 .

$29^{\circ}$ Au point de vue de la constitution et de l'état général à l'arrivée :

Très bons 2, bons 52, passables 14, mauvais $\%$.

$30^{\circ} \mathrm{Au}$ point de vue des maladies et infirmités, à l'arrivée:

31 maladies et infirmités, à répartir entre 24 individus: 21 Français (dont 2 Corses), 1 Italien, 2 divers.

Soit : bronchite bacillaire 2 , hypertrophie du cour 1, artérite chronique avec dégénérescence athéromateuseprononcée 1 , accidents syphilitiques 2 , scrofule 1 , atrophie de la jambe 1 , hernie inguinale droite 1 , gauche 1 , double 2 , hernie ombilicale 1 , obésité 1 , varices 1 , varicocèle 1 , borgne 1 , myopie 5 , presbytie 8 , surdité légère 1 .

$$
* * *
$$

31. Au point de vue du lieu du crime :

Lieu de naissance: 13 individus ( 8 urbains et 5 ruraux, tous avec domicile). 
Département du lieu de naissance : 13 individus (9 ruraux et 4iurbains, dont 1 sans domicile).

Autre département: 49 individus, dont 19 sans domicile (10 urbains et 9 ruraux).

$32^{\circ}$ Au point de vue de la date du crime :

4 en janvier, 4 en février, 4 en mars, 6 en avril, 3 en mai, 6 en juin, 5 en juillet, 7 en août, 1 en septembre, 5 en octobre, 2 en novembre, 8 en décembre, 20 pendant l'année.

$$
\begin{aligned}
& \text { Soit : Hiver . . . . . . . . . . . . . . . } 16 \\
& \text { Printemps . . . . . . . . . . . . . . } 13 \\
& \text { Été . . . . . . . . . . . } 18 \\
& \text { Automne. . . . . . . . . . . . . . . } 8 \\
& \text { Pendant l'annie. . . . . . . . } 20 \\
& 75 \\
& \text { *** }
\end{aligned}
$$

$33^{\circ}$ Au point de vue de la juridiction :

Les peines avaient été prononcées: 54 par des tribunaux, 21 par des cours d'assises.

$3^{\circ}$ Au point de vue de la durée de la peine :

22 ont été condamnés à 2 et 3 ans; 12 , à 5 ans et plus; 10 , ¿ 3 et 4 ans; 7 , à 13 mois; 7 , à 15 et 18 mois; 6 , à 4 et 5 ans; $6, \dot{a} 1$ an et 1 jour; 5 , à 18 mois et 2 ans .

Un Cantalien, né le 2 juillet 1834, mariè (en secondes noces), sachant lire, écrire et calculer, rural, cultivateur, vivant de son 
travail et du revenu de ses propriétés, a été condamné, le $1^{\text {er }}$ mars 1895, par le tribunal de Mauriac, à 15 mois de prison, pour ( abus de blanc-seing ).

La cour d'appel de Riom, par arrêt du 3 avril 1895, a confirmé le jugement. ci-dessus énoncé, et le pourvoi en cassation a été rejeté, le 3 mai de la même année.

Cet individu, antérieurement condamné à de légères peines, dont une - la plus forte - à 6 jours de prison, pour escroquerie, avait acheté une petite propriété ( 2,800 francs) et remis en payement, au vendeur, un billet de 2.000 francs, portant la signature de sa femme et la sienne, ainsi qu'une valeur de 930 francs, signée par une de ses connaissances.

Il garantissait le paiement de cette dernière valeur, mais la clause de garantie le gênait, car il était sûr que le signataire ne payerait pas.

"Il avait, en effet, commis un abus de blanc-seing, ayant rempli, du chiffre de 930 francs, un billet qui devait n'être que de 800 francs », et, au lieu de donner 800 francs en espèces, il avait remis, au signataire de la valeur, un billet d'égale somme, escroqué à un tiers et inutilisable.

Il eut donc recours à un subterfuge; il obtint du vendeur une signature en blanc et rédigea, lui-même, au-dessus de cette signature, la décharge de garantie.

Taille $1 \mathrm{~m}$. 61. Envergure 1 m. 63. Buste 0,889. Pied gauche 0,243.

Tète : longueur 0,181 ; largeur 0,155 . Indice céphalique 85,63 .

Oreille droite: longueur 0,066 ; largeur $0,03 \%$. Indice auriculaire 36,06 .

Front : arcades moyennes; inclinaison intermédiaire; hauteur et largeur moyennes.

Nez : cavité (de la racine) moyenne; dos rectiligne, sinueux; base horizontale; saillie petite; hauteur et largeur moyennes.

Bouche : moyenne, à coins abaissés; ouverture intermédiaire. Menton : saillant, rond; hauteur intermédiaire.

Visage ovale. Iris pigmenté de jaune. 
Teint clair. Barbe et cheveux gris. Sourcils chàtain clair, réunis. Carrure petite. Bonne santé. Myopie.

Un parfait hypocrite. - Sparterie. - Obs. $13 \%$

$35^{\circ}$ Au point de vue de l'interdiction de séjour :

8 sont frappés d’interdiction de séjour, parmi lesquels, 2, par une condamnation antérieure.

$$
\text { *** }
$$

$36^{\circ}$ A.u point de vue du travail en prison :

Bons travailleurs 49, passables 20, mauvais 6 .

$37^{\circ}$ Au point de vue de la conduite en prison :

Bonne conduite 43, passable 1\%, mauvaise 15.

$$
\text { ** }
$$

$38^{\circ} \mathrm{Au}$ point de vue de l'expulsion :

10 étrangers sur 12. 


\section{XIII}

FABRICATION ET ÉMISSION DE FAUSSE hONNAIE

12 individus

$1^{\circ}$ Au point de vue de la naissance :!

Pas d'enfart naturel.

$2^{\circ}$ Au point de vue de la nationalité :

9 Français, 2 Italiens, 1 Suisse.

Le Suisse, âgẻ de 18 ans, urbain, né de parents français, compte, à son actif, 4 condamnations (dont une, à 2 mois de prison, pour vagabondage).

Il sait lire et écrire et est domicilié à Lyon.

On le dit ouvrier bijoutier, fin connaisseur en matière d'orfèvrerie, adonné à l'ivrognerie.

La rumeur publique l'accusait de ne vivre que d'expédients et de vols.

Par arrêt de la Cour d'assises du Rhône, en date du 26 juillet 1894, il lui a été infligé 4 ans d'emprisonnement, 5 ans d'interdiction de séjour et cent francs d'amende, pour " émission de fausse monnaie et outrages aux agents ".

Taille I m. 7I. Envergure I m. 74. Buste 0,90\%. Pied gauche 0,20̆8. Tète : longueur 0.181 ; largeur 0.133 . Indice céphalique 83,63 . 
Oreille droite : longueur 0,063 ; largeur 0,03 . Indice auriculaire วั5̆,つ̆. Écartement postérieur.

Front: arcades moyennes; inclinaison intermédiaire; largeur petite ; hauteur moyenne.

Nez : cavité (de la racine) movenne ; dos concave; base relevée ; saillie, hauteur et largeur moyennes.

Bouche : moyenne, rectiligne; ouverture intermédiaire ; lèvres épaisses.

Menton : fuyant, rond ; hauteur intermédiaire.

Visage ovale. Iris pigmenté de jaune.

Teint mat. Barbe, cheveux et sourcils chàtain clair. Tatoué.

Carrure moyenne. Santé bonne. Manières éveillées.

C'est un travailleur. La conduite laisse parfois à désirer. Pipes. - Obs. 138.

\section{$3^{\circ} \mathrm{Au}$ point de vue de l'âge :}

10 , de 18 a 35 ans ; 2 , de plus de 10 ans.

Parmi les vieux, figure un tailleur d'habits, réputé bon buveur, né, en 1841, dans une ville des Basses-Alpes.

Il sait lire, écrire et calculer, et a eu, quatorze fois. maille a partir avec la justice (délits divers).

La cour d'assises des Bouches-du-Rhône l'a condamné, le 25 mars 1895, à 5 ans de réclusion (peine commuée en prison) età 100 francs d'amende, pour "fabrication de fausse monnaie".

A son domicile, qu'il occupait en commun avec un jardinier (1) (enfant de l'Hérault, urbain, âgé de ringt ans, illettré,

(1) Taille $1 \mathrm{~m} .73$. Envergure $1 \mathrm{~m}$. 77. Buste 0,870. Pied gauche 0,298.

Tête : longueur 0,188 ; largeur 0,159 . Indice céphalique 84,57 .

Oreille droite : longueur 0,065 ; largeur 0,036 . Indice auriculaire 5̆.3.,

Front: arcades moyennes: inclinaison intermédiaire; hauteur et largeur moyennes.

Nez : cavité (de la racine) moyenne : dos concave : base relevée : hauteur, saillie et largeur moyennes.

Bouche : grande, restiligne; ouverture intermédiaire.

Menton : saillant, rond, bas, à houppe.

Visage arrondi. Iris pigmente de châtain. kegard en dessous.

Teint brun. Barbe, clreveux el sourcils châtains. Tatout.

Carrure grande. Constitution et élat général bons.

Chaisier habile; très vicieux. - Obs. 140. 
à la dixième peine, sans moyens d'existence connus), on avait découvert diverses matières, ayant servi à la fabrication de la fausse monnaie.

En outre, au moment de son arrestation, il était porteur d'un couteau " ayant encore, à la pointe, une certaine quantité de métal analogue à celui des pièces fausses émises par lui »).

Taille $1 \mathrm{~m}$. 72. Envergure $1 \mathrm{~m} .80$. Buste 0,913. Pied gauche 0,262. Tète : longueur 0,485 ; largeur 0,13 I. Indice céphalique 81.62 .

Oreille droite: longueur 0,062 ; largeur 0,039 . Indice auriculaire 62,90 .

Front : arcades moyennes; inclinaison intermédiaire; largeur petite; hauteur movenne.

Nez: cavité (de la racine) moyenne; dos rectiligne; base horizontale; hauteur, saillie et largeur moyeunes.

Bouche : moyenne, à coins abaissés; ouverture intermédiaire.

Menton : droit, large, à fossette; hauteur intermédiaire.

Visage allongé. Iris pigmenté de marron. Physionomie dure.

Teint brun. Barbe, cheveux et sourcils châtains. Tatoué.

Carrure moyenne. Santé délicate. Insuffisance valvulaire; conjonctivite chronique.

Quartier des vieillards. - Obs. 139.

\section{Au point de vue de l'état civil :}

Tous sont célibataires.

\section{$5^{\circ} \mathrm{Au}$ point de vue de l'instruction :}

7 savent lire et écrire; 4 savent lire, écrire et calculer; 1 n'a reçu aucune instruction.

$6^{\circ} \mathrm{Au}$ point de vue de la profession :

1 cuisinier, 1 marchand ambulant, 5 professions agricoles, 5 ouvrier's d'ateliers et de fabriques. 
Un électricien, né, à Montpellier, le 20 mai 1863, sachant lire, écrire et calculer, à la dixième peine, vivant en concubinage, a été condamné, à 5 ans de prison et à 100 francs d'amende, par arrèt de la cour d'assises du Gard, en date du 4 aout 1893, "pour fabrication et émission de fausse monnaie ".

Il avait émis des pièces fausses de 5 francs, obtenues à l'aide d'un moule en plâtre, et on avait trouvé, en sa possession, une lime ayant servi à enlever les bavures.

Taille $1 \mathrm{~m} .785$ Envergure $1 \mathrm{~m}$. 790. Buste 0.95\%. Pied gauche 0,273. Tète : longueur 0,181 ; largeur 0,1333 . Indice céphalique $84,53$.

Oreille droite : longueur 0,059 ; largeur 0,034 . Indice a uriculaire 57,62 .

Écartement total.

Front : arcades proéminentes; inclinaison verticale; hauteur grande ; largeur moyenne.

Nez : cavité (de la racine) moyenne; dos rectiligne, sinueux ; base horizontale; saillie grande; hauteur et largeur moyennes.

Bouche : petite, rectiligne; ouverture intermédiaire.

Menton : rond, droit ; hauteur intermédiaire.

Visage ovale, sans physionomie. Iris pigmenté d'orange, truité.

Teint brun. Barbe, cheveux et sourcils chàtains.

Carrure grande. Santé bonne.

Il a des chambres vides dans la tête et n'obéit qu'en rechignant. - Pantoufles. - Obs. 141.

$7^{\circ}$ Au point de vue de la population :

3 ruraux, 9 urbains.

$8^{\circ}$ Au point de vue du domicile :

2 sans domicile, 10 avec domicile. 


\section{Au point de vue du nombre des condamnations :}

9 sont des repris de justice.

L'un d'entre eux a en compte 20 condamnations. Sa mère le dressa au vol; il fut déporté à la Nouvelle-Calédonie, a la suite des événements de la commune.

Cet homme, né dans une ville de l'Allier, est âgé de soixantesix ans. Il sait lire, écrire et calculer. On ne lui connaît pas de domicile fixe.

"Après une vie des plus agitėes, je rencontrai, dit-il, à Nice, trois individus, qui fabriquaient de la fausse monnaie.

" Ils m'embauchèrent. Nous avions des cabanons, depuis Marseille jusqu'à Vintimille. Étant le plus vieux, je faisais la cuisine. On m'apportait tout ce qu'il fallait. En vendant du papier à lettres, mes camarades échangeaient les pièces fausses.

" Bien nourri, bien couvert la nuit et de l'argent à ma suffisance, j'étais très heureux; cela durait depuis quatre ans, lorsqu'un jour (12 février 1895), à Brignoles, on nous arrêta. Cependant, je n'avais jamais fabriqué, ni émis une seule pièce. Il est vrai que je portais le matériel... limes, moules, etc. Voyant que je ne pouvais m'en tirer, je pris tout à ma charge, pour éviter une condamnation à mes patrons, qui ne m'avaient fait que du bien. Le jury du Var m'a appliqué 4 ans de prison et $100 \mathrm{fr}$. d'amende (30 avril 1895)."

Taille $1 \mathrm{~m}$. 56. Envergure 1.m. 65. Buste 0,848. Pied gauche 0, 240 . Tète : longueur 0,186 ; largeur 0,157 . Indice céphalique 84,40 . Oreille droite: longueur 0,0 วัว ; largeur 0,031 . Indice auriculaire 56,36 . Front: arcades grandes; inclinaison intermédiaire ; hauteur et largeur moyennes.

Nez: cavité (de la racine) moyenne; dos concave ; base horizontale ; hauteur petite ; largeur grande ; saillie moyenne.

Bouche: moyenne, à coins relevés; ouverture intermédiaire.

Menton : droit, roud, bas, à fossette. 
Visage ovale. Iris pigmenté d'orange. Des yeux vifs.

Teint brun. Barbe, cheveux et sourcils chàtains. Tatoué.

Carrure moyenne. Santé bonne.

C'est un matois d'autant plus raffiné qu'il affecte plus de simplicitè. - Quartier des vieillards. - Obs. 142.

$10^{\circ}$ Au point de vue de l'oisiveté :

11 oisifs.

11. Au point de vue de l'ivrognerie :

4 s'adonnaient à l'ivrognerie.

$12^{\circ}$ Au point de vue du libertinage et de la débauche :

2 se livraient au libertinage et à la débauche.

$13^{\circ} \mathrm{Au}$ point de vue du concubinage :

Un seul vivait en concubinage.

14. Au point de vue de la note de la commune:

1ucun bien noté.

$15^{\circ}$ Au point de vue de la taille:

Lans la catégor ie de 16 à 20 ans : taille de $1 \mathrm{~m} 60$ à $1 \mathrm{~m}$. 70, 1 individu; de $1 \mathrm{~m}$. 70 et au-dessus, 1.

Soit, moyenne de la taille $1 \mathrm{~m} .70$. 
De 20 a 25 ans : taille au-dessous de $1 \mathrm{~m} .60,2$ individus : de $1 \mathrm{~m} .60$ à $1 \mathrm{~m}$. 70, 1 ; de $1 \mathrm{~m}$. 70 et au-dessus, 1 .

Soit, moyenne de la taille $1 \mathrm{~m} .633$.

De 30 à 40 ans : taille au-dessous de $1 \mathrm{~m} .60,1$ individu ; de $1 \mathrm{~m} .60$ à $1 \mathrm{~m}$. 70, 2: de $1 \mathrm{~m}$. 70 et au-dessus, 1 .

Soit, moyenne de la taille $1 \mathrm{~m} .668$.

De 40 à 50 ans : 1 individu.

Soit, taille $1 \mathrm{~m} .72$.

De 50 ans et au-dessus: 1 individu.

Soit, taille $1 \mathrm{~m} .56$.

En résumé : taille au-dessous de $1 \mathrm{~m} .60,4$ individus; de $1 \mathrm{~m}$. 60 à $1 \mathrm{~m} .70,4$; de $1 \mathrm{~m}$. 70, et au-dessus, 4 .

Soit, moyenne de la taille $1 \mathrm{~m} .65 \%$.

$16^{\circ}$ Au point de vue de l'envergure :

Dans la catégorie de 16 à 20 ans : envergure supérieure à la taille, de 0 à 4 cent., 1 individu ; de 4 à 8 cent., 1 .

Soit, moyenne de l'envergure $1 \mathrm{~m} .745$.

De 20 à 25 ans : envergure supérieure à la taille, de 0 à 4 cent., 2 individus; de 4 à 8 cent., 2 .

Soit, moyenne de l'envergure $1 \mathrm{~m} .675$.

Le 30 a 40 ans: envergure inférieure a la taille, 1 individu; supérieure à la taille, de 0 à 4 cent., 2 ; de 8 à 16 cent., 1 .

Soit, moyenne de l'envergure $1 \mathrm{~m} .682$.

De 40 à 50 ans : envergure supérieure à la taille, de 8 a 16 cent., 1 individu.

Soit, envergure $1 \mathrm{~m} .80$. 
De 50 ans et au-dessus : envergure supérieure à la taille, de 8 à 16 cent., 1 individu.

Soit, envergure $1 \mathrm{~m} .65$.

En résumé : envergure inférieure à la taille, 1 individu ; supérieure à la taille, de 0 à 4 cent., 5 ; de 4 à 8 cent., 3 ; de 8 à 16 cent., 3 .

Soit, moyenne de l'envergure 1 m. 697.

17. Au point de vue du buste :

Dans la catégorie de $16 \dot{\therefore} 20$ ans : buste supérieur à la moitié de la taille, de 0 à 5 cent., 2 individus.

Soit, moyenne du buste 0,891 .

De 20 à 25 ans : buste supérieur à la moitiè de la taille, de 0 à 5 cent., 3 individus; de 5 à 10 cent., 1 .

Soit, moyenne du buste 0,862 .

De 30 à 40 ans: buste supérieur à la moitié de la taille, de 0 à 5 cent., 1 individu; de 5 à 10 cent., 3.

Soit, moyenne du buste 0,898 .

De 40 à 50 ans : buste supérieur à la moitié de la taille, de 5 à 10 cent., 1 individu.

Soit, hauteur du buste 0,903 .

De 50 ans et au-dessus: buste supérieur à la moitié de la taille, de 5 à 10 cent., 1 individu.

Soit, hauteur du buste 0.848 .

En résumé: buste supérieur à la moitié de la taille, de 0 à 5 cent., 6 individus; de 5 à 10 cent., 6 .

Soit, moyenine du buste 0,881 . 
$18^{\circ}$ Au point de vue du pied :

Dans la catégorie de 16 à 20 ans : pied de 24 à 26 cent. , 1 individu ; de 26 à 28 cent., I.

Soit, moyenne du pied $0,26 \%$.

De 20 à 25 ans; pied de 24 à 26 cent., 3 individus, de 28 à 30 cent., 1 .

Soit, moyenne du pied 0,264.

De 30 a 40 ans : pied de 22 à 24 cent., 1 individu ; de 26 à 28 cent., 3.

Soit, moyenne du pied 0,258.

De 40 à 50 ans : pied de 26 à 28 cent., 1 individu.

Soit, longueur du pied 0,262.

De 50 ans et au-dessus : pied de 24 à 26 cent., 1 individu. Soit, longueur du pied 0,240.

En résumé: pied de 22 à 24 cent., 1 individu; de 24 à 26 cent., 5 ; de 26 à 28 cent., 5 ; de 28 à 30 cent., 1.

Soit, moyenne du pied 0,260.

\section{$19^{\circ}$ Au point de vue de la tête :}

1 mésaticéphale, 4 sous-brachycéphales, 7 brachycéphales vrais.

D'autre part, les calculs donnent:

Longueur moyenne de la tête 0,1874 ; largeur moyenne de la tête 0,1559 .

D'où : Indice céphalique 83,19. 
$20^{\circ}$ Au point de vue de l'oreille:

Indice auriculaire: au-dessous de 52, 1 individu; de 52 a 56,2 ; de 56 à 60,5 ; de 60 à 65,3 ; de 65 et au-dessus, 1 .

D'autre part, les calculs donnent :

Longueur moyenne de l'oreille 0,061; largeur moyenne de l'oreille 0,0358.

D'où : Indice auriculaire 58,68 .

$$
\text { ** } *
$$

21. Au point de vue du visage :

Rond 1, large ou carré 1, ovale 8, allongé 1 , en toupie 1.

$22^{\circ} \mathrm{Au}$ point de vue du front:

Arcades : grandes 3 , petites 2 , moyennes $\%$. Inclinaison : verticale 2 , fuyante 2 , intermédiaire 8 . Hauteur : grande 1, petite 2, moyenne 9. Largeur : grande 2 , petite 5 , moyenne 5.

23. Au point de vue du nez:

Cavité (de la racine) : petite 3, moyenne 9 .

Dos : rectiligne 6 , concave 5 , convexe 1 .

Base : horizontale 8 , relevée 4 .

Hauteur : petite 2, moyenne 10 .

Saillie : grande 1, moyenne 11.

Largeur : grande 1, moyenne 11. 
$24^{\circ}$ Au point de vue de la bouche :

Dimension : grande 3 , petite 3 , moyenne 6 .

Inclinaison des angles : rectiligne 8 , à coins abaissés 2 , à coins relevés 2 .

Degré habituel d’ouverture : pincée 1, intermédiaire 11.

25. Au point de vue du menton :

Inclinaison générale: menton saillant 2 , fuyant 2 , droit 8 . Avec et sans houppe: plat 2 , à houppe 1, intermédiaire 9 . Hauteur : haut 2 , bas 4 , intermédiaire 6 .

Forme: large 3 , rond 9 .

$26^{\circ}$ Au point de vue de l'œil :

Iris : pigmenté de jaune 2 , d'orange 3 , de châtain 6 , de marron 1.

$27^{\circ}$ Au point de vue du teint :

Brun 8, mat 2, clair 2.

$28^{\circ}$ Au point de vue de la carrure:

Grande 6, moyenne 5, petite 1 .

$29^{\circ} \mathrm{Au}$ point de vue de la constitution et de l'état général, à l'arrivèe :

Très bons 1, bons 10 , passables 1 . 
$30^{\circ} \mathrm{Au}$ point de vue des maladies et infirmitès à l'arrivẻe :

4 maladies, à répartir entre 3 individus (Français).

Soit : insuffisance valvulaire 1, conjonctivite chronique 1 , imbécillité 1 (obs. 141), déséquilibration mentale 1 .

Le cléséquilibré (Auvergnat, âgé de trente-cinq ans, sachant lire et écrire, journalier, urbain, ayant un domicile, à la $3^{\text {me }}$ peine, adonné à l'ivrognerie, a été condamné, malgré ses dénégations, à 4 ans de prison, par la cour d'assises de l'Ardèche, pour "fabrication et émission de fausse monnaie ".

Taille $1 \mathrm{~m} .67$. Envergure $1 \mathrm{~m}$. 7̈̈. Buste 0,903. Pied gauche 0,26ə̈. Tète : longueur 0,193 ; largeur 0,163 . Indice céphalique 84,61.

Oreille droite : longueur 0,062; largeur 0,037. Indice auriculaire 59,6\%. Forme ovale. Écartement total.

Front: arcades moyennes; inclinaison fuyante; hauteur moyenne; largeur petite.

Nez: cavité (de la racine) petite ; dos concave; base horizontale ; hauteur, saillie et largeur moyennes.

Bouche : movenne, rectiligne ; ouverture intermédiaire.

Uenton : saillant, rond; hauteur intermédiaire.

Visage ovale. Iris pigmenté de chàtain.

Teint mat. Barbe, cheveux et sourcils châtains. Tatoué.

Carrure moyenne. Constitution forte. Large et profonde cicatrice au front, consécutive à une chutè.

C'est un maniaque (fort dangereux) dont la physionomie prend, d'un instant à l'autre, les expressions les plus diverses.

Quartier des vieillards. - Obs. 143.

31. Au point de vue du lieu du crime :

Hors du département du lieu de naissance 12.

Ch. Perrier. 
32. Au point de vue de la date du crime :

1 en janvier, 2 en février, 2 en juin, 1 en octobre, 2 en novembre, 3 en décembre, 1 pendant l'année.

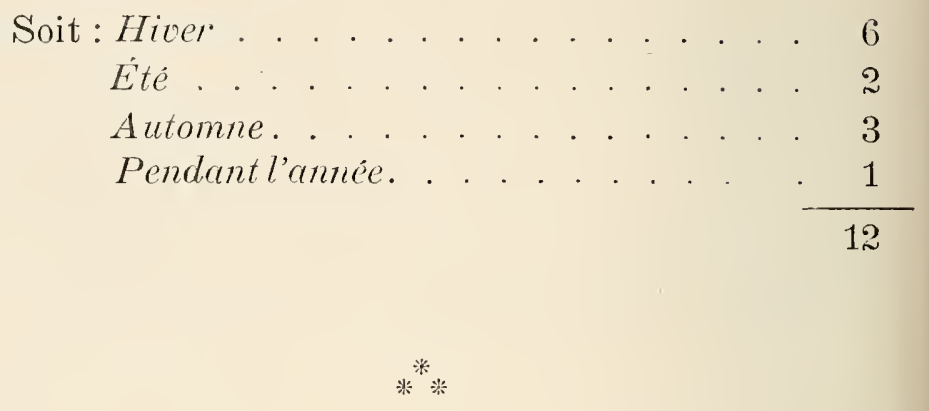

$33^{\circ}$ Au point de vue de la juridiction :

La cour d'assises, voilà leur tribunal criminel.

$34^{\circ}$ Au point de vue de la durée de la peine:

$S$ de ces individus ont été condamnés à 5 ans de prison; $3, \dot{a} 1$ ans; 1 , a. 36 mois.

La peine de 36 mois fut prononcée (y compris 5 ans d'interdiction de séjour et cent francs d'amende) par la cour d'assises des Bouches-du-Rhône, le 18 mai 1894, pour " fabrication de fausse monnaie ", contre un limeur-ajusteur, âgé de vingt et un ans, sachant lire et écrire, récidiviste, né à Nice et domicilié à Marseille, qui servait de guide à un aveugle.

Tailie I m. 63. Envergure $1 \mathrm{~m}$. 66. Buste 0,889. Pied gauche 0,2:58. Tête: Inngueur 0,190 ; largeur 0,130 . Indice céphalique 83,13 . Oreille droite: longueur 0,059 ; largeur 0,033 . Indice auriculaire 59,32 . 
Front: arcades grandes; inclinaison intermédiaire; hauteur et largeur moyennes.

Nez : cavité (de la racine) petite; dos rectiligne; base relevée ; hauteur, largeur et saillie moyennes.

Bouche : petite, rectiligne; ouverture intermédiaire.

Menton : droit, large, plat; hauteur intermédiaire.

Visage en toupie. Iris pigmenté de chàtain.

Teint brun. Barbe, cheveux et sourcils chàtain foncé.

Carrure petite. Constitulion et santé bonnes. Esprit obséquieux.

Il travaille ferme; mais, quelles moeurs ! - Lits en fer. Obs. 144.

$35^{\circ}$ Au point de vue de l'interdiction de séjour :

3 sont frappés d'interdiction de séjour.

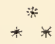

$36^{\circ}$ Au point de vue du travail en prison :

Bons travailleurs 4, passables 5, mauvais 3.

$3^{\circ} \mathrm{Au}$ point de vue de la conduite en prison :

Conduite passable 6 , mauvaise 6.

$$
\text { *** }
$$

38. Au point de vue de l'expulsion :

2 étrangers sur 3. 


\section{XIV}

INCENDIE

$\ddot{3}$ individus

$1^{\circ}$ Au point de vue de la naissance :

4 enfants légitimes, 1 enfant naturel.

$\boldsymbol{2}^{\circ} \mathrm{Au}$ point de vue de la nationalité :

5 Français.

$\mathbf{3}^{\circ} \mathrm{Au}$ point de vue de l'âge :

2 , de 40 à 50 ans; 3 , de 50 ans et plus.

4. Au point de vue de l'ètat civil :

2 célibataires, 2 mariés, 1 veuf.

Ce dernier (Aveyronnais, âgé de quarante-cinq ans, illettré, rural, sans domicile fixe, condamné 2 fois pour tentative d'escroquerie) exerçait la profession de cultivateur.

La cour d'assises de son département lui a infligé 3 ans de prison, par arrêt du 12 décembre 1893, pour " incendie de récoltes en meules $)$. 
A la suite d'un échange de coups, au sujet d'une ancienne dette dont il exigeait le paiement, il avait affirmé, devant plusieurs témoins, qu'il se vengerait.

Or, dans la nuit du 9 au 10 juillet 1893, un incendie dévorait un gerbier appartenant à son débiteur et, au moment où il éclatait, deux personnes apercevaient notre homme sur les lieux du crime.

Le jury a admis les circonstances atténuantes.

Taille $1 \mathrm{~m}$. 588. Envergure $1 \mathrm{~m}$. 620. Buste 0,882. Pied gauche 0, 20̈1. Tète : longueur 0,188 ; largeur 0,152 . Indice céphalique $80,8:$.

Oreille droite : Jongueur 0,060 ; largeur $0,030 ̈$. Indice auriculaire $₫ 8,33$.

Front: arcades grandes; inclinaison intermédiaire; hauteur et largeur moyennes.

Nez: cavité (de la racine) grande; dos rectiligne; base horizontale; saillie grande; largeur et hauteur moyennes.

Bouche : moyenne, bée, rectiligne; lèvre inférieure épaisse.

Henton : fuyant, bas, rond, à houppe.

Visage ovale. Iris pigmenté de jaune. Physionomie banale.

Teint brun. Barbe, cheveux et sourcils chàtain clair.

Carrure moyenne. Santé bonne.

Dėtenu bien noté. - Filoches. - Obs. 145.

\section{$5^{\circ} \mathrm{Au}$ point de vue de l'instruction :}

3 savent lire et écrire; 2 ne possèdent aucune instruction.

\section{$6^{\circ} \mathrm{Au}$ point de vue de la profession :}

1 forgeron, 2 cultivateurs, 1 portefaix, 1 domestique.

Le forgeron (Isérois, âgé de soixante-neuf ans, sachant lire et écrire, rural, sans domicile) vivait dans l'oisiveté et se livrait au libertinage et à la débauche. 
On lui connait 24 condamnations antérieures (dont une, pour incendie).

La peine de 3 ans, qu'il subit, a été prononcée, le 28 novembre 1893, par la cour d'assises du Gard.

Dans la soirée du 9 septembre, il mit volontairement le feu $\dot{a}$ une meule de paille; puis, il alla se constituer prisonnier, $\dot{a}$ la gendarmerie.

Taille $1 \mathrm{~m}$. 73̈. Envergure $1 \mathrm{~m}$. 80. Buste 0,920. Pied ganche 0,268. Tète : longuenr 0,184 ; largeur 0,164 . Indice céphalique 89,13 .

Oreille droite: longneur 0,069 ; largeur 0,042. Indice auriculaire 60,86 .

Front: arcades moỵennes; inclinaison fuyante; hauteur grande; largeur moyenne.

Nez : cavité (de la racine) moyenne; dos concave, aplati ; base horizontale ; largeur grande; hauteur et saillie petites.

Bouche : grande, à coins abaissés; ouverture intermédiaire.

Mentou : fuyant, bas, rond.

Visage ovale. Iris impigmenté. Des yeux éteints.

Teint brun. Barbe et cheveux gris; sourcils chàtains (en brosse). Carrure moyenne. Atrophie du cœur. Presbytie.

Infirmeric. - Obs. 146.

F. Au point de vue de la population :

2 urbains, 3 ruraux.

\section{$8^{\circ}$ Au point de vue du domicile :}

Un seul avait un domicile.

Il est âgé de soixante et un ans, marié, illettré, cultivateur, urbain, récidiviste, et a été condamné, à 2 ans de prison, le 29 avril 1895, par la cour d'assises du Gard, pour avoir mis le feu, le 15 février de la même année, à un édifice lui appartenant, assuré à la Compagnie: "le Soleil ». 
Taille $1 \mathrm{~m}$. 72. Envergure $1 \mathrm{~m}$. 69. Buste 0,910. Pied gauche 0,28ว̈.

Tète : longueur 0,199 ; largeur 0,166 . Indice céphalique 83,11 .

Oreille droite : longueur 0,069 ; largeur 0,039 . Indice auriculaire $56,5 \%$. Forme triangulaire.

Front: arcades moyennes; inclinaison fuyante; hauteur et largeur moyennes.

Yez : cavité (de la racine) moyenne ; dos rectiligne ; base abaissée; largeur grande; saillie et hauteur moyennes.

Bouche: petite, rectiligne; ouverture intermédiaire.

Menton : plat, droit, rond; hauteur intermédiaire.

Visage ovale. Iris pigmenté de jaune. Figure conmune.

Teint brun. Barbe, cheveux et sourcils chàtains.

Carrure grande. Santé bonne. Surdité et presbytie.

Il passe son temps à regarder comment se lève et se couche le soleil. - Quartier des Fieillards. - Obs. 147.

\section{$9^{\circ}$ Au point de vue du nombre des condamnations :}

3, condamnés 2 fois; 1 , 15 fois; le $5^{\mathrm{e}}, 24$ fois.

L'individu 15 fois condamné est nè, à Marseille, le 29 mai 1851, de père inconnu.

Il sait lire et écrire. C'est un portefaix, sans domicile, qui buvait comme un trou.

La cour d'assises de l'Ardèche lui a inflig̉é, le 5 août 1895 , 3 ans de prison, pour avoir incendié, le $2 \%$ mai de la même année, des récoltes en tas ou en meules.

Taille $1 \mathrm{~m}$. ว̈8. Envergure $1 \mathrm{~m}$. 62. Buste 0,883. Pied gauche 0,94. Tète : longueur 0,188 ; largeur $0,13 \%$. Indice céphalique 81,91 . Oreille droite : longuenr 0,058 ; largeur 0,033 . Indice auriculaire 56,89 . Front: arcades moyennes; inclinaison intermédiaire ; hauteur et largeur movennes.

Nez: cavité (de la racine) moyenne; dos rectiligne; base horizontale; largeur grande; hauteur et saillic petites.

Bouche : moyenne, à coins abaissés; ouverture intermédiaire. Menton : bas, pointu, droit. 
Visage en losange. Iris pigmenté d'orange. Regard incertain. Teint brun. Barbe, cheveux et sourcils chàtains; sourcils sinueux. Carrure moyenne. Constitution et état général mauvais. Myopie.

On est satisfait de sa conduite et de son travail. - Ravaudage. - Obs. 148.

$10^{\circ}$ Au point de vue de l'oisiveté :

3 oisifs.

$1^{\circ} \mathrm{Au}$ point de vue de l'ivrognerie :

2 ivrognes.

$12^{\circ} \mathrm{Au}$ point de vue du libertinage et de la débauche 1 libertin et débauché.

$13^{\circ}$ Au point de vue du concubinage : Aucun ménage irrégulier.

$14^{\circ}$ Au point de vue de la note de la commune :

Tous mal notés.

$$
\text { ** }
$$

$15^{\circ} \mathrm{Au}$ point de vue de la taille :

Dans la catégorie de 40 à 50 ans : taille au-dessous de $1 \mathrm{~m} .60$, 2 individus.

Soit, moyenne de la taille $1 \mathrm{~m} .584$. 
De 50 ans et au-dessus : taille au-dessous de $1 \mathrm{~m} .60,1$ individu; de $1 \mathrm{~m}$. 70 et au-dessus, 2.

Soit, moyenne de la taille $1 \mathrm{~m} .676$.

En résumé: taille au-dessous de $1 \mathrm{~m}$. 60, 3 individus; de $1 \mathrm{~m} .70$ et au-dessus, 2 .

Soit, moyenne de la taille $1 \mathrm{~m} .639$.

\section{$16^{\circ}$ Au point de vue de l'envergure :}

Dans la catégorie de 10 à 50 ans : envergure supérieure à la taille, de 0 à 4 cent., 1 individu ; de 4 à 8 cent., 1 .

Soit, moyenne de l'envergure 1.620.

De 50 ans et au-dessus : envergure inférieure à la taille, 2 individus; supérieure à la taille, de 4 à 8 cent., 1 .

Soit, moyenne de l'envergure $1 \mathrm{~m} .676$.

En résumé : envergure inférieure à la taille, 2 individus; supérieure à la taille, de 0 à 4 cent., 1 ; de 4 à 8 cent., 2 .

Soit, moyenne de l'envergure $1 \mathrm{~m} .654$.

\section{$17^{\circ} \mathrm{Au}$ point de vue du buste :}

Dans la catégorie de 40 à 50 ans : buste supérieur à la moitié de la taille, de 5 à 10 cent., 2 individus.

Soit, moyenne du buste 0,882 .

De 50 ans et au-dessus: buste supérieur à la moitié de la taille, de 0 à 5 cent., 2 individus; de 5 à 10 cent., 1 . Soit, moyenne du buste 0,885 . 
En résumé: buste supérieur à la moitié de la taille, de 0 a 5 cent., 2 individus; de 5 à 10 cent., 3 .

Soit, moyenne du buste 0,884 .

18. Au point de vue du pied :

Dans la catérgorie de 40 à 50 ans:pied de 24 à 26 cent., 2 individus.

Soit, moyenne du pied 0,246.

De 50 ans et au-dessus : pied de 24 à 26 cent., 1 individu : de 26 à 28 cent., 1 ; de 28 à 30 cent., 1 .

Soit, movenne du pied $0,26 \%$.

En résumé: pied de 24 à 26 cent., 3 individus; de 26 à 28 cent., 1 ; de 28 à 30 cent., 1.

Soit, moyenne du pied 0,258.

$19^{\circ}$ Au point de vue de la tête:

Sous-brachycéphales 3 , brachycéphales vrais 2.

D'autre part, les calculs donnent :

Longueur moyenne de la tête 0,1884 ; largeur moyenne de la tête 0,1566 .

D'où : Indice céphalique 83,12.

$20^{\circ} \mathrm{Au}$ point de vue de l'oreille:

Indice auriculaire : de 52 à 56, 1 individu; de 56 à 60,3 ; de 60 à 65,1 . 
D'autre part, les calculs donnent :

Longueur moyenne de l'oreille 0,0634; largeur moyenne de l'oreille 0,0366 .

D'où : Indice auriculaire $57, \% 2$.

$$
*^{*} *
$$

$21^{\circ} \mathrm{Au}$ point de vue du visage:

Ovale 3, losange 2.

$22^{\circ} \mathrm{Au}$ point de vue du front:

Arcades: grandes 1 , moyennes 4.

Inclinaison : fuyante 2 , intermédiaire 3 .

Hauteur : grande 1, moyenne 4.

Largeur : moyenne 5.

$23^{\circ}$ Au point de vue du nez:

Cavité (de la racine) : grande 1, petite 1, moyenne 3 .

Dos : rectiligne 4, concave 1.

Base : horizontale 4, abaissée 1.

Hauteur : petite 2, moyenne 3.

Saillie: grande 1, petite 2 , moyenne 2.

Largeur : grande 3 , moyenne 2. 
$24^{\circ} \mathrm{Au}$ point de vue de la bouche :

Dimension : grande 1, petite 1, moyenne 3.

Inclinaison des angles : rectiligne 2 , à coins abaissés 3 .

Degré habituel d'ouverture : bėe 1, intermédiaire 4 .

$25^{\circ} \mathrm{Au}$ point de vue du menton :

Inclinaison générale: droit 3 , fuyant 2.

Avec et sans houppe: plat 2, à houppe 1, intermédiaire 2.

Hauteur: bas 3 , intermédiaire 2 .

Forme: large 1, rond 3, pointu 1.

26. Au point de vue de l'œil:

Iris : impigmenté 1, pigmenté de jaune 3, d'orange 1.

$27^{\circ}$ Au point de vue du teint:

Brun 4, clair 1.

$$
\text { ** }
$$

$28^{\circ} \mathrm{Au}$ point de vue de la carrure:

Grande 1, moyenne 4.

$29^{\circ}$ Au point de vue de la constitution et de l'état gènéral, à l'arrivẻe:

Bons 2, manuais 3. 
$30^{\circ}$ Au point de vue des maladies et infirmités, à l'arrivèe:

6 maladies et infirmités, à répartir entre 4 individus.

Atrophie du cour 1, presbytie 2, myopie 1, surdité 1, imbécillité 1 .

$$
\text { *** }
$$

$31^{\circ}$ Au point de vue du lieu du crime:

Lieu de naissance: 1 individu.

Département du lieu de naissance: $\mathbf{2}$.

Autre département: 2 .

$32^{\circ}$ Au point de vue de la date du crime :

2 en septembre, 1 en février, 1 en mai, 1 en juillet.

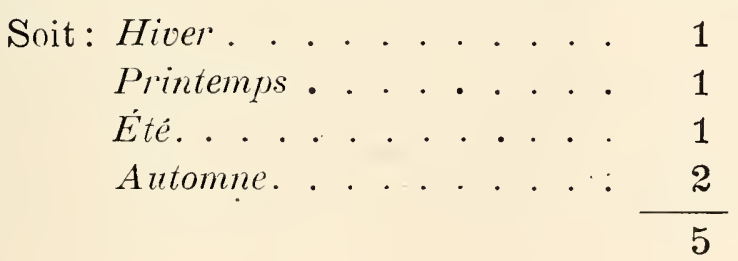

$33^{\circ}$ Au point de vue de la juridiction :

Cour d'assises 5. 
$34^{\circ} \mathrm{Au}$ point de vue de la durée de la peine:

3 subissent une peine de 3 ans; 2 font 2 ans.

Il a été reconnu, le 20 janvier 1896, par-devant la cour d'assises de la Drôme, que les facultés mentales de l'un des condamnés à 2 ans de prison (domestique, né le 27 octobre 1840, marié, sachant lire et écrire, rural, sans domicile fixe, rivant d'expédients et de mendicité, récidiviste, adonné à l'irrognerie), sans être atteintes au point de supprimer la responsabilité, avaient cependant subi l'influence de la vie irrégulière, par lui menée depuis longtemps.

Après avoir mis, volontairement, le feu (29 septembre 1895) a deux meules de paille, il avait donné, pour tout motif de cet acte criminel, l'état d'irritation provoqué chez lui par les aboiements du chien du propriétaire de ces meules.

Taille $1 \mathrm{~m}$. 56. Envergure $1 \mathrm{~m}$. 34. Buste 0,823̈. Pied gauche 0,248. Tète: longueur 0,183 ; largeur 0,148 . Indice céphalique 80,87 :

Oreille droite: longueur 0,061 ; largeur $0,03 \%$. Indice auriculaire ว̈3,73.

Front: arcades moyennes; inclinaison intermédiaire; hauteur et largeur moyennes.

Nez : cavité (de la racine) petite; dos rectiligne; base horizontale; hauteur, largeur et saillie moyennes.

Bouche : moyenne, à coins abaissés; ouverture intermédiaire.

Menton : plat, large, droit; hauteur intermédiaire.

Visage en losange. Iris piģmente de jaune. Regard voilé.

Teint clair. Barbe, cheveux et sourcils châtains.

Carrure moyenne. Constitution et état général mauvais.

Il cause très lentement, avec difficulté, et traine une vie misérable au quartier des vieillards. - Obs. 149.

$35^{\circ} \mathrm{Au}$ point de vue de l'interdiction de sejour:

Néant. 


$$
\text { **** * }
$$

$36^{\circ}$ Au point de vue du travail en prison:

Bon travailleur 1, passable 1, mauvais 3.

37. Au point de vue de la conduite en prison:

Bonne conduite 5 .

$$
\text { *** }
$$

38. Au point de vue de l'expulsion:

Néant. 


\section{$\mathrm{XV}$ \\ FABRICATION DENGINS EXPLOSIFS \\ 1 individu}

Homme noté, âgé de trente-cinq ans, ayant un domicile, libertin, intrépide buveur, né dans une petite commune des Bouches-du-Rhône.

La cour d'Aix l'a condamné, à cinq ans de prison et à 50 francs d'amende, le 12 avril 1894, sur appel d'un jugement rendu (même peine) par le tribunal de Marseille (31 janvier 1894).

Il avait fabriqué et détenu, sans autorisation, des engins meurtriers ou incendiaires, agissant par explosion ou autrement.

Excellent ouvrier mécanicien, bien vu chez les différents patrons qui l'ont occupé, et sans antécédents judiciaires, ce détenu, qui est père de famille et possède une instruction primaire complète, a la ferme résolution de tenir désormais une conduite exempte de tout reproche.

Taille $1 \mathrm{~m}$. 69̋̈. Envergure $1 \mathrm{~m}$. 750. Buste 0.884. Pied gauche 0,265. Tète : longueur 0,185 ; largeur 0,134 . Indice céphalique 83,24 .

Oreille droite: longueur 0,063 ; largeur 0,03 . Indice auriculaire 5 ว̆,ว̆̋̈.

Front: arcades moyennes; inclinaison intermédiaire; hauteur et largeur moyennes. 
Nez : cavité (de la racine) grande; dos concave ; base relevée; hauteur, saillie et largeur moyennes.

Bouche: moyenne, rectiligne, bée.

Menton : bas, droit, rond.

Visage arrondi. Iris pigmenté d'orange. OEil vif et sévère.

Teint brun. Barbe, cheveux et souıcils châtains. Tatoué d'un petit cœur peu apparent.

Carrure moyenne. Santé vigoureuse. Tempérament nervo-sanguin.

Service général. - Obs. 150 . 


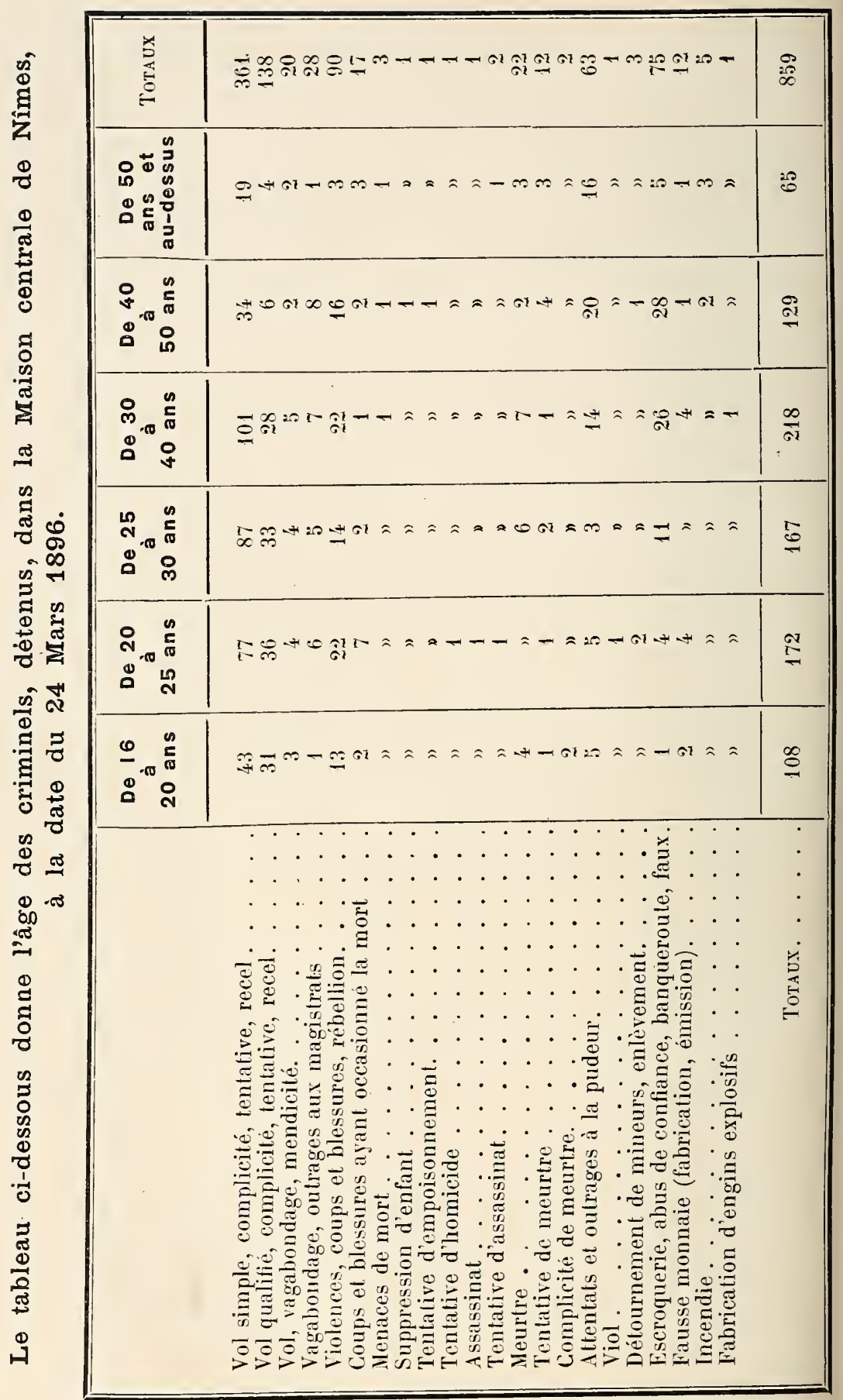




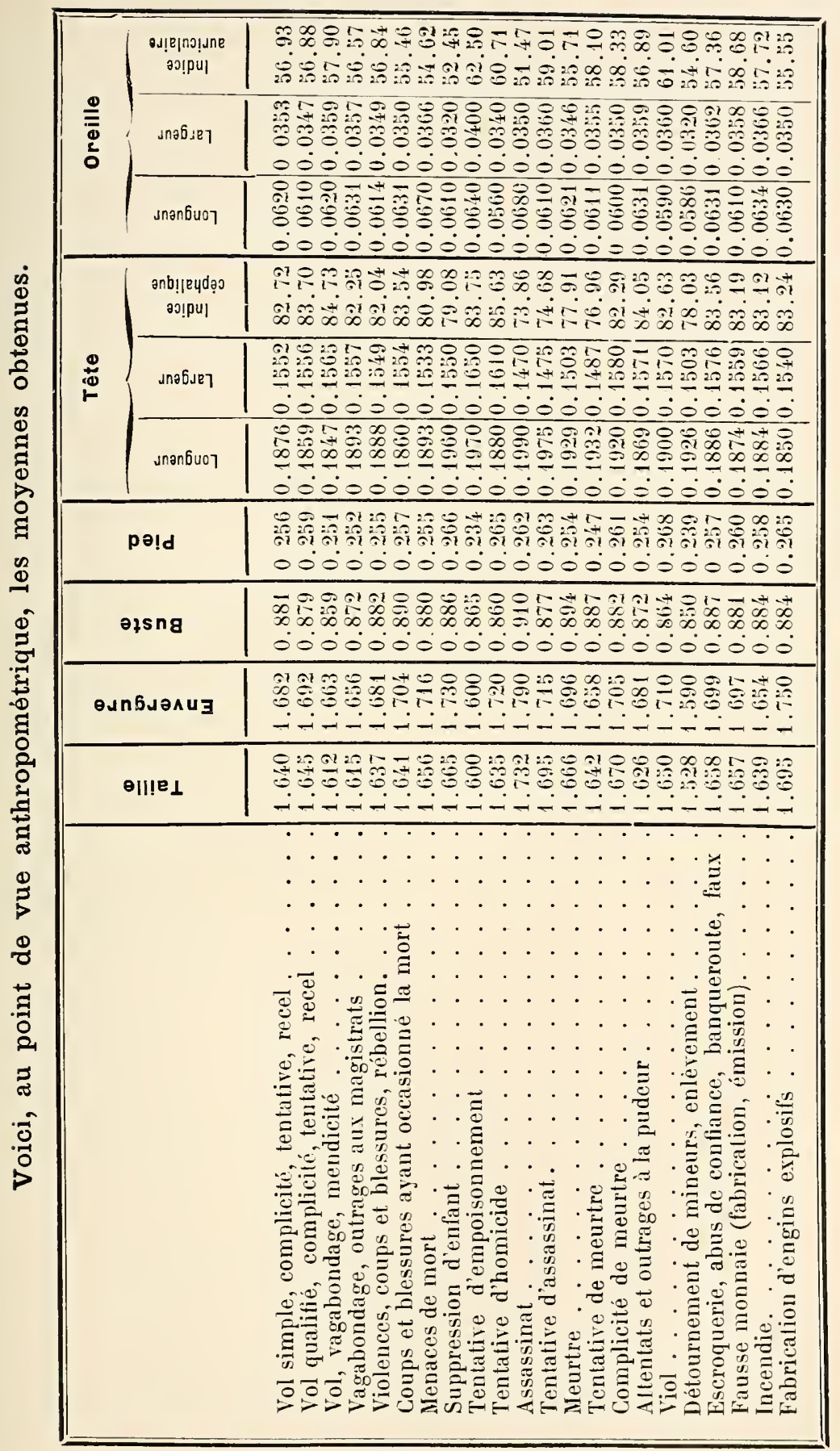





\section{CHAPITRE II}

Si on groupe ces crimes et délits, en 4 catégories, on trouve :

10 Vols, vagabondage, mendicité, outrages aux magistrats, fausse monnaie, incendie, fabrication d'engins explosifs . . . 563̈ soitp.cent $6 \ddot{3.77}$ 2 Escroquerie, abus de confiance, banqueroute, faux, etc. . . . . . 75 - 873 $3^{\circ}$ Attentats contre la vie . . . . . . . . . $152 \quad-\quad 17.79$

40 Attentats contre les mœurs . . . . . . . 67 - 7.70

$$
\text { Total. . . . } \overline{839} \quad \overline{99.99}
$$

L'examen de chacune de ces catégories fournit les indications suivantes:

VOLS - VAGABONDAGE MENDICITÉ - OUTRAGES AUX MAGISTRATS FAUSSE MONNAIE

INCENDIE - FABRIGATION D'ENGINS EXPLOSIFS

10 NAissance :

Enfants lègitimes 541, naturels 21, trouvés 3.

2 ' Nationalité :

Français 409 (dont 35 Corses), Italiens 90, divers 66. 
$3^{\circ} \mathrm{AgE}$ :

De 16 à 20 ans, 80; de 20 à 25 ans, 127 ; de 25 à 30 ans, 129 ; de 30 à 40 ans, 146 ; de 40 a 50 ans, 53 ; de 50 ans et au-dessus, 30.

$4^{n}$ ÉtTat CIVIL :

Célibataires $46 \%$, mariés 85 , veufs 10 , divorcés 3 .

\section{$5^{\circ}$ INSTRUCTION :}

Illettrés 71 , sachant lire 48 , sachant lire et écrire 372 , sachant lire, écrire et calculer 62 , instruction primaire 10 , supérieure 2 .

\section{6o Profession :}

Propriétaire, rentier 1, employés de banque et de commerce 42. commerçants et fabricants 15. professions alimentaires 46 , ouvriers d'ateliers et de fabriques 100 , ouvriers du bâtiment et du mobilier 69, professions agricoles, journaliers, domestiques 223, nomades 33, sans profession 36.

\section{Population:}

Urbains 35\%, ruraux 208.

\section{$8^{\circ}$ DOMICILE :}

Avec domicile 317, sans domicile 248.

9o Nombre des Condamnations :

Sans condamnation antérieure 145, 1 a 5 condamnations 272 , 5 condamnations et plus 148 .

\section{$10^{\circ}$ OisivetÉ :}

Oisifs 439, travailleurs 126. 
11. IVROGNERIE :

Ivrognes 195 , sobres 370 .

\section{Libertinage et DÉbauche :}

Se livrant au libertinage et à la débauche 200, ne se livrant pas au libertinage et à la débauche 365 .

\section{$13^{\circ}$ Concubinage :}

Vivant en concubinage 56, ne vivant pas en concubinage 509.

\section{$14^{\circ}$ Note De la COMMUNe :}

Bien notés 12, mal notés 553.

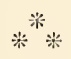

150 TAILLE :

Dans la catégorie de 16 à 20 ans: Taille au-dessous de $1 \mathrm{~m} .60,18$ individus; de $1 \mathrm{~m} .60$ à $1 \mathrm{~m}$. 70, 51; de $1 \mathrm{~m}$. 70 et au-dessus, 11 .

Soit, moyenne de la taille $1 \mathrm{~m} .632$.

De 20 a 25 ans : Taille au-dessous de $1 \mathrm{~m}$. 60, 33 individus; de $1 \mathrm{~m} .60$ à $1 \mathrm{~m} .70,77$; de $1 \mathrm{~m}$. 70 et au-dessus, 17 .

Soit, moyenne de la taille $1 \mathrm{~m} .633$.

De 25 à 30 ans: Taille au-dessous de $1 \mathrm{~m}$. 60, 30 individus ; de $1 \mathrm{~m} .60$ a $1 \mathrm{~m} .70,70$; de $1 \mathrm{~m}$. 70 et au-dessus, 29 .

Soit, moyenne de la taille $1 \mathrm{~m} .644$.

De 30 à 40 ans : T'aille au-dessous de $1 \mathrm{~m}$. 60, 35 individus: de $1 \mathrm{~m} .60$ a $1 \mathrm{~m} .70,82$; de $1 \mathrm{~m}$. 70 et au-dessus, 29 .

Soit, moyenne de la taille $1 \mathrm{~m} .646$. 
De 40 a 50 ans: Taille au-dessous de $1 \mathrm{~m} .60,15$ individus; de $1 \mathrm{~m} .60$ a $1 \mathrm{~m}$. 70, 29; de $1 \mathrm{~m} .70$ et au-dessus, 9 .

Soit, moyenne de la taille $1 \mathrm{~m} .639$.

De 50 ans et au-dessus : Taille au-dessous de $1 \mathrm{~m}$. 60, 9 individus; de $1 \mathrm{~m} .60$ a $1 \mathrm{~m} .70,14$; de $1 \mathrm{~m}$. 70 et au-dessus, 7 .

Soit, moyenne de la taille $1 \mathrm{~m} .642$.

En résumé: Taille au-dessous de $1 \mathrm{~m} .60,140$ individus; de $1 \mathrm{~m} .60$ à $1 \mathrm{~m} .70,323$; de $1 \mathrm{~m}$. 70 et au-dessus, 102 .

Soit, moyenne de la taille $1 \mathrm{~m} .640$.

\section{$16^{\circ}$ Envergure :}

Dans la catégorie de 16 à 20 ans : Envergure inférieure à la taille, de 0 à 8 cent., 10 individus; égale à la taille, 4 ; supérieure à la taille, de 0 à 4 cent., 28 ; de 4 à 8 cent., 22 de 8 à 16 cent., 16 .

Soit, moyenne de l'envergure $1 \mathrm{~m} .671$.

De 20 à 25 ans : Envergure inférieure à la taille, de 0 à 8 cent., 19 individus; égale à la taille, 2 ; supérieure à la taille, de 0 à 4 cent., 43 ; de 4 à 8 cent., 41 ; de 8 à 16 cent. 21 ; infirme 1.

Soit, moyenne de l'envergure $1 \mathrm{~m} .670$.

De 25 à 30 ans: Envergure inférieure à la taille, de 0 à 8 cent., 10 individus; égale à la taille, 3 ; supérieure à la taille, de 0 à 4 cent., 35 ; de 4 à 8 cent., 52 ; de 8 à 16 cent., 29.

Soit, moyenne de l'envergure $1 \mathrm{~m} .692$.

De 30 à 40 ans : Envergure inférieure à la taille, de 0 à 8 cent. 14 individus; égale à la taille, 3 ; supérieure à la taille, de 0 à 4 cent., 39 ; de 4 à 8 cent., 60 ; de 8 à 16 cent., 30 .

Soit, moyenne de l'envergure $1 \mathrm{~m} .692$. 
De 40 à 50 ans : Envergure inférieure à la taille, de 0 à 8 cent., 5 individus; égale à la taille, 2 ; supérieure à la taille, de 0 à 4 cent., 9 ; de 4 à 8 cent., 24 ; de 8 à 16 cent., 13 .

Soit, moyenne de l'envergure $1 \mathrm{~m} .690$.

De 50 ans et au-dessus : Envergure inférieure à la taille, de 0 à 8 cent., 5 individus; égale à la taille, 2 ; supérieure á la taille, de 0 à 4 cent., 9 ; de 4 à 8 cent., 8 ; de 8 à 16 cent., 6 .

Soit, moyenne de l'envergure 1,674 .

En résumé: Envergure inférieure à la taille, de 0 à 8 cent,, 63 individus; égale à la taille, 16 ; supérieure à la taille, de 0 à 4 cent., 163 ; de 4 à $S$ cent., 207 ; de $S$ à 16 cent., 115 ; infirme 1.

Soit, moyenne de l'envergure $1 \mathrm{~m} .683$.

\section{$17^{\circ}$ Buste:}

Dans la catégorie de 16 à 20 ans: buste supérieur à la moitié de la taille, de 0 à 5 cent., 22 ; de 5 à 10 cent., 55 ; de 10 à 18 cent., 3.

Soit, moyenne du buste 0,877 .

De 20 à 25 ans : Buste supérieur à la moitiè de la taille, de 0 à 5 cent., 36 individus; de 5 à 10 cent., 85; de 10 à 18 cent., 6 .

Soit, moyenne du buste 0.878 .

De 25 à 30 ans: Buste inférieur à la moitié de la taille, 1 individu; supérieur à la moitié de la taille, de 0 à 5 cent., 41 ; de 5 à 10 cent., s0; de 10 à 18 cent., 7 .

Soit, moyenne du buste 0,880 .

De 30 à 40 ans: Buste inférieur à la moitié de la taille, 1 indivirlu; supérieur à la moitié de la taille, de 0 a 5 cent., 41 ; de 5 à 10 cent., 96 ; de 10 à 18 cent., 8 .

Soit; moyenne du buste 0,883 . 
De 40 à 50 ans : Buste inférieur à la moitié de la taille, 1 individu; supérieur à la moitié de la taille, de 0 à 5 cent., 11 ; de 5 à 10 cent., 40 ; de 10 à 18 cent., 1 .

Soit, moyenne du buste 0,881 .

De 50 ans et au-dessus : Buste égal à la moitié de la taille, 1 individu; supérieur à la moitié de la taille, de 0 à 5 cent., 12 ; de 5 à 10 cent., 16 ; de 10 à 18 cent., 1 .

Soit, moyenne du buste 0,873 .

En résumé : Buste inférieur à la moitié de la taille, 3 individus; égal à la moitié de la taille, 1 ; supérieur à la moitié de la taille, de 0 à 5 cent., 163 ; de 5 à 10 cent, 372 ; de 10 à 18 cent., 26.

Soit, moyenne du buste 0,880 .

\section{PIED :}

Dans la catégorie de 16 à 20 ans : Pied de 22 a 24 cent., 3; de 24 à 26 cent., 45 ; de 26 à 28 cent., 29 ; de 28 à 30 cent., 3 .

Soit, moyenne du pied 0,257.

De 20 à 25 ans : Pied de 22 à 24 cent., 7 individus; de 24 à 26 cent., 79 ; de 26 à 28 cent., 38 ; de 28 à 30 cent., 3.

Soit, moyenne du pied 0,255.

De 25 à 30 ans : Pied de 22 à 24 cent., 16 individus; de 24 à 26 cent., 63 ; de 26 à 28 cent., 46 ; de 28 à 30 cent., 4 .

Soit, moyenne du pied 0,256.

De 30 à 40 ans: Pied de 22 à 24 cent., 10 individus; de 24 à 26 cent., 67 ; de 26 à 28 cent., 67 ; de 28 à 30 cent., 2.

Soit, moyenne du pied 0,25\%. 
De 40 à 50 ans : Pied de 22 à 24 cent., 7 individus; de 24 à 26 cent., 25 ; de 26 à 28 cent., 21 .

Soit, moyenne du pied 0,255.

De 50 ans et au-dessus : Pied de 22 à 24 cent., 1 individu; de 24 à 26 cent., 15 ; de 26 à 28 cent., 13 ; de 28 à 30 cent., 1 . Soit, moyenne du pied $0,25 \%$.

En résumé: Pied de 22 à 24 cent., 44 individus; de 24 à 26 cent., 294 ; de 26 à 28 cent., 214 ; de 28 à 30 cent., 13. Soit, moyenne du pied 0,256.

\section{$19^{\circ}$ TÊTE :}

16 dolichocéphales vrais, 41 sous-dolichocéphales, 86 mésaticéphales, 156 sous-brachycéphales, 266 brachycéphales vrais.

D'autre part, les calculs donnent :

Longueur moyenne de la tète 0,1872 ; largeur moyenne de la tête 0,1554 .

D'où : Indice céphalique 83,01.

\section{$20^{\circ}$ Oreille :}

Indice auriculaire : au-dessous de 52,50 individus; de 52 a 56,171 ; de 56 à 60,201 ; de 60 à 65,127 ; de 65 et audessus, 16.

D'autre part, les calculs donnent :

Longueur moyenne de l'oreille 0,0618; largeur moyenne de l'oreille 0,0352.

D’oú : Indice auriculaire 56,95. 


$$
\text { **** }
$$

\section{$21^{\circ}$ VISAge :}

En tronc de pyramide, 6 ; en losange, 36 ; rond, 53 ; large ou carré, 70 ; ovale, 376 ; allongé, 16 ; en toupie, 8.

\section{FRONT :}

Arcades grandes, 104 ; petites, 57; moyemmes, 404.

Inclinaison verticale, 80 ; fuyante, 115; intermédiaire, 370. Hauteur grande, 64 ; petite, 51 ; moyenne, 450.

Largeur grande, 52 ; petite, 90 ; moyenne, 423.

\section{$23^{\circ} \mathrm{NEZ}$ :}

Cavité (de la racine) grande, 41 ; petite, 149 ; movenne, 375 Dos rectiligne, 349 ; convexe, 92 ; concave, 124.

Base horizontale, 355; relevée, 178 ; abaissée, 32. Hauteur grande, 63 ; petite, 52 ; moyenne, 450. Saillie grande, 70 ; petite, 39 ; moyenne, 456. Largeur grande, 70 ; petite, 16 ; moyenne, 479.

\section{Bouche:}

Grande, 67 ; petite, 69 ; moyenne, 429.

Rectiligne, 396 ; à coins abaissés, 75 ; à coins relevés, 94 Bée, 70 ; pincée, 67 ; ouverture intermédiaire, 428.

\section{Menton :}

Saillant, 95 ; droit, 382 ; fuyant, 88.

Plat, 91 ; à houppe, 79 ; intermédiaire, 395.

Bas, 162 ; haut, 93 ; intermédiaire, 310.

Large, 106 ; rond, 419 ; pointu, 40. 


\section{6 $6^{\circ}$ GiL :}

Iris impigmenté, 52 ; pigmenté de jaune, 128 ; d'orange, 242 ; de châtain, 98 ; de marron, 44 ; aveugle, 1.

\section{$27^{\circ}$ TEINT :}

Brun, 383; mat, 16 ; basané, 2 ; mulâtre, 1 ; clair, 144 ; blond, 17 ; pâle, 2.

\section{$28^{\circ}$ CARrure :}

Grande, 108 ; petite, 32 ; moyenne, 425.

29 Constitution et état GÉnéral, a l'Arrivée :

Très bons, 53 ; bons, 340 ; passables, 95 ; mauvais, 70 ; très mauvais, $\%$.

\section{INFIRMES ET MALADES, A L'ARRIVÉE:}

Infirmes et malades, à l'arrivée, $16 \%$; valides, sans infirmité ni maladie, 398 .

$$
\text { *** * }
$$

$31^{\circ}$ LIEU DU CRIME :

Lieu de naissance, 104 ; département du lieu de naissance, 99 ; autre département, 362. 
$32^{\circ}$ DATE DU CRIME :

Hiver (décembre, 54 ; janvier, 53; février, 52) 159 ; printemps (mars, 36 ; avril, 49 ; mai, 47) 132; été (juin, 38 ; juillet. 39 ; août, 37) 114 ; automne (septembre, 45 ; octobre, 49 ; novembre, 44) 138 ; pendant l'année, 22.

$$
\text { *** }
$$

$33^{\circ}$ JURIDICTION :

Cour d'assises, 208 ; tribunaux, 353 ; conseil de guerre, 2 ; tribunal supérieur de Monaco, 2.

34 DuRÉE DE LA PEINE:

1 an 1 jour. $44: 1$ an 1 jour à 5 ans, $397 ; 5$ ans et plus, 124 .

$35^{\circ}$ INTERDICTION DE SÉJOUR :

Frappés d'interdiction, 95; non frappés d'interdiction, 470.

$$
\text { *** }
$$

$36^{\circ}$ Travail en PRISON :

Bons travailleurs, 325 ; passables, 147 ; mauvais, 93.

$37^{\circ}$ Conduite EN PRISON :

Bonne conduite, 225 ; passable, 178 ; mauvaise, 162.

$$
\text { **** }
$$

$38^{\circ}$ Expulsion :

Étrangers expulsés, 132; non expulsés, 24. 
ESCROQUERIE - ABUS DE CONFIANCE - BANQUEROUTE - FAUX, etc.

(Voir page 2/8)

\section{III}

ATTENTATS CONTRE LA VIE

\section{$1^{\circ}$ Naissance :}

Enfants légitimes 143, naturels 9 .

\section{$2^{\circ}$ Nationalité :}

Français 124 (dont 60 Corses), Italiens 26, divers 2 .

\section{$3^{\circ}$ Age :}

De 16 à 20 ans, 22 ; de 20 à 2.5 ans, 33 ; de 25 à 30 ans, 24; de 30 à 10 ans, 32 ; de 40 à 50 ans, 27 ; de 50 ans et audessus, 14. 


\section{0 État Civil :}

Célibataires 103, mariés 38, veufs 10 , divorcés 1 .

\section{$5^{0}$ Instruction :}

Illettrés 32, sachant lire 15, sachant lire et écrire 92 , sachant lire, écrire et calculer 11 , instruction primaire complète 2.

\section{$6^{\circ}$ Profession :}

Propriétaires, rentiers 4, employés de banque et de commerce 4 , commercants et fabricants 3 , professions alimentaires 8 , ouvriers d'ateliers et de fabriques 26 , ouvriers du bâtiment et du mobilier 16, professions agricoles, journaliers, domestiques 85 , nomades 4 , sans profession 2.

\section{Population :}

Urbains 64 , ruraux 88 .

\section{Domicile :}

Avec domicile 135, sans domicile 17.

\section{Nombre des condamnations :}

Sans condamnation antérieure 65,1 à 5 condamnations 67 , 5 condamnations et au-dessus 20 .

$10^{\circ}$ Oisiveté :

Oisifs 54, travailleurs 98.

$11^{\circ}$ Ivrognerie :

Ivrognes 84 , sobres 68 . 


\section{Libertinage ET DÉBauche :}

Se livrant au libertinage et à la débauche 38 , ne se livrant pas au libertinage et à la débauche 114 .

\section{$13^{\circ}$ Concubinage :}

Vivant en concubinage 13, ne vivant pas en concubinage 139.

$14^{\circ}$ Note de la comaune:

Bien notés 18, mal notés 134 .

$$
*^{*} *
$$

$15^{\circ}$ TAille :

Dans la catégorie de 16 à 20 ans: Taille au-dessous de $1 \mathrm{~m} .60,6$ individus ; de $1 \mathrm{~m} .60$ i $1 \mathrm{~m}$. 70, 13 ; de $1 \mathrm{~m}$. 70 et au-dessus, 3.

Soit, moyenne de la taille 1,631 .

De 20 at 25 ans : Taille au-dessous de $1 \mathrm{~m} .60,6$ individus: de $1 \mathrm{~m} .60$ à $1 \mathrm{~m}$. 70, 22: de $1 \mathrm{~m}$. 70 et au-dessus, 5 .

Soit, moyenne de la taille 1,648.

De 25 it 30 ans: Taille au-dessous de $1 \mathrm{~m}$. 60, 2 individus; de $1 \mathrm{~m} .60$ a $1 \mathrm{~m} .70,16$; de $1 \mathrm{~m}$. 70 et au-dessus, 6 .

Soit, moyenne de la taille 1,661 .

De 30 à 40 ans: Taille au-dessous de $1 \mathrm{~m} .60,6$ individus: de $1 \mathrm{~m} .60$ a $1 \mathrm{~m}$. 70 , 21; de $1 \mathrm{~m}$. 70 et au-dessus, 5 .

Soit, moyenne de la taille 1,645 . 
De 40 à 50 ans : Taille au-dessous de $1 \mathrm{~m} .60,10$ individus; de $1 \mathrm{~m} .60$ à $1 \mathrm{~m} .70,13$; de $1 \mathrm{~m}$. $\% 0$ et au-dessus, 4 .

Soit, moyenne de la taille 1,628 .

De 50 ans et au-dessus : Taille au-dessous de $1 \mathrm{~m} .60,2$ individus; de $1 \mathrm{~m} .60$ à $1 \mathrm{~m}$. 70, 9 ; de $1 \mathrm{~m}$. 70 et au-dessus, 3 . Soit, moyenne de la taille 1,655 .

En résumé : Taille au-dessous de $1 \mathrm{~m} .60,32$ individus; de $1 \mathrm{~m} .60$ à $1 \mathrm{~m}$. 70, 94 ; de $1 \mathrm{~m}$. 70 et au-dessus, 26 .

Soit, moyenne de la taille 1,644.

\section{$16^{\circ}$ Envergure :}

Dans la catégorie de 16 à 20 ans : Envergure inférieure à la taille, de 0 à 8 cent., 4 individus; supérieure à la taille, de 0 à 4 cent., 5 ; de 4 à 8 cent., 6 ; de 8 à 16 cent., $\%$.

Soit, moyenne de l'envergure 1,672.

De 20 à 25 ans : Envergure inférieure à la taille, de 0 à 8 cent., 2 individus; supérieure à la taille, de 0 à 4 cent., 8 ; de 4 à 8 cent., 13 ; de $S$ à 16 cent., 10.

Soit, moyenne de l'envergure 1,699.

De 25 à 30 ans: Envergure inférieure à la taille, de 0 à 8 cent., 5 individus; égale à la taille, 2 ; supérieure à la taille, de 0 à 4 cent., 4 ; de 4 à $S$ cent., 9 ; de $S$ à 16 cent., 4 .

Soit, moyenne de l'envergure 1,703.

De 30 à 40 ans : Envergure inférieure à la taille, de $0 \grave{a}$ 8 cent., 1 individu; égale à la taille, 1 ; supérieure à la taille, de 0 à 4 cent., 15 ; de 4 à $S$ cent., 10 ; de $S$ à 16 cent., 4 ; infirme, 1.

Soit, moyenne de l'envergure 1,679. 
De 40 à 50 ans : Envergure inférieure à la taille, de 0 à $S$ cent., 3 individus; égale à la taille, 1 ; supérieure à la taille, de 0 à 4 cent., 7 ; de 4 à $S$ cent., 15 ; de $S$ à 16,1 .

Soit, moyenne de l'envergure 1,666.

De 50 ans et au-dessus : Envergure inférieure à la taille, de 0 à 8 cent., 3 individus; égale à la taille, 1 ; supérieure à la taille, de 0 à 4 cent.. 2 ; de 4 à 8 cent., 4 : de 8 à 16 cent., 4 .

Soit, moyenne de l'envergure 1,704.

En résumé: Envergure inférieure à la taille, de 0 à $S$ cent., 18 individus; égale à la taille, 5 ; supérieure à la taille, de 0 à 4 cent., 41 ; de 4 à 8 cent., $5 \%$; de 8 à 16 cent., 30 ; infirme, 1.

Soit, moyenne de l'envergure 1,686.

\section{$1 \%$ Buste:}

Dans la catégorie de 16 à 20 ans: Buste supérieur à la moitié de la taille, de 0 à 5 cent., 8 individus; de 5 à 10 cent., 12 ; de 10 à 18 cent., 2.

Soit, moyenne du buste 0,879 .

De 20 à 25 ans: Buste supérieur à la moitié de la taille, de 0 à 5 cent., 6 individus; de 5 à 10 cent., 26 ; de 10 à 18 cent., 1.

Soit, moyenne du buste 0,892.

De 25 à 30 ans : Buste supérieur à la moitié de la taille, de 0 à 5 cent., 7 individus; de 5 à 10 cent., 16 ; de 10 à 18 cent., 1.

Soit, moyenne du buste 0,891 
De 30 à 40 ans: Buste inférieur à la moitié de la taille, 1 individu : supérieur à la moitié de la taille, de 0 à 5 cent., 3 ; de 5 à 10 cent., 27 ; de 10 à 18 cent., 1 .

Soit, moyenne du buste 0,887 .

De 40 à 50 ans: Buste supérieur à la moitié de la taille, de 0 à 5 cent., 5 individus; de 5 à 10 cent., 21 ; de 10 à 18 cent, 1 .

Soit, moyenne du buste 0,880 .

De 50 ans et au-dessus: Buste égal à la moitié de la taille, 1 individu; supérieur à la moitié de la taille, de 0 à 5 cent., 5 ; de 5 à 10 cent., 7 ; de 10 à 18 cent., 1 .

Soit, moyenne du buste 0,874 .

En résumé: Buste inférieur à la moitié de la taille, 1 individu; égal à la moitié de la taille, 1 ; supérieur à la moitié de la taille, de 0 à 5 cent., 34 ; de 5 à 10 cent., 109; de 10 à 18 cent., $\%$

Soit, moyenne du buste 0,885 .

18. Pied :

Dans la catégorie de 16 à 20 ans: Pied de 22 à 24 cent., 2 individus ; de 24 à 26 cent., 12 ; de 26 à 28 cent., 7 ; de 28 à 30 cent., 1.

Soit, moyenne du pied 0,254.

De 20 à 25 ans: Pied de 22 à 24 cent., 1 ; de 24 à 26 cent., 16; de 26 à 28 cent., 15 ; de 28 à 30 cent., 1.

Soit, moyenne du pied 0,258.

De 25 a 30 ans: Pied de 22 à 24 cent., 1 individu ; de 24 à 26 , 14: de 26 à 28 cent., 8 ; de 28 à 30 cent., 1 .

Soit, moyenne du pied 0,258. 
De 30 à 40 ans: Pied de 22 à 24 cent., 5 individus; de 24 à 26 cent., 18 ; de 26 à 28 cent., 8 ; de 28 à 30 cent., 1 .

Soit, moyenne du pied 0,252.

De 40 a 50 ans: Pied de 22 à 24 cent., 3 individus; de 24 à 26 cent., 19 ; de 26 à 28 cent., 4 ; de 28 a 30 cent., 1 .

Soit, moyenne du pied 0,253.

De 50 ans et au-dessus: Pied de 24 i 26 cent., 8 individus; de 26 à 28 cent., 6 .

Soit, moyenne du pied 0,255.

En réstumé: Pied de 22 à 24 cent., 12 individus; de 24 a 26 cent., 87 ; de 26 à 28 cent., 48 ; de 28 à 30 cent., 5 .

Soit, movenne du pied 0,255.

\section{9॰ TÈTE :}

19 dolichocéphales vrais, 23 sous-dolichocéphales, 25 mésaticéphales, 27 sous-brachycéphales, 58 brachycéphales vrais.

D'autre part, les calculs donment :

Longueur moyenne de la tête 0,1897 ; largeur moyenne de la tête 0,1538 .

D'où : Indice céphalique $81,0 \%$.

\section{$20^{\circ}$ Oreille :}

Indice auriculaire : au-dessous de 52,12 individus; de 52 i 56,53 ; de 56 à 60,53 ; de 60 à 65,33 ; de 65 et audessus, 1. 
D'autre part, les calculs donnent:

Longueur moyenne de l'oreille 0,0618; largeur moyenne de l'oreille 0,0350 .

D'où : Indice auriculaire 56,63.

$$
\text { *** }
$$

$21^{\circ}$ VISAGE :

En tronc de pyramide, 1; en losange, 16 ; rond, 13 ; large ou carré, 15 ; ovale, 98 ; allongé, 7 ; en toupie, 2.

\section{$22^{\circ}$ Front:}

Arcades grandes, 29; petites, 13; moyennes, 110.

Inclinaison verticale, 25; fuyante, 26 ; intermédiaire, 101 Hauteur grande, 19; petite, 10 ; moyenne, 123.

Largeur grande, 15; petite, 28; moyenne, 109.

\section{$23^{\circ} \mathrm{NEZ}$ :}

Cavité (de la racine) grande, 15 ; petite, 50 ; moyenne, 87. Dos rectiligne, 100 ; convexe, 25 ; concave, 27.

Base horizontale, 103 ; relevée, 38 ; abaissée, 11. Hauteur grande, 14 ; petite, 12 ; moyenne, 126.

Saillie grande, 19 ; petite, 16 ; moyenne, 117.

Largeur grande, 21 ; petite, 5 ; moyenne, 126.

\section{$24^{\circ}$ BOUCHE :}

Grande, 19 ; petite, 17 ; moyenne, 116.

Rectiligne, 97 ; à coins abaissés, 30 ; à coins relevés, 25.

Bée, 13; pincée, 15 ; ouverture intermédiaire, 124. 


\section{Menton :}

Saillant, 28 ; droit, 93 ; fuyant, 31.

Plat, 28 ; à houppe, 21 ; intermédiaire 103.

Bas, 32 ; haut, 33 ; intermédiaire, 87.

Large, 30; rond, 113; pointu, 9.

26. CEIL:

Iris impigmenté, 10 ; pigmenté de jaune, 33; d'orange, 75 ; de châtain, 28 ; de marron, 6.

\section{2\% Teint :}

Brun, 110; mat, 2; clair, 35 ; blond, 3 ; pâle, 2.

$$
\text { *** }
$$

28. CARrure :

Grande, 24 ; moyenne, 124 ; petite, 4.

29 Constitution ET ÉtAT GÉNÉRAL, A L'ARrivéE :

Très bons, 25; bons, 83 ; passables, 22; mauvais, 21; très mauvais, 1.

30' INFIRMES ET MALAdES, A L'ARRIVÉE :

Infirmes et malades, à l'arrivée, 46 ; valides, sans infirmité ni maladie, 106. 
$31^{\circ}$ LIEU DU CRINE :

Licu de naissance, 75 ; département du lieu de naissance, 27 ; autre département, 50 .

\section{DATE DU CRIME:}

Hiver (décembre 10, janvier 5, février 5) 20 ; printemps (mars 12, avril 13, mai 11) 36; été (juin 19, juillet 16 , août 23) 58 ; automne (septembre 11 , octobre 15, novembre 9$) 35$; pendant l'année, 3.

$$
\text { *** }
$$

33॰ JURIDICTION :

Cour d'assises, 81 : tribunaux, 70 ; conseil de guerre, 1.

$34^{\circ}$ DuRÉE DE LA PEINE :

1 an et un jour, 11 ; de 1 an et un jour a 5 ans, 94 ; 5 ans et plus, 47.

35º INTERDICTION DE SÉJOUR :

Frappés d'interdiction, 35; non frappés d'interdiction, 117. 


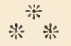

36 ${ }^{\circ}$ TRAVAIL, EN PRISON :

Bons travailleurs, 89 ; passables, 38 ; mauvais, 25.

3\% CONDUITE, EN PRISON :

Bonne conduite, 86 ; passable, 32 ; mauvaise, 34

$$
\text { *** }
$$

\section{Expulsion :}

Étrangers expulsés, 24 ; non expulsés, 4. 


\section{IV \\ ATTENTATS CONTRE LES MOEURS}

\section{NAissance :}

Enfants légitimes, 63 ; enfants naturels, 4.

$2^{\circ}$ NAtionalité :

Français, 56 (dont 6 Corses); Italiens, 9; divers, 2.

\section{$3^{\circ} \mathrm{AgE}$ :}

De 16 à 20 ans, 5 ; de 20 à 25 ans, 8 ; de 25 à 30 ans, 3 ; de 30 à 40 ans, 14 ; de 40 à 50 ans, 21 ; de 50 ans et au-dessus, 16.

\section{$4^{\circ}$ Etat-civil :}

Célibataires, 39 ; mariés, 17; veufs, 10 ; divorcé, 1.

\section{$5^{\circ}$ INSTRUCTION :}

Illettrés, 20; sachant lire, 8; sachant lire et écrire, 32; sachant lire, écrire et calculer, 5 ; instruction primaire, 2. 


\section{$6^{\circ}$ Profession :}

Propriétaires, rentiers, 2 ; employés de banque et de commerce, 3 ; commercants et fabricants, 2; professions alimentaires, 3 ; ouvriers d'ateliers et de fabriques, 16 ; ouvriers du bâtiment et du mobilier, 3 ; professions agricoles, journaliers, domestiques, 33 ; nomades, 1 ; sans profession, 4.

\section{Population:}

Urbains, 30 ; ruraux, 37 .

S॰ Donitile :

Avec domicile, 61 ; sans domicile, 6 .

9. Nombre des CONDAMNATIONS:

Sans condamnation antérieure, 28 ; de 1 à 5 condamnations, $33 ; 5$ condamnations et plus, 6 .

$10^{\circ}$ OISIVETÉ :

Oisifs, 23; travailleurs, 44.

\section{$11^{\circ}$ IVRognerie •}

Ivrognes, 36 ; sobres, 31.

\section{Libertinage et débauche:}

Se livrant au libertinage et à la débauche, 40 ; ne se livrant pas au libertinage et à la débauche, 27.

\section{$13^{\circ}$ Concubinage :}

Vivant en concubinage, 11; ne vivant pas en concubinage, 56.

$14^{\circ}$ Note de la commune:

Bien notés, 4 ; mal notés, 63 . 


$$
\text { ** } *
$$

15. Taille :

Dans la catégorie de 16 à 20 ans: Taille au-dessous de $1 \mathrm{~m} .60,1$ individu; de $1 \mathrm{~m} .60$ à $1 \mathrm{~m}$. 70, 3; de $1 \mathrm{~m} .70$ et au-dessus, 1.

Soit, movenne de la taille 1.632 .

De 20 i 25 ans: Taille au-dessous de $1 \mathrm{~m} .60,3$ individus ; de $1 \mathrm{~m}$. 60 à $1 \mathrm{~m}$. 70, 5 .

Soit, moyenne de la taille 1,594.

De 25 a 30 ans : Taille au-dessous de $1 \mathrm{~m} .60,2$ individus ; de $1 \mathrm{~m} .60$ à $1 \mathrm{~m} .70,1$.

Soit, moyenne de la taille 1,604.

De 30 à 40 ans : Taille au-dessous de $1 \mathrm{~m} .60,2$ individus; de $1 \mathrm{~m}$. 60 à $1 \mathrm{~m}$. 70, 10; de $1 \mathrm{~m}$. 70 et au-dessus, 2 .

Soit, moyenne de la taille 1,645.

De 40 à 50 ans : Taille au-dessous de $1 \mathrm{~m} .60,6$ individus; de $1 \mathrm{~m} .60$ à $1 \mathrm{~m}$. 70, 14 ; de $1 \mathrm{~m}$. 70 et au-dessus, 1 .

Soit, moyenne de la taille 1,634 .

De 50 ans et au-dessus: Taille au-dessous de $1 \mathrm{~m} .60,8$ individus; de $1 \mathrm{~m} .60$ à $1 \mathrm{~m} .70$, 7; de $1 \mathrm{~m}$. 70 et au-dessus, 1 . Soit, moyenne de la taille 1,600 .

En résumé: Taille au-dessous de $1 \mathrm{~m}$. 60, 22 individus; de $1 \mathrm{~m}, 60$ à $1 \mathrm{~m}$. 70, 40 ; de $1 \mathrm{~m} .70$ et au-dessus, 5 .

Soit, moyenne de la taille 1,622. 


\section{$16^{\circ}$ Envergure :}

Dans la catégorie de 16 à 20 ans: Envergure supérieure à la taille, de 0 à 4 cent., 1 individu; de 4 à 8 cent., 4 .

Soit, moyenne de l'envergure 1,682.

De 20 à 25 ans: Envergure inférieure à la taille, de 0 à 8 cent., 1 individu; supérieure à la taille, de 0 à 4 cent., 1 ; de 4 à 8 cent., 4 ; de 8 à 16 cent., 2 .

Soit, moyenne de l'envergure 1,647.

De 25 à 30 ans: Envergure supérieure à la taille, de 0 à 4 cent., 2 individus; de 8 à 16 cent., 1.

Soit, moyenne de l'envergure 1,660.

De 30 à 40 ans: Envergure inférieure à la taille, de 0 à 8 cent., 2 individus; égale à la taille, 1 ; supérieure à la taille, de 0 à 4 cent., 2 ; de 4 à 8 cent., 7 ; de 8 à 16 cent., 2 .

Soit, moyenne de l'envergure 1,686.

De 40 à 50 ans : Envergure égale à la taille, 1 individu ; supérieure à la taille, de 0 à 4 cent., 1 ; de 4 à 8 cent., 10 ; de 8 à 16 cent., 9 .

Soit, moyenne de l'envergure 1,701.

De 50 ans et au-dessus: Envergure inférieure à la taille, de 0 à 8 cent., 1 individu; égale à la taille, 1 ; supérieure à la taille, de 0 à 4 cent., 4 ; de 4 à 8 cent., 5 ; de 8 à 16 cent., 4 ; infirme, 1.

Soit, moyenne de l'envergure 1,655.

En résumé: Envergure inférieure à la taille, de 0 à 8 cent., 4 individus; égale à la taille, 3 ; supérieure à la taille, de 0 à 4 cent., 11 ; de 4 à 8 cent., 30 ; de 8 à 16 cent., 18 ; infirme, 1.

Soit, moyenne de l'envergure $1,67 \%$. 


\section{$17^{\circ}$ Buste :}

Dans la catégorie de 16 à 20 ans : Buste supérieur à la moitié de la taille, de 0 à 5 cent., 1 individu; de 5 à 10 cent., 4 .

Soit, moyenne du buste 0,879 .

De 20 à 25 ans: Buste supérieur à la moitié de la taille, de 0 à 5 cent., 1 individu; de 5 à 10 cent., 5; de 10 à 18 cent., 2 .

Soit, moyenne du buste 0,875 .

De 25 à 30 ans: Buste supérieur à la moitié de la taille, de 0 à 5 cent., 1 individu ; de 5 à 10 cent., 2 .

Soit, moyenne du buste 0,864 .

De 30 à 40 ans: Buste supérieur à la moitié de la taille, de 0 à 5 cent., 3 individus; de 5 à 10 cent., 11 .

Soit, moyenne du buste 0,887 .

De 40 à 50 ans: Buste supérieur à la moitié de la taille, de 0 à 5 cent., 6 individus; de 5 à 10 cent., 14 ; de 10 à 18 cent., 1 .

Soit, moyenne du buste 0,875 .

De 50 ans et au-dessus: Buste inférieur à la moitié de la taille, 1 individu; supérieur à la moitié de la taille, de 0 à 5 cent., 7 ; de 5 à 10 cent., 8 .

Soit, moyenne du buste 0,848 .

En résumé: Buste inférieur à la moitié de la taille, 1 individu; supérieur à la moitié de la taille, de 0 à 5 cent., 19 ; de 5 à 10 cent., 44 ; de 10 à 18 cent., 3 .

Soit, moyenne du buste 0,871. 


\section{$18^{\circ}$ Pied :}

Dans la catégorie de 16 à 20 ans: Pied de 22 à 24 cent., 1 individu; de 24 à 26 cent., 1 ; de 26 à $2 S$ cent., 2 ; de 28 à 30 cent., 1.

Soit, moyenne du pied 0,260.

De 20 à 25 ans : Pied de 22 à 24 cent., 1 individu; de 24 à 26 cent., 5 ; de 26 à 28 cent., 2 .

Soit, moyenne du pied 0,249.

De 25 a 30 ans : Pied de 24 à 26 cent., 3 individus.

Soit, moyenne du pied 0,248 .

De 30 à 40 ans : Pied de 22 à 24 cent., 2 individus; de 24 à 26 cent., 7 ; de 26 à 28 cent., 5 .

Soit, moyenne du pied 0,252.

De 40 à 50 ans: Pied de 24 à 26 cent., 12 individus; de 26 à 28 cent., 8 ; de 28 à 30 cent., 1.

Soit, moyenne du pied 0,259.

De 50 ans et au-dessus : pied de 22 à 24 cent., 4 individus ; de 24 à 26 cent., 9 ; de 26 à $2 S$ cent., 3 .

Soit, moyenne du pied 0,250.

En résumé: pied de 22 à 24 cent., 8 individus; de 24 à 26 cent., 37 ; de 26 a 28 cent. , 20 ; de 28 à 30 cent., 2 . Soit, moyenne du pied 0,254.

19॰ TÊTE :

5 dolichocéphales vrais, 6 sous-dolichocéplıales, 4 mésaticéphales, 15 sous-brachycéphales, 37 brachycéphales vrais. 
D'autre part, les calculs donnent:

Longueur moyenne de la tête 0,1872 ; largeur moyenne de la tête 0,1568 .

D'où : Indice céphalique 83,76 .

\section{$20^{\circ}$ OREIlle :}

Indice auriculaire : au-dessous de 52,7 individus; de 52 à 56 , 22 ; de 56 à 60,24 ; de 60 à 65,10 ; de 65 et au-dessus, 4 .

D'autre part, les calculs donnent :

Longueur moyenne de l'oreille 0,0628; largeur moyenne de l'oreille $0,035 \%$.

D'où : Indice auriculaire 56,84.

$$
\text { *** }
$$

$21^{\circ}$ VISAGE :

En losange, 2 ; rond, 7 ; large ou carré, 7 ; ovale, 47 ; allongé, 3 ; en toupie, 1.

\section{$22^{\circ}$ Front :}

Arcades grandes, 15; petites, 7 ; moyennes, 45.

Inclinaison verticale, 7 ; fuyante, 19; intermédiaire 41.

Hauteur grande, 2 ; petite, 7 ; moyenne, 58.

Largeur grande, 6 ; petite, 9 ; moyenne, 52.

\section{$23^{\circ} \mathrm{NEZ}$ :}

Cavité (de la racine) grande, 6 ; petite, 24 ; moyenne, 37.

Dos rectiligne, 46 ; convexe, 14 ; concave, 7. 
Base horizontale, 37 ; relevée, 26 ; abaissée, 4.

Hauteur grande, 4 ; petite, 2 ; moyenne, 61.

Saillie grande, 5 ; petite, 7 ; moyenne 55.

Largeur grande, 14 ; petite, 6 ; moyenne, 47.

\section{$24^{\circ}$ Bouche :}

Grande, 12 ; petite, 2 ; moyenne, 53.

Rectiligne, 38 ; à coins abaissés, 21 ; à coins relevés, 8 .

Bée, 4 ; pincée, 11 ; ouverture intermédiaire. 52.

\section{$25^{\circ}$ Menton :}

Saillant, 11 ; droit, 48 ; fuyant, 8.

Plat, 12 ; à houppe, 9 ; intermédiaire, 46.

Bas, 22; haut, 13 ; intermédiaire, 32.

Large, 24; rond, 38; pointu, 5.

26. FiL :

Iris impigmenté, 8 ; pigmenté de jaune, 13 ; d'orange, 21 ; de châtain, 20; de marron, 5 .

$27^{\circ}$ TEINT :

Brun, 49 ; mat, 3 ; clair, -14 ; blond, 1.

$$
\text { *** }
$$

28. CARrure:

Grande, 9 ; moyenne, 54 ; petite, 4 .

29 Constitution et ÉtAT GÉNÉRAL, A L'ARrivéE :

Bons, 29; passables, 17 ; mauvais, 18 ; très mauvais, 3. 
30 INFIRMES Et MALAdES, A L'ARRIVÉE:

Infirmes et malades, à l'arrivée, 33 ; valides, sans infirmité ni maladie, 34 .

$$
\text { * * * }
$$

$31^{\circ}$ LIEU DU CRIME :

Lieu de naissance, 24 ; département du lieu de naissance, 16 ; autre département, 27.

$32^{\circ}$ DATE DU CRIME :

Hiver (décembre 4, janvier 4, février 1), 9 ; printemps (mars 4, avril 5, mai 2), 11 ; été (juin 11 , juillet 9 , août 8 ), 28 ; automne (septembre 3 , octobre 3 , novembre 5), 11 ; pendant l'année, 8 .

$$
\text { *** }
$$

33 JURIDICTION :

Cour d'assises, 57 ; tribunaux, 10.

34 DurÉE DE LA PEINE :

1 an et un jour, $3 ; 1$ an et un jour à 5 ans, $49 ; 5$ ans et audessus, 15. 
$35^{\circ}$ INTERDICTION DE SÉJOUR :

Frappés d'interdiction, 5 ; non frappểs d'interdiction, 62.

$$
\text { *** }
$$

$36^{\circ}$ Travail, EN PRison :

Bons travailleurs, 29; passables, 23 ; mauvais, 15.

$37^{\circ}$ Conduite, EN PRison:

Bonne conduite, 35 ; passable, 20 ; mauvaise, 12.

$$
\text { *** }
$$

$38^{\circ}$ Expulsion :

Etrangers expulsés, 10 ; non expulsés, 1. 


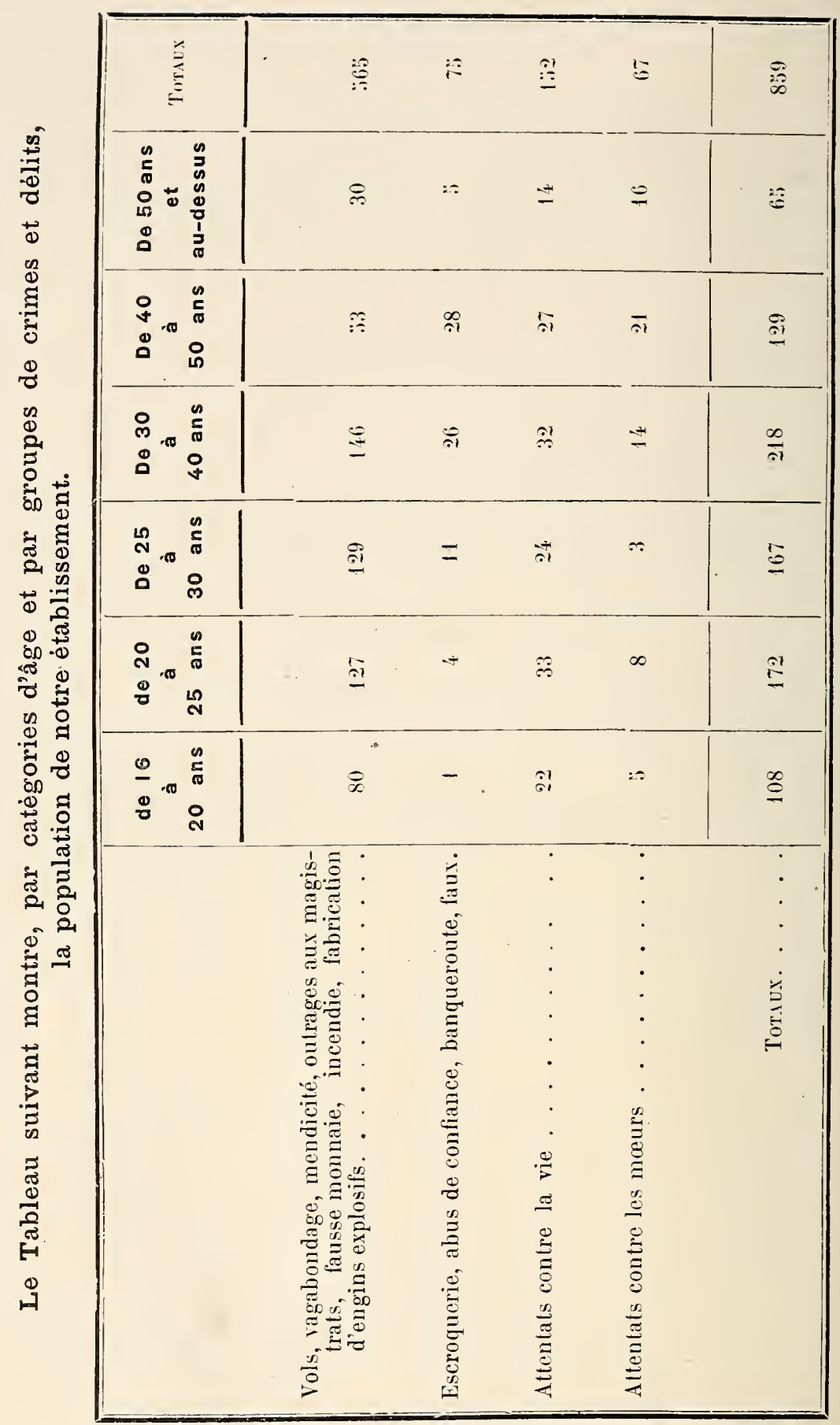




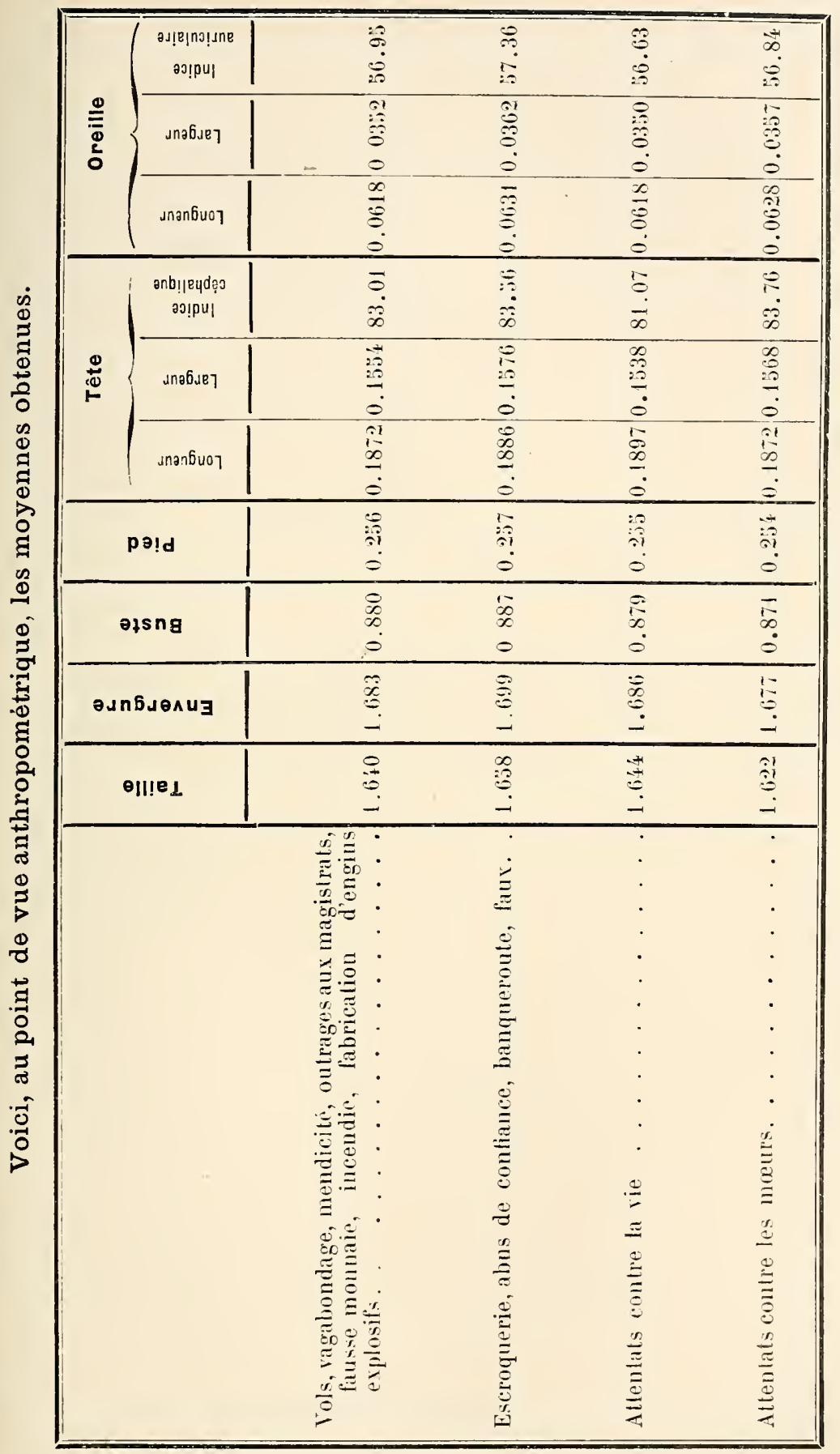





\section{CHAPITRE III}

Classés en criminels contre les propriétés et en criminels contre les personnes, ces 859 condamnés se présentent dans l'ordre suivant :

40 Criminels contre les propriétés . . . 640 soit pour cent 74.60

$2 \circ$ Criminels contre les personnes . . 219 — 20.49

Total. . . . $\overline{859} \quad-\overline{99.99}$

On rencontre :

I

CRIMES-PROPRIÉTÉS

10 Naissance :

Enfants légitimes 614, naturels 23, trouvés 3.

$2^{\circ}$ NATionalité :

Français 472 (dont 41 Corses), Italiens 95, divers 73. 


\section{$3^{\circ} \mathrm{AgE}$ :}

De $16 \dot{a} 20$ ans, 81; de 20 à 25 ans, 131; de 25 à 30 ans, 140; de 30 à 10 ans, 172; de 40 à 50 ans, 81; de 50 ans et au-dessus, 35.

\section{$4^{0}$ ÉtTat CIVIL :}

Célibataires 513, mariés $10 \%$, veufs 15 , divorcés 5 .

\section{$5^{\circ}$ INSTRUCTION :}

Illettrés 74, sachant lire 59, sachant lire et écrire 404, sachant lire, écrire et calculer $7 \%$, possédant une instruction primaire 23, supérieure à l'instruction primaire 3.

\section{$6^{\circ}$ Profession :}

Propriétaires, rentiers 5, employés de banque et de commerce 59, commerçants et fabricants 27 , professions alimentaires 54, ouvriers d'ateliers et de fabriques 109 , ouvriers du bâtiment et du mobilier 73, prọfessions agricoles, journaliers, domestiques 230 , nomades 41 , sans profession 42.

\section{7o Population :}

Urbains 392, ruraux 248 .

\section{$8^{\circ}$ DOMICILE :}

Avec domicile 372, sans domicile 268.

\section{9o Nombre DES CONDAMnations :}

Sans condampation antérieure 159 , de 1 à 5 condamnations 308 , 5 condamnations et plus 173 .

$10^{\circ}$ OISIVEtÉ :

Oisifs 486, travailleurs 154. 
11० IVROGNERIE :

Ivrognes 209 , sobres 431 .

$12^{\circ}$ Libertinage et Débauche :

Se livrant au libertinage et a la débauche 233, ne se livrant pas au libertinage et à la débauche $40 \%$.

\section{$13^{\circ}$ Concubinage :}

Vivant en concubinage 72 , ne vivant pas en concubinage 568.

$14^{\circ}$ Note de la Commune :

Bien notés 16 , mal notés 624 .

$$
\text { *** }
$$

$15^{\circ}$ TAILlE :

Dans la catégorie de 16 à 20 ans: Taille au-dessous de $1 \mathrm{~m} .60,18$ individus; de $1 \mathrm{~m} .60$ à $1 \mathrm{~m}$. 70, 52; de $1 \mathrm{~m}$. 70 et au-dessus, 11.

Soit, moyenne de la taille $1 \mathrm{~m} .633$.

De 20 à 25 ans: Taille au-dessous de $1 \mathrm{~m} .60,33$ individus; de $1 \mathrm{~m} .60$ à $1 \mathrm{~m} .70,79$; de $1 \mathrm{~m} .70$ et au-dessus, 19 .

Soit, moyenne de la taille $1 \mathrm{~m} .634$.

De 25 a 30 ans: Taille au-dessous de $1 \mathrm{~m} .60,32$ individus; de $1 \mathrm{~m} .60$ a $1 \mathrm{~m} .70,77$; de $1 \mathrm{~m}$. 70 et au-dessus, 31 .

Soit, moyenne de la taille $1 \mathrm{~m} .645$.

De 30 a 40 ans : Taille au-dessous de $1 \mathrm{~m} .60,42$ individus; de $1 \mathrm{~m} .60$ à $1 \mathrm{~m} .70,97$; de $1 \mathrm{~m}$. 70 et au-dessus, 33 .

Soit, moyeune de la taille $1 \mathrm{~m} .645$. 
De 40 à 50 ans: Taille au-dessous de $1 \mathrm{~m} .60,16$ individus; de $1 \mathrm{~m} .60$ a $1 \mathrm{~m}$. 70, 47 ; de $1 \mathrm{~m}$. 70 et au-dessus, 18 .

Soit, moyenne de la taille $1 \mathrm{~m} .652$.

De 50 ans et au-dessus : Taille au-dessous de $1 \mathrm{~m} .60,10$ individus; de $1 \mathrm{~m} .60$ à $1 \mathrm{~m}$. 70, 17 ; de $1 \mathrm{~m}$. 70 et au-dessus, 8 .

Soit, moyenne de la taille $1 \mathrm{~m} .641$.

En résumé: Taille au-dessous de $1 \mathrm{~m} .60,151$ individus; de $1 \mathrm{~m} .60$ à $1 \mathrm{~m}$. 70, 369; de $1 \mathrm{~m}$. 70 et au-dessus, 120 .

Soit, moyenne de la taille $1 \mathrm{~m} .642$.

\section{$16^{\circ}$ Envergure :}

Dans la catégorie de 16 à 20 ans : Envergure inférieure à la taille, de 0 à 8 cent.; 10 individus; égale à la taille, 4 ; supérieure à la taille, de 0 à 4 cent., 29 ; de 4 à 8 cent., 22 ; de 8 à 16 cent., 16 .

Soit, moyenne de l'envergure $1 \mathrm{~m} .671$.

De $20 \dot{\alpha} 25$ ans : Envergure inférieure à la taille, de 0 à 8 cent., 19 individus; égale à la taille, 2 ; supérieure à la taille, de 0 à 4 cent., 44 ; de 4 à 8 cent., 42 ; de 8 à 16 cent. 23 ; infirme 1.

Soit, moyenne de l'envergure $1 \mathrm{~m} .672$.

De $25 \dot{a} 30$ ans: Envergure inférieure à la taille, de 0 à 8 cent., 13 individus; égale à la taille, 3 ; supérieure à la taille, de 0 à 4 cent., 36 ; de 4 à 8 cent., 58 ; de 8 à 16 cent., 30 .

Soit, moyenne de l'envergure $1 \mathrm{~m} .692$.

De 30 a 40 ans : Envergure inférieure à la taille, de 0 à 8 cent., 17 individus; égale à la taille, 4 ; supérieure à la taille, de 0 à 4 cent., 46 ; de 4 à 8 cent., 69 ; de 8 à 16 cent., 36 .

Soit, moyenne de l'envergure 1 m. 691. 
De 40 à 50 ans : Envergure inférieure à la taille, de 0 a 8 cent.,

7 individus; égale à la taille, 3 ; supérieure à la taille, de

0 à 4 cent., 21 ; de 4 a $S$ cent., 32 ; de 8 a 16 cent., 18 .

Soit, moyenne de l'envergure $1 \mathrm{~m}$. 700.

De 50 ans et au-dessus : Envergure inférieure à la taille, de 0 à $S$ cent., 5 individus; égale à la taille, 2 ; supérieure à la taille, de 0 à 4 cent., 11 ; de 4 à 8 cent., 11; de 8 à 16 cent., 6 .

Soit, moyenne de l'envergure 1,673.

En résumé: Envergure inférieure à la taille, de 0 à 8 cent., 71 individus; égale à la taille, 18 ; supérieure à la taille, de 0 à 4 cent., 187; de 4 à 8 cent., 234; de 8 à 16 cent., 129 ; infirme 1.

Soit, moyenne de l'envergure $1 \mathrm{~m} .685$.

\section{$17^{\circ}$ Buste :}

Dans la catégorie de 16 à 20 ans: buste supérieur à la moitié de la taille, de 0 à 5 cent., 22 individus; de 5 à 10 cent., 56; de 10 à 18 cent., 3.

Soit, moyenne du buste 0,877 .

De 20 a 25 ans: Buste supérieur à la moitié de la taille, de 0 à 5 cent., 39 individus; de 5 à 10 cent., 86; de 10 à 18 cent., 6 .

Soit, moyenne du buste 0,878 .

De 25 a 30 ans: Buste inférieur à la moitié de la taille, 1 individu; supérieur à la moitié de la taille, de 0 à 5 cent., 44 ; de 5 à 10 cent., 87 ; de 10 à 18 cent., s.

Soit, moyenne du buste 0,880 .

De 30 à 40 ans: Buste inférieur à la moitié de la taille, 1 individu; supérieur à la moitié de la taille, de 0 à 5 cent., 47 ; de 5 à 10 cent., 116 ; de 10 à 18 cent., 8 .

Soit, moyenne du buste 0,883 . 
De 40 à 50 ans : Buste inférieur à la moitié de la taille, 1 individu; supérieur à la moitié de la taille, de 0 à 5 cent., 17 ; de 5 à 10 cent., 62 ; de 10 à 18 cent., 1 .

Soit, moyenne du buste 0,886 .

De 50 ans et au-dessus : Buste inférieur a la moitie de la taille, 1 individu; égal à la moitié de la taille, 1 individu; supérieur à la moitié de la taille, de 0 à 5 cent., 12 ; de 5 à 10 cent., 19 ; de 10 à 18 cent., 2 .

Soit, moyenne du buste 0,873 .

En résumé : Buste inférieur à la moitié de la taille, 4 individus; égal à la moitié de la taille, 1 ; supérieur à la moitié de la taille, de 0 à 5 cent., 181 ; de 5 à 10 cent , 426 ; de 10 à 18 cent., 28 .

Soit, moyenne du buste 0,880 .

\section{$18^{\circ}$ PIED :}

Dans la catégorie de 16 à 20 ans : Pied de 22 à 24 cent., 3 individus; de 24 a 26 cent., 46 ; de 26 à 28 cent., 29 ; de 28 à 30 cent., 3 .

Soit, moyenne du pied 0,25\%.

De $20 \dot{a} 25$ ans : Pied de $22 \dot{a} 24$ cent., 7 individus; de 24 à 26 cent., 80 ; de 26 à 28 cent., 41 ; de 28 à 30 cent., 3.

Soit, moyenne du pied 0,256.

De 25 d 30 ans : Pied de 22 à 24 cent., 16 individus; de 24 à 26 cent., 72 ; de 26 à 28 cent., 48 ; de 28 à 30 cent., 4 .

Soit, moyenne du pied 0,256.

De 30 à 40 ans: Pied de 22 à 24 cent., 12 individus; de 24 a 26 cent., 83 ; de 26 à 28 cent., 74 ; de 28 à 30 cent., 3.

Soit, moyenne du pied 0,256 . 
De 40 à 50 ans: Pied de 22 a 24 cent., 7 individus; de 24 à 26 cent., 39 ; de 26 à 28 cent., 33 ; de 28 à 30 cent., 2 .

Soit, moyenne du pied 0,25\%.

De 50 ans et au-dessus : Pied de 22 à 24 cent., 2 individus; de 24 à 26 cent., 17 ; de 26 à 28 cent., 15 ; de 28 à 30 cent., 1.

Soit, moyenne du pied 0,256 .

En résumé: Pied de 22 à 24 cent., 47 individus; de 24 à 26 cent., 337 ; de 26 à 28 cent., 240 ; de 28 à 30 cent., 16.

Soit, moyenne du pied 0,256.

\section{$19^{\circ}$ TÊTE :}

18 dolichocéphales vrais, 47 sous-dolichocéphales, 100 mésaticéphales, 172 sous-brachycéphales, 303 brachycéphales orais.

D'autre part, les calculs donnent :

Longueur moyenne de la tête 0,1873 ; largeur moyenne de la tête 0,1556 .

D'où : Indice céphalique $83,0 \%$.

$20^{\circ}$ OReilite :

Indice auriculaire : au-dessous de 52, 58 individus; de 52 a 56,191 ; de 56 à 60,227 ; de 60 à 65,145 ; de 65 et audessus, 19.

D'autre part, les calculs donnent:

Longueur moyenne de l'oreille 0,0619; largeur moyenne de l'oreille 0,0353 .

D'où : Indice auriculaire 57,02. 


\section{$*^{* *}$}

$21^{\circ}$ VISAGE :

En tronc de pyramide, 6 ; en losange, 37 ; rond, 61 ; large ou carré, 80 ; ovale, 429 ; allongé, 18 ; en toupie, 9.

\section{FRONT :}

Arcades grandes, 119 ; petites, r1; moyennes, 450.

Inclinaison verticale, 86 ; fuyante, 133 ; intermédiaire, 421. Hauteur grande, 73 ; petite, $5 \%$; moyenne, 510.

Largeur grande, 57 ; petite, 98 ; moyenne, 485.

\section{$23^{\circ} \mathrm{NEZ}$ :}

Cavité (de la racine) grande, 50 ; petite, 168 ; moyenne, 422. Dos rectiligne, 394 ; convexe, 109 ; concave, 137.

Base horizontale, 410 ; relevée, 192 ; abaissée, 38.

Hauteur grande, 76 ; petite, 54 ; moyenne, 510.

Saillie grande, 85 ; petite, 43 ; moyenne, 512.

Largeur grande, 81 ; petite, 22 ; moyenne, $53 \%$.

\section{$24^{\circ}$ BOUCHE :}

Grande, 72 ; petite, 76 ; moyenne, 492.

Rectiligne, 442 ; à coins abaissés, 93 ; à coins relevés, 105.

Bée, 75 ; pincée, 79 ; ouverture intermédiaire, 486.

\section{Menton :}

Saillant, 109 ; droit, 435 ; fuyant, 96.

Plat, 104; à houppe, 89 ; intermédiaire, 447.

Bas, 181 ; haut, 104 ; intermédiaire, 355.

Large, 122 ; rond, 478 ; pointu, 40. 
$26^{\circ}$ GIL :

Iris impigmenté, 60 ; pigmenté de jaune, 153 ; d'orange, 261 ; de châtain, 116 ; de marron, 49 ; aveugle, 1.

\section{2\%0 TEINT :}

Brun, 434; mat, 17 ; basané, 2 : mulâtre, 1 ; clair. 166 ; blond, 18 ; pâle, 2.

$$
\text { *** }
$$

$28^{\circ}$ Carrure :

Grande, 128 ; petite, 37 ; moyenne, 475.

29 Constitution et ÉtAT GÉNÉRAL, A L'ARrivéE :

Très bons, 55; bons, 392; passables, 109; mauvais, 77; très mauvais, $\%$.

30 INFIRMES ET MALADES, A L'ARRIVÉE:

Infirmes et malades, à l'arrivée, 191; valides, sans infirmité ni maladie, 449.

$$
\text { 䊑 }
$$

$31^{\circ}$ LIEU dU CRINe :

Lieu de naissance, 117; département du lieu de naissance, 112; autre département, 411. 
$32^{\circ}$ DATE DU CRIME :

Hiver (décembre 62, janvier 57, février 56), 175; printemps (mars 40, avril 55, mai 50), 145; èté (juin 44, juillet 44 . août 44), 132; automne (septembre 46, octobre 54 . novembre 46), 146 ; pendant l'année, 42.

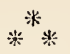

$33^{\circ}$ JURIDICTION :

Cour d'assises, 229 ; tribunaux, 407 ; conseil de guerre, 2 ; tribunal supérieur de Monaco, 2.

34 DurÉE de LA PEINE:

1 an 1 jour, $50 ; 1$ an 1 jour à 5 ans, $454 ; 5$ ans et plus, 136 .

$35^{\circ}$ INTERDICTION DE SÉJOUR :

Frappés d'interdiction, 103; non frappés d'interdiction, $53 \%$.

$36^{\circ}$ Travail, EN PRISON :

Bons travailleurs, 374 ; passables, 167 ; mauvais, 99.

$37^{\circ}$ Conduite, en PRison :

Bonne conduite, 268 ; passable, 195 ; mauvaise, $17 \%$.

$$
\text { *** }
$$

$38^{\circ}$ Expulsion :

Étrangers expulsés, 142; non expulsés, 26. 
$1^{\circ}$ NAISSANCE :

Enfants légitimes 206, naturels 13 .

$2^{\circ}$ NATIONALitÉ :

Français 180 (dont 66 Corses), Italiens 35, divers 4.

$3^{\circ}$ AGE :

De 16 à 20 ans, 27; de 20 à 25 ans, 41 ; de $25 \dot{a} 30$ ans, 27; de 30 à 40 ans, 46; de 40 à 50 ans, 48; de 50 ans et au-dessus, 30.

$4^{n}$ ÉTAT CIVIL :

Célibataires 142, mariés 55, veufs 20 , divorcés 2 . Сн. Рекиен. 


\section{$5^{\circ}$ Instruction :}

Illettrés 52, sachant lire 23, sachant lire et écrire 124, sachant lire, écrire et calculer 16, possédant une instruction primaire complète 4.

\section{$6^{\circ}$ Profession :}

Propriétaires, rentiers 6, employés de banque et de commerce 7, commerçants et fabricants 5, professions alimentaires 11, ouvriers d'ateliers et de fabriques 42 , ouvriers du bâtiment et du mobilier 19, professions agricoles, journaliers, domestiques 118, nomades 5, sans profession 6 .

\section{7o Population :}

Urbains 94, ruraux 125.

\section{So Domicile:}

Avec domicile 196, sans domicile 23.

\section{$9^{\circ}$ Nombre des condamations :}

Sans condamnation antérieure 93, 1 à 5 condamnations 100, 5 condamnations et au-dessus 26 .

\section{$10^{\circ}$ Oisiveté :}

Oisifs 7\%, travailleurs 142.

$11^{\circ}$ IvRognerie :

Ivrognes 120, sobres 99 . 
$12^{\circ}$ Libertinage ET DÉBAUChe :

Se livrant au libertinage et à la débauche 78, ne se livrant pas au libertinage et à la débauche 141 .

\section{$13^{\circ}$ Concubinage:}

Vivant en concubinage 24, ne vivant pas en concubinage 195.

$14^{\circ}$ Note de la Commune :

Bien notés 22. mal notés 197.

$$
\text { *** }
$$

$15^{\circ}$ TAILle :

Dans la catégorie de 16 à 20 ans : Taille au-dessous de $1 \mathrm{~m} .60$, 7 individus; de $1 \mathrm{~m} .60$ a $1 \mathrm{~m}$. 70, 16; de $1 \mathrm{~m} .70$ et au-dessus, 4 .

Soit, moyenne de la taille 1,631.

De 20 a 25 ans : Taille au-dessous de $1 \mathrm{~m} .60,9$ individus: de $1 \mathrm{~m} .60$ à $1 \mathrm{~m}$. 70, 27; de $1 \mathrm{~m}$. 70 et au-dessus, 5 .

Soit, moyenne de la taille $1,63 \%$.

De 25 à 30 ans: Taille au-dessous de $1 \mathrm{~m} .60,4$ individus; de $1 \mathrm{~m} .60$ à $1 \mathrm{~m} .70,17$; de $1 \mathrm{~m}$. 70 et au-dessus, 6 .

Soit, moyenne de la taille 1,655.

De 30 à 40 ans: Taille au-dessous de $1 \mathrm{~m} .60$, 8 individus: de $1 \mathrm{~m} .60$ a $1 \mathrm{~m} .70,31$; de $1 \mathrm{~m}$. 70 et au-dessus, 7 .

Soit. moyenne de la taille 1,645 . 
De 40 a 50 ans : Taille au-dessous de $1 \mathrm{~m} .60,16$ individus; de $1 \mathrm{~m} .60$ à $1 \mathrm{~m}$. 70, 27; de $1 \mathrm{~m}$. 70 et au-dessus, 5 .

Soit, moyenne de la taille 1,631 .

De 50 ans et au-dessus : Taille au-dessous de $1 \mathrm{~m} .60,10$ individus; de $1 \mathrm{~m} .60$ à $1 \mathrm{~m}$. 70, 16 ; de $1 \mathrm{~m}$. 70 et au-dessus, 4 . Soit, moyenne de la taille 1,626 .

En résumé : Taille au-dessous de $1 \mathrm{~m}$. 60, 54 individus ; de

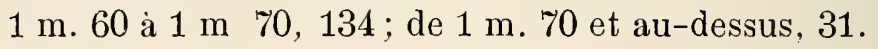

Soit, moyenne de la taille $1,63 \%$.

\section{$16^{\circ}$ Envergure :}

Dans la catégorie de 16 à 20 ans: Envergure inférieure à la taille, de 0 à 8 cent., 4 individus; supérieure à la taille, de 0 à 4 cent., 6 ; de 4 à 8 cent., 10 ; de 8 à 16 cent., $\%$.

Soit, moyenne de l'envergure 1,674.

De 20 à 25 ans : Envergure inférieure à la taille, de 0 à 8 cent., 3 individus ; supérieure à la taille, de 0 à 4 cent., 9 ; de 4 à 8 cent., 17 ; de 8 à 16 cent., 12 .

Soit, moyenne de l'envergure 1,689 .

De 25 à 30 ans: Envergure inférieure à la taille, de 0 à 8 cent., 5 individus; égale à la taille, 2 ; supérieure à la taille, de 0 à 4 cent., 6 ; de 4 à 8 cent., 9 ; de 8 à 16 cent., 5 .

Soit, moyenne de l'envergure 1,698.

De 30 à 40 ans : Envergure inférieure à la taille, de 0 à 8 cent., 3 individus; égale à la taille, 2 ; supérieure à la taille, de 0 à 4 cent., 17 ; de 4 à 8 cent., 17; de 8 à 16 cent., 6 ; infirme, 1.

Soit, moyenne de l'envergure 1,681. 
De 40 à 50 ans : Envergure inférieure à la taille, de 0 à 8 cent., 3 individus; égale à la taille, 2 ; supérieure à la taille, de 0 à 4 cent., 8 ; de 4 à 8 cent., 25; de 8 à 16, 10 .

Soit, moyenne de l'envergure 1,681.

De 50 ans et au-dessus : Envergure inférieure à la taille, de 0 à 8 cent., 4 individus; égale à la taille, 2 ; supérieure à la taille, de 0 à 4 cent., 6 ; de 4 à 8 cent., 9 ; de 8 à 16 cent., 8 ; infirme, 1 .

Soit, moyenne de l'envergure 1,678.

En résumé: Envergure inférieure à la taille, de 0 à $S$ cent., 22 individus; égale à la taille, 8 ; supérieure à la taille, de 0 à 4 cent., 52 ; de 4 à 8 cent., 87 ; de $S$ à 16 cent., 48 ; infirmes, 2 .

Soit, moyenne de l'envergure 1,683.

\section{$17^{\circ}$ Buste :}

Dans la catégorie de 16 à 20 ans: Buste supérieur à la moitié de la taille, de 0 à 5 cent., 9 individus; de 5 à 10 cent., 16 ; de 10 à 18 cent., 2.

Soit, moyenne du buste 0,879 .

De 20 à 25 ans: Buste supérieur à la moitié de la taille, de 0 à 5 cent., 7 individus; de 5 à 10 cent., 31; de 10 à 18 cent., 3.

Soit, moyenne du buste 0,888 .

De 25 à 30 ans : Buste supérieur à la moitié de la taille, de 0 à 5 cent., 8 individus; de 5 à 10 cent, 18; de 10 à 18 cent., 1 .

Soit, moyenne du buste 0,888 . 
De 30 à 40 ans: Buste inférieur à la moitié de la taille, 1 individu; supérieur à la moitié de la taille, de 0 a 5 cent., 6 ; de 5 à 10 cent., 38 ; de 10 à 18 cent., 1 .

Soit, moyenne du buste $0,88 \%$.

De 40 à 50 ans: Buste supérieur à la moitié de la taille, de 0 à 5 cent., 11 individus; de 5 à 10 cent., 35 ; d॰ 10 à 18 cent., 2.

Soit, moyenne du buste $0,87 \%$.

De 50 ans et au-dessus : Buste inférieur à la moitié de la taille, 1 individu; égal à la moitié de la taille, 1 ; supérieur à la moitié de la taille, de 0 à 5 cent., 12 ; de 5 a 10 cent., 15 ; de 10 à 18 cent., 1 .

Soit, moyenne du buste 0,860 .

En résumé: Buste inférieur à la moitié de la taille, 2 individus; égal à la moitié de la taille, 1 ; supérieur á la moitié de la taille, de 0 à 5 cent., 53 ; de 5 à 10 cent., 153; de 10 à 18 cent., 10 .

Soit, moyenne du buste 0,881 .

\section{$18^{\circ}$ PIED :}

Dans la catégorie de 16 à 20 ans: Pied de 22 à 24 cent., 3 individus; de 24 à 26 cent., 13 ; de 26 a 28 cent., 9 ; de 28 à 30 cent., 2 .

Soit, moyenne du pied 0,255.

Le 20 à 25 ans : Pied de 22 à 24 cent. , 2 individus; de 24 à 26 cent., 21 ; de 26 à 28 cent., 17 ; de 28 à 30 cent., 1 .

Soit, moyenne du pied 0,25\%.

De 25 a 30 ans: Pied de 22 à 24 cent., 1 individu; de 24 à 26 cent., 17; de 26 à 28 cent., 8 ; de 28 à 30 cent., 1 .

Soit, moyenne du pied 0,25\%. 
De 30 à 40 ans: Pied de 22 à 24 cent., 7 individus: de 24 à 26 cent., 25 ; de 26 a 28 cent., 13 ; de 28 à 30 cent., 1 .

Soit, moyenne du pied 0,252.

De 40 à 50 ans : Pied de 22 a 24 cent., 3 individus; de 24 a 26 cent., 31 ; de 26 à 28 cent. 12 ; de 28 à 30 cent., 2 .

Soit, movenne du pied 0,256 .

De 50 ans et au-dessus: Pied de 22 à 24 cent., 4 individus; de 24 à 26 cent., 17 ; de 26 à 28 cent.. 9.

Soit, moyenne du pied 0,253 .

En résumé: Pied de 22 a 24 cent., 20 individus; de 24 a 26 cent., 124 ;'de 26 a 28 cent., 68 ; de 28 a 30 cent., $\%$ Soit, moyenne du pied 0,255 .

19॰ TÊTE :

24 dolichocéphales vrais, 29 sous-dolichocéphales, 29 mésaticéphales, 42 sous-brachycéphales, 95 brachycéphales vrais.

D'autre part, les calculs donnent:

Longueur moyenne de la tête 0,1890 ; largeur moyenne de la tête $0,154 \%$.

D’où : Indice céphalique 81,85 .

\section{$20^{\circ}$ Oreille:}

Indice auriculaire : au-dessous de 52, 19 individus; de 52 a 56 , 75 ; de 56 à 60 , 77 ; de 60 à 65 , 43; de 65 et audessus, 5 . 
D'autre part, les calculs donnent :

Longueur moyenne de l'oreille 0,0621; largeur moyenne de l'oreille 0,0352.

D’où : Indice auriculaire 56,68.

$$
\text { * * * * }
$$

\section{$21^{\circ}$ VISAgE :}

En tronc de pyramide, 1; en losange, 18; rond, 20; large ou carré, 22 ; ovale, 145 ; allongé, 10 ; en toupie, 3.

\section{$22^{\circ}$ Front :}

Arcades grandes, 44 ; petites, 20 ; moyennes, 155.

Inclinaison verticale, 32 ; fuyante, 45 ; intermédiaire, 142.

Hauteur grande, 21 ; petite, 17 ; moyenne, 181.

Largeur grande, 21 ; petite, 37 ; moyenne, 161.

\section{$23^{\circ} \mathrm{NEZ}$ :}

Cavité (de la racine) grande, 21 ; petite, 74 ; moyenne, 124. Dos rectiligne, 146 ; convexe, 39 ; concave, 34 . Base horizontale, 140 ; relevée, 64 ; abaissée, 15. Hauteur grande, 18 ; petite, 14 ; moyenne. 187. Saillie grande, 24 ; petite, 23 ; moyenne, 172. Largeur grande, 35 ; petite, 11 ; moyenne, 173.

\section{$24^{\circ}$ Bouche :}

Grande, 31 ; petite, 19 ; moyenne, 169.

Rectiligne, 135; à coins abaissés, 51 ; à coins relevés, 33.

Bẻe, 17 ; pincée, 26 ; ouverture intermédiaire, 176. 


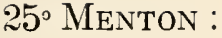

Saillant, 39 ; droit, 141 ; fuyant, 39.

Plat, 40 ; à houppe, 30 ; intermédiaire 149.

Bas, 54 ; haut, 46 ; intermédiaire, 119.

Large, 54; rond, 151; pointu, 14.

\section{EIL :}

Iris impigmenté, 18 ; pigmenté de jaune, 46 ; d’orange, 96 ; de châtain, 48 ; de marron, 11.

\section{7\% TEINT :}

Brun, 159: mat, 5; clair, 49 ; blond, 4 ; pâle, 2.

$$
\text { ** } *
$$

28. CARrure :

Grande, 33 ; petite, 8 ; moyenne, 178.

29 Constitution ET ÉtAT GÉNÉRAL, A L'ARrivÉE :

Très bons, 25; bons, 112 ; passables, 39 ; mauvais, 39 ; très mauvais, 4 .

30 INFIRMES ET MALAdES, A L'ARRIVÉE :

Infirmes et malades, à l'arrivée, 79 ; valides, sans infirmitẻ ni maladie, 140 . 
310 LIEU DU CRINE :

Lieu de naissance, 99 ; département du lieu de naissance, 43; autre département, $7 \%$.

32 DAte DU CRIME:

Hiver (décembre 14, janvier 9, février 6) 29: printemps (mars 16, avril 18, mai 13) 47; été (juin 30, juillet 25 . août 31) 86 ; automne (septembre 14, octobre 18, novembre 14) 46 ; pendant l'année, 11.

$$
\text { *** }
$$

$33^{\circ}$ JURIDICTION :

Cours d'assises, 138 : tribunaux, 80 ; conseil de guerre, 1.

$34^{\circ}$ Durée de LA PEINE :

1 an et un jour, 14 ; de 1 an et un jour à 5 ans, $143 ; 5$ ans et plus, 62.

35' INTERDICTION DE SÉJOUR :

Frappés d'interdiction, 40; non frappés d'interdiction, 179. 


$$
\text { *** }
$$

$36^{\circ}$ Travall, en prison:

Bons travailleurs, 118 ; passables, 61 ; mauvais, 40 .

$3 \%$ Conduite, En prison:

Bonne conduite, 121 ; passable, 52 ; mauvaise, 46.

$$
\text { *** }
$$

$38^{\circ}$ Expulsion :

Étrangers expulsés, 34 ; non expulsés, 5. 


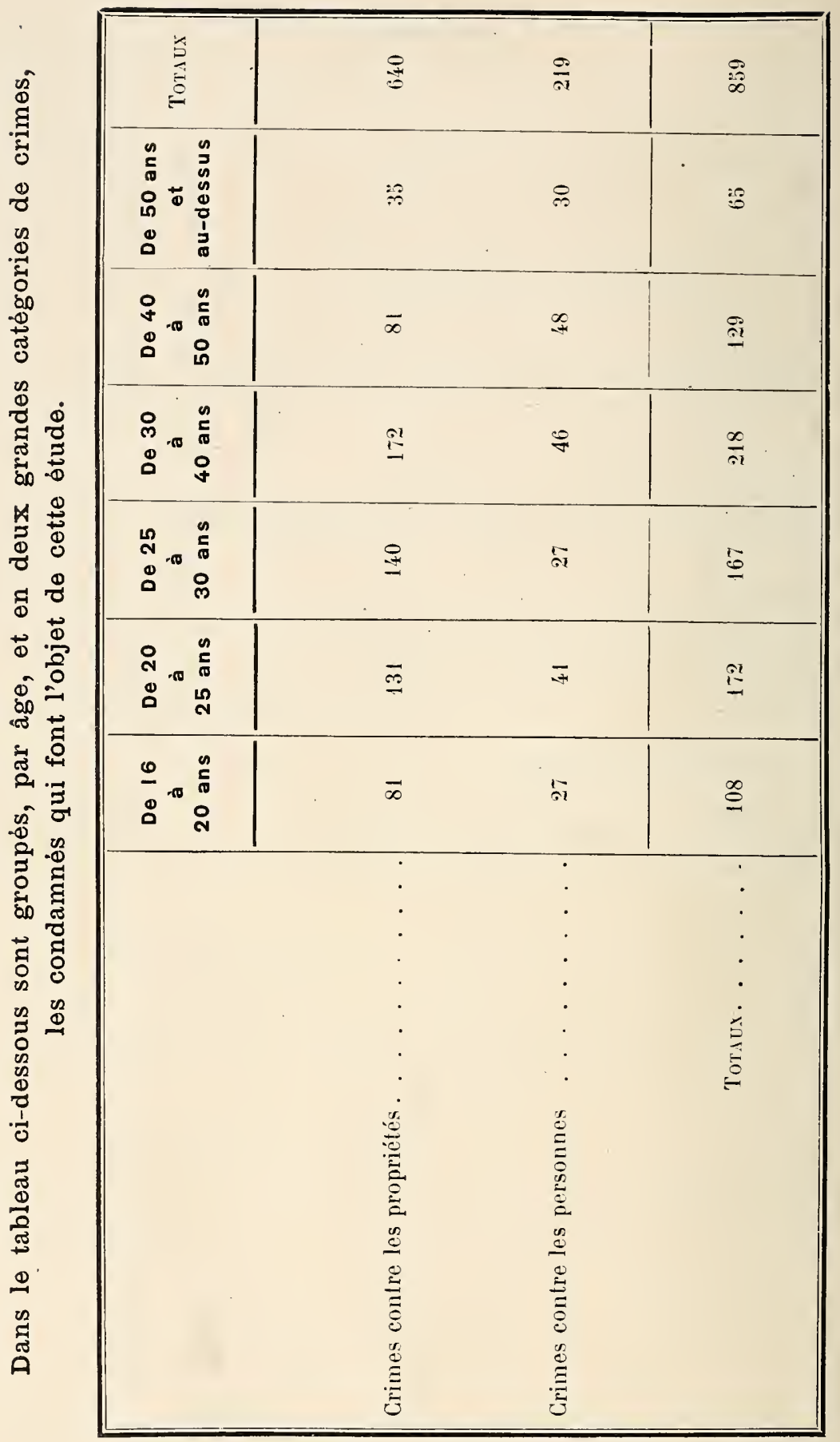




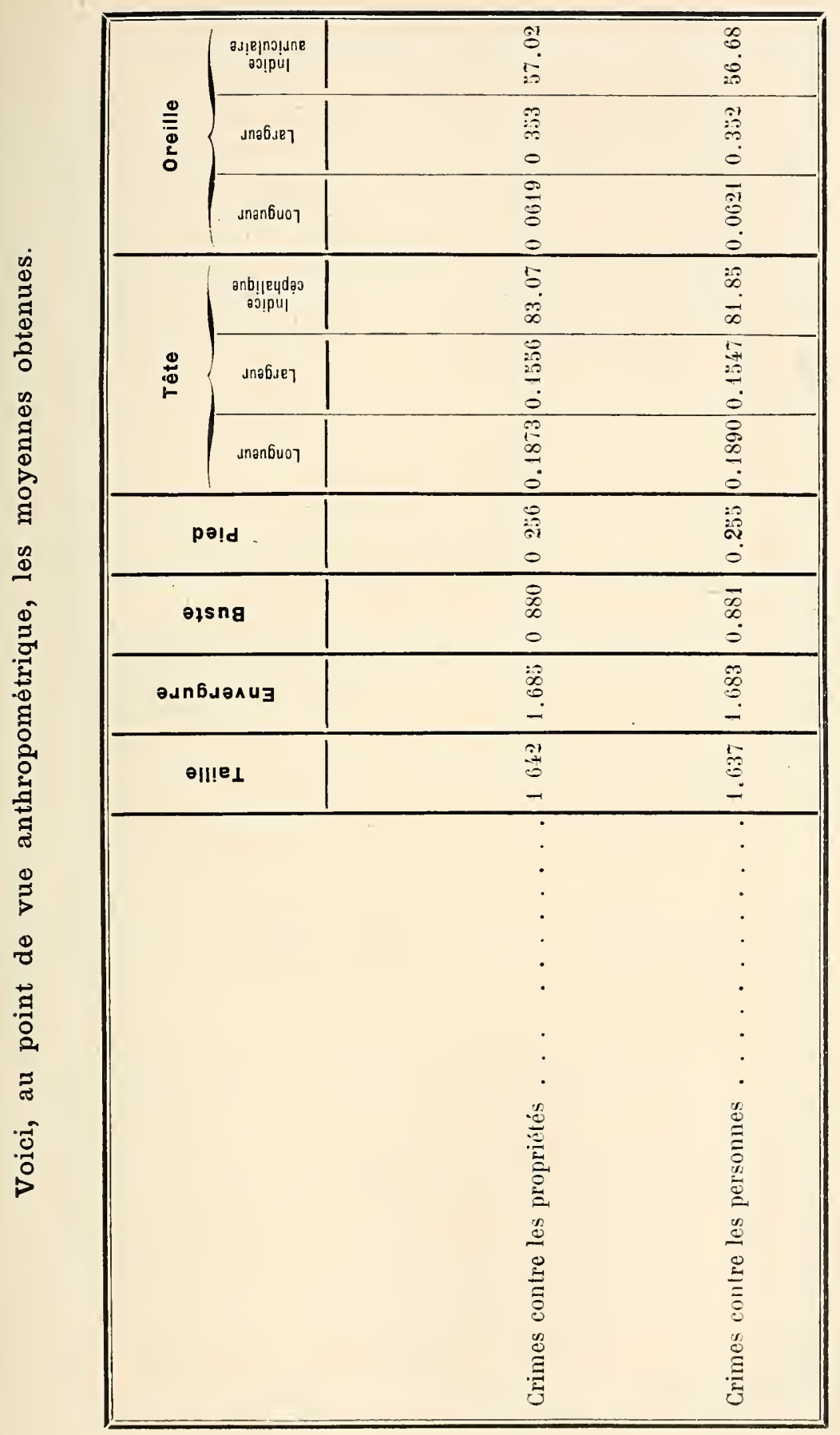





\title{
CHAPITRE IV
}

\section{Renseignements divers et liste des victimes, par catégories de crimes et délits}

\author{
I \\ CRIMES-PROPRIÉTÉS
}

Les crimes-propriétés comprennent deux catégories :

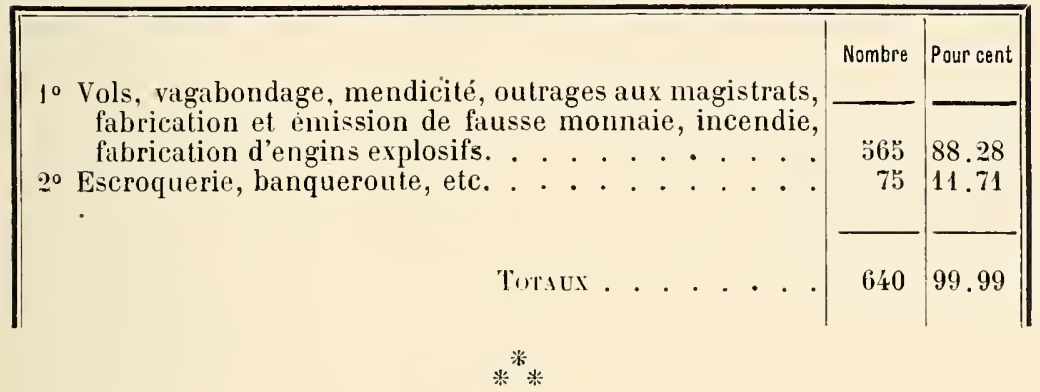

On note dans la première catégorie:

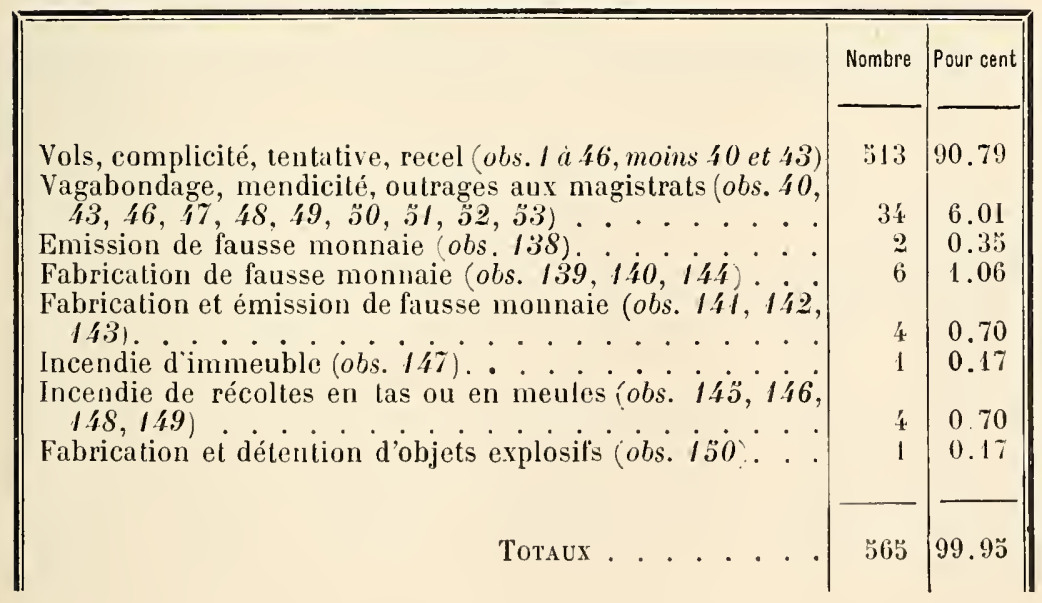


Les vols se subdivisent en :

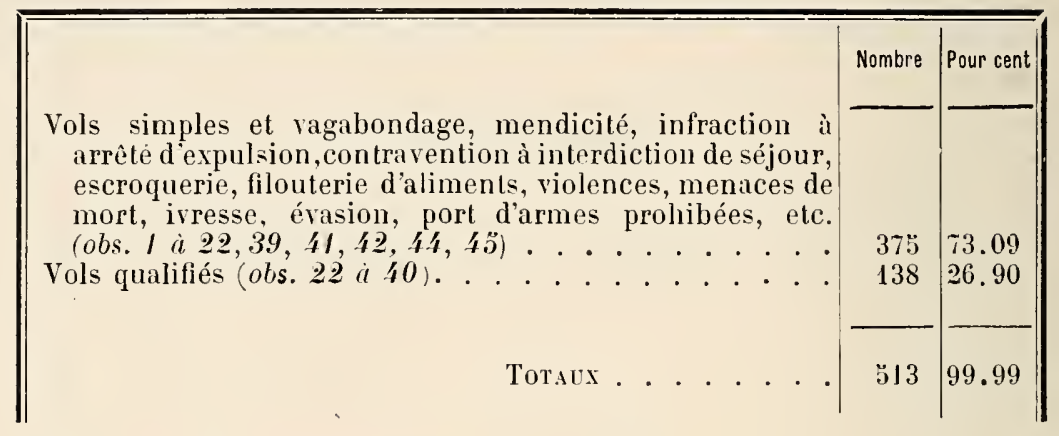

soit, parmi les vols simples:

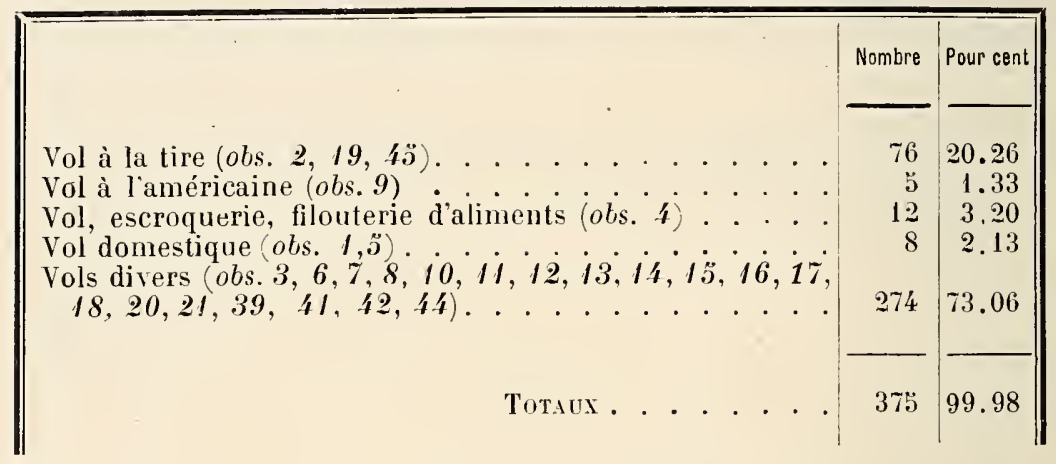

Les vols avaient été commis :

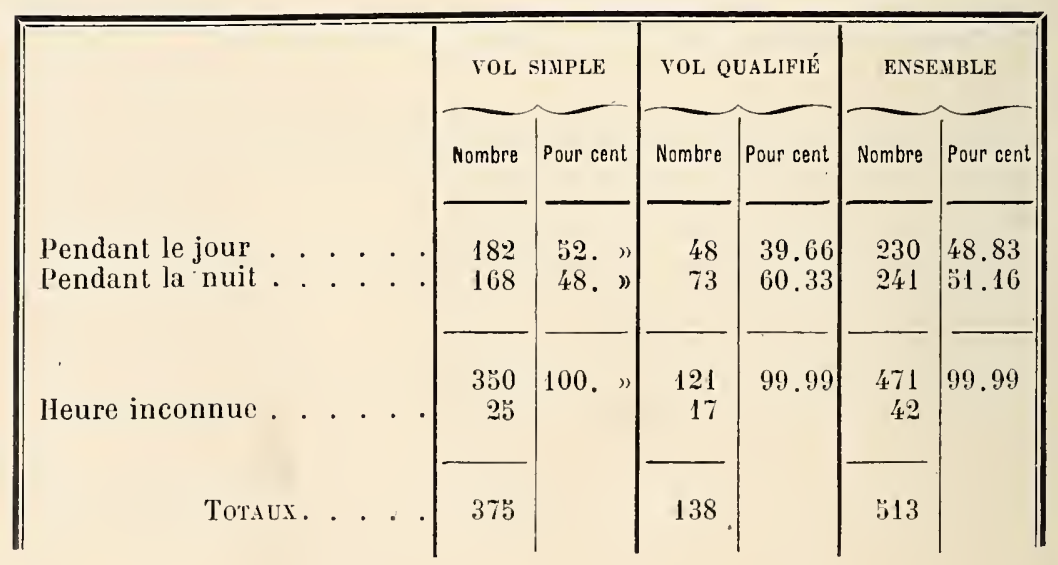


soit :

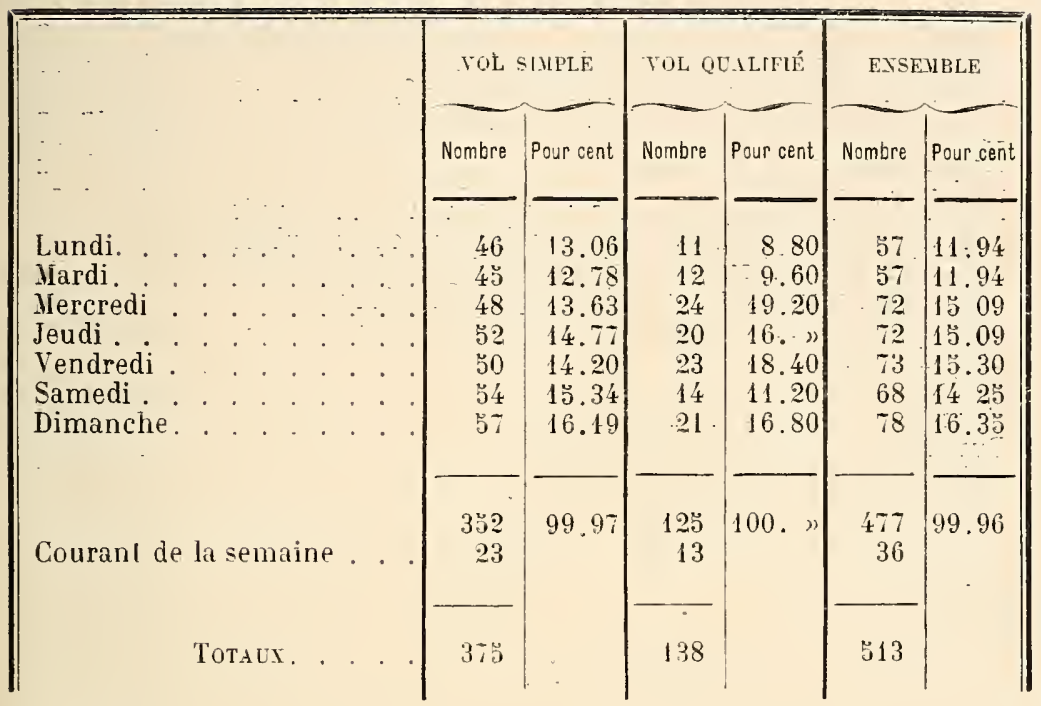

Voici un aperçu des sommes et objets volés:

40.648 fr. ; 30.000 fr.; 4.000 fr. ; 3.104 fr.; etc. etc.; sommes diverses. Montres; bijoux; boucles d'oreilles; tour de cou en or; rivière en diantants; obligations au porteur; bracelets ; pápiers timbrés; portefeuille; portemonnaie.

Effets de lingerie; ustensiles de ménage; livres; tricots; ballots de toile; bérets ; casquettes; restons; parapluies; chaussures ; pautalons; bottines ; bottes; balles de soie; valise ; meubles ; foulards ; cliemises ; couteaux ; tapis ; lampes; brosses; horloge ; pendule; couverts (argenterie, ruolz).

Croquants; café ; fromage; sucre; riz; fèves; graisse; sacs de sézame ; sacs de blé ; chocolat; jambons ; lard ; poules ; agneaux ; lapius ; canards; bouteilles de vin et de liqueurs ; tabac ; cigares ; articles de fumeur.

Fùt de pétrole ; fusil ; liège ; câbles ; paillassons ; piuceaux ; luzerne ; billes de billard; panoplie d'armes; bicyclettes; harnais; voitures (à bras et attelées); cheval ; oiseans servant d'appelauts ; vache; troupeau de 8.3 moutous.

СH. PEHLEк. 
Dressons la liste des victimes:

\section{Frère}

Patron (ancien ou nouveau) (obs. $i, j, 12$ )

Individus divers (obs. $2,3,4,7,13,16,19,2 \dot{3}, 25,30$ $31,32,37,38,41,42,44,45,146,148,149 !$.

Toisins (ots. 6).

II ${ }^{\text {me }}$ Théo (obs. 8).

Négociants, cafetiers, jardiniers, marchands de nouveautés, boulangers, quincailliers, marchands de meubles, hôteliers, marchands de primeurs (obs. 9).

Compagnie transatlantique, Compagnie des docks.

Compatriotes (obs. 10,20,21, 24, 26, 27, 28, 36, 39)

Bijoutiers (obs. 11, 22)

Amis

Conseiller à la Cour de Nîmes $(o b s$, 3 ) . . . . .

Bureaux et entrepôts de tabacs . . . . . . . .

Fille publique (obs. 14).

"Au Grand Paris " de Nice.

$23^{\mathrm{e}}$ bataillon de chasseurs à pied (obs. 17,18$)$.

Maison de banque (ols. 29)

Epiciers (obs. 33 )

Eglises (obs. 34)

Client de son maître (abs. $3 \ddot{j})$

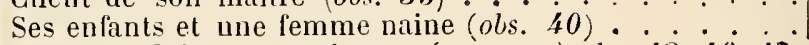

Charité publique ; magistrats (outrages) obs. 43,46 , 47.

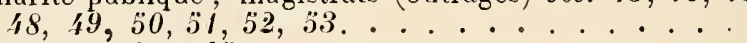

Débiteur (obs. 140̈).

Compagnie d'assurance "Le Soleil " (obs. 147 )

Société $\left\{\begin{array}{c}\text { Fausse monnaie (obs. 138, 139, 140, 141, 142, } \\ \text { Fabrication d'engins explosils (obs. iso). . . }\end{array}\right.$

ToTAlX

\begin{tabular}{|c|c|}
\hline Nombre & Pour cent \\
\hline 1 & 0.17 \\
\hline 22 & 3.89 \\
\hline 266 & 47.07 \\
\hline 24 & 424 \\
\hline 1 & 0.17 \\
\hline 乌̆ & 9.73 \\
\hline 2 & $\begin{array}{lll}0 & 35\end{array}$ \\
\hline 83 & 14.69 \\
\hline 20 & 3.53 \\
\hline 4 & 070 \\
\hline 1 & 0.17 \\
\hline 10 & 1.77 \\
\hline 1 & 0.17 \\
\hline 2 & $03 \breve{~}$ \\
\hline 2 & $0.3 i$ \\
\hline 1 & $\begin{array}{lll}0 & 17\end{array}$ \\
\hline 21 & 371 \\
\hline 3 & 0.53 \\
\hline 1 & 0.17 \\
\hline 1 & 0.17 \\
\hline 29 & 5.13 \\
\hline 1 & 0.17 \\
\hline 1 & 017 \\
\hline i 2 & 2.12 \\
\hline 1 & 0.17 \\
\hline 10.1. & 99.86 \\
\hline
\end{tabular}

$$
\text { 米米 }
$$

Figurent dans la seconde catėgorie:

\begin{tabular}{|c|c|c|}
\hline & Nombre & Pour cent' \\
\hline $\begin{array}{r}\text { Escroquerie (complicité, tentative) (obs. 120, 122, 124, } \\
127,128)\end{array}$ & 28 & 37.33 \\
\hline $\begin{array}{l}\text { Tentative d'escroquerie et usurpation de l'onctions publi- } \\
\text { ques }(\text { obs. } 126) \text {. }\end{array}$ & 3 & 4. $" 1$ \\
\hline Escroquerie et filouterie d'aliments (obs. 13 t $)$ & 1 & 1.33 \\
\hline Escroquerie et abus de confiance (obs. 121,133 ) & 1 & 1.33 \\
\hline Abus de confiance (obs. 123) & 12 & 16." " \\
\hline Abus de confiance et faux (obs. 936 ) & 1 & 1.33 \\
\hline Faux et usage de laux (obs. 120, 129) & $1 \ddot{3}$ & 20. \\
\hline en écriture publique ou authentique (obs. 132 ) & 2 & 2.66 \\
\hline eroute frauduleuse (obs. 131 ) & 9 & 12." \\
\hline Chantage et excitation de mineurs à la debauche (obs. 130). & 1 & 1.33 \\
\hline - (ahs 137$)$ & 1 & 1.33 \\
\hline Délit d'extorsion de valeurs (obs, 1330 ) & 1 & 1.33 \\
\hline
\end{tabular}


On remarque, parmi les sommes, marchandises, et objets détournés par manœuvres frauduleuses:

70.000 francs ; 43.311 fr. $79 ; 26.000$ francs; 18.000 francs $; 9.000$ francs; 8.36 f franes ; 6.000 francs ; 4.500 francs ; 3.000 francs ; 3.000 francs ; 1.600 francs; $1.3 \Xi 0$ francs; 1.000 francs; sommes diverses.

Actif de faillite; mandat-poste ; traites ; livret-postal ; actions au porteur; bijoux.

Vin; récoltes; marchandises diverses; bicyclettes; voiture et cheval.

Le tableau suivant donne la liste des victimes:

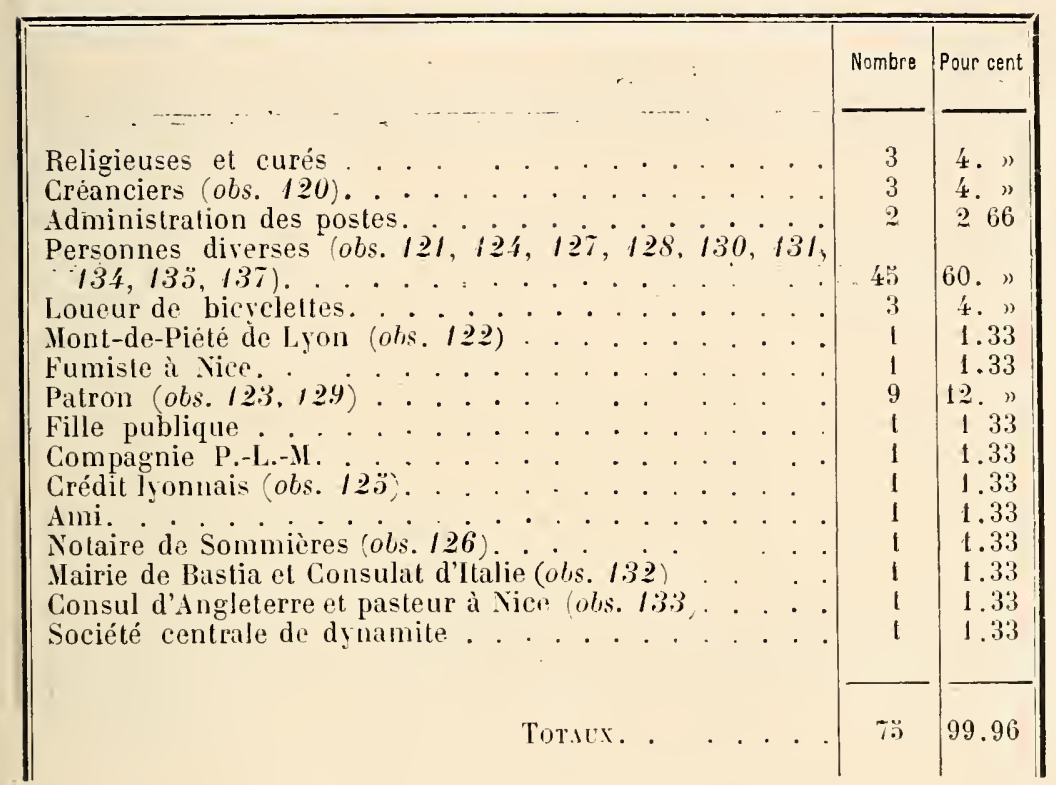


CRIMES-PEISSONNES

Il existe deux catégories :

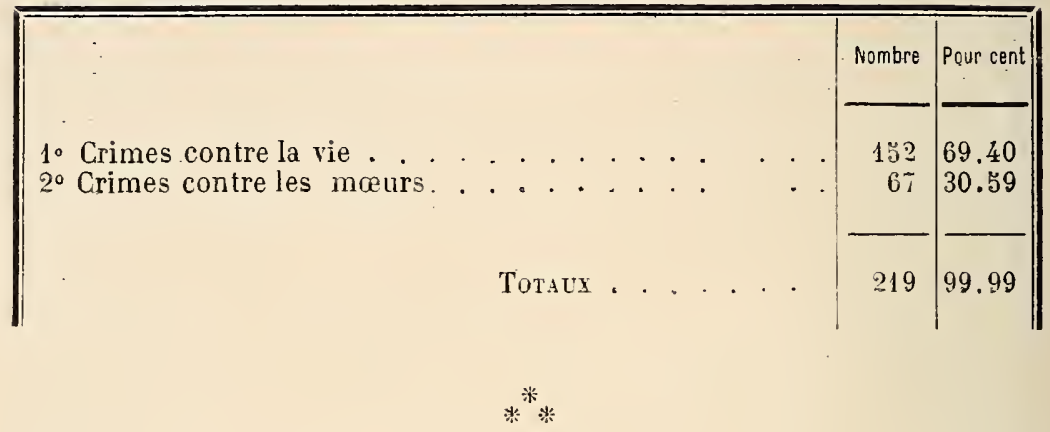

Les crimes contre la vie comprennent:

Violences, voies de fait, rébellion, port d'armes prohibées.

Coups et blessures volontaires

Coups et blessures avec prémeditation

Refus d'obéissance à un ordre relatif au service. . . . .

Coups et blessures ayant occasionné la mort . . . . . . 1

Mlenaces de mort.

Suppression d'enfan

Tentative d'empoisonnement . . . . . . . . . . . .

Tentative d'homicide

Assassinat .

Tentative d'assassinat.

Meurtre provoqué.

Tentative de meurtre provoqué

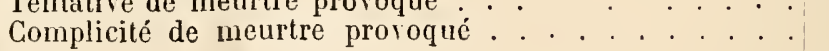

\begin{tabular}{|r|r|}
\hline Nombre & Pour cent \\
\cline { 1 - 1 } 24 & 15.78 \\
59 & 38.81 \\
6 & 3.94 \\
1 & 0.65 \\
17 & 11.18 \\
3 & 1.97 \\
1 & 0.65 \\
1 & 0.63 \\
1 & 0.63 \\
1 & 0.65 \\
2 & 1.31 \\
22 & 14.47 \\
12 & 7.89 \\
2 & 1.31 \\
& \\
\hline 132 & 99.91 \\
\hline
\end{tabular}

Torate 
On rencontre, parmi les armes et corps divers, ayant servi a la perpétration des crimes :

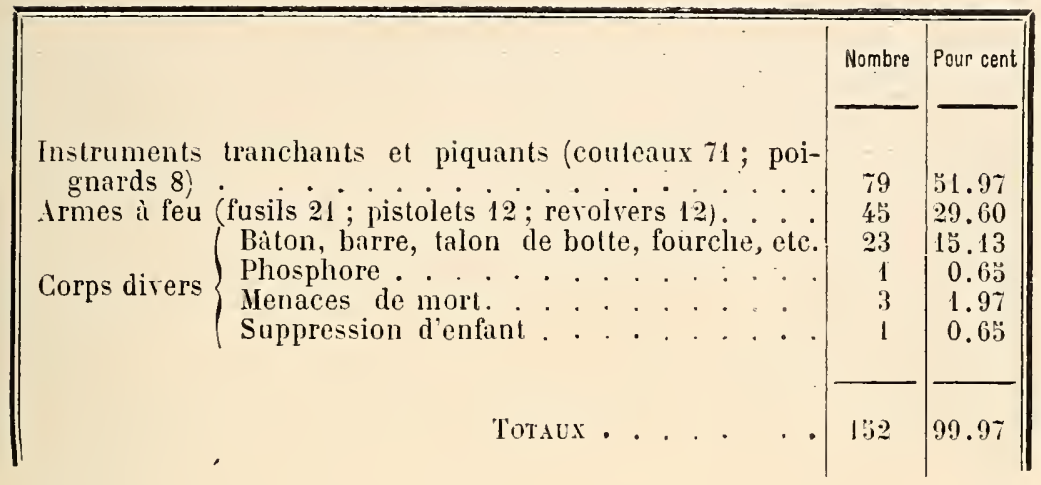

Ces armes et corps divers étant rapprochés de la nationalité des condamnés, on trouve :

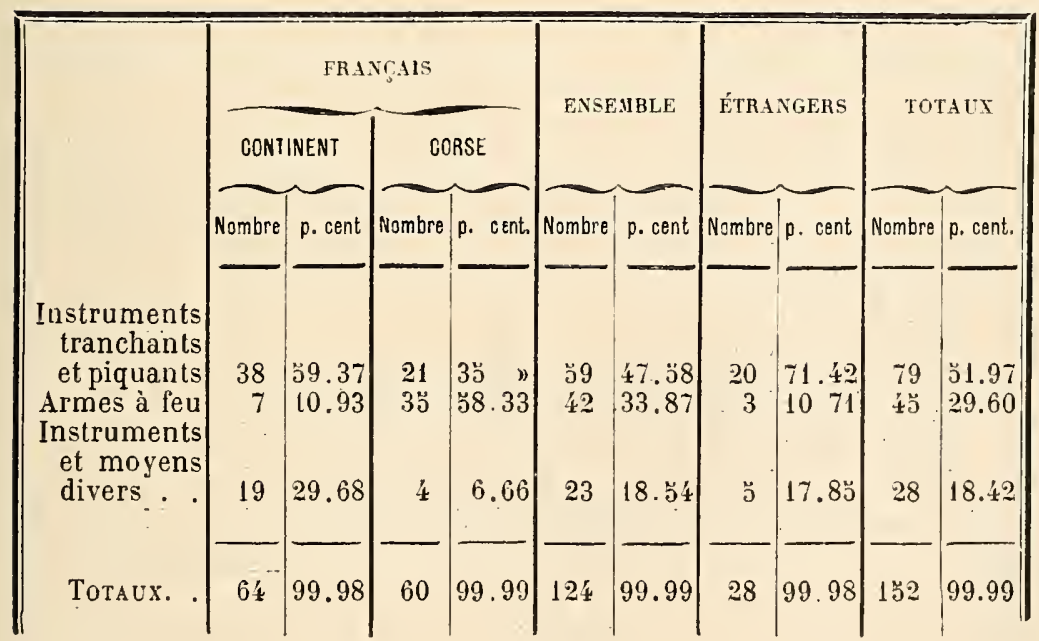


Le mobile du crime fut:

Discussions, disputes (obs. $\ddot{3}, \ddot{3} 8,309,62,63,6 \ddot{3}, 69$, $70,72,73,74,70,77,82,83,84,90,91,93,94)$. Demandes d'argent (obs $54,61,76,81)$. Jalousie (obs. $60,79,80,8 \tilde{)})$

Questions d'intèrêt (obs. 64, $7 i, 8 \%, 92)$

T'entative et complicité de vol $(o b s .66,68)$

Déposition défarorable (obs 89 ).

Inimitiés de famille (obs. $8 S$ )

Contrariété dans l'emploi du temps (ols. 86 )

Inconduite de la fille (obs. $\tilde{\sigma} 6$ ).

Inceste $(o b s .78)$.

Passion politique (obs. 5\%).

Indiscipline militaire (ols. 6\%).

Totaux. . . . . . .

\begin{tabular}{r|r|r|} 
Nombre & Pour cent \\
\hline & & \\
89 & 38.53 \\
15 & 9.86 \\
13 & $8.5:$ \\
12 & 7.89 \\
10 & 657 \\
2 & 1.31 \\
4 & 2.63 \\
3 & 1.97 \\
1 & 0.65 \\
1 & 0.65 \\
1 & 0.65 \\
1 & 0.63 \\
\hline 132 & 99.93 \\
\hline
\end{tabular}

Faisons la liste des victimes:

P’̀̀ (ols. $\ddot{3} 9,61,61$ )

Nì̀re (obs. 69)

Femme $(o b s .72, \dot{\tau} 9)$

Enfant nouveau-né (obs. is)

Frère (obs. 92)

Beau-père (obs. 8j)

Membres de la famille (obs. it

Gendarmes (obs. 57 )

Commissaire de police (abs. $\ddot{\jmath} 6$

Agents $(o b s, 5 \%,, \tilde{0} 6) \cdots \cdots$

Clients (obs. 90)

Associé (obs. 86)

Rival (obs. 8.̈)

Fille publique (obs. 80 )

Camaradé

Compatriote (obs. $28,60,70,71,73,81,82,83$,

$88,89,91$.

Officier (obs. $6 \pi$ )

Personnes diverses (obs. $04,62,68,76,94$ ).

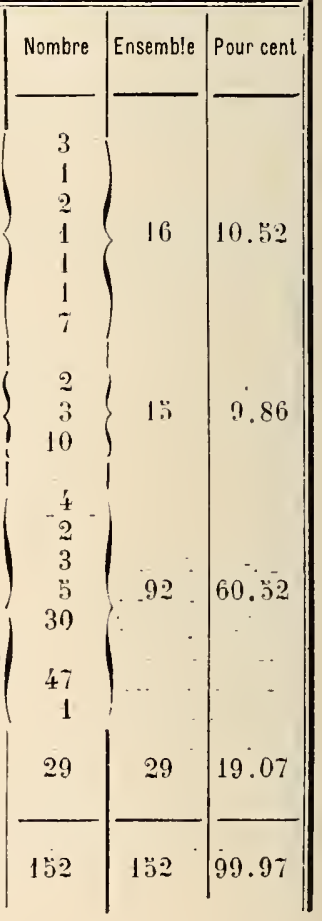




$$
\text { *** }
$$

Rentrent dans la catégorie des crimes contre les mœurs:

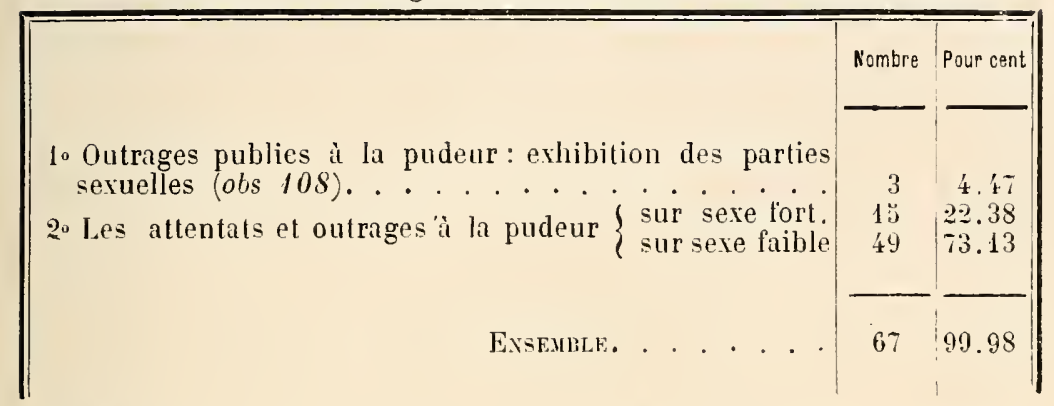

Ces crimes - les outrages publics à la pudeur (exhibition des parties sexuelles) mis a part - se répartissent de la façon suivante:

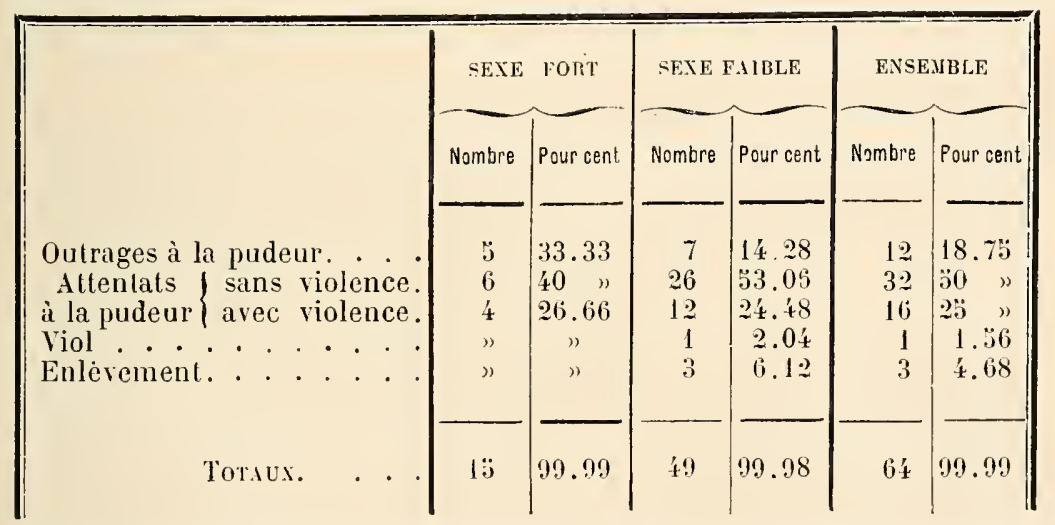

L'acte, ayant motivé la condamnation, fut :

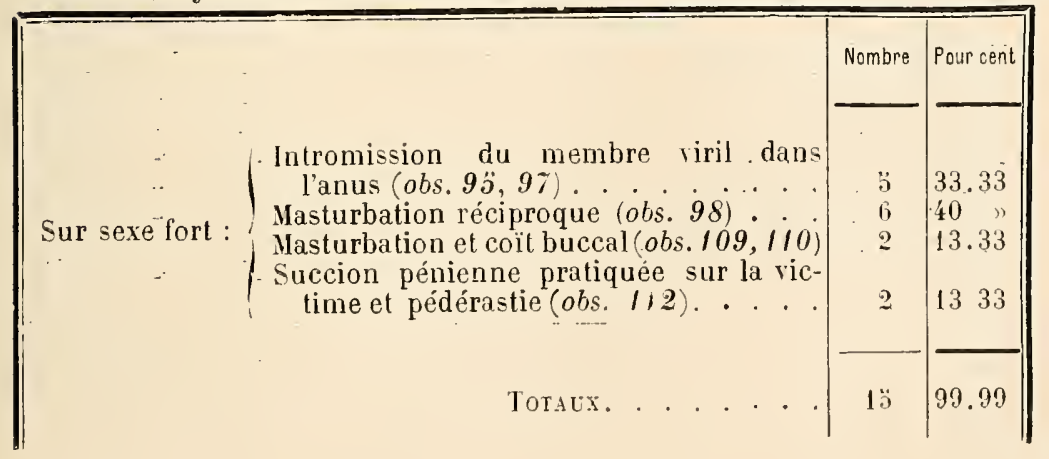




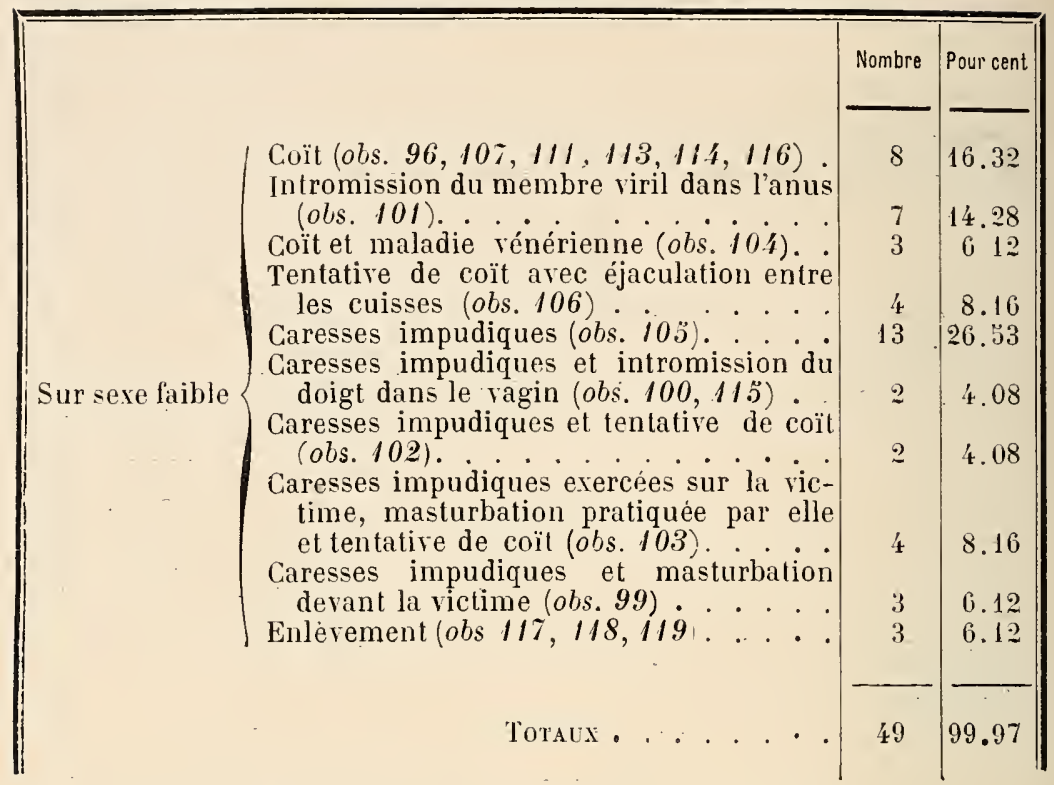

Le tableau, ci-dessous, donne l'âge des victimes:

\begin{tabular}{|c|c|c|c|c|c|c|}
\hline \multirow{17}{*}{ 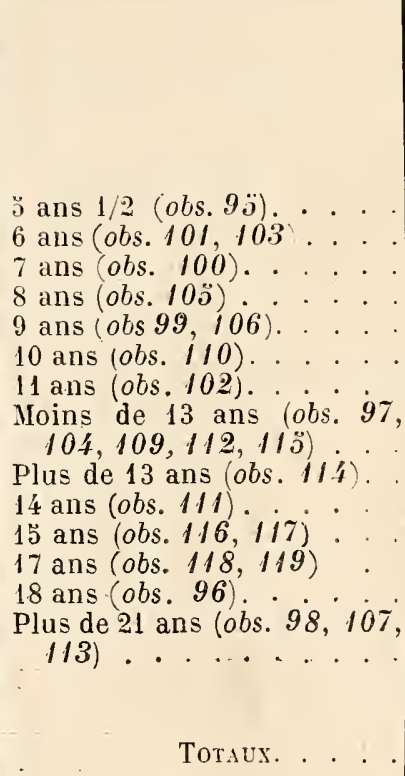 } & \multirow{2}{*}{\multicolumn{2}{|c|}{$\overbrace{\text { Nombre }}^{\text {SEXE Four cent }}$}} & \multicolumn{2}{|c|}{ SEXE FAIBLE } & \multicolumn{2}{|c|}{ ENSENBLE } \\
\hline & & & Nombre & Pour cent & Nombre & Pour cent \\
\hline & 1 & 6.66 & ") & ” & 1 & 1.356 \\
\hline & 1 & 6.66 & $\dot{4}$ & 8.16 & 5 & 7.81 \\
\hline & 1 & 666 & 3 & $\begin{array}{ll}6 & 12\end{array}$ & 4 & $62 \mathbf{2 5}$ \\
\hline & 2 & 1.3 .33 & 4 & 8.16 & 6 & 9.37 \\
\hline & 1 & 666 & 3 & 6.12 & $\dot{t}$ & 6.23 \\
\hline & 2 & $13 \quad 33$ & 3 & 6.12 & 5 & 7.81 \\
\hline & 1 & 6.66 & 3 & 6.12 & 4 & 6.20 \\
\hline & \pm & 26.26 & 16 & 3263 & 20 & $31.2 \partial$ \\
\hline & ” & ” & 2 & 4.08 & 2 & 3.12 \\
\hline & $\eta$ & ) & 1 & 2.04 & 1 & 1.56 \\
\hline & 1 & 6.66 & 3 & 6.12 & \pm & 6.25 \\
\hline & " & 3 & 2 & 4.08 & 2 & 3.12 \\
\hline & ?" & 》). & 2 & 4.08 & 2 & 3.12 \\
\hline & 1 & 6.66 & 3 & 6.12 & 4 & 6.25 \\
\hline & 15 & $99.9 x$ & 49 & 9998 & 64 & 99.97 \\
\hline
\end{tabular}


soit:

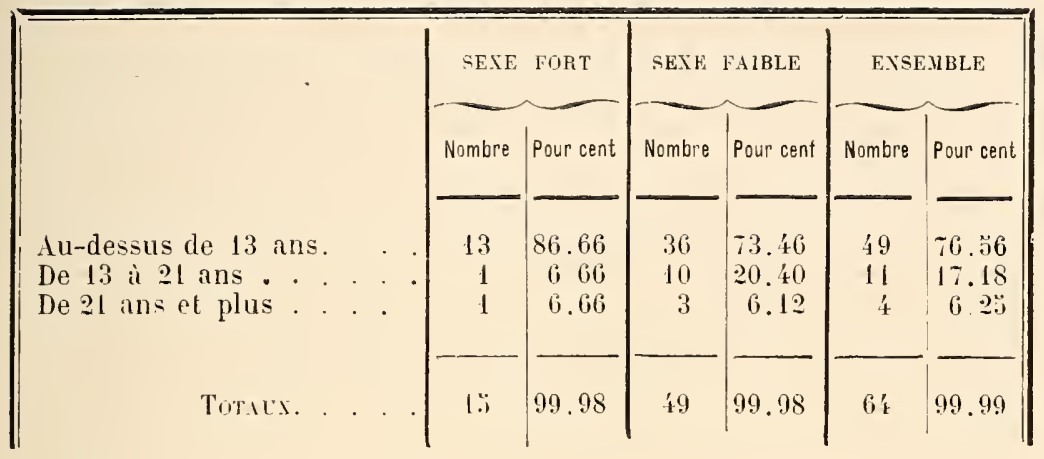

Voici la liste des victimes:

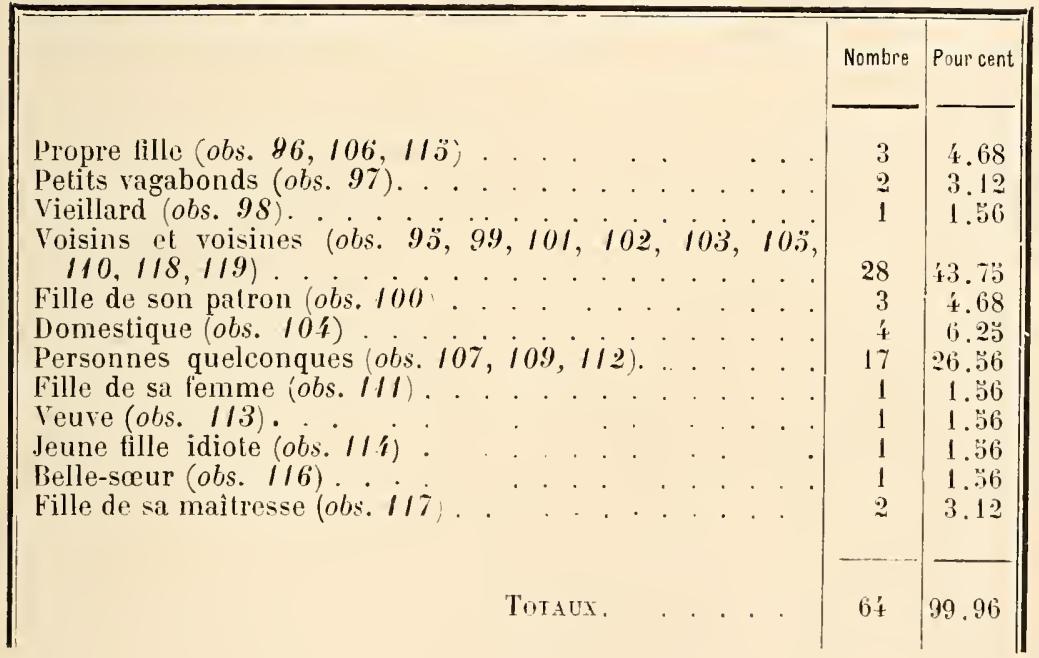





\title{
C.HAPITRE $\mathrm{V}$
}

\author{
PROCEDÉS DES MALFAITELRS \\ ARrOT
}

I.ISTE GENERALE DES VICTIMES

Dans le vol " a la tire », l'adresse, déployée par les pickpockets, tient parfois du prodige.

Le canif ou sacagne, que quelques-uns emploient, pour couper les vêtements au niveau des poches, a donné lieu à bien des commentaires.

S'il faut en croire Macé, il existe, dans les pays voisins du nôtre, des professeurs pour ce genre de vol.

"Après plusieurs leçons, ces professeurs font subir à leurs élèves des examens théoriques et pratiques sur un mannequin. Ce mannequin d'épreuves, habillẻ comme un homme et surchargé de grelots, est suspendu au plafond, par un fil de fer, de sorte qu'au moindre contact les grelots se mettent én branle. Un enfant est jugé apte à travailler dans la foule, lorsque, à diverses reprises et sans faire vibrer un seul grelot, il enleve une bourse ou un portefeuilie dans les poches du mannequin

L'épreuve la plus difficile consiste, sur un mannequin d'homme, à défaire le bouton de gilet pour sortir la barrette de la chaine, et, sur un mannequin de femme, a retrousser la double jupe pour atteindre la poche dissimulée sous le premier vêtement. ") (Unjoli monde.) 
Les pick-pockets introduisent la main dans les poches, l'index et le médius étendus, les autres doigts repliés.

$\mathrm{Au}$ contact de l'objet à saisir, l'index et le médius s'écartent et "font les ciseaux ». - Voir obs. 2.

A Paris, les pick-pockets fréquentent certains cafés que dirigent d'anciens collègues, retirés des affaires. Ils se distribuent, journellement, les quartiers où ils doivent opérer. Les plus habiles font les grands magasins. Ici, surtout, l'association est utile et féconde; elle s'impose même, car, pour se débarrasser de la pièce à conviction, le voleur "à la tire " ne saurait se passer de paravent (complice).

Unis pour le hutin. ces gens-là sont divisés au partage.

Chose digne de remarque, les pick-pockets des grandes villes ne veulent pas laisser travailler, dans leur fief, les ouvrier's qu'ils ne connaissent pas. A moins d'une grande dextérité de main et d'une roublardise imposante, tout nouveau venu est traité en paria et a bien de la peine à se défendre contre les pièges qu'on lui tend.

Les pick-pockets qui se donnent un genre, se réclament ordinairement de la blonde Albion.

En chemin de fer ou à table d'hôte, un Anglais vous adresset-il la parole, méfiez-vous! L'Anglais de bonṇe famille ne parle qu'aux personnes qui lui ont été présentées.

Si habiles qu'ils soient, les pick-pockets viennent, tòt ou tard, s'échouer en prison, où on les retrouve, parfois, sous des noms différents.

A quelques exceptions près, ce ne sont pas des gens dangereux.

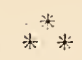

Un grand nombre de voleurs "à l'américaine ) parlent plusieurs langues avec agrément.

Pour mieux rouler le petit monde, ils ont le truc de paraitre 
se confier à lui. Un compère est chargé d'éveiller les convoitises. Il met en vedette un sac, soi-disant plein dor, dans lequel il plonge, de temps à autre, négligemment, la main, ramenant chaque fois une douzaine de louis. Le sac est à double fond et les jaunets sont séparés, d'une certaine somme en monnaie de billon, par un lacet élastique.

Le temps des dupes ne passera point!

Aussi bien, on ne s'explique pas la facilité avec laquelle la plupart d'entre eux se prêtent aux avances des fripons, en acceptant des repas copieux, arrosés de bon vin. - Voir obs. 9 .

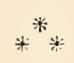

C'est en vagon, dans le voisinage des grands centres, que se pratique le vol " au bonneteau ».

Deux acolytes ou barons filent leur " homme " et s'installent auprès de lui, dans son compartiment. A la station voisine, le teneur ou bonneteur se montre. Après un échange de paroles banales, celui-ci tire de sa poche trois cartes, légèrement voûtées en long. Il les tient dans le sens de la largeur : deux sont placées, l'une au-dessus de l'autre, à un travers de doigt de distance, entre le pouce et le médius gauches; la troisième est saisie entre les mêmes doigts de la main droite.

Il fait passer les cartes de la main gauche, à la droite -après avoir montré la carte de dessous, qui est la carte gagnante - et celle de la main droite à la gauche; ensuite, il les remet en place, deux à gauche et une à droite. Alors. " il passe la main droite, dans laquelle il ne tient qu'unc carte, à gauche, dépose la carte, passe la gauche à droite, fait semblant d'y déposer la carte de dessous et revient á gauche, soi-disant pour placer la carte supérieure à côté cle la première. Enfin, il change lentement les trois cartes de place, tandis que le joueur retient toujours la première cartc, mise a 
droite, et la suit. des yeux-».. Manuel pratique d'instruction judiciaire, par Gross. Tome II, page 433).

Les barons, l'un après l'autre, jouent et gagnent constamment. Leur veine est telle que le voỵgeur se décide à ponter ; il perd tous les coups. Le mot cri, prononcé par le bonneteur, avertit les complices que la carte gagnante està droite. Si c'est $\operatorname{cr} a$, elle est à gauche. Le silence indique le milieu.

Pour commettre un vol " au rendez-moi ", un couple de fourbes est suffisant.

Après avoir mis une marque sur une pièce de 20 francs, les deux filous entrent simultanément dans un magasin (bureau de tabac, épicerie, etc.).

L'un s'offire divers objets qu'il paie avec le jaunet en question.

Si le marchand ne s'aperçoit pas de la marque, l'autre - un lard (vieille femme), souventes fois - renseigné par un mouvement de chapeau, s'empresse d'acheter a son tour; puis, une pochette à la main, complètement vide, il va et vient en personne qui attend sa monnaie.

" Mais, vous ne m'avez rien donné, dit le vendeur.

" - Comment! je vous ai remis 20 francs. Il ne peut y avoir erreur. Je navais que cette pièce; elle est rayée (d'un $\mathrm{X}$ ou d'un V) au revers. ")

Devant la preuve de cette allégation, il est rare que le marchand se refuse i s exécuter.

Le " rendez-moi à la coupure " diffère peu du vol précéclent. Il s'agit d'embrouiller le caissier.

Les deux copains déposent, en méme temps, sur le burcau. un billet d'égale valeur.

Pendant que celui-ci règle sa note, celui-là - feignant 
d'avoir oublié un article quelconque - retire son bleut et s'éloigne.

Aussitôt après le départ du compère, il se présente à la caisse, pour réclamer son argent.

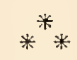

Le chantage " à l'adultère ) vieillit tous les jours.

En notre temps, on fait surtout chanter à l'aide de jeunes garçons.

Le pédé se laisse prendre aux mignardises du chasseur. On l'entraîne dans un endroit écarté, et, à l'instant où il lâche la bride à ses passions, un tiers, toujours suivi d'un complice, intervient. Il se dit le frère du gamin, auquel il donne deux ou trois soufflets, et menace le "vieux sale ) de révélations à la justice. Voir obs. 135.

Le reste se devine.

$$
\text { 类㫧 }
$$

On appelle "mendicité " : l'industrie qui consiste à ennuyer tout le monde de ses complaintes, à ouvrir la portière des voitures, à simuler des infirmités, à tendre la main, à la sortie de l'église, les jours de fétes et d'enterrements, et à se trainer, de maison en maison, invoquant d'une voix cherrotante le secours pécuniaire de chacun.

Les mendiants instruits peuvent être qualifiès d'escrocs.

Que penser de celui qui avait fait insérer dans les journaux cette annonce alléchante: "Plus de maladies vẻnériennes! Moyen infaillible! Envoyer un franc, en timbres-poste, à monsieur X..., telle rue, etc. "), et qui, en échange de la petite somme demandée, adressait aux naïs une vulgaire " capote anglaise ")? 
Couvert de haillons, un bâton à la main et une besace sur les épaules, le vagabond chemine, d'une ville à l'autre, soulevant avec avidité tous les objets qu'il rencontre, s'embauchant pendant la belle saison, couchant dans les grangès ou les meules de foin et se livrant à toutes les vilenies qu'engendrent la paresse et la promiscuité.

$$
*^{*} *:
$$

Les rats - voleurs, aux apparences cossues - se présentent, avec une valise contenant des effets sans valeur, dans les hôtels de premier et de deuxième ordre. Il's demandent une chambre. Bonne note étant prise de la forme des clefs, à table et au jugé, ils choisissent la victime. C'est vers une heure du matin qu'ils pratiquent le barbotage. - Voir obs. 4.

D'aucuns poussent leurs investigations jusque sous le traversin; ils observent les mouvements respiratoires du dormeur et n'avancent la main que pendant le temps de l'expiration.

On leur connaît deux instruments, pour ouvrir les portes dont la clef est sur la serrure, du côté opposé : la queue de rat et le sifflet.

La queue de rat se compose de deux lamelles en acier, longues de 10 à 15 centimètres, très effilées à leur extrémité libre, à face interne concave.

Ces lamelles sont montées sur une poignée en fer et taraudées, extérieurement, près de celle-ci.

Un écrou permet de les rapprocher et de les écarter, à volonté, suivant les dimensions de la clef à saisir.

Le sifflet n'est autre chose qu'un tube en fer, cuivre ou acier, fendu, à l'un de ses bouts, d'une ouverture de 2 centimètres de long sur 3 millimètres environ de large. On le glisse, tout doucement, sur la clef et on va à la recherche du panneton. Quand celui-ci est engagé dans la rainure rlu tube, on fait aller le pène. 
Lors de son arrestation, l'un de nos pensionnaires avait en poche ces deux instruments. Il jugea prudent de se débarrasser de la queue de rat. Le sifflet fut déposé au greffe. En ouvrant, à moitié, la lame qu'il porte à l'une de ses extrémités, on a une poignée toute faite.

$$
*^{* * *}
$$

Un mot sur les " anesthésieurs."

Ainsi se nomment les chahuteurs au narcotique. Ils endorment les gogos, disposés à trinquer avec le premier venu, en versant dans leur verre certains liquides, dont l'effet procure un assoupissement de plus ou moins longue durée.

$$
\text { **** }
$$

Bon gré, mal gré, par tous les temps, il faut que la femme marche. Les souteneurs n aiment pas à vivre dans la purée.

A l'occasion, bravement, par derrière, ils sautent à la gorge du bourgeois et lui serrent le kilii : ce procédé a reçu le nom de ríble. - Voir obs. 7.

Quand ils font le " coup du père François ", l'un d'eux passe un foulard autour du cou de la victime et la charge sur son dos.

Dans cette posture, la face vers le ciel et le corps privé de point d'appui, un homme, si fort qu'il soit, est absolument sans défense.

Mais il arrive que le bourgeois se transforme en chanude (agent de la sûreté). Alors, commence une lutte sanglante.

Le "coup de tête " dans le creux de l'estomac est classique chez le souteneur. La seule parade-riposte consiste à relever, d'un coup de genou dans la figure, la tête de l'agresseur.

Dans le "corps à corps " avec un Alphonse très vigoureux, 
on échappe, au danger de perdre la respiration dans une forte étreinte, par un violent coup de talon sur les orteils. La douleur enlève, momentanément, les forces et fait lâcher prise:

Pour parer le coup " dit des lunettes », les agents placent le bord de la main, sur le milieu du front, parallèlement à la ligne du nez. Sans résultat, viennent se heurter contre la main l'index et le médius de l'agresseur, quand, raidis et écartés en $Y$, celui-ci s'efforce de les plonger, d'un g'este brusque, dans les yeux.

Tout souteneur fait de ses propres vices les vertus de sa condition. Il doit protéger sa notx (femme), connaître toutes les brigades d'agents et être capable de tout.

Tel est le métier qu'embrassent: ceux pour qui il n'y a pas d'occupation plus douce, plus béatifiante, que celle d'admirer une sour qui cagole et qui facilite des intrigues galantes ceux qu'une gigolette distingua, à cause de leur force brutale, lors d'une bataille dans un cabaret mal famé - ceux enfin qui comptent, parmi les refendeurs, les chiqueurs et les nervis, soit un frère, des parents ou des amis. - Voir obs. 55.

Un type à part, parmi les champions des filles, est le dos vert lyonnais; il vit, à peu près exclusivement, de ce que gagne sa femme et ne redoute rien tant que de la mener à Marseille.

En n'ayant pas d'exigences et en travaillant, par lui-même, de différentes façons, le Marseillais, dit-il, gâte le métier.

De telle sorte que les gigolettes lyonnaises, qui ont le gout friand, ne tardent pas, sous le beau ciel de la Cannebière, à se mettre avec un brochet du pays. Et cela, malgré la surveillance la plus active.

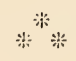

Un bon trousseau de rossignols rend d'immenses "services») aux carroubleurs. Quelques-uns donnent la préférence à gente "clef articulée ", pouvant être introduite dans les serrures à clef pleine et à clef forée, indifféremment. 
Cette clef comprend :

$1^{\circ}$ Un canon, privé de sa moitié supérieure par un coup de. scie dans toute sa longueur;

2 Un demi-panneton, en forme de $T$ renversé, dans la partie inférieure duquel est pratiquée une rainure longitudinale, à queue d'aronde.

Si on la place en face du trou d'une serrure, son demipanneton reste á une certaine distance du fond de ce trou.

Pour avoir une clef complète, les malfaiteurs adaptent au demi-panneton tel embout en gutta-percha. découpé suivant l'un des nombreux modèles de clefs Fichet.

Le système des serrures, soi-disant de sûreté, repose, en effet, sur une série de gorges dont la mise en jeu nécessite l'extrémité seule du panneton.

Un ancien maître serrurier a eu en sa possession trois " clefs articulées », de grandeur différente, et deux cents embouts à formes variées. Il se flatte de compter les serrures récalcitrantes, contre lesquelles il s'est cassé le nez.

Pour l'empreinte des clefs, la cire est toujours le produit préféré.

$$
\text { 米 }
$$

Sous les verrous, les condamnés pour cambriolage n'ont pas de plus mortels ennemis que leurs trois ou quatre collègues d'affaires.

A l'Instruction, ils se sont chargés, mutuellement, le plus possible. N'empêche qu'après la libération, si l'occasion d'un bon coup se présente, ils n'hésitent pas à se donner la main.

La " pince-monseigneur " est leur instrument favori.

En présence d'une serrure compliquée ou incrochetable, ils font une pesée, à 30 centimètres au-dessous des gâches, et, dans l'entre-bâillement de la porte, ils glissent un coin en bois ou en fer; puis, à 60 centimètres au-dessus de ce coin, de la même façon, ils en introduisent un autre. 
Ces coins exercent sur la serrure une force notoire qu'on augmente ì volonté. en les rapprocliant par de nouvelles pesées.

Voilà comment les pènes sautent sans trop de bruit.

Au contraire, si les pesées sont faites de bas en haut ou sur un des côtés de la porte. solidement maintenue avec le pied, ce n'est qu'après de terribles secousses qu'on obtient le résultat désiré. Généralement, le clıambranle et une partie de la maçon nerie cèdent sous la pression de la pince. Aussi, tous les malins de s'écrier: “ On ne peut que hausser les épaules devant les dégâts commis par les voleurs au fric-firac (cassement de portes) ou esclappeurs. "

Dans certains cas, à l'aide d'une mèche en acier, fixée à l'alvéole d'un vilebrequin. les cambrioleurs percent plusieurs trous, en carré, dans le panneau de la porte; ils élargissent ces trous et $y$ introduisent une petite scie, fine, flexible, résistante et graissée fortement, qui pratique, en moins de rien, une ouverture capable de donner passage à un homme.

$$
\text { *** }
$$

On désigne, sous le nom de vanterniers, les voleurs qui s'introduisent dans les appartements. par les fenêtres.

Rien n'est moins sûr qu'un contrevent à persiennes. Un canif bien affilè met, très vite, deux ou trois lames en morceaux. On peut, de la sorte, saisir l'espagnolette et faire tourner le volet sur ses gonds.

Face à face avec la croisée, les malfaiteurs la brisent, si le bruit ne doit pas donner l'éveil.

Dans la crainte du contraire, certains démastiquent et enlèvent, avec précaution, le carreau situé à la hauteur de la poignée de fermeture.

D'autres glissent la pointe du couteau, en arrière des bords 
de la vitre, au niveau de l'angle démastiqué, le plus rapproché de l'espagnolette, sur lequel a été délimité, avec un diamant, le morceau de verre à enlever. Par une pesée légère, exercée sur le manche qui porte la lame, ils font voler en éclats, sourdement, dans le mouchoir ou dans la basque de la veste, une partie du carreau (assassinat de $\mathrm{M}^{\text {lle }}$ de Boisset, à Nîmes, 25 septembre 1898$)$.

C'est en rond que. de prime abord, les fidèles du pétillard (diamant) coupent la vitre. Contre la surface ainsi circonscrite, ils appliquent un lambeau d'étoffe ou de drap, enduit de poix chaude. Quand le tout est devenu adhérent, ils arrachent le fragment de verre incisé. Des petits coups, frappés avec la main, dans le voisinage et en dehor's du sillon tracé par le diamant, aident à la réussite de l'opération.

Dès lors, l'ouverture de la fenêtre n'offre aucune difficulté.

$$
\text { *** }
$$

S'agit-il de forcer un coffre fort et celui-ci est-il à rivets, les malfaiteurs arrachent, l'un après l'autre, les rivets situés sur le pourtour de la porte, en soulevant, à l'aide d'une pince, les plaques en fer sur lesquelles ceux-ci reposent. Et quand, par des pesées nouvelles, les plaques et rivets qui se trouvent au centre ont cédé, ils dévissent les charnières, ainsi découvertes, et enlèvent la porte, en l'inclinant en dedans.

Contre les coffres-forts a parois lisses, nos braves gens recommandent l'emploi de la " perforeuse ". instrument très connu à Marseille.

Cet instrument - invention d'un Turinois - se compose : $1^{0}$ D'une tige en acier, longue de 40 centimètres environ, portant, a l'une de ses extrémités, un tourne-a-gauche, et à l'autre, un taraud, destiné a être vissé dans le trou de la serrure;

$2^{\circ}$ D'un manchon, de même nature, ayant près de 15 centi- 
mètres de diamètré, mobile autour de cette tige, armé, dans sa partie inférieure, d'une couronne en dents de scie;

$3^{\circ}$ D'une barre de fer, sorte de levier à main, qui s'enchâsse sur le manchon et permet de l'actionner;

$4^{\circ}$ D'un écrou, servant à rapprocher le manchon de la paroi du coffre, au fur et à mesure que les dents mordent sur lui. (Celles-ci sont renforcées à leur base et amincies sur le tranchant; une vis les fixe, séparément, au cylindre).

La plaque - circonscrite par le manchon - étant enlevée, les pesées de la pince et du levier jettent la porte à bas.

Disons aussi qu'à l'aide d'un ciseau à froid, d'un maillet et d'une pince, deux repris de justice éventrèrent, en 42 minutes, un coffre-fort dont les parois, séparées par de la terre de pipe tassée, étaient des plaques de fer de 3 millimètres d'épaisseur.

$$
\text { *** }
$$

Ce n'est ni au cabaret ni au bal que les pègres parisiens s'entendent. Ils se donnent rendez-vous sur les boulevards extérieurs ou sur le talus des anciennes fortifications. Toutes dispositions étant prises pour exécuter le travail indiqué, la conversation revêt un caractère banal et chacun rentre chez soi.

Après l'affaire, les marcheur's s'amusent. Malheur à eux, s'ils tombent sur une gigolette, amie de la police! La belle enfant racontera que l'homme, avec lequel elle mange, boit et fait le reste, ne travaille pas, qu'il dépense tout son argent mal a propos et qu'elle lui sait un portefeuille bien garni. Mais, c'est tout! Même dans un milieu sûr, les pègres de Paris'sont maîtres de leur langue. Ils se soutiennent. Et, chose étrange, si vicieux qu'ils soient, il est des moments où ils éprouvent le besoin de faire le bien. Qu'un malheureux se trouve sur leur chemin, ils le secourent de leur bourse. Malgré cela, ils tiennent toujours, pour un objet de mépris, "les victimes d'une honnêteté mal placée »). 
Le Marseillais est tout l'opposé du Parisien.

Cette opinion est défendue avec chaleur par un gonze des plus madrés :

Le jour de son arrivée à Marseille, deux individus vinrent, en plein café, lui proposer l'achat d'un pardessus et d'une montre. Tout d'abord, il crut avoir en sa présence des " voleur's d'occasion ». Il les suivit dans un bar de la vieille Poissonnerie, où l'on s'entretenait, à bouche que veux-tu, de toutes les affaires en cours.

"Quelle cueillette, si j’avais été de la police!"

Le lendemain, après avoir, en leur compagnie, opéré une boutique, il se mit en quête de poisses sérieux.

Il ne rencontra partout que des gens auxquels il ne faut pas conter de secret.

Les Marseillais sont des bavards!

Et il ajoute : nombre d'entre eux se plaisent à reconnaître que la vue de la misère les laisse indifférents.

Durant le vol - s'il est de quelque importance - un complice, au moins, fait le guet. Celui-ci, tout en cherchant à ne pas attirer l'attention des passants, doit avoir un coup d'œil assez exercé pour décider, tout de suite, à la vue d'un importun, s'il y a lieu de donner l'éveil aux amis.

C'est la femme qui remplit, le mieux, le rôle de guetteur. Elle est moins suspecte, plus attentive et surtout plus rusée que l'homme.

Le plus grand nombre de vols se commet pendant la nuit. Ainsi, si l'on s'en rapporte aux 513 cas qui nous occupent, on trouve une différence de $2 / 33$ p. 100, en moins pour le jour.

La nuit, tous chats sont gris, dit le proverbe.

Dans les vols simples, le jour tient la corde. Du matin au soir, en effet, toutes les boutiques sont ouvertes, chacun va et vient sans défiance; il se présente force occasions au voleur. - Voir tableau, page 336.

De tous les jours de la semaine. le dimanche est celui qui a la préférence des voleurs. 
Les cambrioleur's opèrent surlout les mercredis, vendredis et jeudis.

A quelques exceptions près, le samedi est un mauvais jour pour les pègres, car les commerçants ont la "fâcheuse " habitude de vider leur caisse, ce jour-là.

Les lundis et mardis sont considérés comme jours fériés: Quand on a travaillé toute la semaine, il est bien juste de se reposer un peu, "tout au moins le temps d'aplatir la bourse" - ce qui n'est pas long, les cambrioleurs cédant à vil prix les objets les plus précieux. - Voir tableau, page 337.

Un voleur rusé ne pénètre dans une maison qu'après avoir combiné plusieurs plans de sortie. De même, quand il y est entré, il s'inquiète de fermer toutes les portes donnant accès sur la pièce où il opère.

Pris la main dans le sac, la plupart des cambrioleurs n'hésitent pas à donner un mauvais coup. Ceux-là sont " indignes ") de la dénomination de voleurs.

Cette qualification est trop "brillante » pour qu'on l'applique à ceux qui tuent, en proie au vertige et à l'affolement, dans le cours d'un vol.

Quant aux individus que la cupidité mène au crime, ce serait navoir aucun " sentiment d'honneur ) que de se demander s'ils peuvent se parer du titre de voleur.

Les confidences que firent, en état de prévention, à Marseille, Poulain, le meurtrier de sa grand'mère, et Barillot, l'instigateur du crime de la rue du Baignoir, montrent que, pour ces derniers, le vol ne peut être commis sans tuer.

“ Lorsque j'ai rencontré Chabot, disait Poulain, je n'avais pas encore l'idée de tuer ma grand'mère, je voulais tout bonnement la voler. Chabot m'ayant persuadé qu'en la tuant, non seulement on ne s'apercevrait pas du vol, mais encore que j'hëriterais, la pensée du crime ne me quitta plus. Et, c'est avec la ferme intention d'assassiner ma grand'mère que nous nous sommes rendus chez elle, à la Cabucelle. "

Barillot, lui, s'exprima en ces termes: 
“ Du jour où j’ai su que la vieille avait des bijoux et de l'argent, j'ai eu l'idée de la tuer. Comme j'avais peur de ne pas réussir, j'ai fait saouler Simon que je connaissais pour s'adonner à l'ivrognerie. L'ayant conduit chez la vieille, je l'ai invité à saisir celle-ci par le cou. Pendant que je fouillais dans la chambre, il roula avec elle sur le parquet. "Serre fort ", lui dis-je. Il obéit si bien qu'avant d'avoir fini mes recherches, la vieille était morte."

Le voleur véritable ne perd jamais la tète. Connaissant le Code pénal, il aggrave rarement son cas. Sa préoccupation habituelle, quand des fâcheux viennent le déranger, c'est de fuir.

Ainsi pensent les fines lames de l'établissement.

$$
\text { *** }
$$

Les anti-travailleurs considèrent le travail, dans notre socièté moderne, comme une " prostitution ", et le vol comme une "restitution ».

Puisqu'on appelle prostitution, disent-ils, l'action de vendre ou de louer une partie de soi-même, le salarié, qui vend ou loue ses bras et son cerveau, est donc un prostitué, au mème titre que la fille publique.

" Ne voulant pas être cela, nous nous déclarons anti-travailleurs; nous proclamons le droit au vol, pour subvenir à nos besoins matériels et intellectuels, le vol étant à la fois une restitution et un moyen révolutionnaire. "

De toutes les villes, comprises entre la Tech et la Roya, sont arrivées des recrues à ce "groupe ", dont la formation, à Bordeaux, en 1891, souleva la réprobation des " anarchistes théoriciens 》).

La chanson suivante est de la composition d'un Anti, deux fois incarcéré, à Nîmes, pour vol : 


\title{
LES ANTI-TRAVAILLEURS
}

\author{
Air de Roger Bontemps
}

Anti-travailleurs, anarchistes, Fervents disciples de l'Égalité, C'est nous qui faisons, en artistes, Une guerre féroce à la société.

Francs compagnons, énergiques et braves,

Nous fuyons du travail les ignobles entraves, Loin du patron et loin de l'atelier.

Cambrioleurs! voilà notre métier.

\author{
Ne foutant rien, \\ Jamais d'turbin, \\ Un, deux, trois, \\ Marquons l'pas, \\ Les Anti ne turbinent pas! \\ Un, deux, trois, \\ Marquons l'pas, \\ C'est la terreur des bourgeois! \\ Par tous les temps, \\ Foutons-nous sur le flanc; \\ Plus d'exploiteurs, \\ Tous anti-travailleurs!
}

Proclamant l'droit à la paresse, Nous estimons que le paure exploité Commet un acte de bassesse, Se faisant le soutien de la propriété. Car, turbinant, et turbinant sans trève, Il ne consomme pas; devant le tas, il crève. Et pendant que le patron, l'exploiteur, Sur sa misère sait édifier son bonheur,

Brave ouverrier, Faut turbiner, Un, deux, trois, etc. 
Si tous les travailleurs du moude, Cessaieut leur abjecte prostitution, Avec leurs masses profondes,

Nous aurions vite fait notre révolution.

Et sans lusils, sans bombes, sans barricades, Rien qu'en posant l'outil qui tue et qui dėgrade, Grève sur tout et dans tout l'Univers!

Le monde bourgeois serait vite mis à l'envers.

Grève sur toul, Chambard partout, Un, deux, trois, etc.

Quand on verra luire la sociale, Et que, daus l'Univers entier, Devant la fureur générale, S'ouvrira l'ère des grandes luttes sans quartier, Les Anti commenceront la besogne, Qui purgera la terre de toute la charogne. Bourgeois, jugeurs, galonards et patrons, Sous leurs lourdes faux comme des épis tomberont.

Marchant les premiers;

Fauchant sans pitié, Un, deux, trois, L'arme au bras, Les Anti ne reculent pas, etc.

Quand l'Anarchie, par toute la terre, Aura fait son grand ròle épurateur, En se groupant par caractères, l.es Anti devieudront d'excellents travailleurs. Car, le travail u'étant plus l'esclavage, Ils mettront, tous, la main et le creur à l'ouvrage. Pour leurs besoins, travaillant eu commun, Le travail de tous fera le bonheur de chacuu.

Après l'anarchie, C'est l'harmonie.

Pour le droit et pour soi,

L'Anti-travailleur travaillera;

Pour le droit et pour soi, Quand il n'y aura plus de bourgeois,

A ce moment,

Nous levant fièrement,

Saus exploiteurs,

Plus d'Anti-travailleurs! 


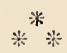

Les pègres donnent le nom "d'indicateur ) au mecque (affranchi ou non) qui propose " le coup ).

Bien qu'il ne participe pas à l'exécution du vol, celui-ci a part au gâteau.

Pour bien remplir sa mission, l'indicateur doit explorer avec soin l'état des lieux et s'enquérir des habitudes, de rentrée et de sortie, des locataires de la maison à mettre à sac.

Les meilleurs indicateurs sont les domestiques.

Ceux du commun se recrutent parmi les employés, les hommes de peine, les colporteurs, mendiants, aiguiseurs de couteaux, tondeurs de chiens, etc.

La plupart des indicateurs sont des repris de justice; ils travaillent dans l'ombre, par crainte de la relégation.

L'ignominie de notre temps sert - non pas d'excuse - mais d'explication à la chute des autres, que la nécessité a entraînés, le besoin excités, fous d'une heure qu'un bon conseil eût arrêtés sur la pente du crime.

Nous faisons dialoguer un indicateur accidentel : X... - et un poisse, de bas étage: Bibi de Montmartre.

La scène se passe, "à la Maubert ", dans un caboulot borgne. - X... entre, regarde de tous côtés, puis se dirige vers Bibi, assis loul seul à une table, en traiu d'etrangler un perroquet.

X... - Bonjour, Monsieur. Si cela ne vous dérange pas, je désirerais vous parler.

Brbi. - Hein! Quoi qu'vous dites? .... Monsieur. ..! Oh! là, là Y Y m'appell' monsieur! Mince, alors! Ousque vous allez? Ousqu'est mon fusil, que je vous naye (noie)?

Ohé! les aminches (amis). Passez-moi une ficelle, que je 
l'attache! Après tout, bourgeois, quoi qu'vous payez ? mais, ne m’appelez pas monsieur; ça me chagrine!

$\mathrm{X}$... - Ne vous fâchez pas, mon ami... (Au garçon) Garçon! une vieille bouteille, ce que vous avez de meilleur!

Bibi. - ( A part) Chouette! Quel chic! C'en est un de la Haute. Faisons-lui voir qu'on est distingué.

(A u monsieur) Posez vos miches su' c'quat' pieds-là (assevezvous sur cette chaise).

$\mathrm{X}$.. - Mon ami, je ne vous comprends pas.

BıBı. - Ça fait rien; c'est du pareil au même.

Quoi qu'vous avez à me jacqter?

$\mathrm{X}$... - parle tout bas et fournit mille indications précises sur un vol à commettre.

Bibi.., - Ah! çà! Dites donc, vous! Pour qui qu'vous m'prenez? On est mal nippé, mais on est honnête! Je vous vois venir; vous êtes de la rousse et vous voulez me faire jaspiner. Changez d'conversation; sinon, je vous pose ma tête sur les babouines... (Au garcon qui passe) Eh! l'enflé ! Encore une bouteille! c'est Monsieur qui paye !

$\mathrm{X}$... - Mon ami, je suis employé dans la maison en question. Si vous en doutez, prenez mon adresse. J'ai absolument besoin d'argent et je ne demande que le tiers de la somme enfermée dans le secrétaire dont voici la clef. Si je ne peux compter sur vous, aidez-moi tout au moins à trouver quelqu'un.

Bibi. - Parlez plus de ça! on verra!

Ousque j' pourrai vous rencontrer, demain, à huit heures du soir (à huit plombes sur la sorgue)?

$\mathrm{X}$... - Venez au pied de la statue, place de la République. Il se lève pour s'en aller.

BiBi. - Pas si vite! aboulez du pognon....., il me faut deux 
écus (tunes)...... (Au garçon) Encore une bouteille! Et ouste! C'est, toujours, Monsieur qui paye!

X... glisse deux pièces de cinq francs à Bibi; il règle les dépenses et sort. Bibi fait sonner en l'air les écus. Il est aussitôt très entouré. Ses amis lui demandent: qui qu' c'est que ce pante?

BiBI répond:

C'est un cavé qui m'fait porter un billet doux à une dame de la Haute.

(S'adressant au garçon) De l'absinthe, comme s'il en pleuvait! Ce coup-là, c'est moi que j'paye!

(A part, à ses deux collègues d'affaires) Chut! Demain, rancard (rendez-vous) au guinche (bal) de la rue des Gravilliers.

Faudra prendre les scions (couteaux) et plaquerles gonzesses. $\mathrm{Y}$ a turbin (travail) et du bath (bon)!

Tous boivent à la santé du Monsieur.

$$
\text { *** }
$$

Le voleur est l'homme lige du receleur, car celui qui ne sait où écouler le produit de ses vols, est à la merci de la police.

On rencontre, parmi les receleurs, des brocanteurs, fripiers, bijoutiers, commerçants, négociants, agents d'affaires, etc., etc. A chacun, sa spécialité : d'un côté, les acheteurs de vêtements, cafés, grains, liquides, chevaux, etc.; de l'autre, les connaisseurs en bijoux, pierres précieuses, tableaux, œuvres d'art, etc., les preneurs de titres et obligations frappés d'opposition - Ceux-ci restituent les valeurs à leur véritable propriétaire, moyennant une somme fixée d'avance, par l'entremise de certaines maisons de crédit, établies à l'étranger.

D'aucuns paient dans les vingt-quatre lieures.

La plupart sont mous à la détente. "Que voulez-vous ? Les 
temps sont durs et le métier, quoique très lucratif, est chanceux!"

Comme tout autre, en effet, le métier de receleur a son apprentissage. Le receleur doit redouter que, tôt ou tard, les voleurs le dénoncent. Souci inquiètant est aussi le flagrant délit de recel. Sans compter le danger auquel expose la vente de la chose volée, surtout si cette vente se fait, par la voie d'un intermédiaire et sous un faux nom.

Il est d'usage de ne montrer au receleur qu'une partie des objets qu'on veut lui vendre, car tout bon receleur est plus voleur que le voleur lui-même. Plus celui-ci paraît embarrassé, plus son complice l'exploite.

Ordinairement, l'or se paie 2 franes le gramme, et l'argent 0,04 centimes. Mais, bien souvent, la balance du receleur est fausse, tout comme les poids.

Un receleur très connu, c'est le Mont-de-piété.

Munis de papiers établissant leur identité, les voleurs offrent les objets volés, en gage de la somme qu'on leur avance. Dans ce cas, disent-ils, il importe de se présenter au Mont-de-piété, avant que le vol n'y ait été signalé.

Tout receleur, qui n'est pas traqué, ne tarde pas à s'enrichir. Après l'arrière-boutique, vient l'entrepôt. Bientôt, il peut faire la nique à la police.

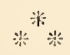

A signaler, parmi les métaux que les faux monnayeurs allient, le plus fréquemment, pour la fabrication des pièces blanches:

$1^{\circ}$ le nickel, le zinc, l'antimoine et le cuivre;

2 le nickel, l'étain, le zinc et le cuivre;

$3^{\circ}$ le nickel, le plomb, le cuivre, l'antimoine et l'étain.

Dans la composition des pièces jaunes, entrent, généralement, du nickel et du cuivre, saupoudrés de bismuth. 
La dorure galvanique aide à la méprise.

Cependant, les pièces fausses se distinguent, par un poids moindre, des pièces frappées à l'hôtel de la Monnaie.

Un creuset en terre réfractaire, une lime douce, des tenailles tranchantes et des moules de différentes dimensions, tels sont les outils du faux monnaveur.

Les moules se préparent avec un mélange de 250 grammes de plâtre fin (pour ornement), 50 grammes d'alun, 50 grammes d'huile de lin, 100 grammes d'eau et quelques grammes de poudre de marbre.

Les pièces á imiter sont décapées.

Ayant choisi une pièce de 2 francs, à l'effigie bien nette, le faux monnayeur la place sur un carreau de vitre et l'entoure, à une certaine distance de ses bords, d'un encaissement, haut de 2 centimètres. Dans l'espace ainsi circonscrit, il coule une quantité suffisante du mélange. Sous l'influence d'une douce chaleur, celui-ci forme un corps solide, résistant.

La pièce s'y trouve emprisonnée, par le côté pile, par exemple.

Pour obtenir l'image du revers, il graisse légèrement toute la surface du plâtre, qui reposait sur le verre, et, sur cette surface, il établit un nouvel encaissement qu'il nivelle avec le mélange.

On sépare les deux parties.

Alors, se pratiquent : la veine, par laquelle s'effectuera le coulage, et la double petite ouverture, en forme d'entonnoir, qui doit permettre au métal en fusion de chasser l'air du moule.

Le moule des pièces de 5 et 20 francs est plus compliqué, en raison de l'inscription : “Dieu protège la France », frappée sur le pourtour.

Des deux côtés de la pièce à imiter, introduite au centre d'un tube en carton, on verse, alternativement, la pâte du mélange.

Le rondin, qui en résulte, est graissé, puis couché dans une boîte-un peu inférieure, en hauteur, au diamètre de la piècequ'on remplit du même plâtre liquide. 
A la surface, après durcissement, il est facile d'établir un encaissement et d'achever le moule.

Celui-ci comprend 5 parties . une pour l'effigie, une pour le revers, et trois pour le pourtour.

$$
*^{* *} *
$$

C'est par un mélange de corps divers, en proportions déterminées, que s'obtiennent les pâtes ou matières explosibles, en usage dans les milieux anarchistes.

Quelques-unes de ces pâtes produisent des effets surprenants, telles :

$1^{\circ}$ Chlorate de potasse, soufre pulvérisé, essence de térébenthine et eau ;

2 Chlorate de potasse, sulfure dantimoine, chrome brûlé, colle de poison et eau ;

$3^{\circ}$ Deutoxyde de plomb, sulfure d'antimoine, chlorate de potasse, colle forte et eau ;

$4^{\circ}$ Picrate de potasse, deutoxyde de plomb, sulfure d'antimoine, colle de poisson et eau.

Les bombes - en général : boîtes, de forme carrée, en ferblanc, ou marmites en métal quelconque - sont de deux sortes :

$1^{\circ}$ A renversement;

2 A temps déterminé.

La bombe "á renversement " a son fond tapissé de projectiles. Sur les projectiles, se trouve la pâte explosible, dans laquelle le doigt a creusé un petit trou qui sert de magasin à poudre. Par-dessus la poudre (une capsule de fulminate la remplace avantageusement), s'étale une couche de sodium. Des balles, clous, etc., remplissent les interstices.

Après immobilisation, les parties sus-mentionnées sont appliquées, sens dessus dessous, sur le couvercle de la boîte, 
qu'une petite cavité, contenant de l'eau, déprime en son milieu.

Voilà l'engin armé.

Un simple renversement suffit pour que l'explosion ait lieu. Au contact de l'eau, le sodium s'enflamme et communique le feu à la poudre.

La bombe "a temps déterminé » est traversée, dans sa partie supérieure, par un tube en verre, rempli de fulmi-coton. L'extrémité inférieure du tube repose sur un tampon de sodium. A l'autre bout, est placé un récipient d'eau. Quand celle-ci arrive sur le sodium, la détonation se produit.

$$
\text { *** }
$$

L'argot varie d'un groupe d'individus à l'autre.

Pour désigner un agent de ville, le " petit voyou " dira : un sergot; le "banquiste » - nomade s'établissant dans une ville, pour la durée d'une fête - emploiera l'expression : la secrète; le "souteneur", le " grec », le " pègre » jargonneront: l'un, la rousse; l'autre, la poule; le troisième, la machine.

Les pègres parlent par figure, quand ils appellent: lourde, une porte; dur, une pince-monseigneur.

Le mot lourde témoigne de la solidité de la porte et du mal qu'il faut se donner pour l'enfoncer. Dur montre la résistance que la pince doit avoir.

Au pluriel, ce dernier mot signifie: travaux forcés.

Dès que le besoin s'en fait sentir, des changements sont apportés dans les termes d'argot. Nos argotiers se piquent, d'ailleurs, d'être dans le mouvement. Aussi bien, n'ont-ils pas mille moyens d'enrichir leur glossaire? De job (fou, idiot), ils ont fait jobard, jobastre, nobard du jo.

Et, qui dirait que nobard du jo, à l'air si barbare, n'est au fond que ce débonnaire et placide jobar'd, maquillé suivant le procédé simpliste des pègres de Lyon, Marseille, Toulouse et autres lieux? 
Le mécanisme est facile a saisir.

La première lettre (j) est remplacée par un $n$, et la syllabe (jo), oú figure la lettre supprimée, est mise à la fin du mot, séparée de lui par l'article $d u$.

A Paris, le mode de transformation diffère légèrement: on met un $L$ a la place de la première lettre, et celle-ci est ajoutée à la fin du mot, avec la terminaison éme ou $e^{\prime}$.

Gardien se dit gaffe, d'où :Laffegé et Laffegème.

Nice a son jargon à part; c'est celui des pégres d'Italie. Turin en est le lieu dorigine.

La singulière arenture. qu un pick-pocket nous raconta, témoigne de l'intérèt qu'il y a de comprendre le jar.

Il déjeunait, au buffet des Ares, à côté de deux individus, vètus très correctement. Ceux-ci causaient à voix basse :

En décarrant, disait l'un, porte none au rupin qu'est à ton coustible et je le servirai (en sortant, bouscule le monsieur qui est pres de toi et je lui prendrai son argent).

A l'aile ou en double (dans quelle poche l'a-t-il : a l'extérieur ou à l'intérieur de la veste) ? demanda l'autre.

En double, répondit le premier.

L'idée lui vint de leur jouer un tour.

Il inscrivit sur un morceau de papier, qu'il plaça bien en vue dans son portefeuille: vous faites four; je suis fauché (vous tombez mal; je n'ai pas le sou). Puis, à table, il attendit que ce fût l'heure de monter en voiture. Alors, il se dirigea, d'un air distrait, vers la porte du quai. A peine en avait-il franchi le pas qu'il fut débarrassẻ de son la:agne.

Les deux compères s'esquivèrent, aux lieux d’aisances, pour examiner le butin.

Juste ciel ! Leur voisin de table était un collègue sans doute. Ils se présentèrent à lui et s'excusèrent. L'entretien se termina par ces mots: Porte none, nous faderons (donneznous un coup de main, on partagera) à Marseille.

Notre lomme eut d'autant moins de peine a se rendre a cette 
invitation qu'il ne pouvait tenir du pèze(argent)à ses maîtresses, précisément dans ce temps-là.

Voici quelques-unes des locutions les plus usitées, dans les prisons, à Nîmes :

Se taire quand il faut, se dit: rengracier, fermer sa boîte $\dot{a}$ temps.

Manger, c'est boulotter, croîter, se gonfler le bidon, morfiller, etc.

Claquer du bec signifie qu'on a faim.

Celui qui fait bonne chère se dore le citron, s'efface les plis.

Sous les verrous, souffrir équivaut à se décoller, tourner en ficelle, se déplumer.

Aller faire du firicandeau à Montpellier, c'est mourir.

Quand on a l'haleine mauvaise, on fouette de la gueule, on renifle de l'entonnoir.

Le poltron est un type qui flasque dans son grimpant; il a le foie blanc.

Un bossu se définit: Mayeux, le Bombé, Sac au dos.

On dira d'un borgne, qu'il a un carreau cassé.

Celui qui louche est un mecque qui regarde dans les coins.

On n'entrave que dale, quand on ne comprend pas un mot d'argot.

Tout vaseux (paysan) qui se corrompt, s'affranchit.

Les faux monnayeurs sont des rétameurs en plâtre ou en jonc, suivant la couleur des pièces qu'ils fabriquent.

L individu, condamné pour attentat à la pudeur, est un tâteur de gosselines, un amateur d'abricots.

Le couteau, arec manche en bois, entouré d'une virole immobilisant la lame, s'appelle un lingue.

On désigne, sous le nom de surin, le couteau à lame large et tranchante, qui se ferme.

Le 22 est un couteau de boucher, à manche plein.

Aller dans le boudar, c'est venir à la Centrale. 


$$
\text { 米类 }
$$

\section{Liste générale des victimes}

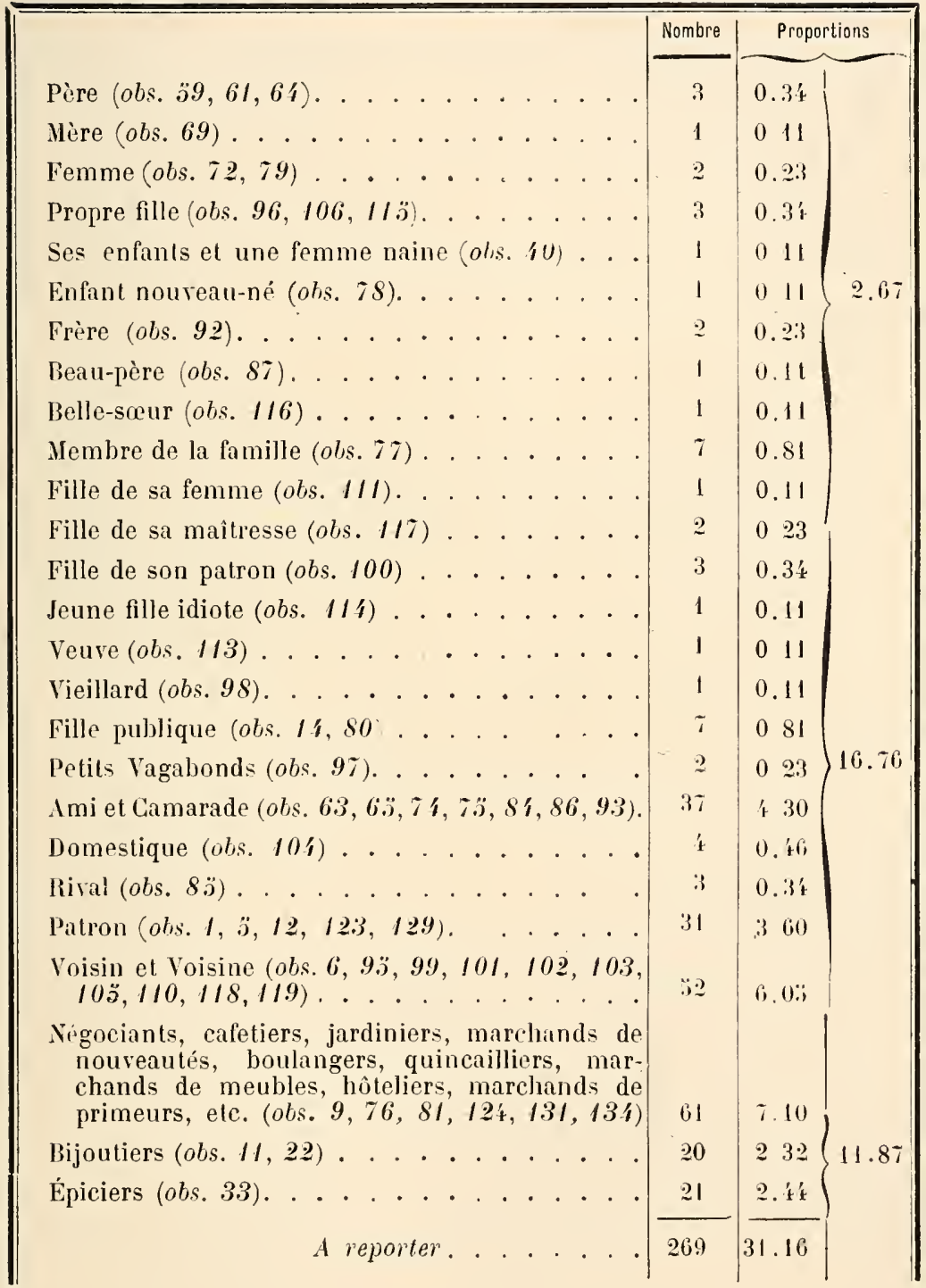


Liste générale des victimes (suite)

\begin{tabular}{|c|c|c|c|}
\hline \multirow[b]{2}{*}{ lieport } & \multirow{2}{*}{$\frac{\text { Nombre }}{269}$} & \multicolumn{2}{|c|}{ Proportions } \\
\hline & & 31.16 & \\
\hline Loueur de biejclettes. . . . . . . . . . & 3 & $0.3 \dot{t}$ & \\
\hline Débiteur (ots. 14כ̈). . . . . . . . . . . & 1 & 0.11 & \\
\hline Crëancier (obs. 120). & 3 & $0.3 \dot{t}$ & \\
\hline Notaire de Sommières (obs. 126). . . . . . & 1 & 0.11 & \\
\hline Consul d'Angleterre et pasteur, à Nice (obs. 133). & 1 & 0.11 & \\
\hline Religieuses et curés & 3 & $0.3 \pm$ & \\
\hline . . . . . . . . . & 1 & 0.11 & \\
\hline Madame Théo (obs. \&) . . . . . . . . & 1 & 0.11 & \\
\hline Conseiller à la cour d'appel de Nimes (obs. 13). & 1 & 0.11 & 60. วั3 \\
\hline $\begin{array}{c}\text { Gendarme, commissaire de police, agent (obs. } \check{0} \text {, } \\
\quad \check{0} 6,07,66)\end{array}$ & 1 כ̆ & 1.74 & \\
\hline Fumiste, à Jice . . . . . . . . . . . . . & 1 & 0.11 & \\
\hline 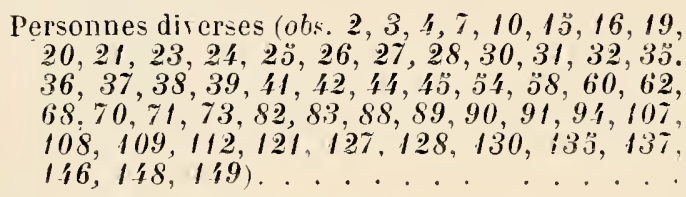 & 489 & 56.92 & -1 \\
\hline A॥ Grand Paris de Nice. . . . . . . . . . . . & 2 & 0.23 & \\
\hline Mont-de-piété de Lyon (obs. 122). . . . . . & 1 & 0.11 & \\
\hline Église (obs. 34) . . . . . . . . . . . . & 3 & $0.3 \mathrm{i}$ & \\
\hline Mairie de Bastia el Consulat d'llalie (obs. 132). & 1 & 0.11 & $24 t$ \\
\hline $23^{\mathrm{e}}$ Bataillon de chasseurs à pied (obs. 17, 18). & 2 & 0.23 & \\
\hline Bureau et Entrepòt de Tabac . . . . . . . . & 10 & 1.16 & \\
\hline Administration des Postes. . . . . . . . . . & 2 & 0.23 & \\
\hline Société génèrale (obs. 29) . . . . . . . . . & 1 & 0.11 & $\begin{array}{lll}093 & \end{array}$ \\
\hline Crédit lyonnais (obs. 123̈) . . . . . . . . . & 1 & 0.11 & 0.20 \\
\hline Compagnie transatlantique et $\mathrm{C}^{\text {ie }}$ des Docks. . . & 2 & 0.23 & \\
\hline Compagnie d'assurances : "Le Soleil" (obs. 147). & 1 & 011 & 8 \\
\hline Compagnie P.-L.-M. . . . . . . . & 1 & 0.11 & 0.00 \\
\hline Société centrale de dynamite (obs. 136). . . . & 1 & 011 & 4.88 \\
\hline $\begin{array}{l}\text { Sharite publique et magistrats (outrages) (obs. } 43 \text {, } \\
\quad 46,47,48,49,50,51,52, \tilde{5} 3)\end{array}$ & 29 & 3.37 & \\
\hline $\begin{array}{r}\text { Societe (obs. 138, 139, 140, 141, 142, 143, 144, } \\
100) .\end{array}$ & 13 & 1.51 & \\
\hline Tutsux. . . . . & 8509 & 99.68 & \\
\hline
\end{tabular}




\title{
TABLE DLS MATIËRES
}

\author{
TOME PREMIER
}

\section{INTRODLCTION}

Natıovılıté : Français, Italiens, Espagnols, Anglais, Arabes, divers .

Professions : Proprictaires et renticrs, employés de banque et de comnerce, commerçants et fabricants, professions alimentaires, ourriers dateliers et de fabriques, ouvriers du billimenl et du mobilier, professions agricoles (journaliers, domestiquest, nomades, sams

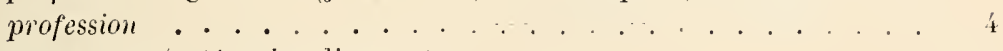

LES CRIMUNes (catégories diverses) :

1. - Pickpockels, chevalices dindustrie el rats d'hitels. . . 6

II. - Faillis, banquerouliers, employés infideles, escrocs médiocres ou faiscurs. . . . . . . . . . . . . i

III. - Paysans et ouvriers; impulsifs . . . . . . . . . . . . 8

IV. - Vagabonds, mendiants, petits voyous, souteneurs timides 8

i. - Souteneurs avérés et royous tragiques. . . . . . . 10

VI. - Anarchistes. . . . . . . . . . . . 11

Criueș et délits ayant hotivé la condahidtion. . . . . . . . . . 12

\section{CHAPITPE PRENIER}

CRIMEs ET DÉLITS, CONEIDÉRÉs a 38 pOINTS UE VUE, ET OBSERVATIONS

I. - rol simple, complicité, tentalire, recel. . . . . . . . 15

II. - Vol qualifié, elc. ............. . 48

flt. - Vol, ragabondage, mendicilé . . . . . . . . . . TE

IV. - Vagabondage, outrages aux magistrats. . . . . . . . 91

V. - Violences, coups el blessures, rébellion . . . . . 109 
VI. - Coups et blessures ayant occasionné la mort, saus intention de la donner........... 134

VII. - Menaces de mort, suppression d'enfant, tentative d'empoisonnement, tentative d'homicide, assassinat, tentative d'assassinat .............. $13 \mathrm{t}$

VIII. - Meurtre, complicitè, tentative. . . . . . . 163

IX. - Attentats et outrages à la pudeur, etc. . . . . . 18'

X. - Viol. . . . . . . . . . . . 213

XI. - Détournement de mineurs, enlèrement . . . . . . $21 \%$

XII. - Escroquerie, abus de confiance, banqueroute, laux, elc. 218

XIII. - Fausse monnaie (fabrication, émission) . . . . . . 246

XIV. - Incendie . . . . . . . . . . . . 260

$\mathrm{XV}$. Fabrication d'engins explosifs . . . . . . . . 272

TABLEAU dES CRIMINELS, PAR CATÉGORIES D'AGE. . . . . . . . . 27'

Thbleau des hoteñes A.titiroponétriques . . . . . . . . . 273

\section{CHAPITRE II}

CruMes ht déltTs, groupés en \pm Catégories . . . . . . . . . .

I. - Vols, vagabondage, mendicité, outrages aux magistrals, lausse monnaie, incendie, fabrication dengins explosifs. . . . . . . . . . . . 277

II. - Escroquerie, banqueroute, faux, etc. . . . . . . . 287

III. - Attentats contre Ia vie. . . . . . . . . . . . . 287

IV. - Attentats contre les mours. . . . . . . . . . . 298

Tableau des Criminels, yar Gatégories D'age. . . . . . . . . 308

Tableau des hoyennes anthroponétriques. . . . . . . . . . . 309

\section{CHAPITRE III}

I. - Crimes-propriétés . . . . . . . . . . . $31 \mathrm{t}$

II. - Crimes-personnes . . . . . . . . . . . . 321

Tabieau des crinhels, par catégories dage. . . . . . . . . . 332

TABleaU des hoYeNnes aNThroponétriques. . . . . . . . . . . 333

\section{CHAPITRE IV}

RENSEIGNEMENTS DIVERS ET LISTE DES VICTIMES, P.AR C.ATÉGORHSS DE CRMES ET DÉLITS

I. - Rapport des crimes-propriétés entre eux . . . . . . 33 3̈

VOLS . . . . . . . . . . . . 336

tleure (jour ou nuil) du crime . . . . . . . . . 336 
Jour (de la semaine) du crime. . . . . . . . . . 337

Sommes et objets volés. . . . . . . . . . . 337

Liste des victimes. . . . . . . . . . . . . . . 338

Escroqueries, etc . . . . . . . . . . . . . 338

Sommes et objets détournés. . . . . . . . 339

Liste des victimes. . . . . . . . . . . . . 339

II. - Rapport des crimes-personnes entre eur . . . . . . 340

Crimes contre la vie. . . . . . . . . . . . . 340

Instruments ayant servi à perpétrer le crime. . . . . . $34 \mathrm{t}$

Nationalité des condamnés et instruments. . . . . . 3 H1

Mobile du crime. . . . . . . . . . . . . . 342

Liste des victimes. . . . . . . . . . . . . . 342

Crimes contre les heurs. . . . . . . . . . . . 343

Sexe de la victime. . . . . . . . . . . . 343

Acte ayant motivé la condamnation. . . . . . . . 343

Age des victimes . . . . . . . . . . . . 344

Liste des victimes. . . . . . . . . . . 343

\section{CHAPITRE V}

Procédés des yalfaiteurs. - Argot. - Eiste générale des victimes

Vol a ̀̀ la tire n (sacagne) (planche 6ă). . . . . . . . . 347

Vol "à l'américaine " (sac à double fond) (planche 6马̈). . . . . 348

Vol " au bonneteau ". . . . . . . . . . . . . . 349

Vol " au rendez-moi " et "à la coupure " . . . . . . . 350

Chantage . . . . . . . . . . . . . . 331

Mendicité et vagabondage . . . . . . . . . . . 331

Les Rats (instruments : queue de rat et siflet) (planche 66). . . 332

Vol " au narcotique" . . . . . . . . . . . . . . . . . 333

Le souteneur (coup du ráble, coup du père François, coup do

tête dans le creux de l'estomac, corps à corps, coup des lunettes). . . . . . . . . . . . . . . . 333

Le carroubleur (clef articulée) (planche 6i) . . . . . . . 354

Les cambrioleurs (pince-monseigneur, vilebrequin, etc.) (pl. 68). 355

Les vanterniers (manière de casser un carreau de vitre). . . 356

Ouverture des coffres-forts à rivets et à parois lisses (perforeuse, etc.) (planche 68). . . . . . . . . . . 357

Comparaison entre les pègres de Paris et ceux de Marseille . . 358

Le guetteur . . . . . . . . . . . . . . . . . 359

Choix du jour el de l'heure, pour le vol. . . . . . . . . 359

Le voleur véritable ne tue pas . . . . . . . . . . . . 361

Les anti-travailleurs (chanson anarchiste). . . . . . . 361

L'indicateur (dialogue entre un indicateur accidentel et un poisse de bas étage). . . . . . . . . . . . . . 364

Le receleur (Mont-de-piété, etc.). . . . . . . . . . 366 
Fabrication de la fausse monnaie (moules en plâtre) (planche 69). 367 Fabrication d'engins explosifs (bombes à renversement et à temps déterminé) (planche 70 ) . . . . . . . . . . . . . 369 Argot (procédés de changement dans les termes d'argot, aventures d'un pickpocket, quelques locutions d'argot). . . . . 370 Liste générale des rictimes. . . . . . . . . . . . . 373 


\section{DESSINS, INSCRIPTIONS, BAS-RELIEFS, PORTRAITS}

Planche 1. - Portrait de l'auteur.

2. - Couverture de la statistique qui a servi de base à ce travail, et qui comprend 173 tableaux, ornés de façons diverses : dessin exécuté, en 1898, par le nº 1659, employé de commerce.

- 3 - Plan de la Maison Centrale de Nîmes (d'après un croquis du Ministère de l'Intèrieur), par le $n^{\circ} 1659$.

4. - Plan du fort (d'après l'historien de Nîmes, Ménard), par le $\mathrm{n}^{0} 2705$, dessinateur.

- $\quad$ 3. - Plan des enceintes successives de la ville de Nîmes, depuis les Romains jusqu'à nos jours (d'après Germer-Durand, architecte), par le $n^{\circ} 1659$.

6. - Le gardien infirmier-major, les secrétaires et les dessinateurs du Docteur, en 1897: dessin exécuté, d’après une photographie, par le no 3480 , vétérinaire.

7. - Entrée du boudar ou de chez mon oncle, à Nîmes : dessin exécuté, d'après une photographie, par le $n^{0} 3001-$ sujet autrichien.

8. - Cour d'honneur, par le même.

9. - Préau $\mathbf{n}^{\circ} 2$, par le même.

10 à 40 . - 30 portraits de condamnés de toutes catégories, exécutés à la plume (d'après photographie), par les $n^{\text {os }} 2705,3480$, et 3049 (sujet espagnol, restaurateur) 15 autographes.

- 40 à 61 . - 24 dessins, inscriptions et bas-reliefs, relevés, pour la plupart, sur les murs et dalles des cellules de punition, comprenant :

L.e portrait de "Nina ", par un de ses adorateurs, cuisinier (cellule 13) (planche 45).

l.inscription : Bientôt on y goûtera, et image, crayonnées, sur le mur de la cellule 1, par un membre de la Société des pédés (planche 46 ).

3 bas-reliefs, exécutés, dans la cellule 20, par le $n^{\circ} 2651$, pêcheur (planches :50, 51 et 52). 
Plarahe 40 à 61 . - 2 dessins, gravés dans la cellule 32, par le n* 2261 (dit Jean Bati), marin, qui "fait 3 ans san le fere espre" (planches $5 \%$ et 56 ).

Et autres dessins, inscriptions, exécutés par les $\mathbf{n}^{\text {os }} 3039$ (dit le Longui), portefaix; 2897 (dit Louis du Pont d'Arenc), maçon; 2587, boulanger; 2412 , journalier; 2097, marin ; 1581 , journalier; etc., etc.

- 61. - Carnet de tatoueur, saisi au n $n^{\circ} 3188$, journalier.

- 62. - Pierrot jouant de la guitare (lommage des $n^{\text {os }} 2705$ et 1418).

- 63. - Arrestation d'un assassin (hommage du $n^{\circ} 3049$ ).

- 64. - Vient de paraitre (hommage du $n^{\circ} 3001$ ).

- 65. - Planq (page 6); Sacagne (pages 17 et 348); Sac à double fond (page 349).

- 66. - Queue de rat et sifflet (pages 20 et 352).

-- 67. - Rossignols et elef articulee (page 334).

- 68. - Pince-monseigneur (page 355); Perforeuse (page 357).

- 69. -- Moules en platre, pour la fabrication de la fausse-monnaie (page 368).

- $\quad$ 70. - Bombes à renversement et à temps déterminé (page 369). 


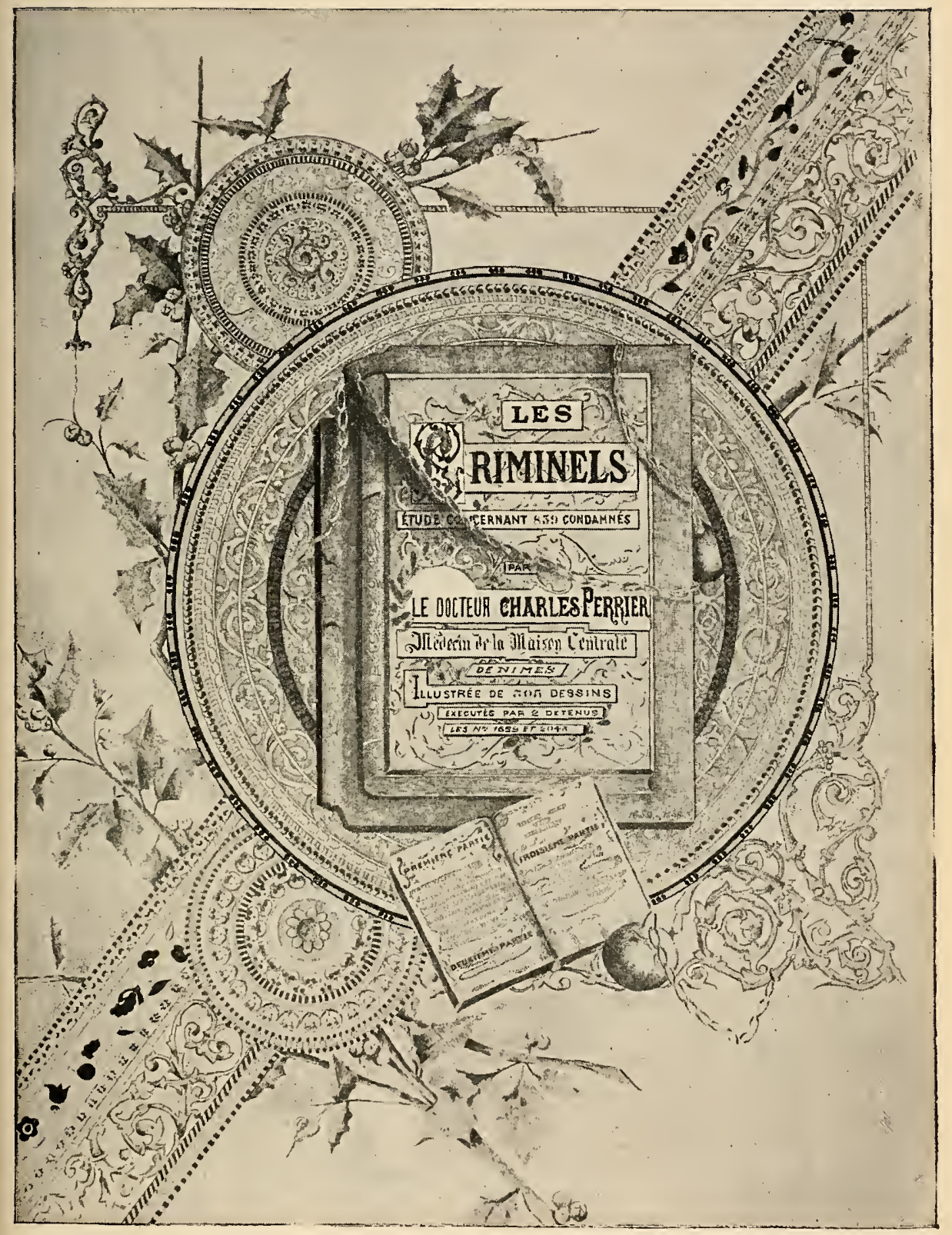

Pl. 2. - Couverture de la statistique. 



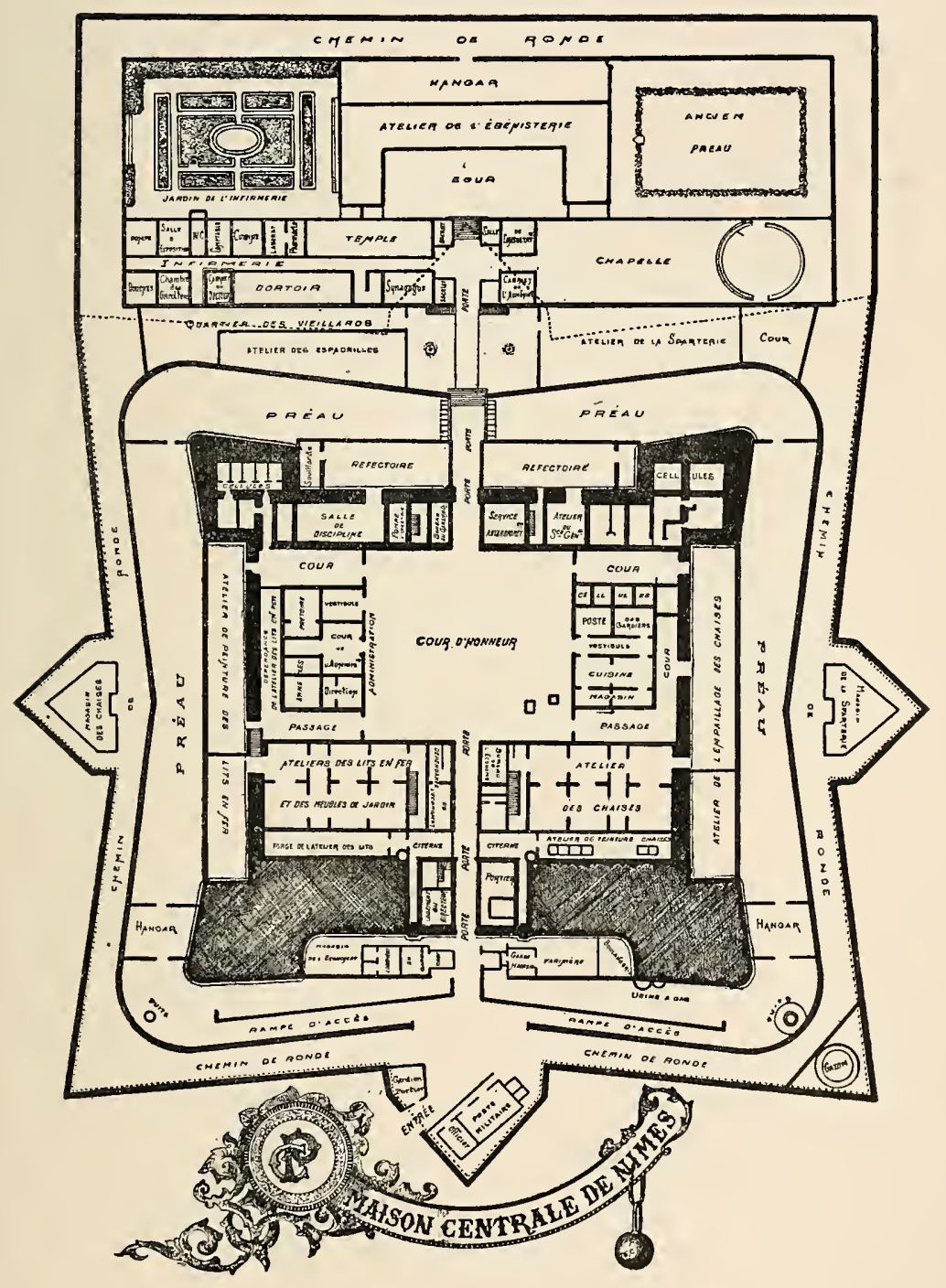

$P l$. 3. - Plan de la Maison Centrale de Nîmes. 



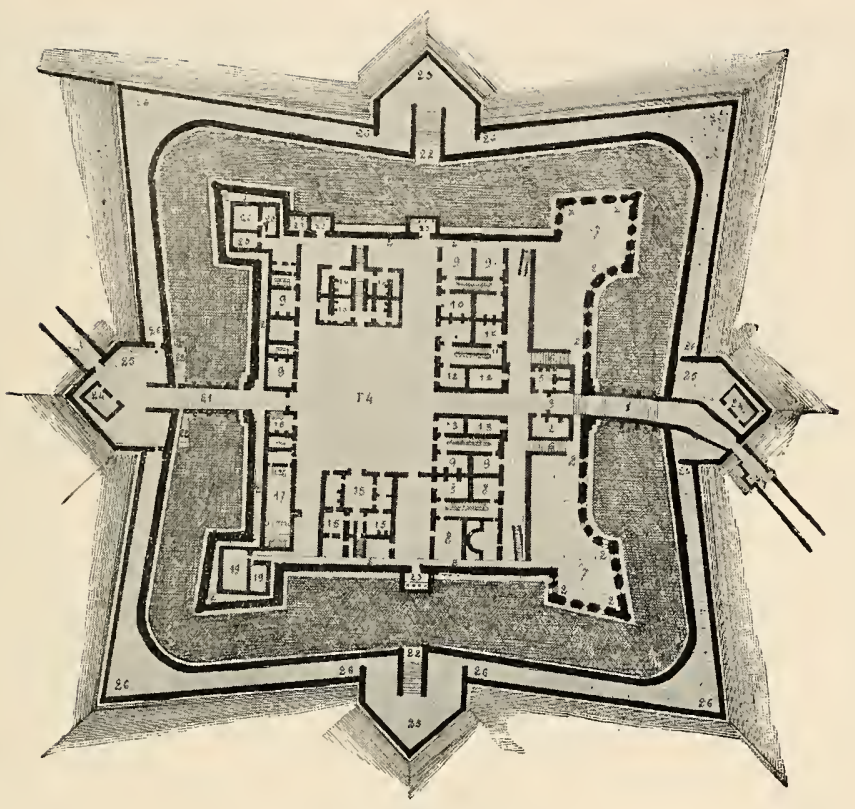

Pl. 4. - Plan du fort.

I. Porte et pont conduisant à la ville.

2. Mur d'enceinte.

3. Vestibule de la porte d'entrée.

4. Corps de garde pour les soldats.

5. Corps de garde de l'officier.

6. Escalier pour monter et descendre au rempart.

7. Bastions.

8. Logement des officiers de la garnison.

9. Casernes.

ro. Logement de la cantine.

11. Corridor avec escalier.

12. Bûchers et caves.

13 Prisons.

14. Place d'armes.
15. Logement du commandant.

16. Logement du major.

17. Chapelle.

18. Logement de l'aumônier.

19. Magasins pour les vivres.

20. Magasin pour les munitions de guerre.

2. Porte et pont, conduisant à la campagne, pour l'entrce des secours.

22. Escalier pour descendre dans le fossé.

23. Latrines.

24. Corps de garde de l'entrée des portes.

25. Ouvrages tenant lieu de places d'armes ou de demi-lunes.

26. Chemin couvert, autour de la place. 



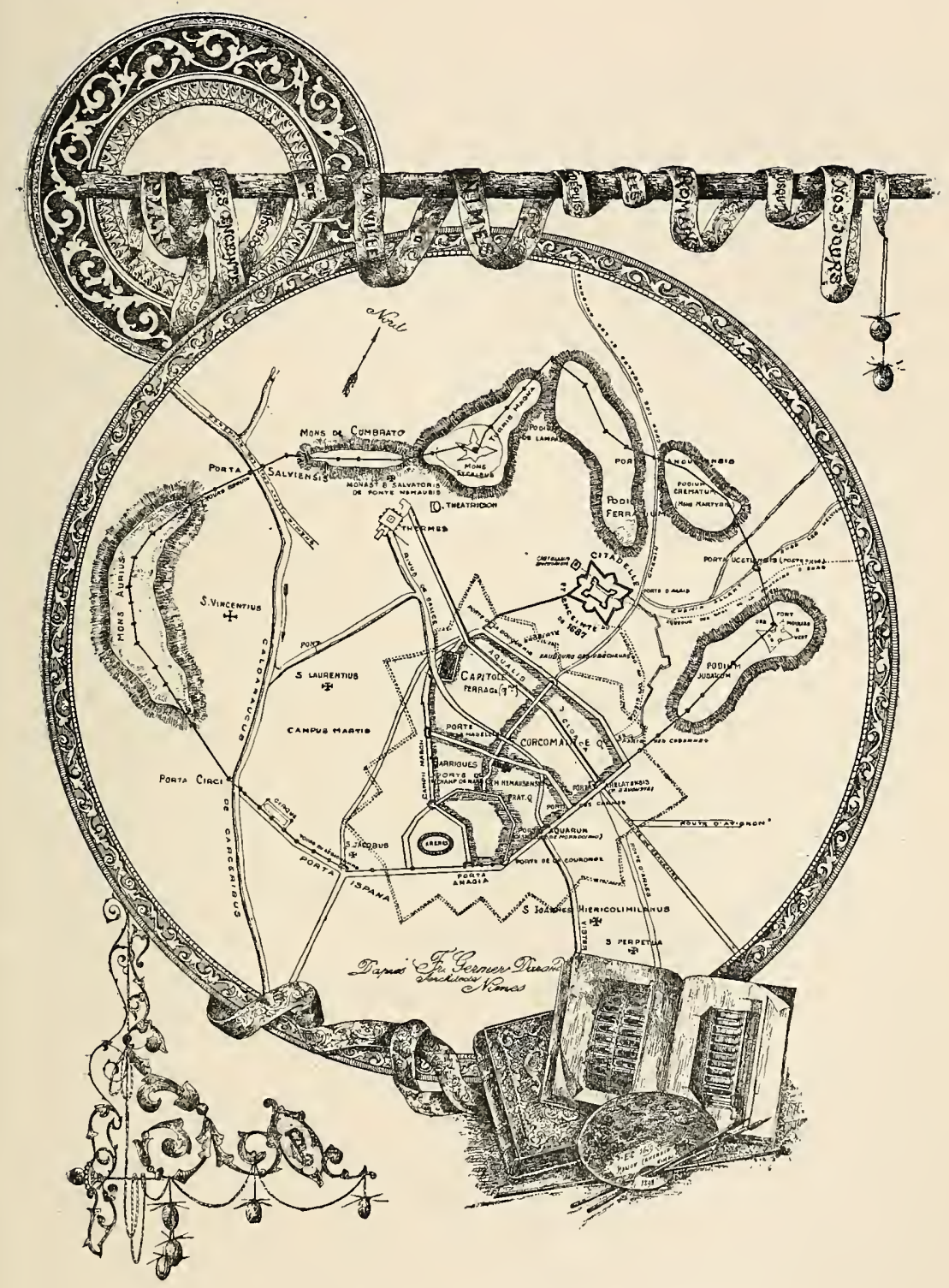

Pl. 5. - Plan des enceintes successives de la ville. 



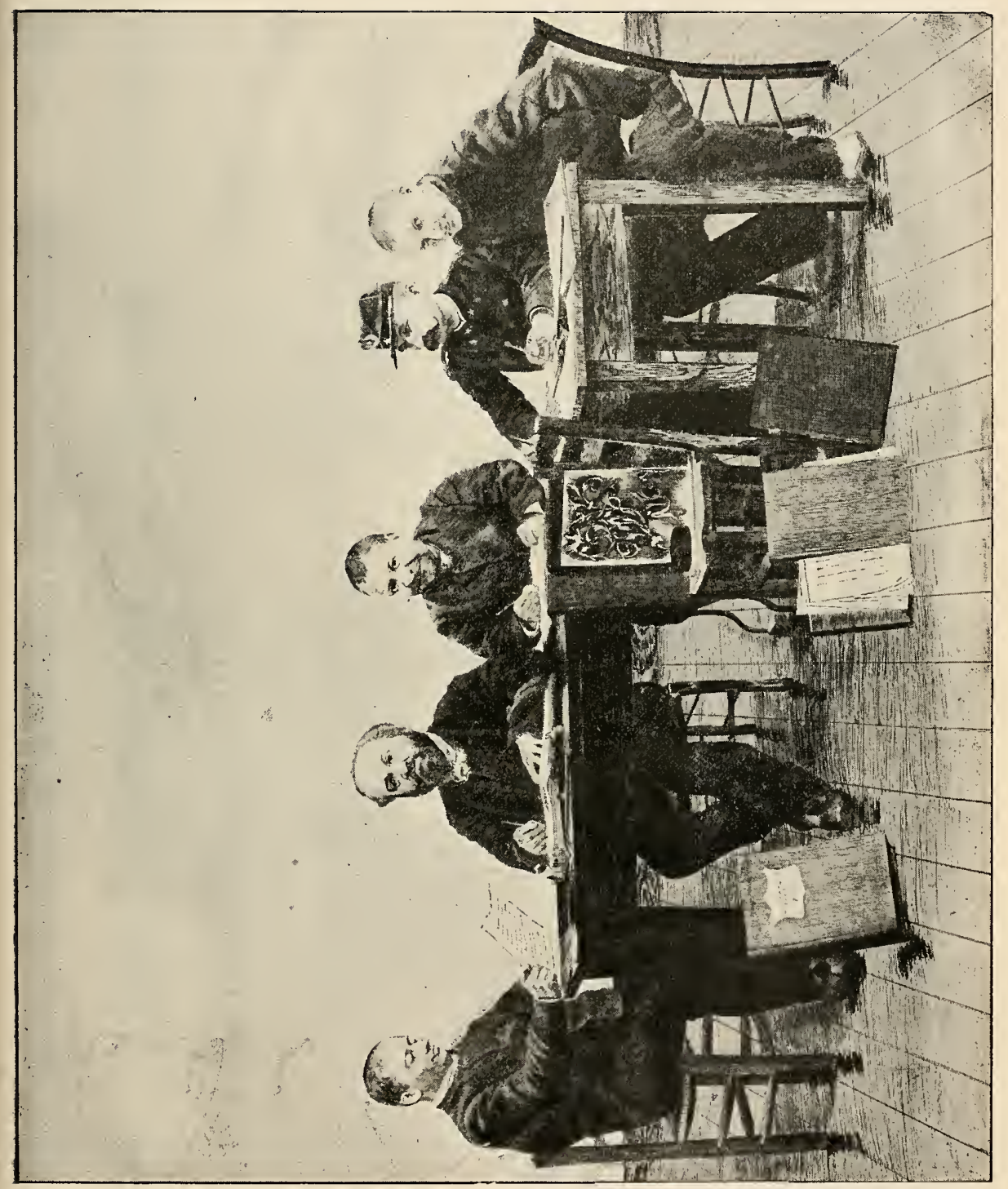

苍 



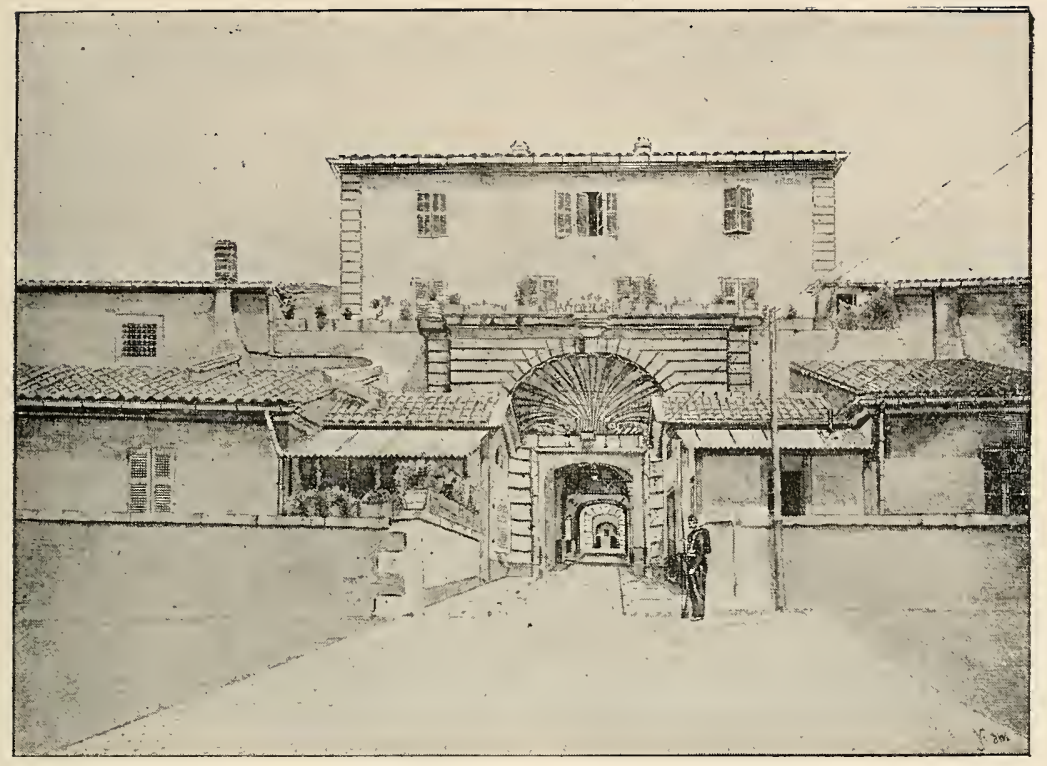

Pl. 5. - Entrée du " Boudar » ou de "Chez mon Oncle », à Nìmes.

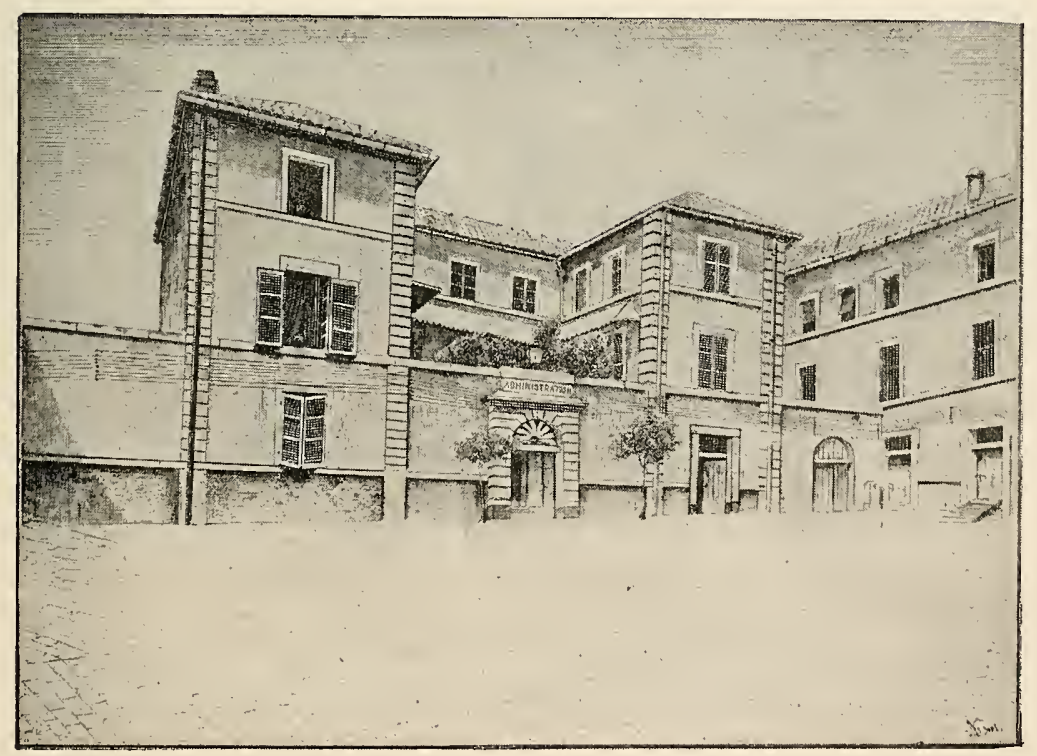

Pl. $8 .-$ Cour d'honneur. 



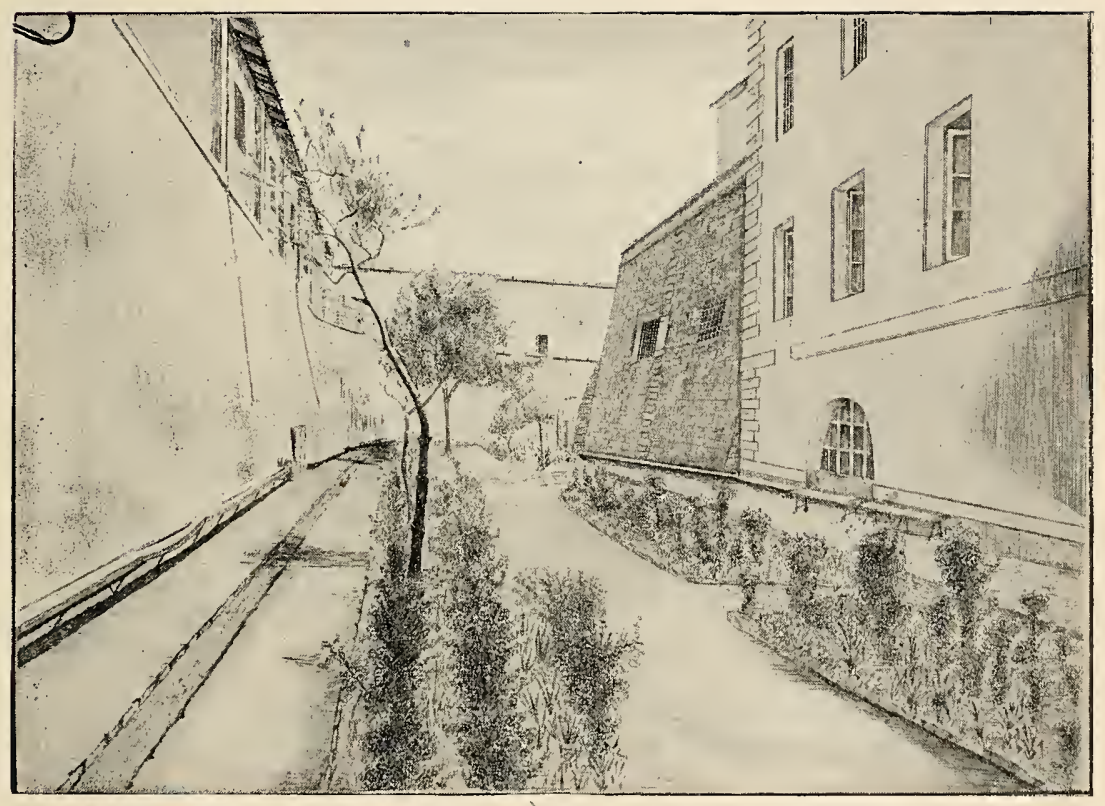

Pl. g. - Préau $\left(\mathrm{N}^{\circ} 2\right)$. 



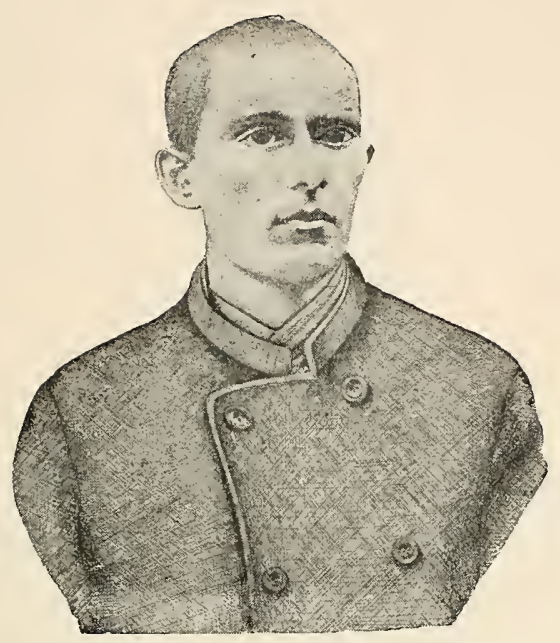

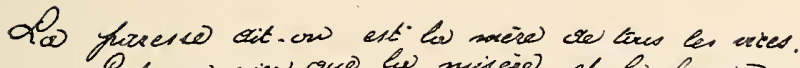

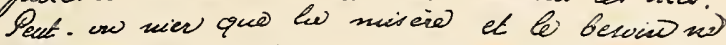

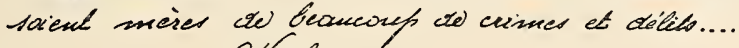
Poila wiquius volew tait ..

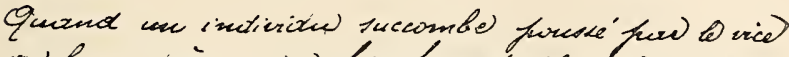

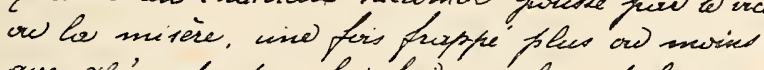

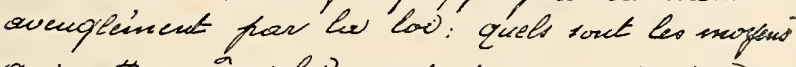

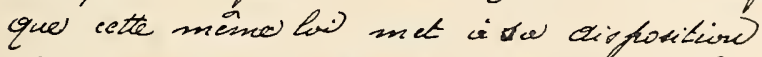

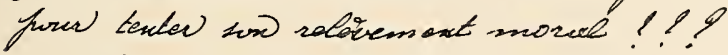

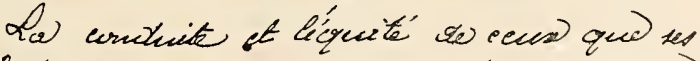

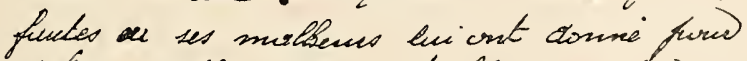

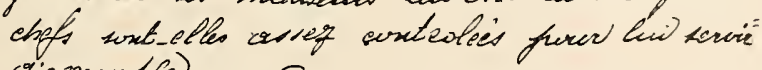

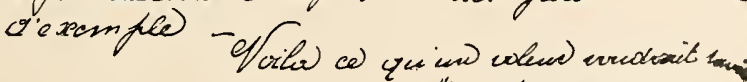

Pl. Io. - Vol, 30 ans, 5 condamnations. 



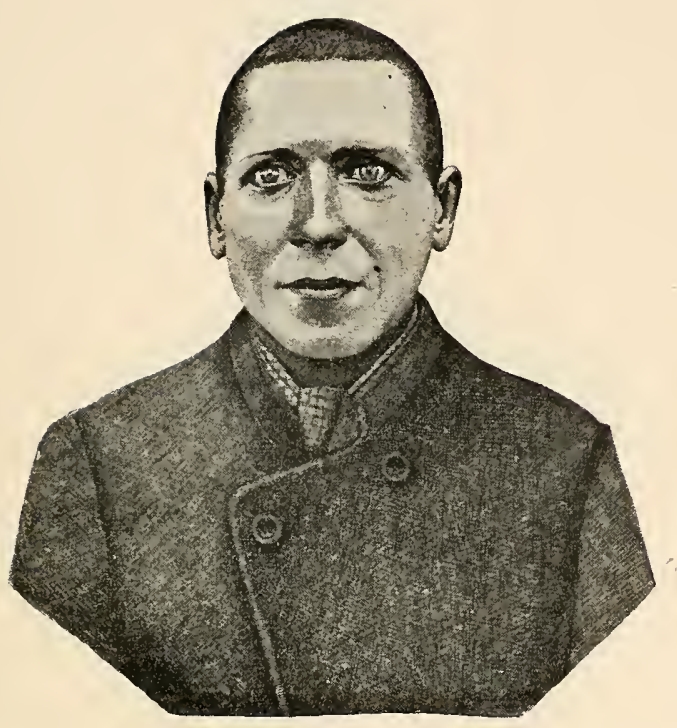

O

ette thate sans chevelure, fortant Te cet affieux horillon; Ressemble outtant à ma fijure. Oue la chemill an prufullon

Hous

Pl. 11 . - Vols et escroquerie, 38 ans, 3 condamnations.

II 



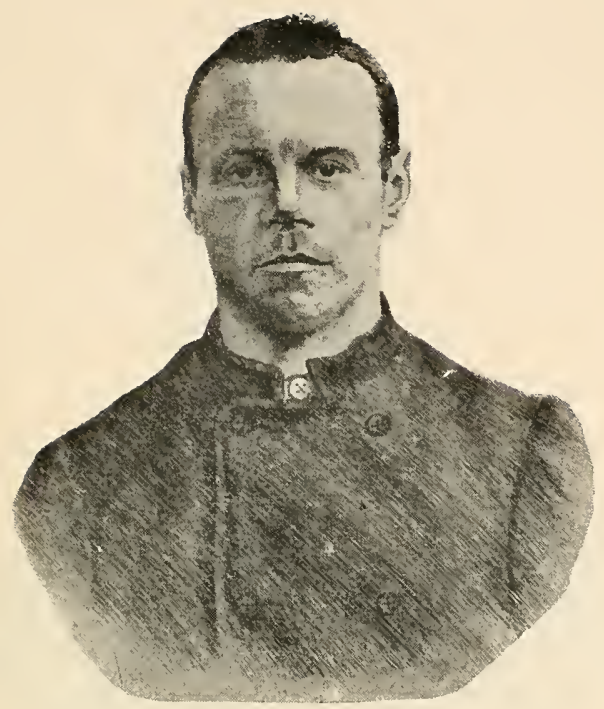

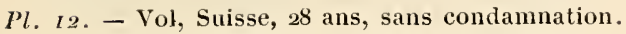

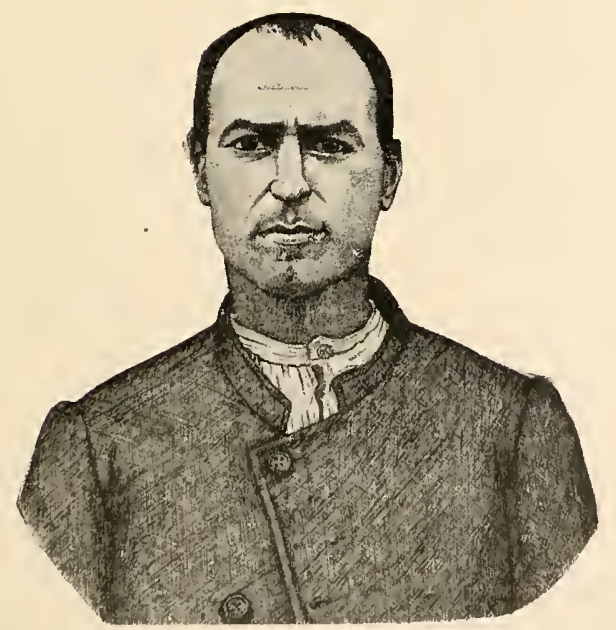

Pl. 13. - Tentative de vol, Espagnol, 32 ans, 3 condamnations. 



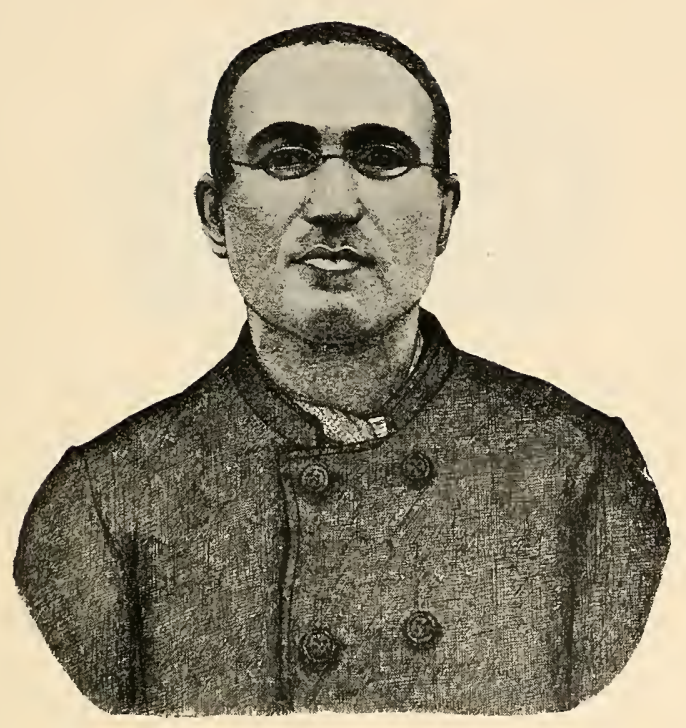

fatems Hilionario che is sarei il pic Oneste some o) ef mionto

Ottombre 1897

Pl. If. - Vol, Italien, 49 ans, 3 condamnations. 



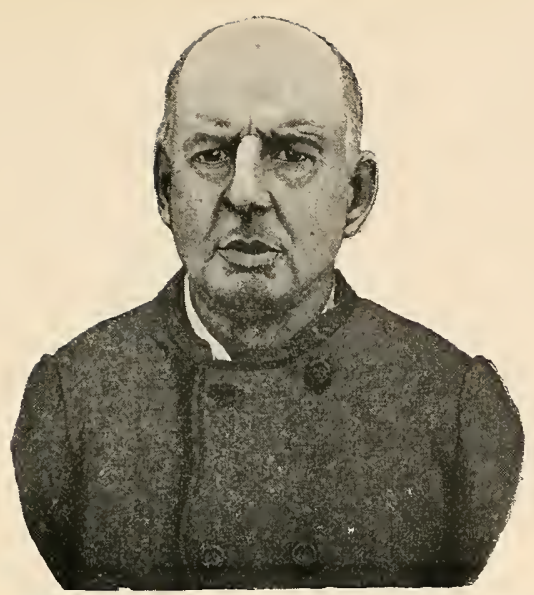

Pl.. 15 - Vol, Anglais, 6o ans, I condamnation.

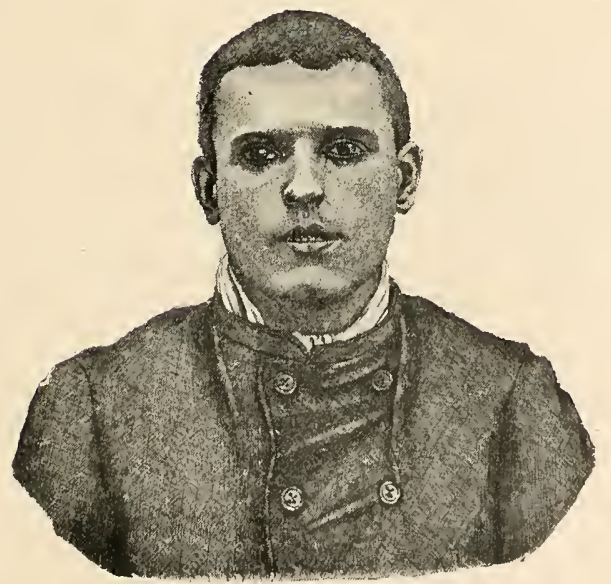

Pl. $16,-$ Vols, $2 \mathrm{I}$ ans, 6 condamnations. 



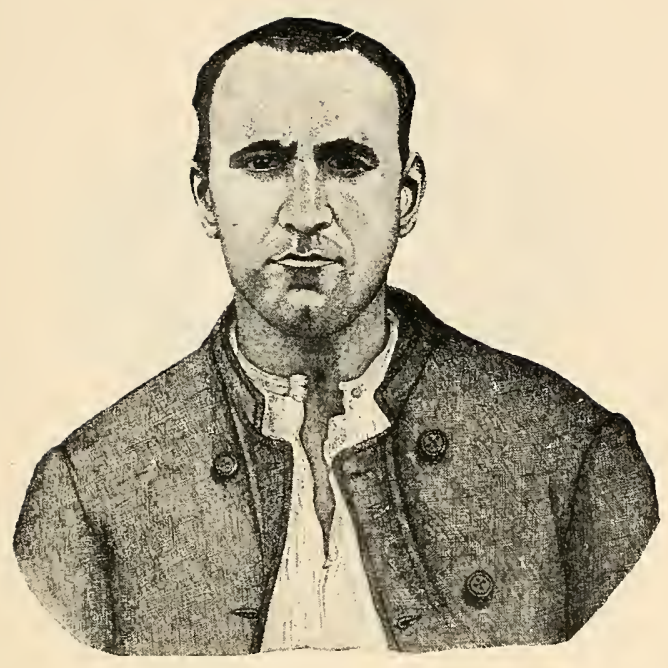

Ho rais rejetai pane mais parent nowis sa me fait riend, fai des bras, of Ses sante parr gagner ma vie. A oncore dee pain on nottement que

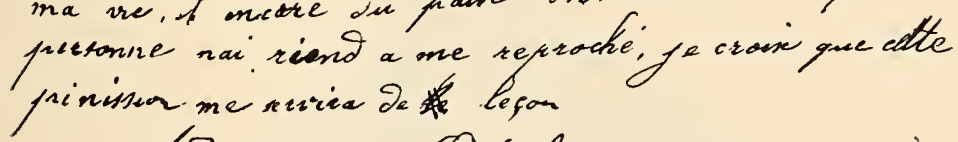

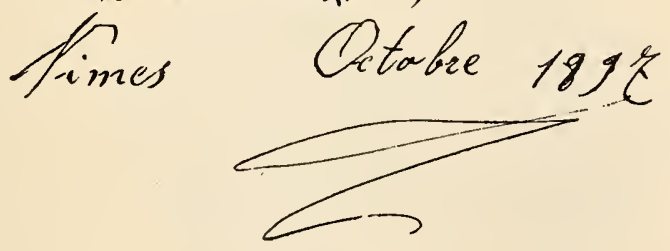

Pl. 17. - Vol, Espagnol, 38 ans, 6 condamnations. 



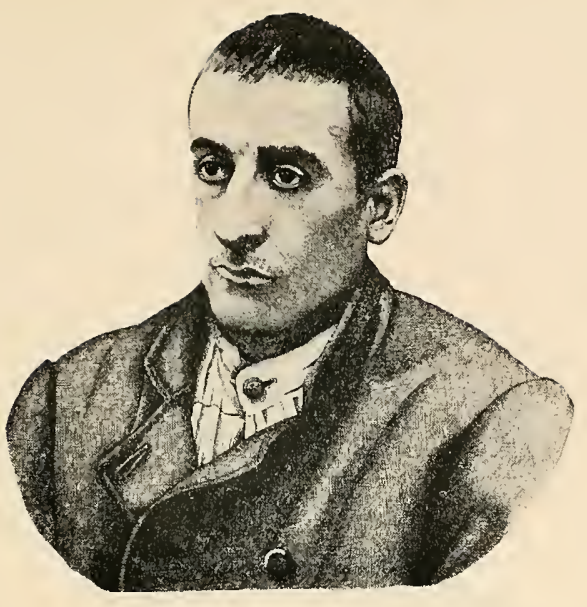

Pl. IS. - Vols, 22 ans, 3 condamnations.

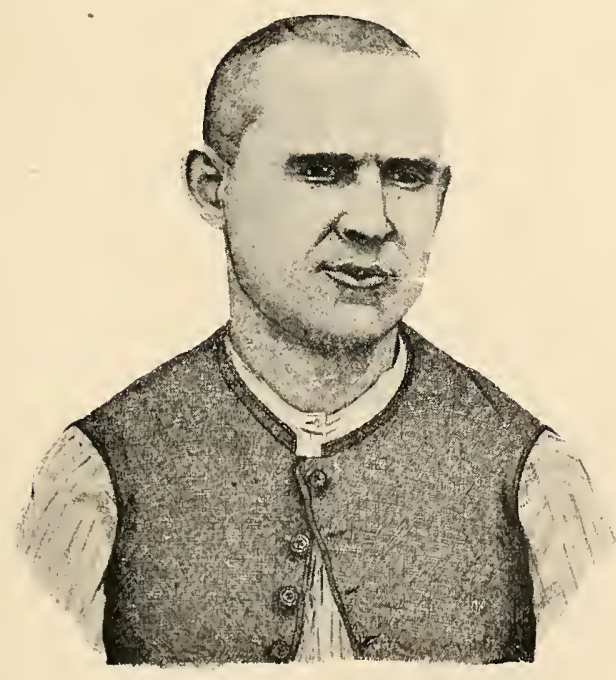

Pl. 19. - Vols, 19 ans, 5 condamnations. 


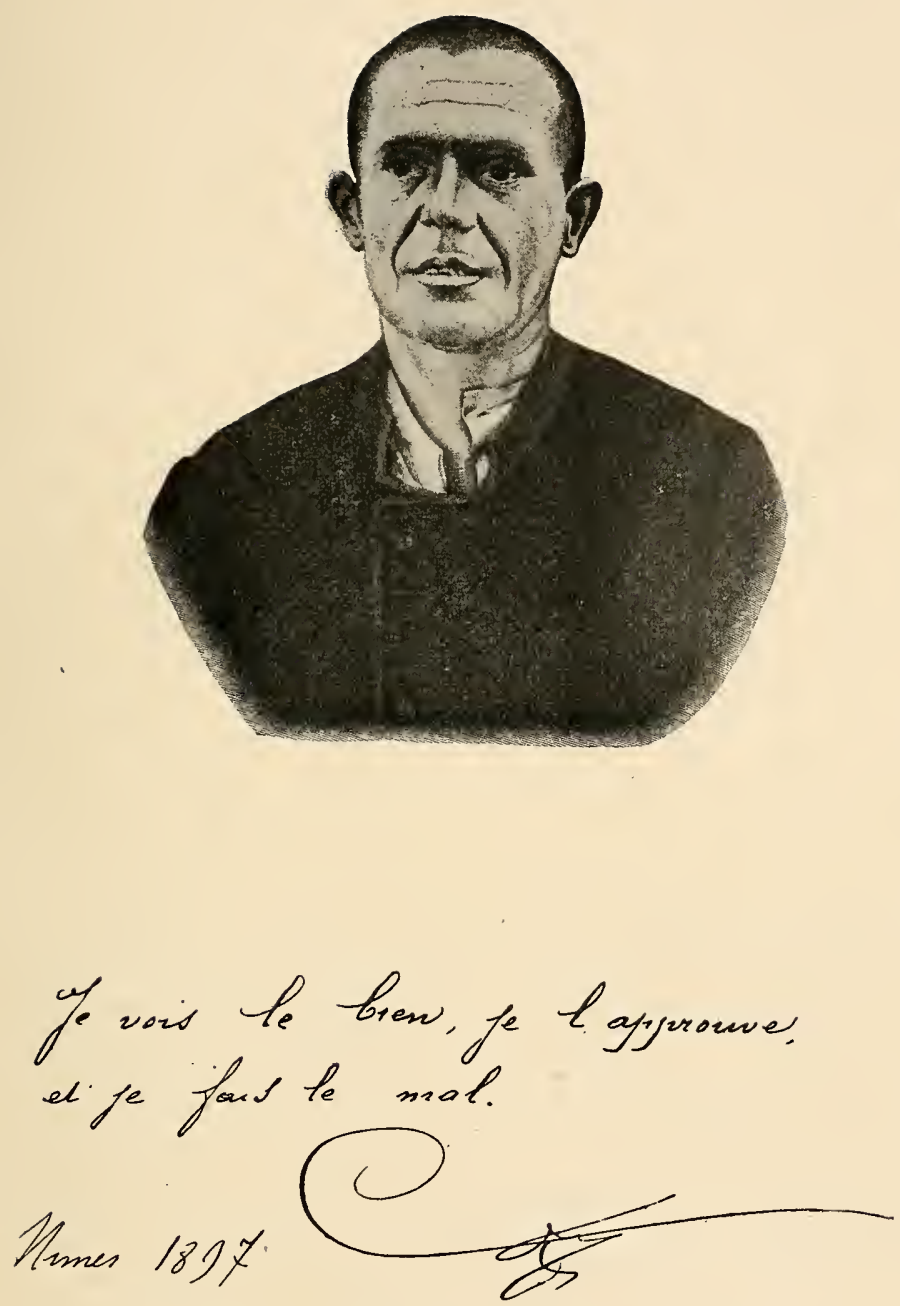

Pl. 2o. - Vol qualifié, 3 j ans, 2 condamnations. 



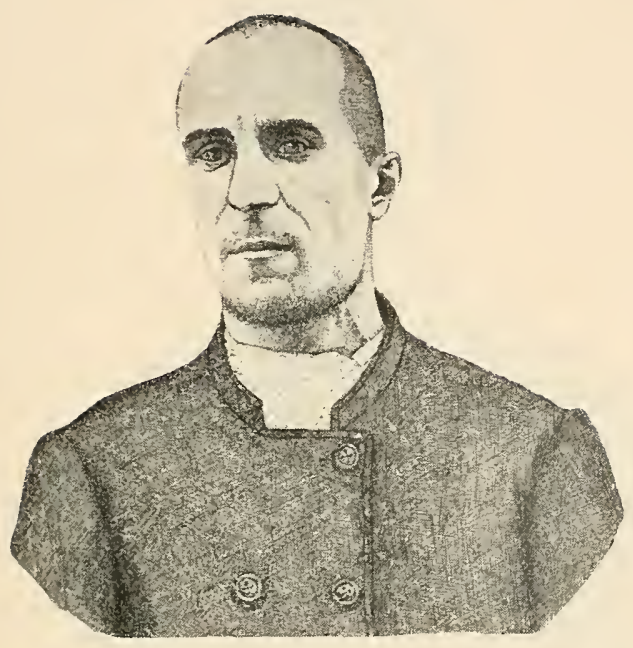

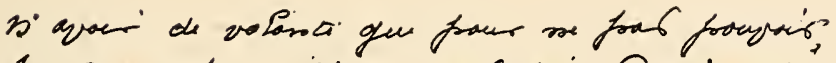

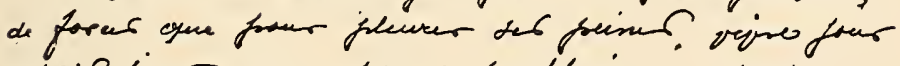

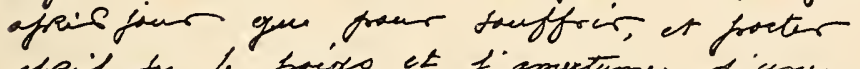

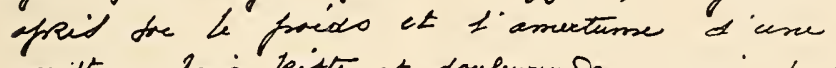

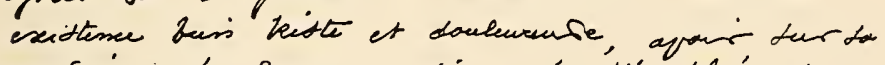
conbeincisle emara d'ero frasti flein de delity et de coimen, itre en frovie sux flur

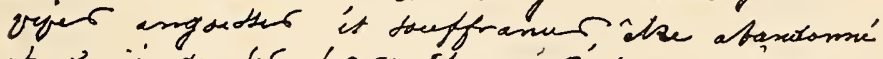

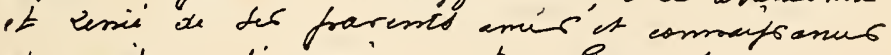
At mpdager 1 agenir an trembart at ape

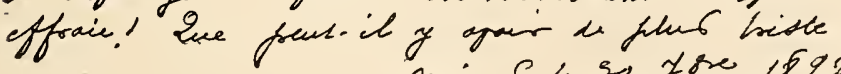

$$
\begin{aligned}
& \text { minis a so fore } 1897 \\
& \text { ly g. मू. }
\end{aligned}
$$

Pl. 2r. - Vol qualifié, 33 ans, 5 condamnations. 



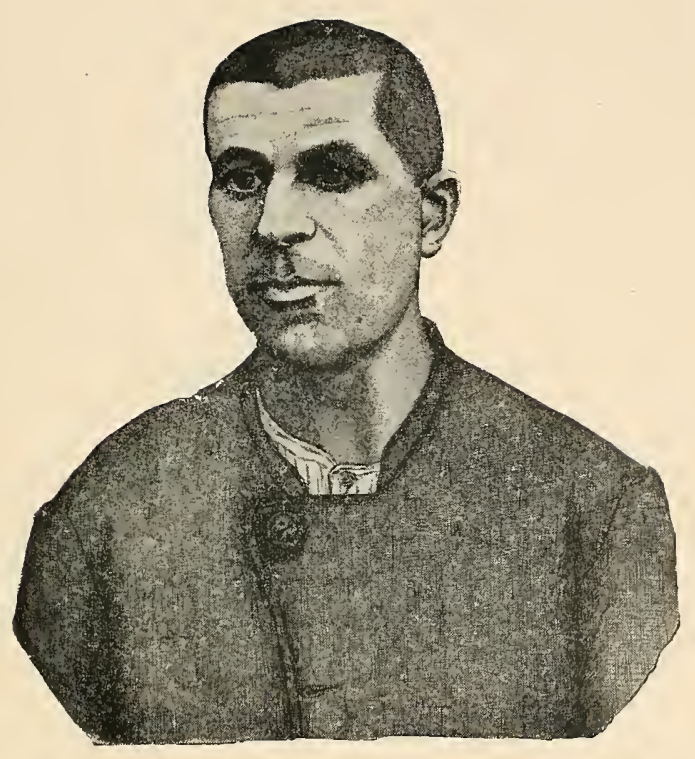

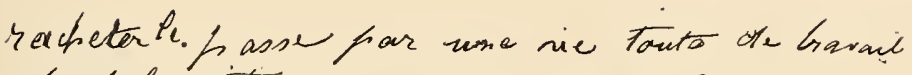
ofs of homideter, vaila olesmisiai le but of we

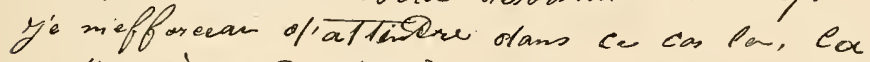

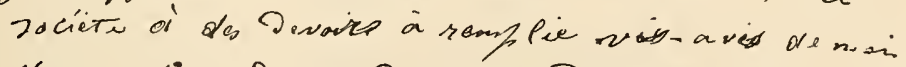

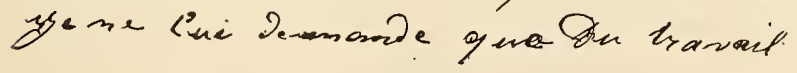
Contabe 199y

Pl. 22 - Vol qualifie, 35 ans, 7 condamnations.

III 



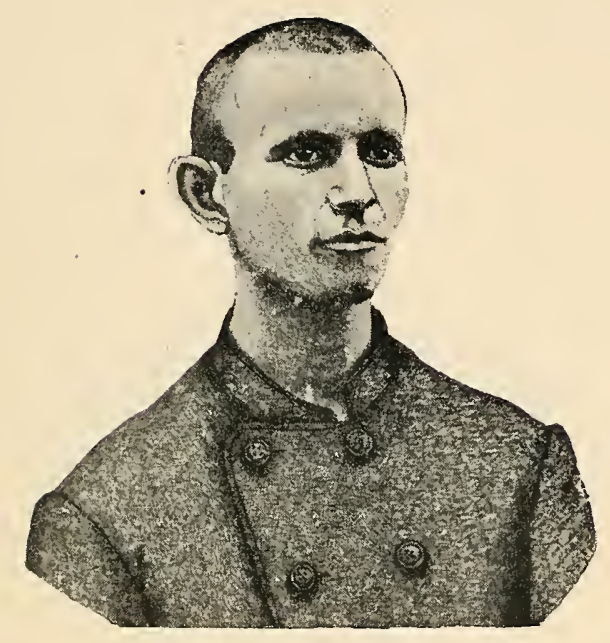

Mon seul Pesu est ma hberte. Ine frac.je a max sortie: fe n'm sais sin.

Oetohe 189 \%

Pl. 2\%: - Yol qualifie, 23 ans, 3 condamnations. 



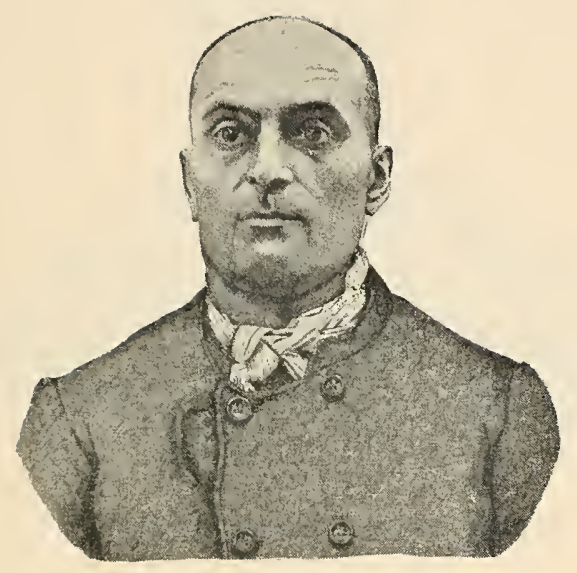

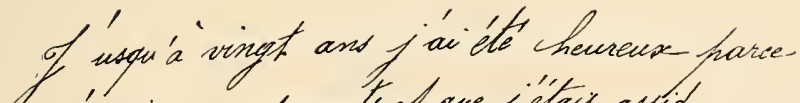
avous mes frarents et que fetais astidu au

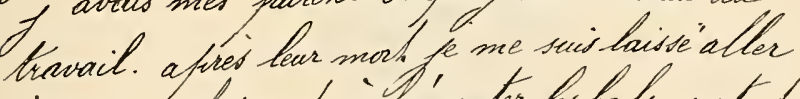
a ne rien faire es a frequenter bes bals sutout.

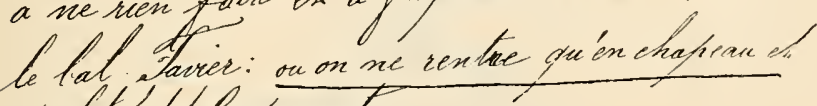
pratelot dit la haneaste

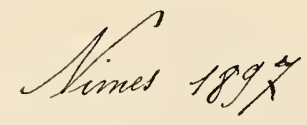

$P l .2 f$. - Vagabondage, outrages aux magistrats. 37 ans, 26 condamnations. 



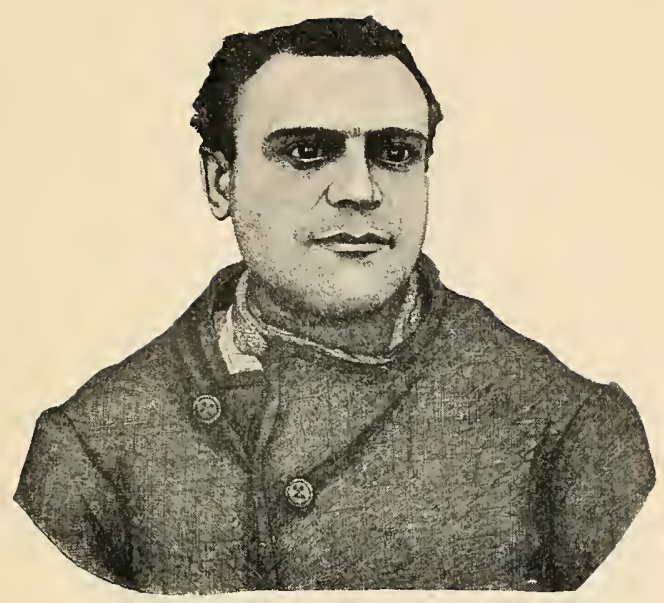

Pl. 25. - Violences, coups et blessures, rébellion, 25 ans, 6 condamnations.

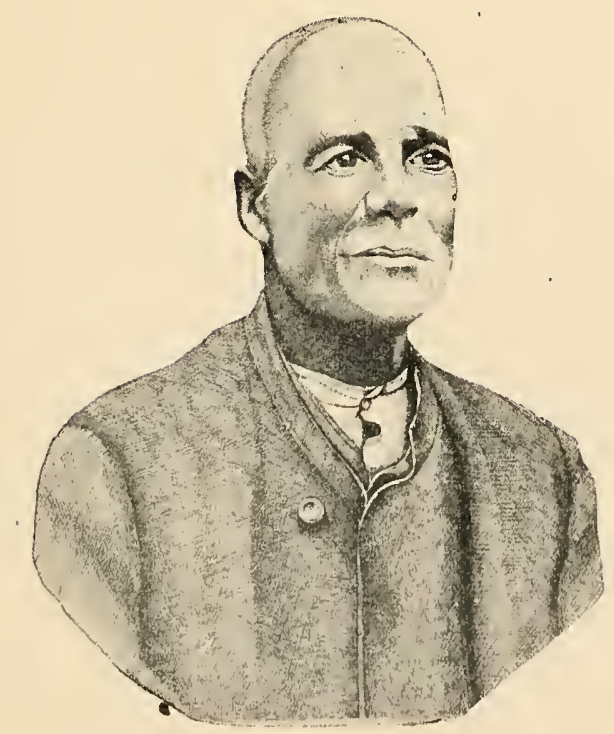

J1. 26. - Tentative d'assassinat, 56 ans, sans antédents judiciarires. 
<smiles>[CH]1CC1</smiles> 


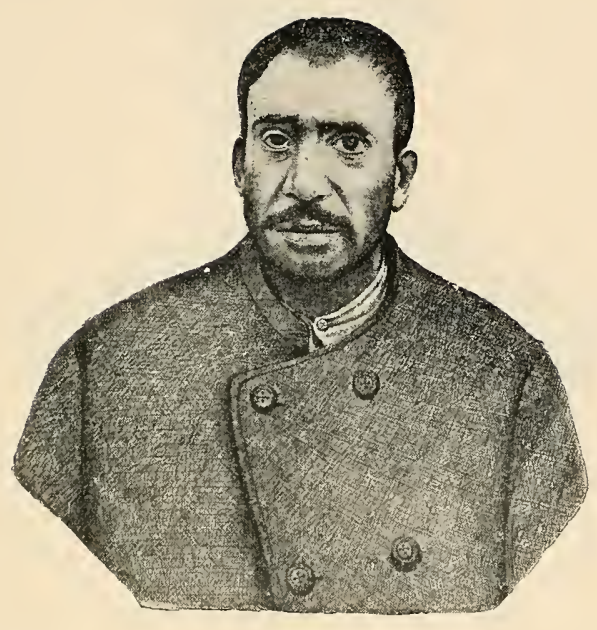

Cles láffantsé oun Saitse venger it pumir pras hivimence et nan ficu furaevration celivi Sant-il a à se plainine telb sant nas santinent

Doines 189x

Pl. 27. - Coups et blessures grares, 3 ans, 4 condamnations. 



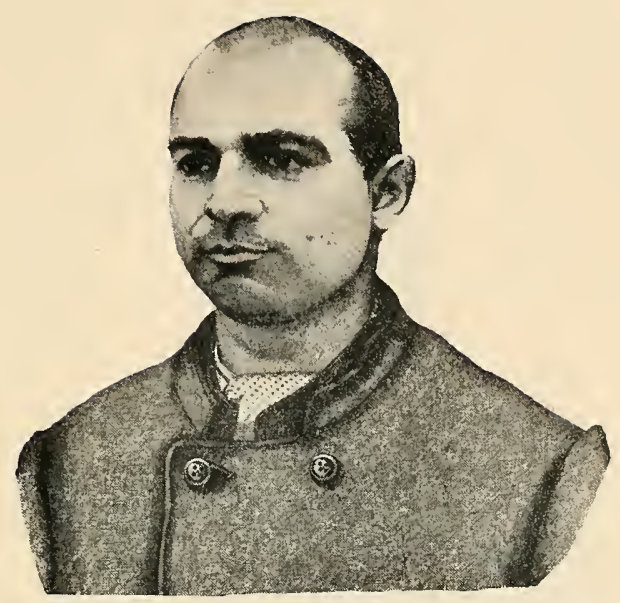

$P l .2 S$. - Meurtre, 31 ans, sans antecédents judiciaires.

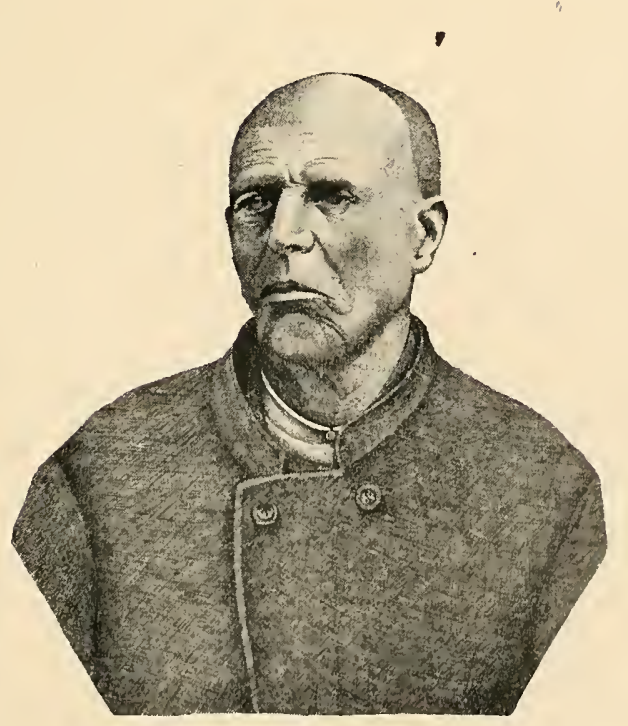

Pl. 29. - Meurtre, Italien, 56 ans, 3 condamnations. 



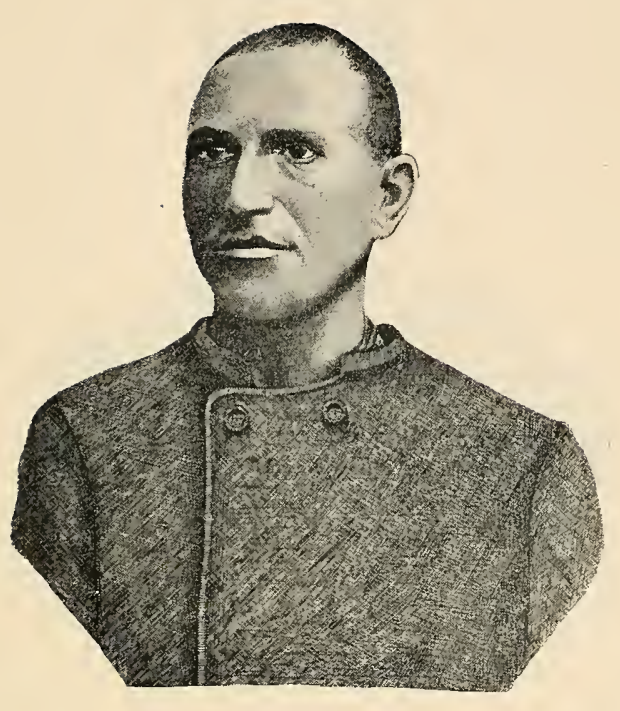

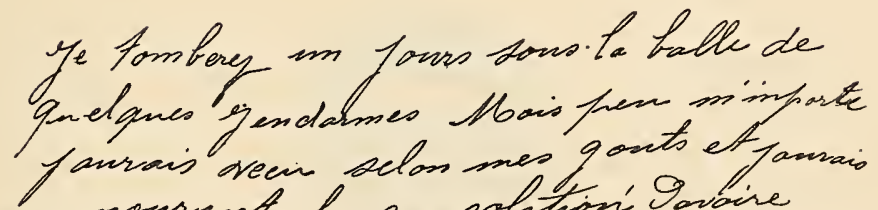
en mourent la eansolation Tovire exereer lanthe finnersi de mafamille de leqitimes refresaseles

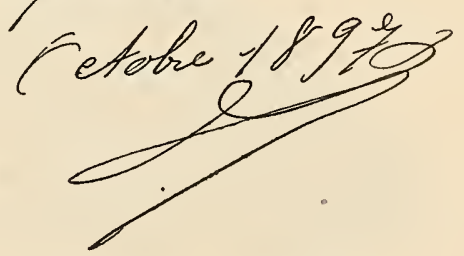

Pl. 3o. - Mcurtre, 28 ans, I condamnation. 



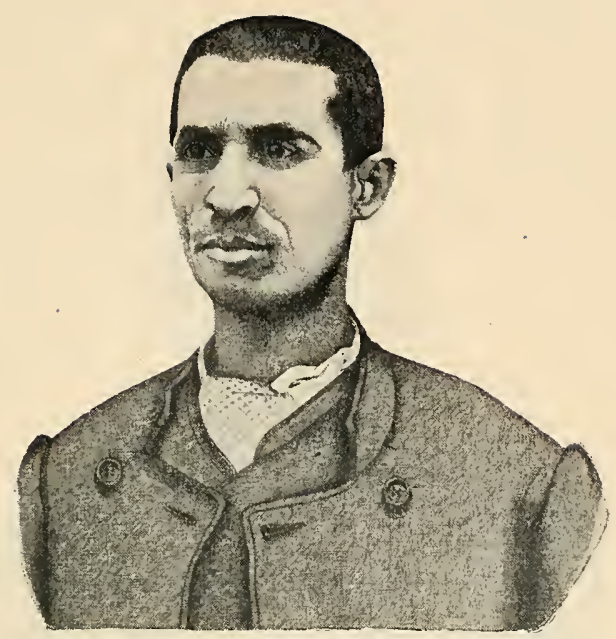

Pl. 3I. - Neurtre, 37, sans antécédents judieiaires.

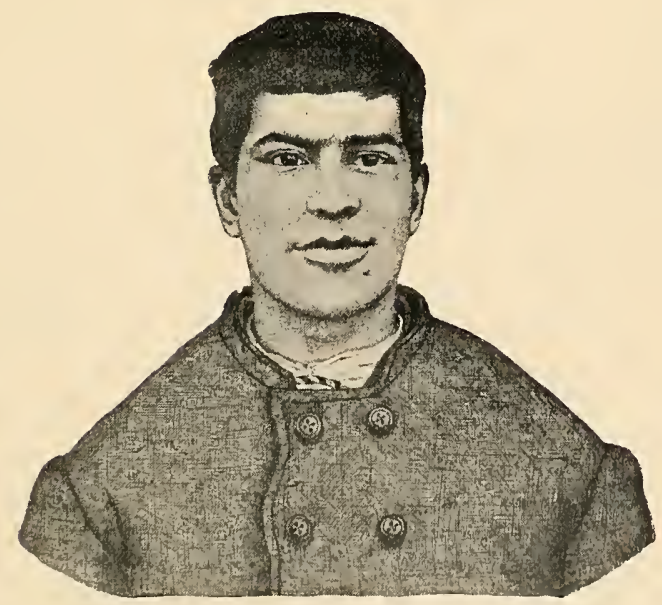

Pl. 32, - Attentat à la pudeur, Italien, 19 ans, sans antécèdents judiciaires. 



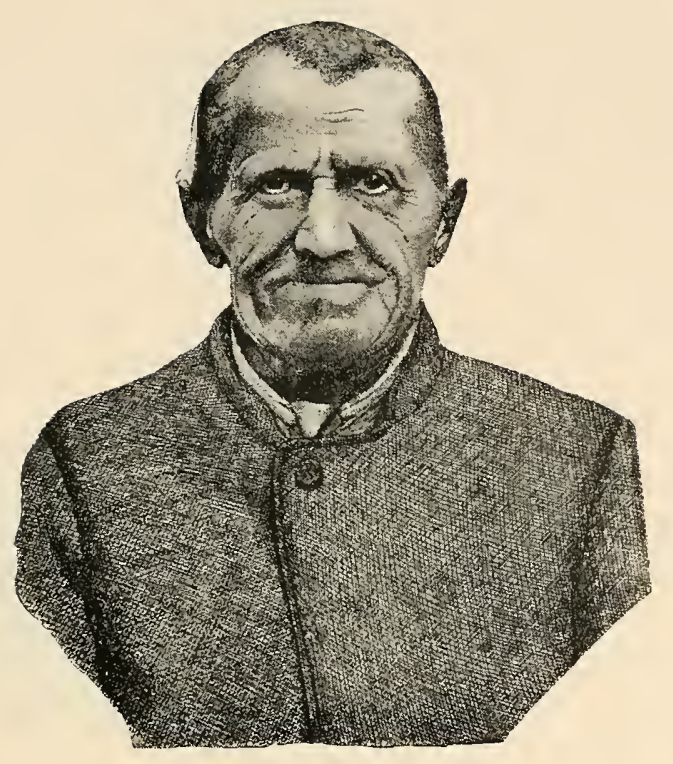

si on me Dize Cóluit Ee pation Whis non cetait pros la pration yp pous

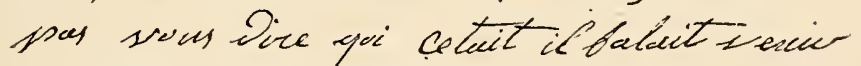
asetayes poun tornbé exprive

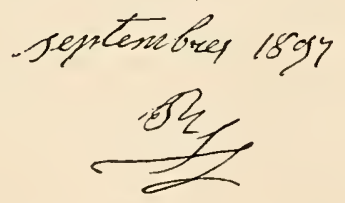

Pl. 33. - Attentat à la pudeur, J4 ans, 1 condamnation. 



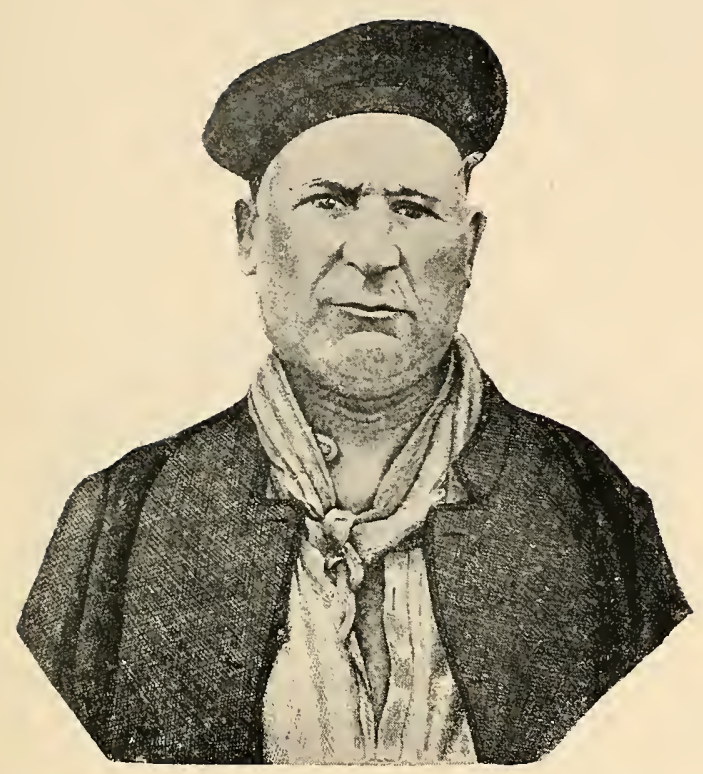

Plime 1896

une fori sorth de cettejuenitina

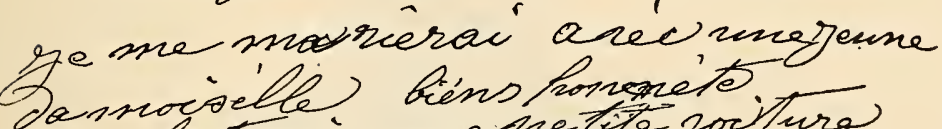

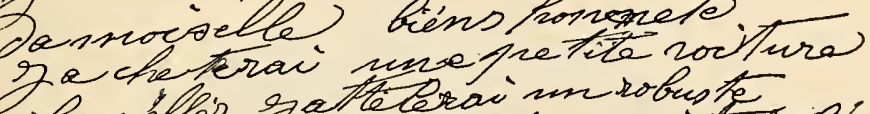
ata quelles galteterai m robus to

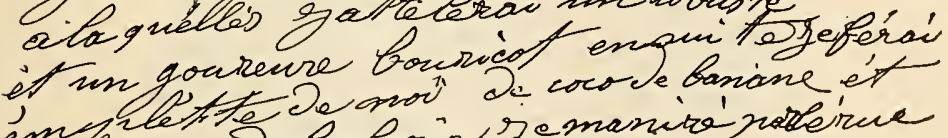

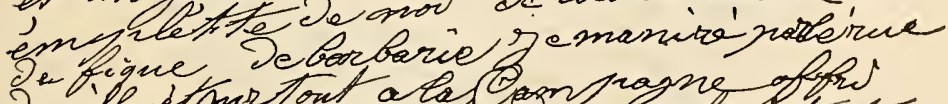

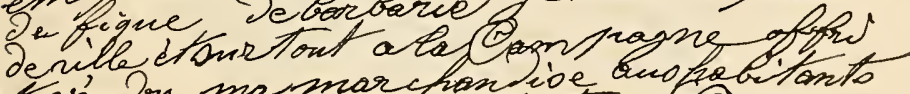

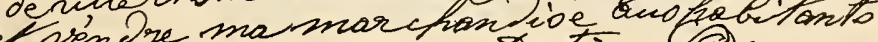
Draine

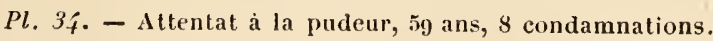





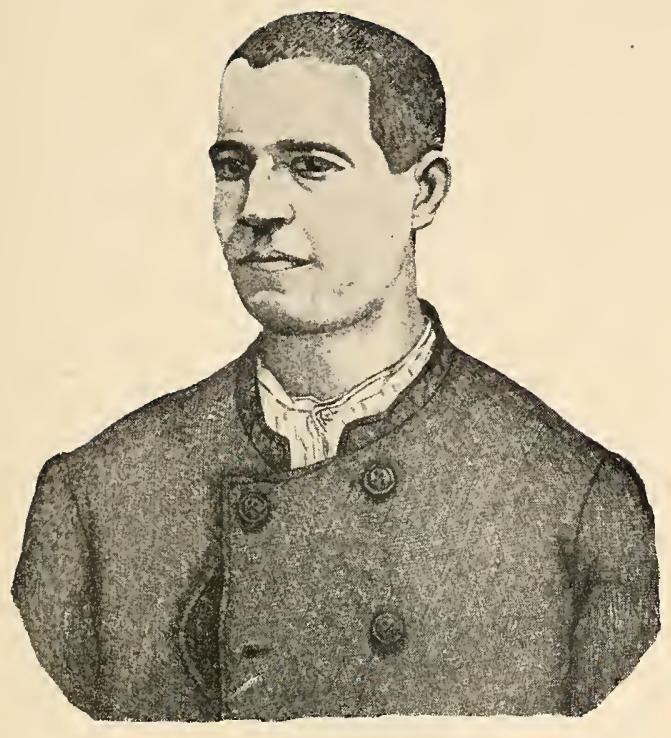

Pl. 35. - Attentat à la pudeur, 20 ans, I condamnation.

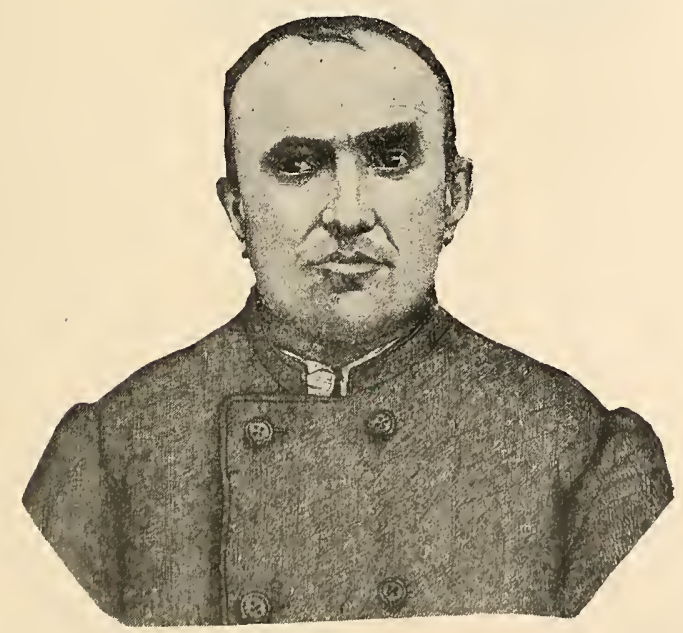

I'l. 36. - Escroquerie, 45 ans, 4 condamnations. 



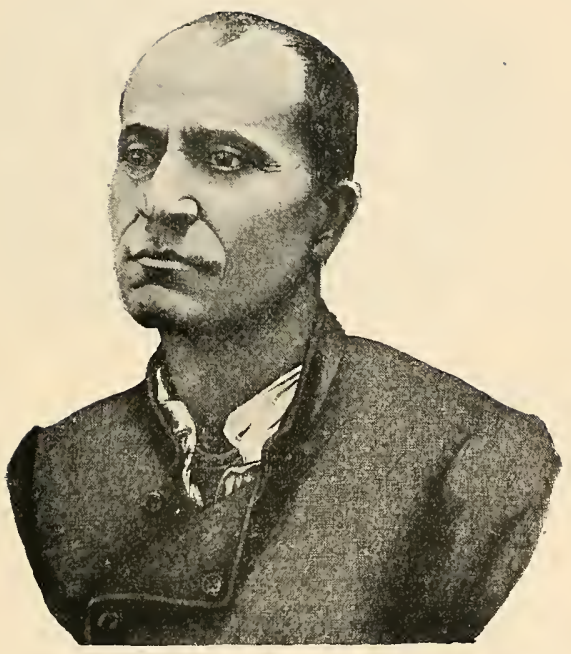

Pl. 3-. - Escroqueries, 40 ans, 2 condamnations. 



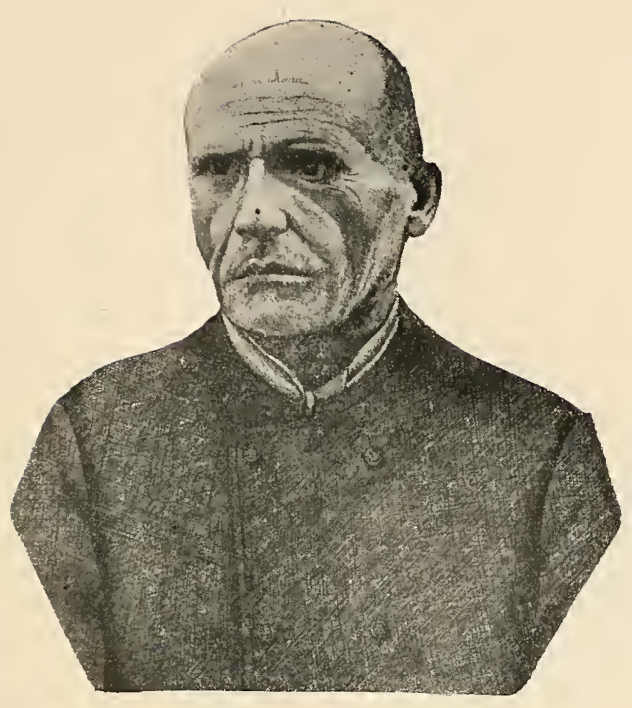

It Le 25 septembre 189\% stant Tres wancé Jouge.

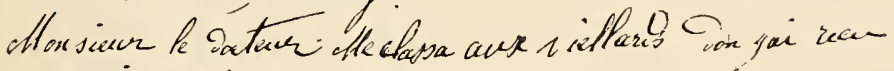

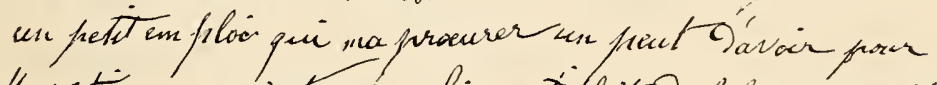

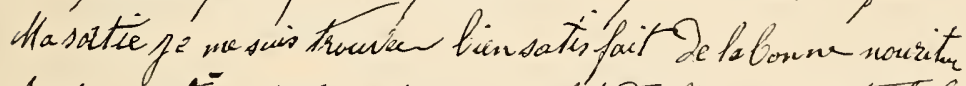

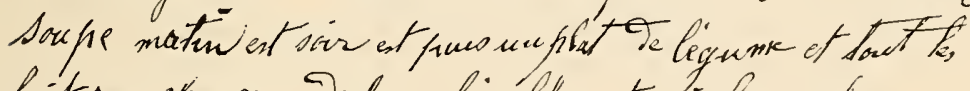

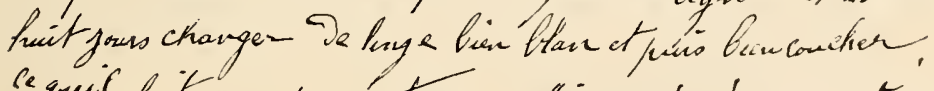

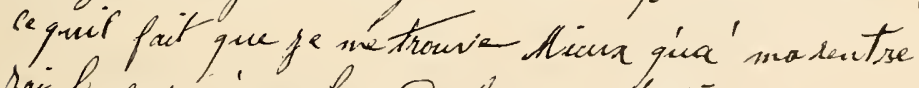

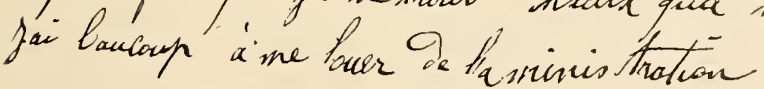

Ph.

Pl. 38. - Fausse monnaie, 68 ans, 20 condamnations. 



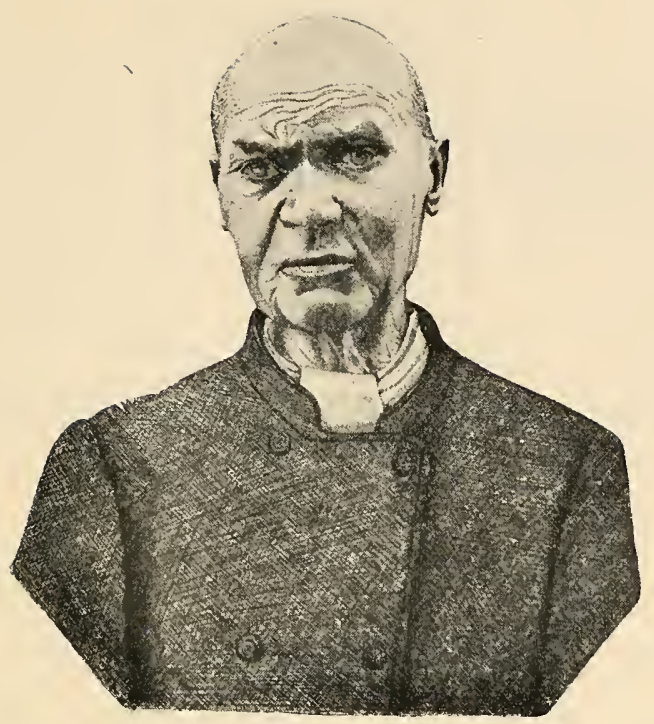

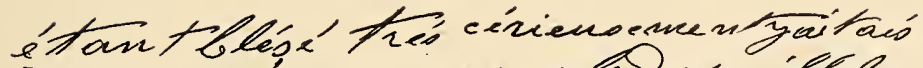

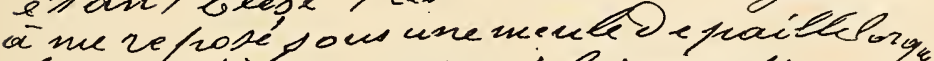

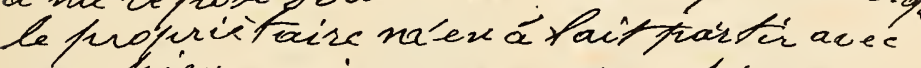
un etrien quoique ye se fruse/reesque

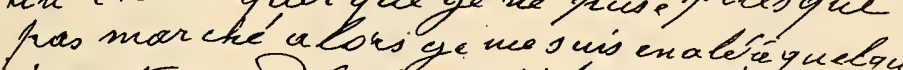

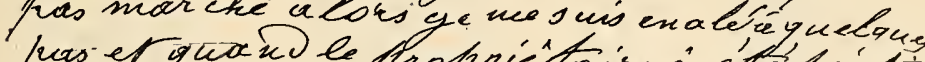

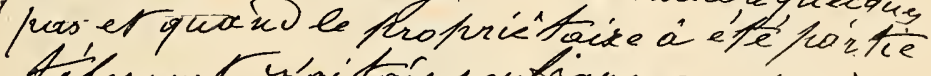
felinen y'aitour soufianc gue yave nuis le fen à la menle De raulle

Princes

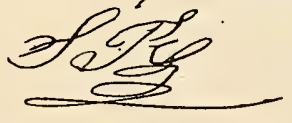

Pl. 39 . - Incendie, 73 ans, 24 condamnations. 


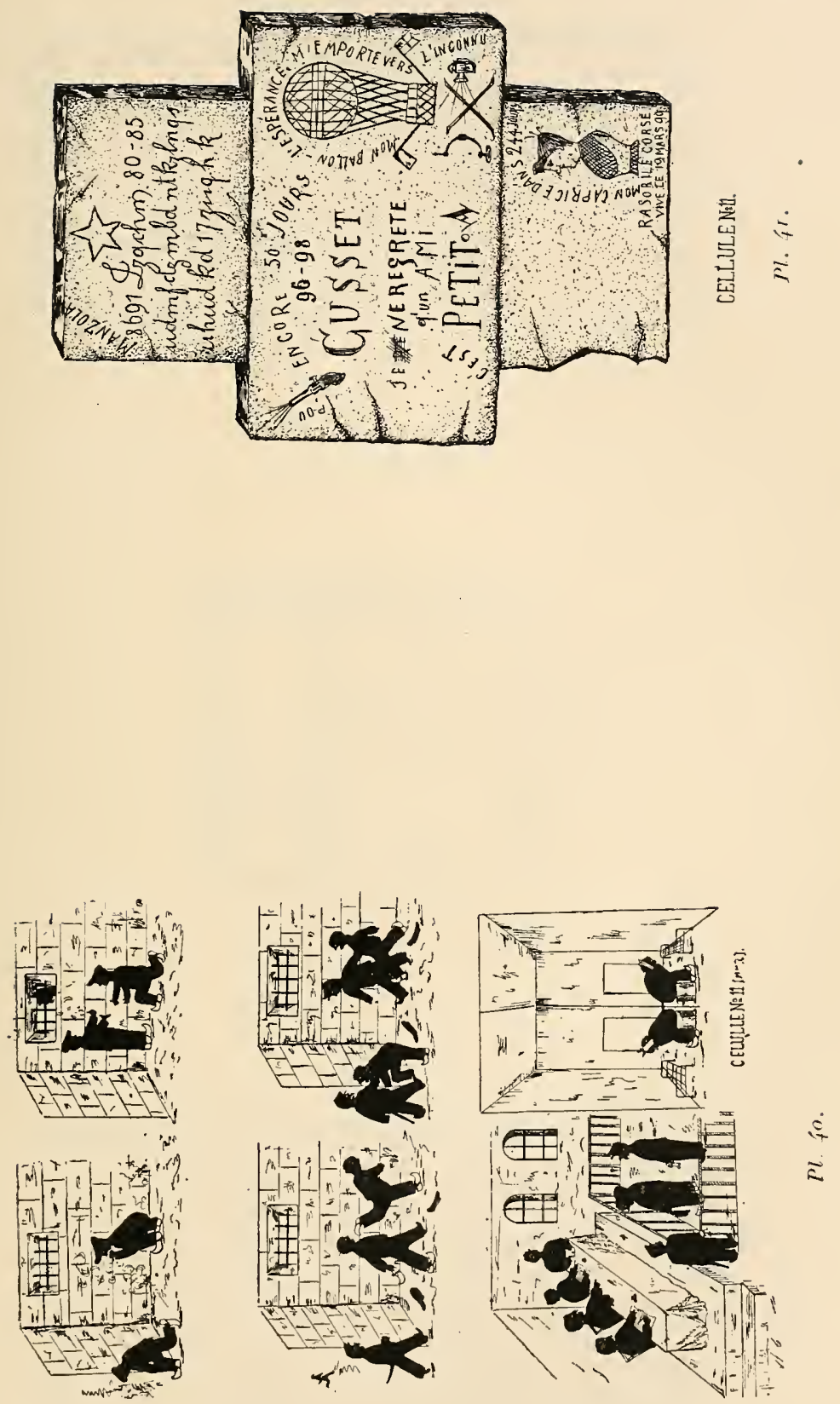



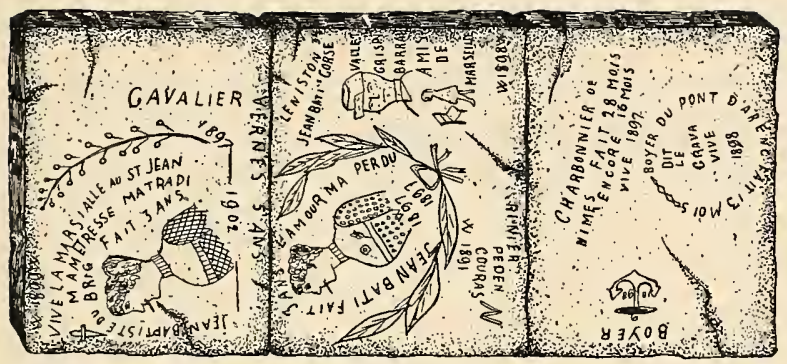

学
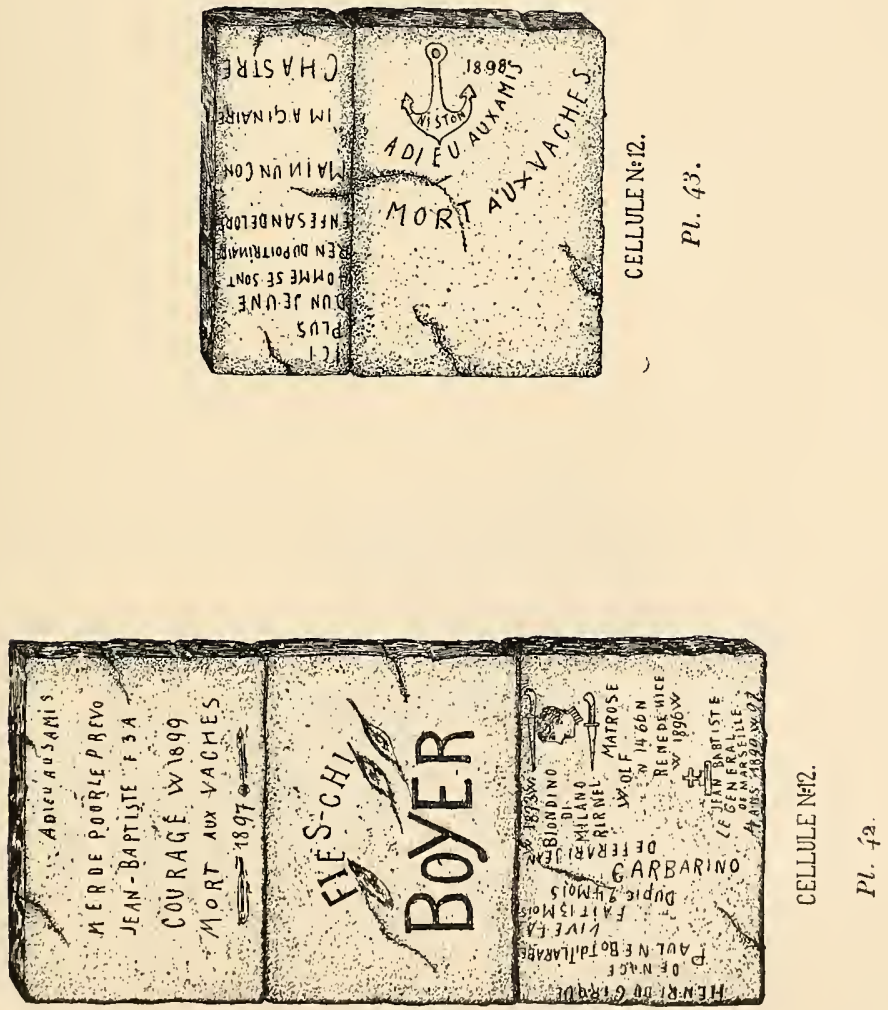


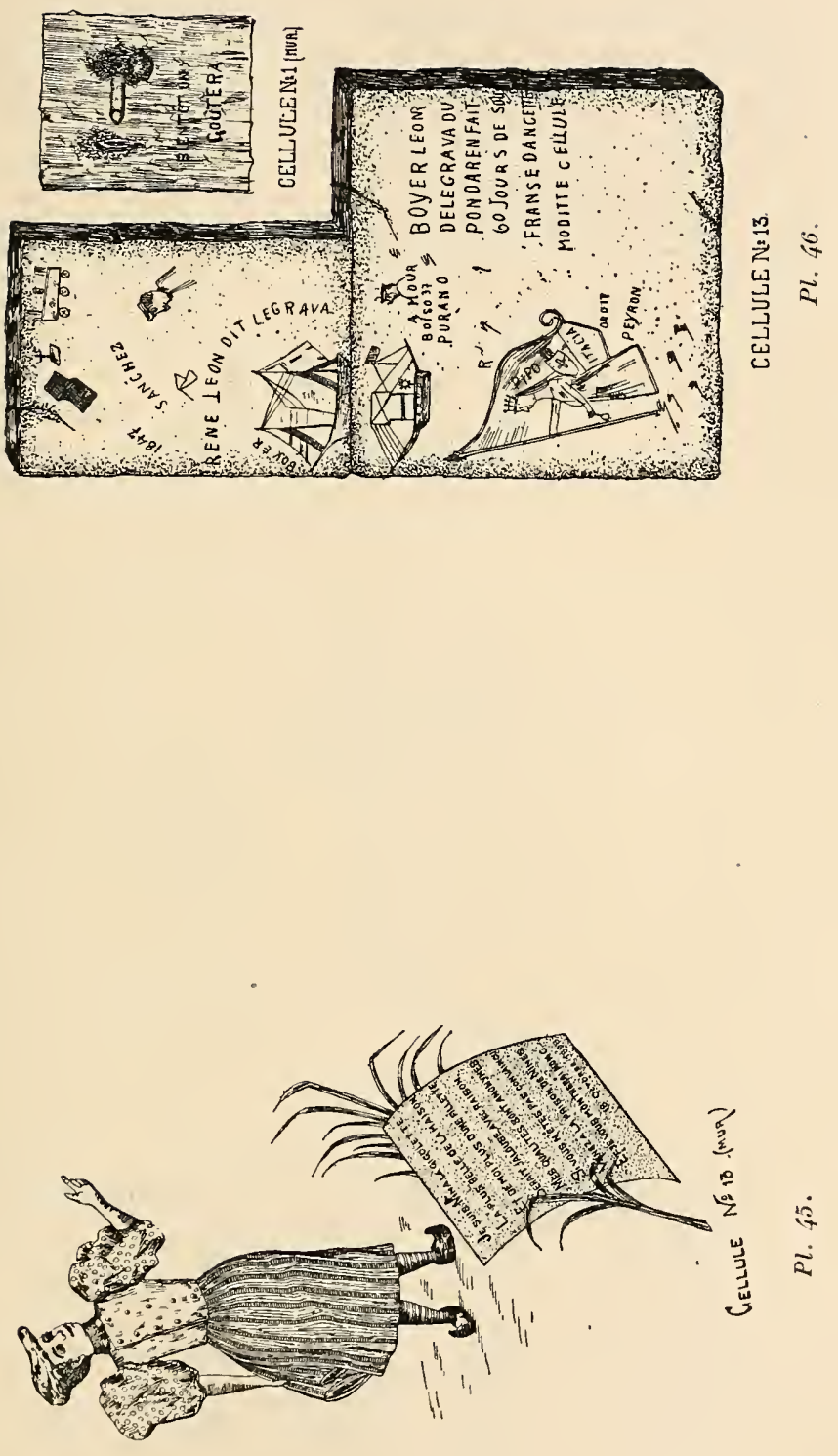


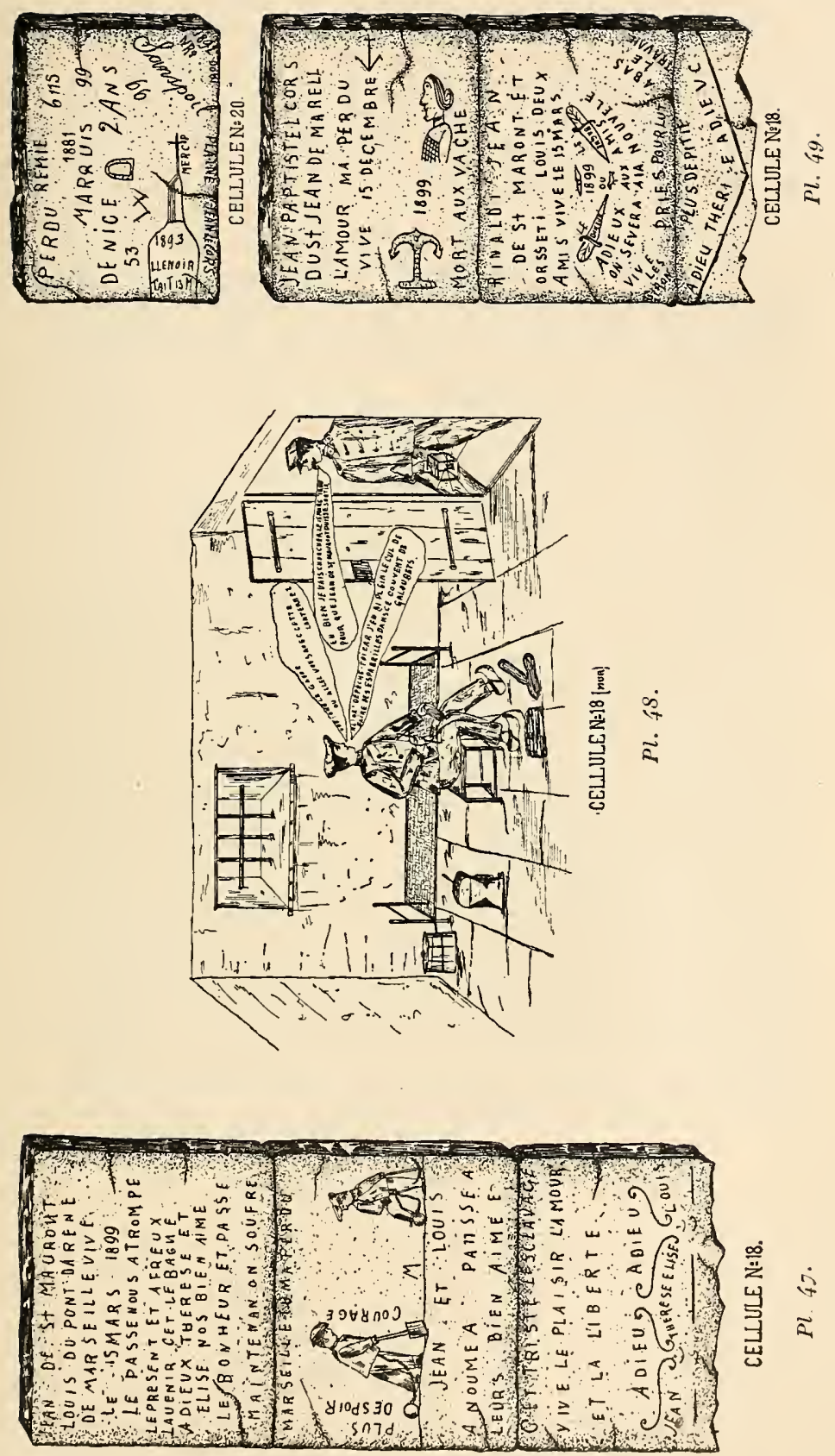



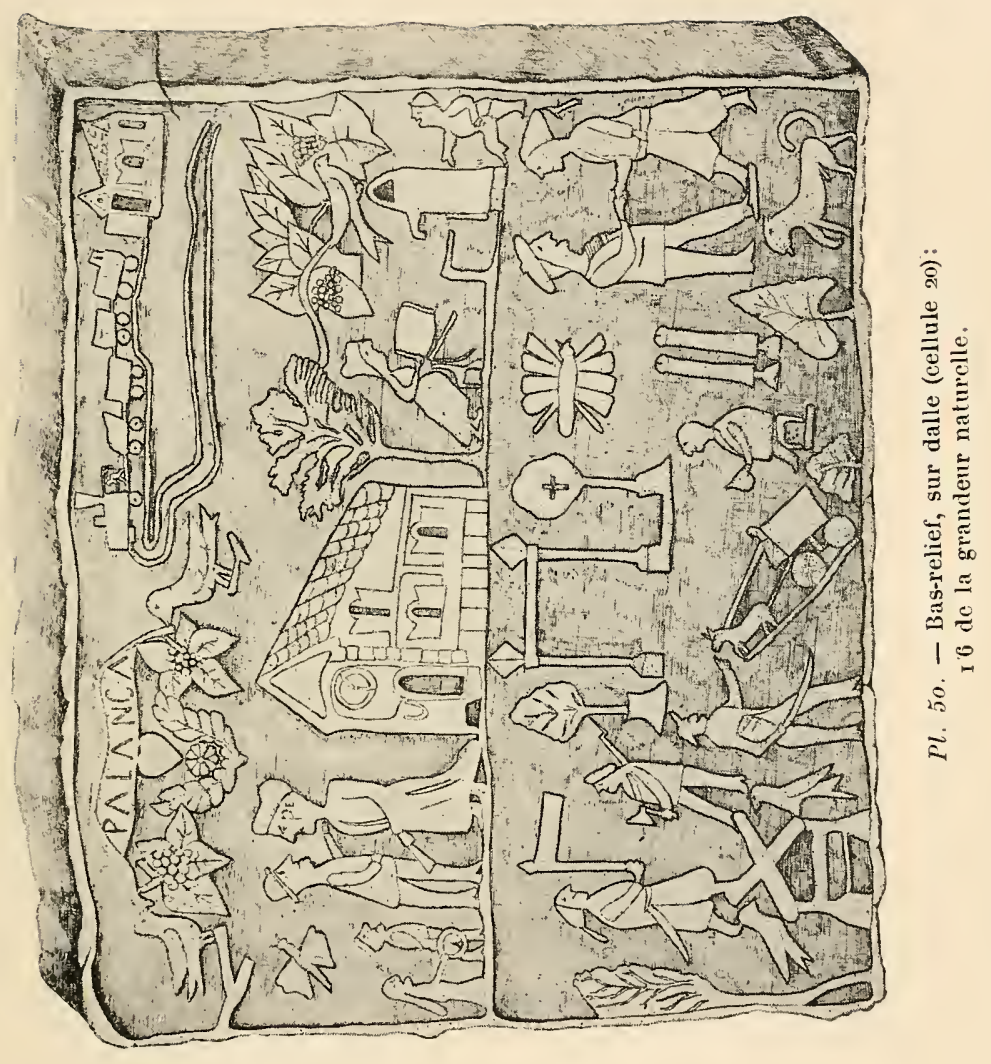





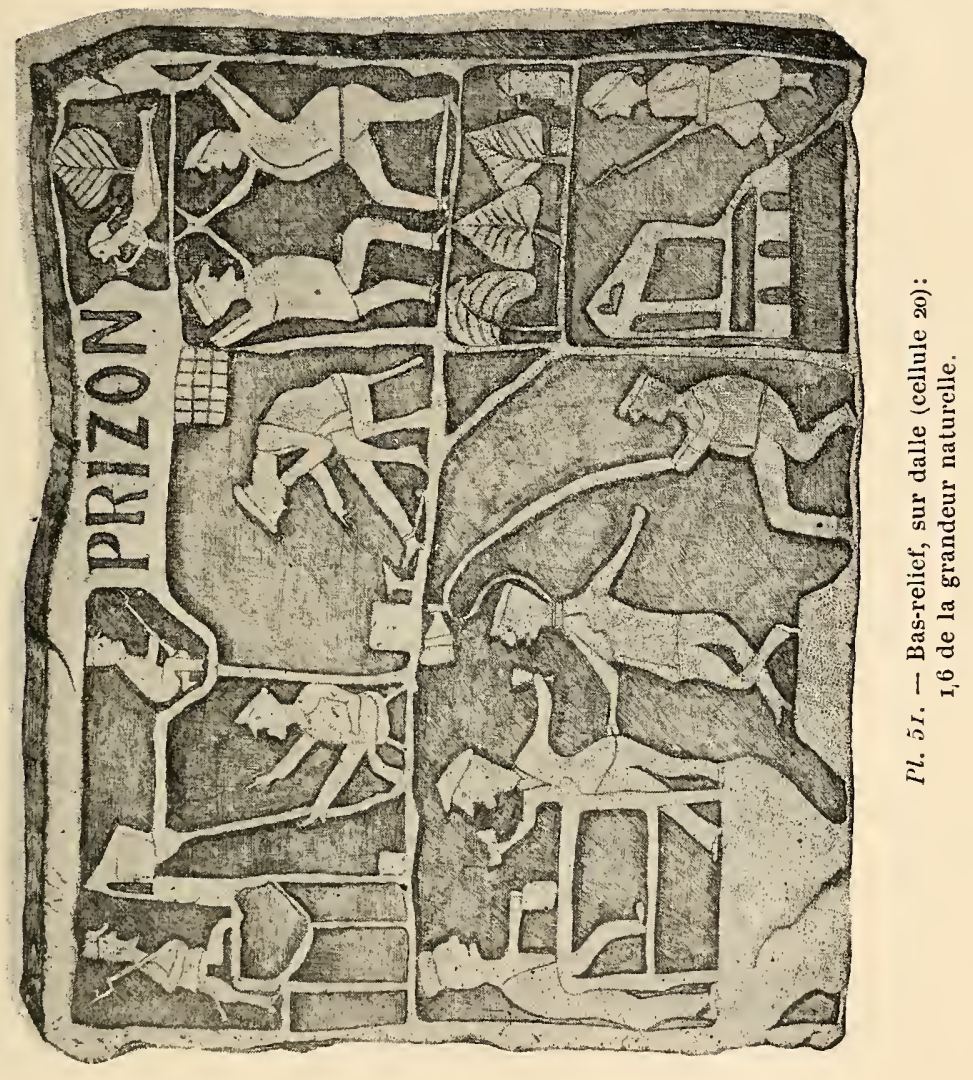





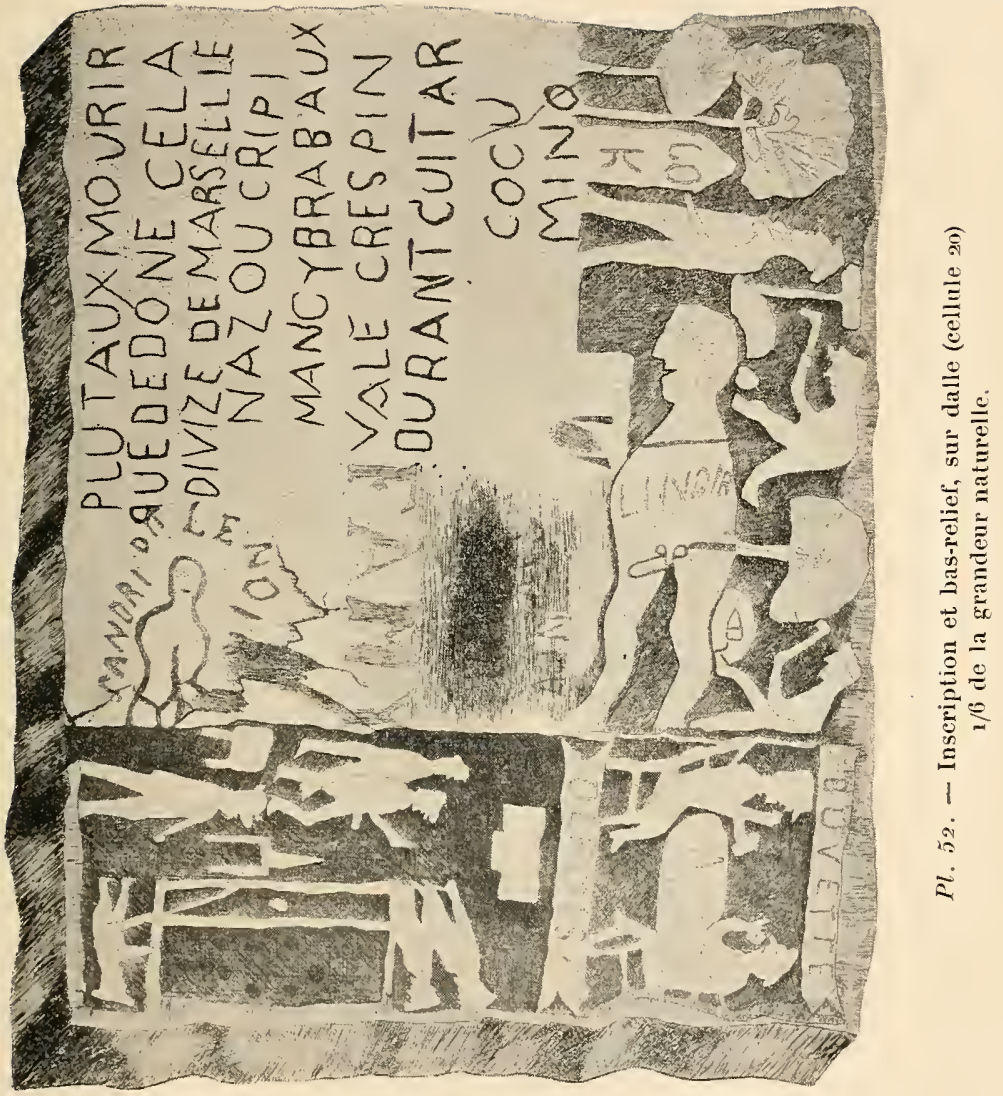





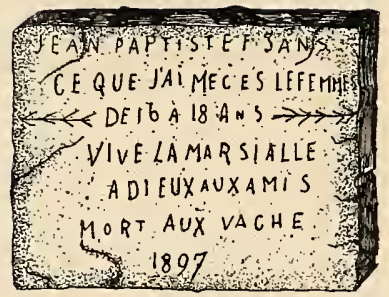

CELLULEN:23.

Pl. 53.

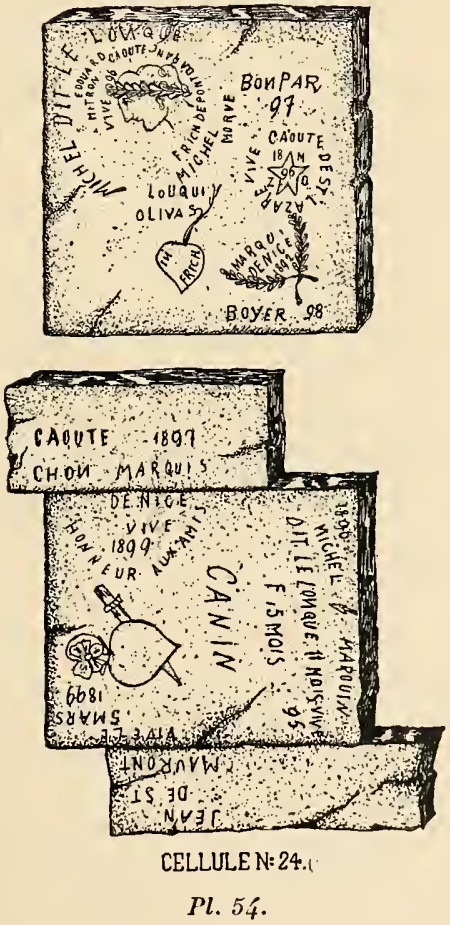




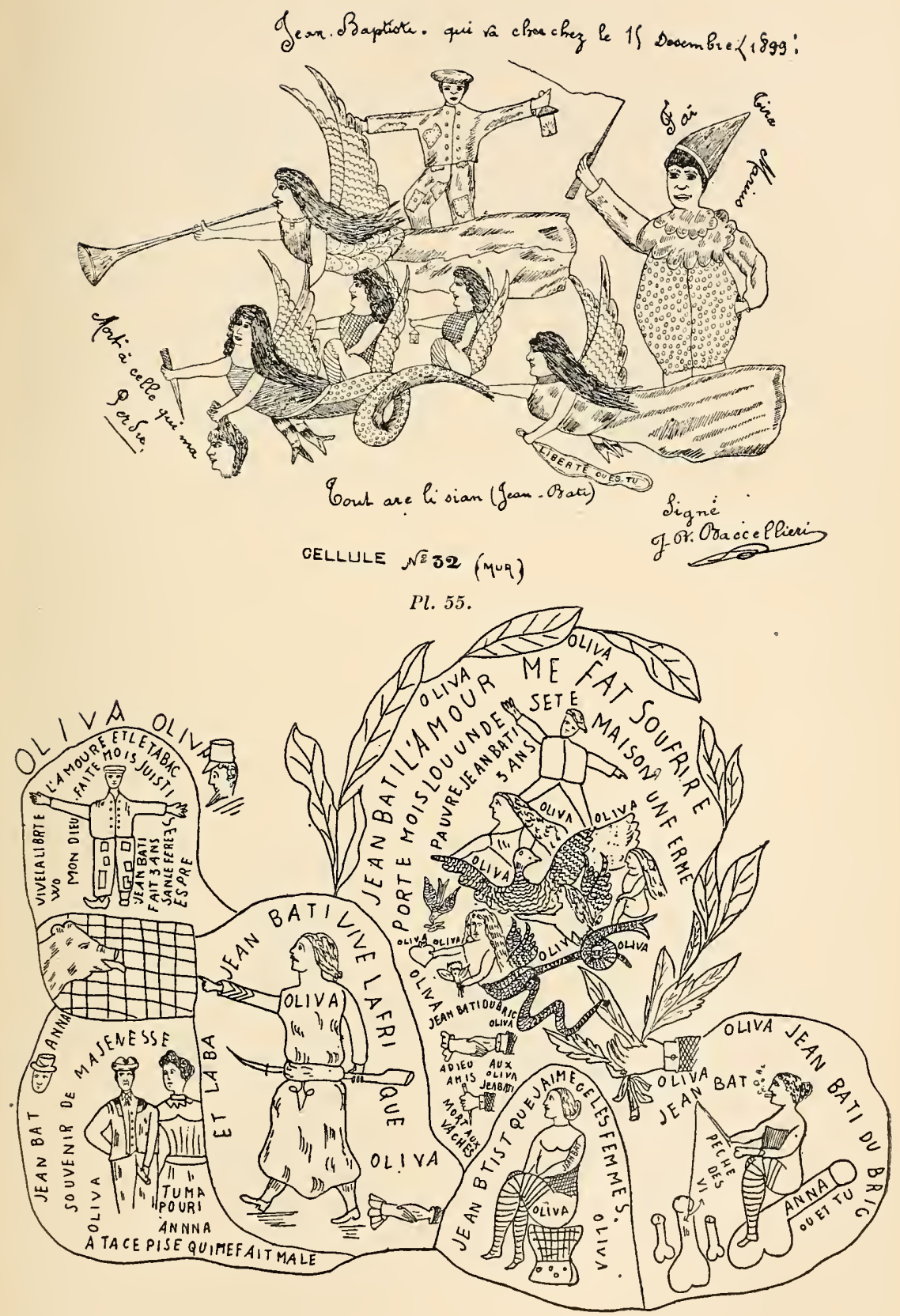

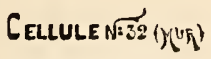

$P l .56 .-1 / f$ de la grandeur naturelle. 


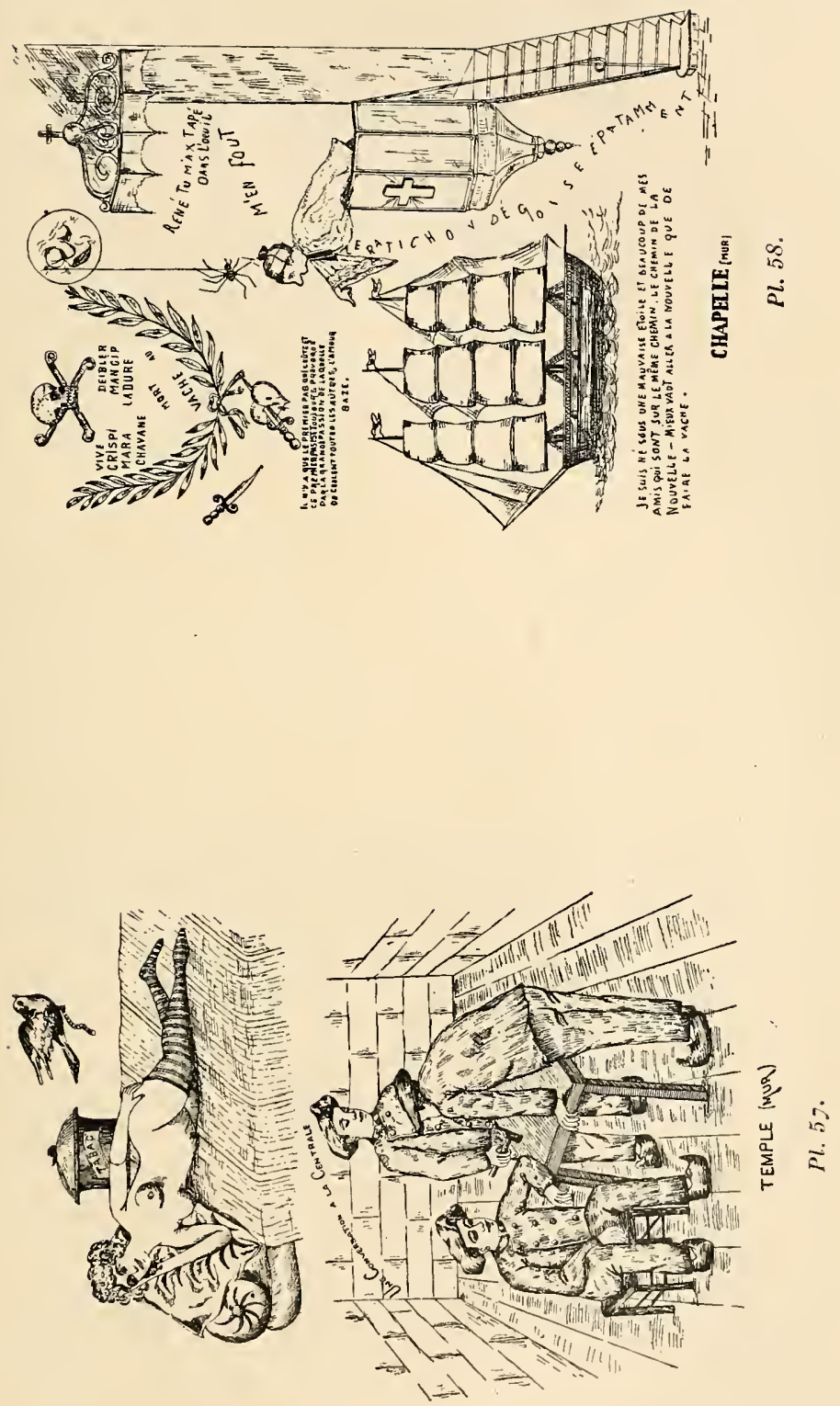


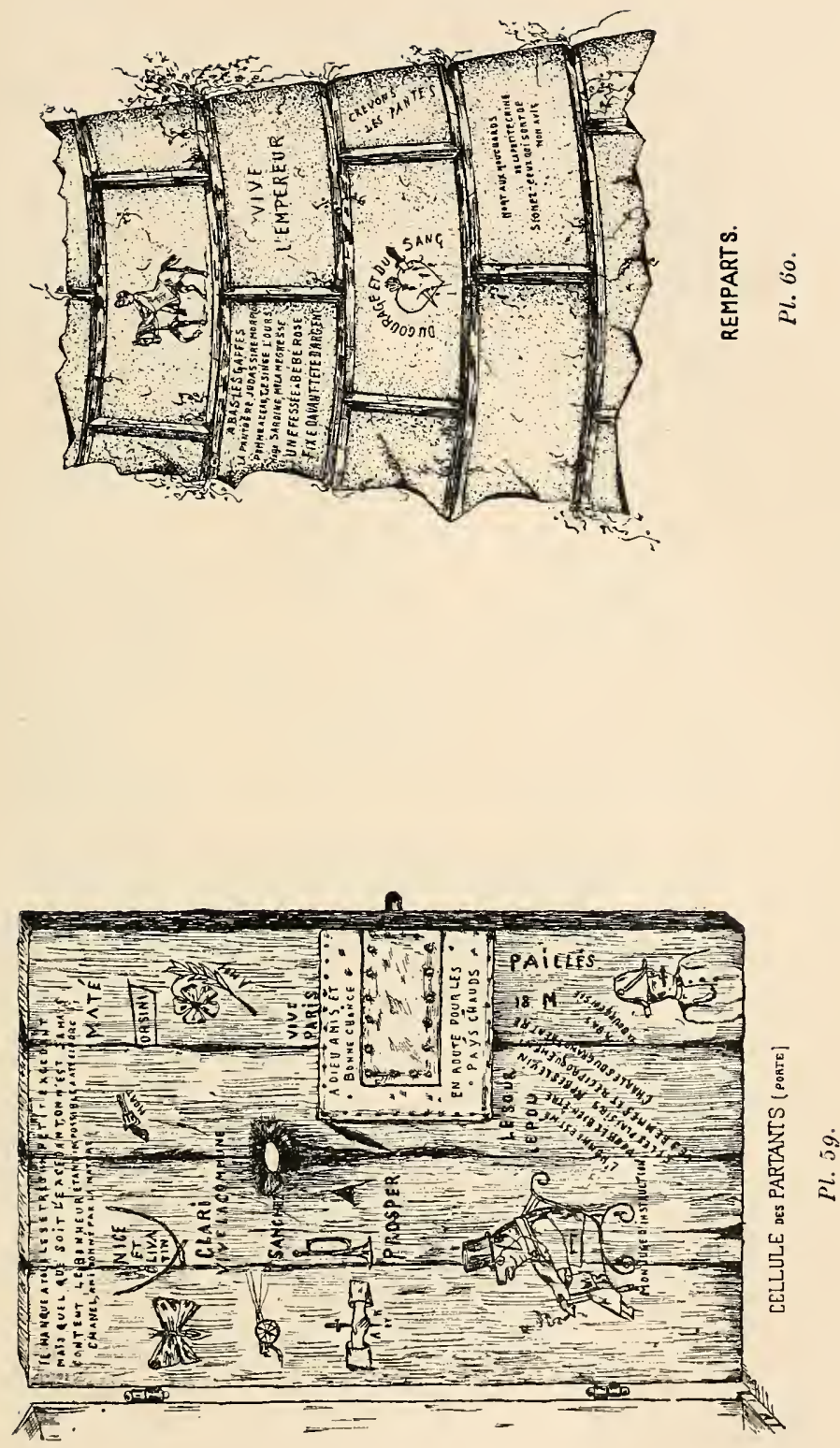



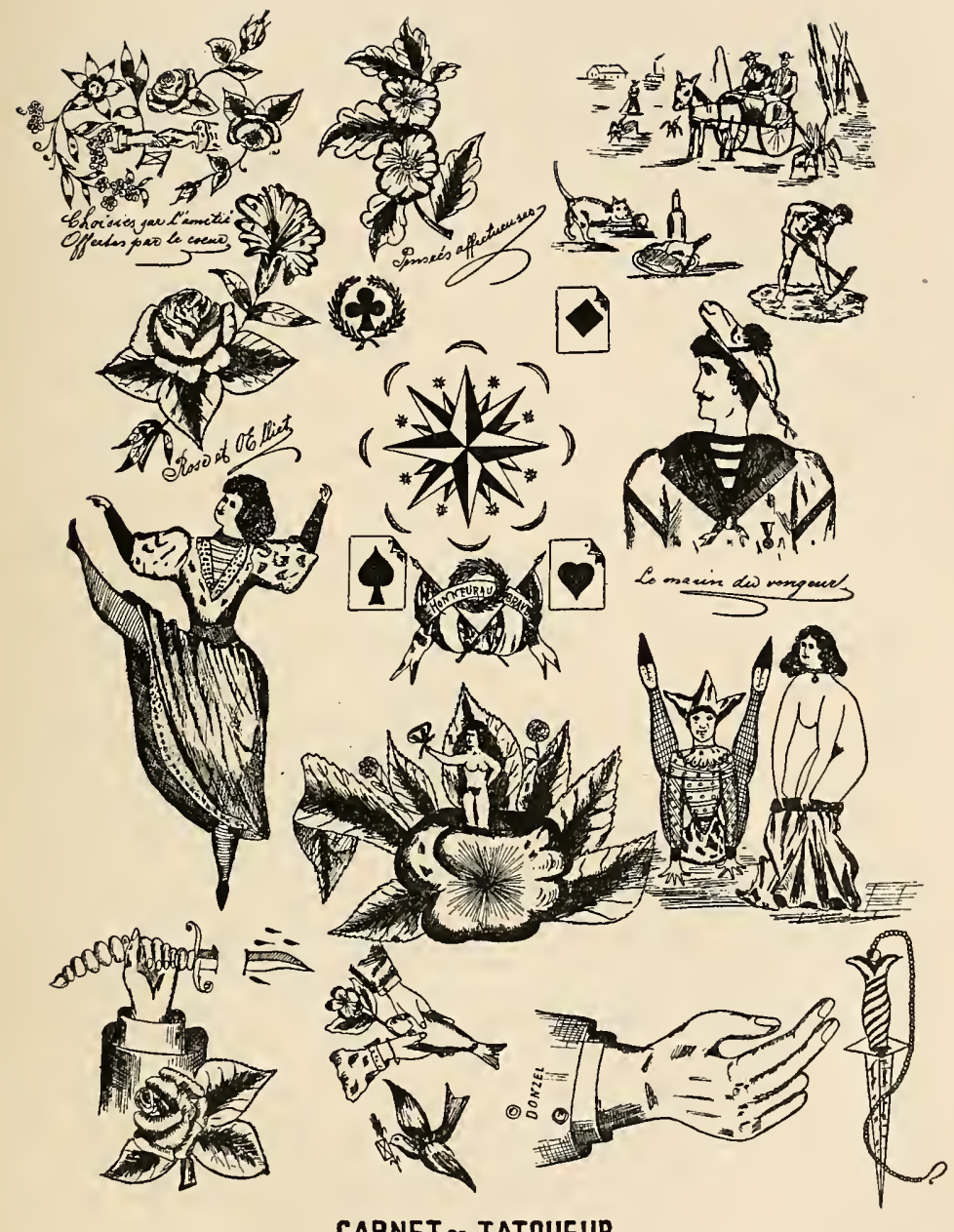

CARNET oE TATOUEUR

sacis, le 4 autil 1899, on/ruson

Pl. $6 \iota$. 



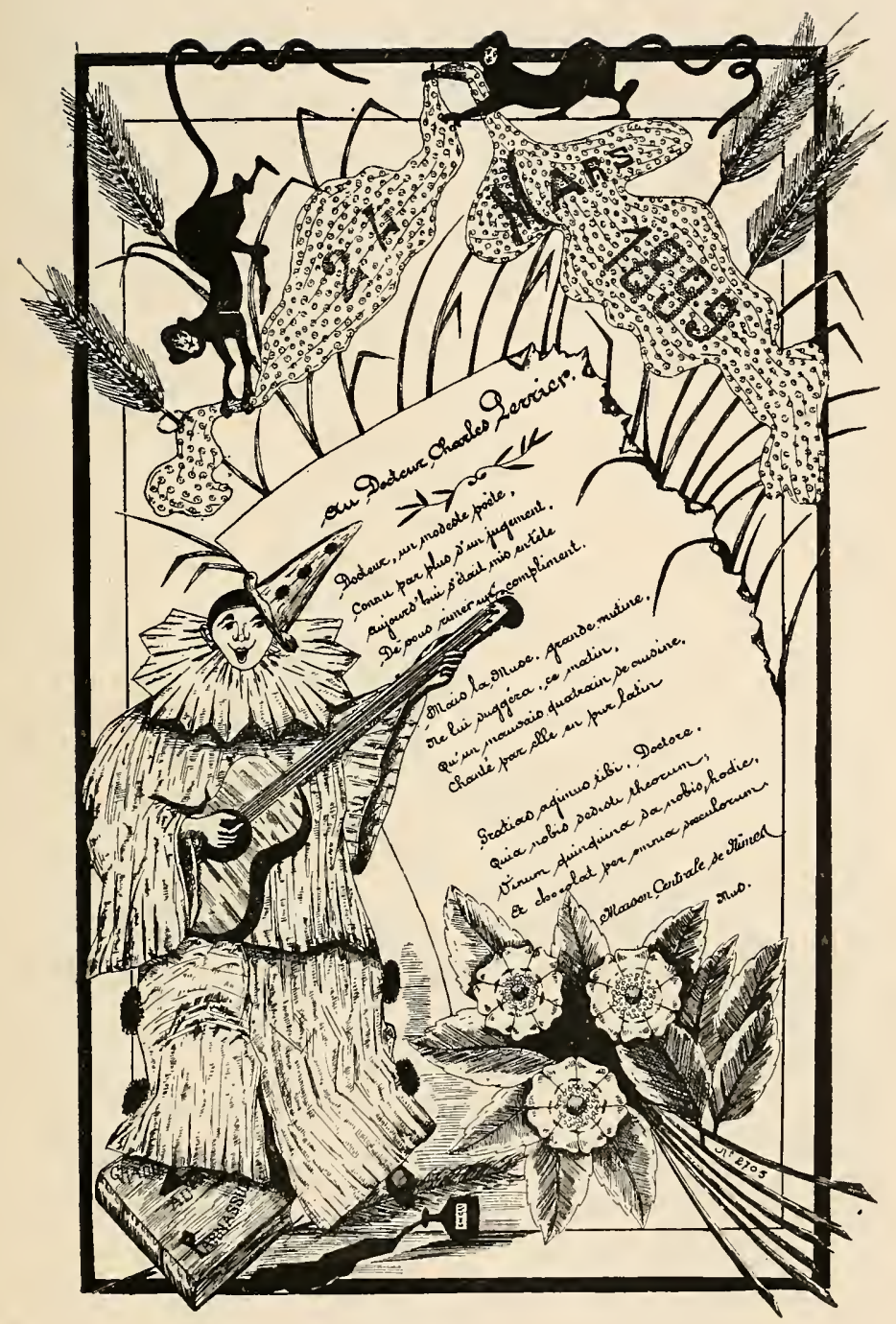

Pl. 62 . 



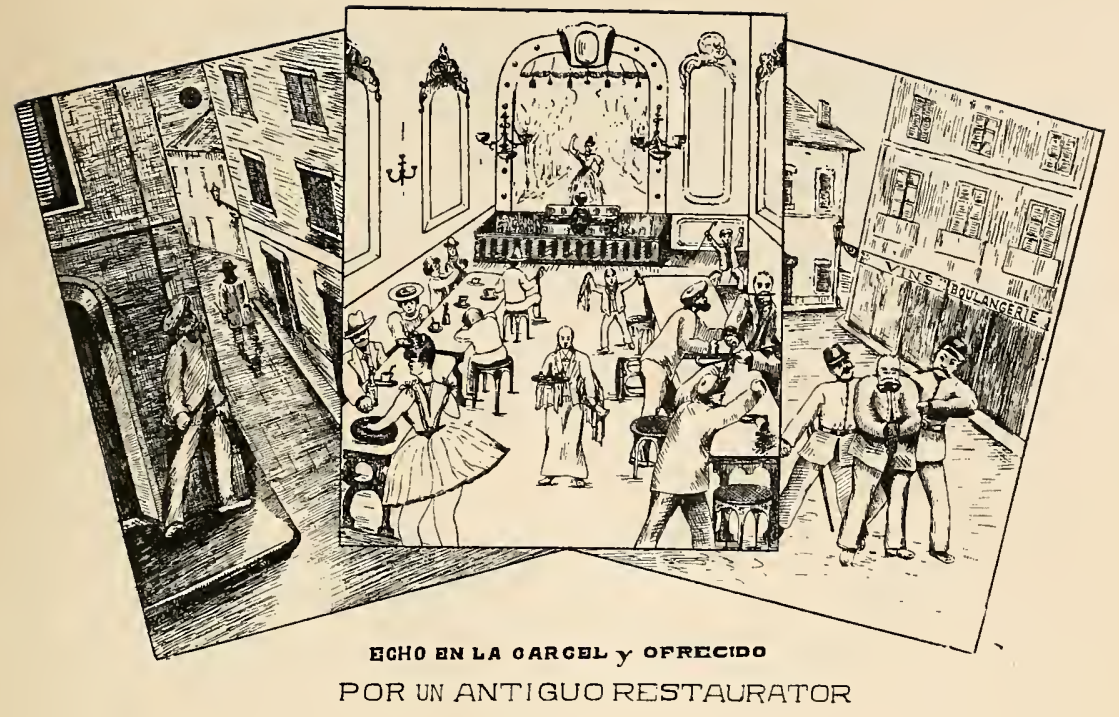

Pl. 63.

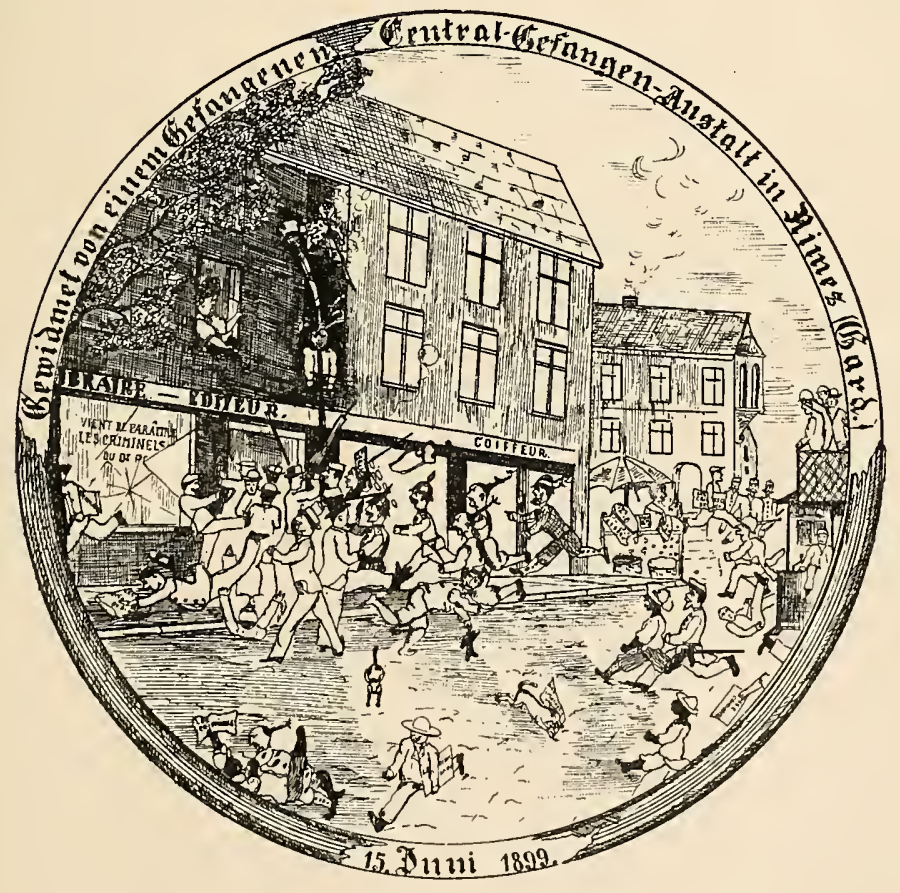

Pl. 6f́. 



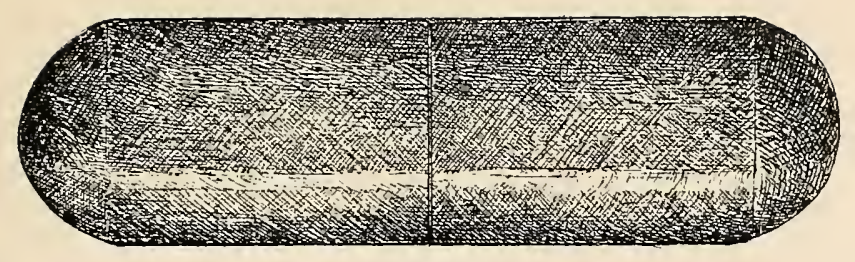

Planq.
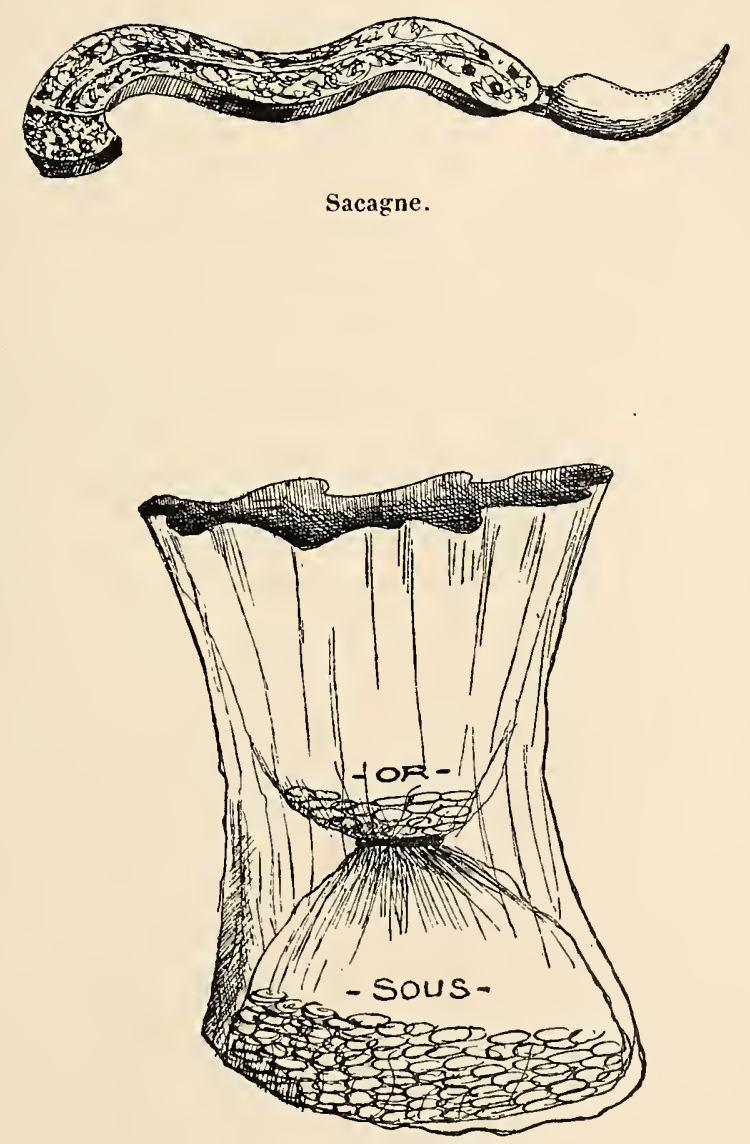

Sac à double fond.

Pl. 65. 


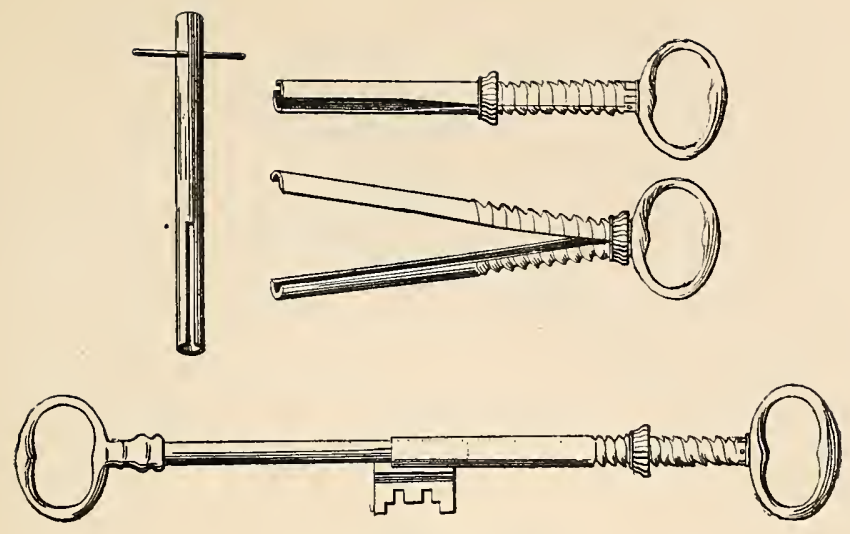

Queue de rat et sifflet.

Pl. 66 .
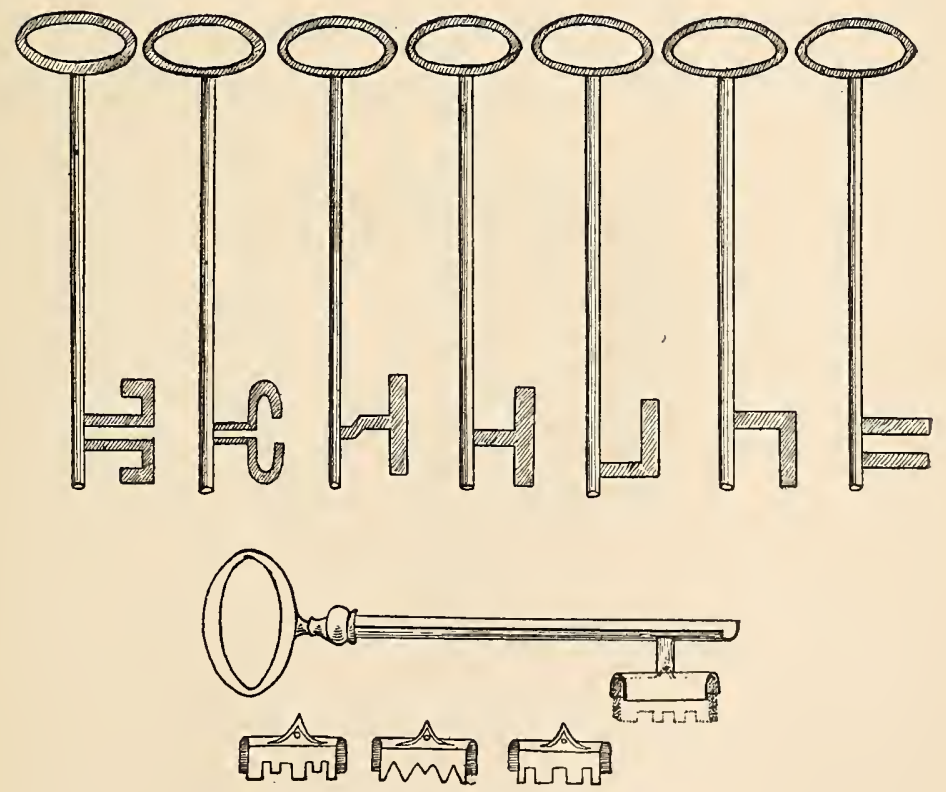

Rossignols et clef articulèe.

Pl. 67 . 


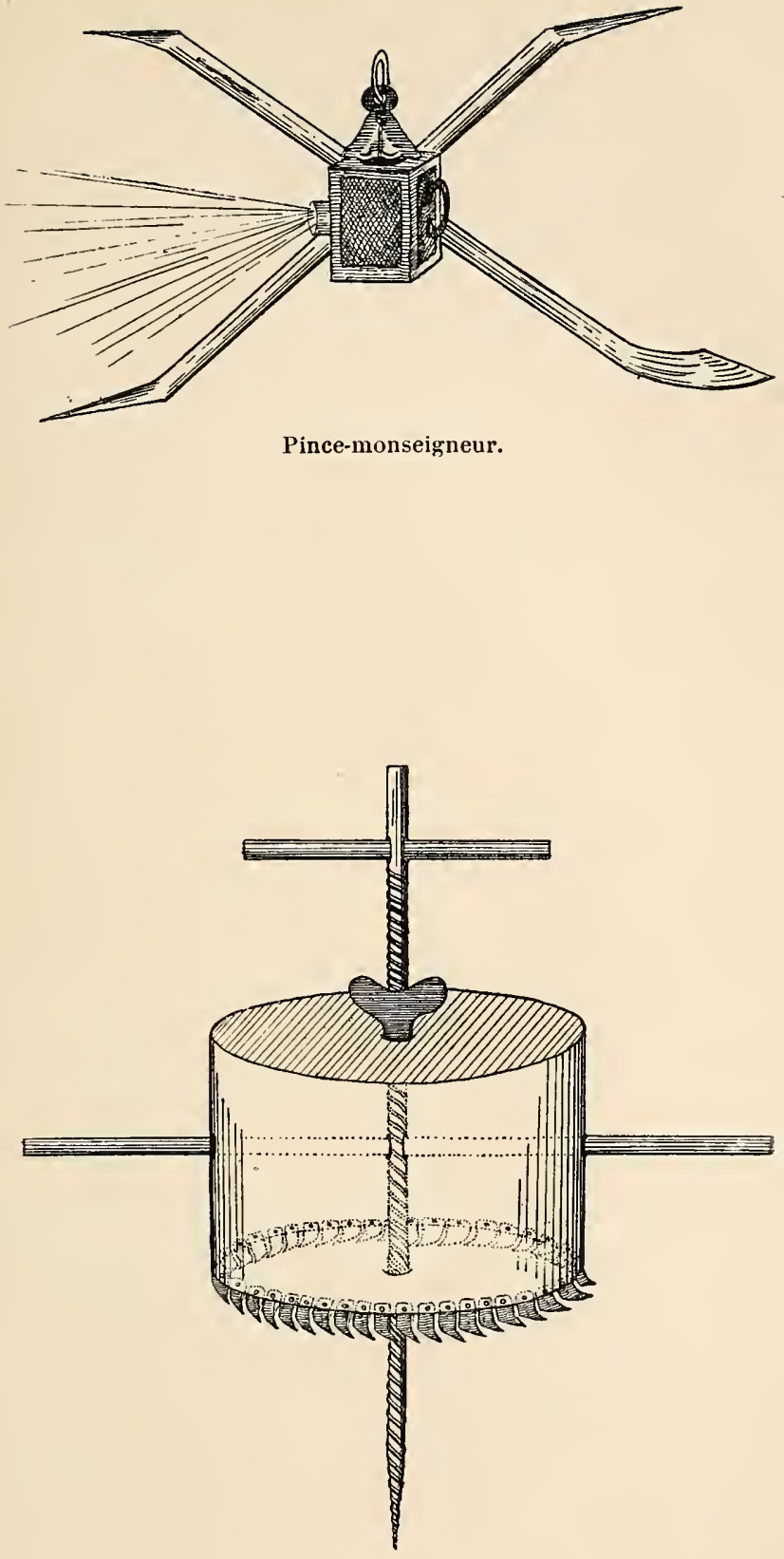

Perforeuse.

Pl. 68 . 



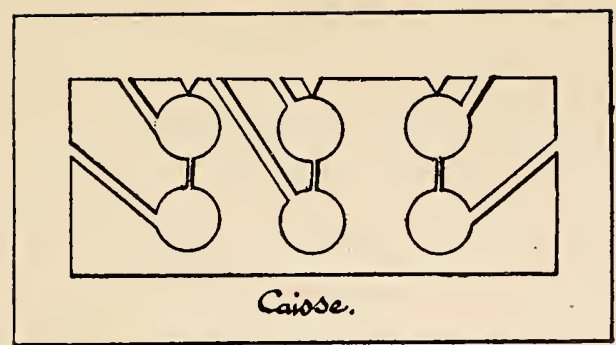

elloule, (2iices de 2 frances.)-
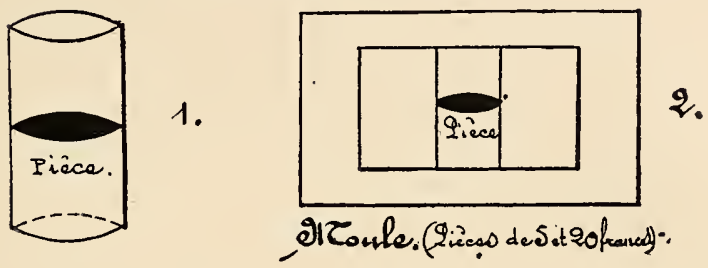

Pl. 69 .
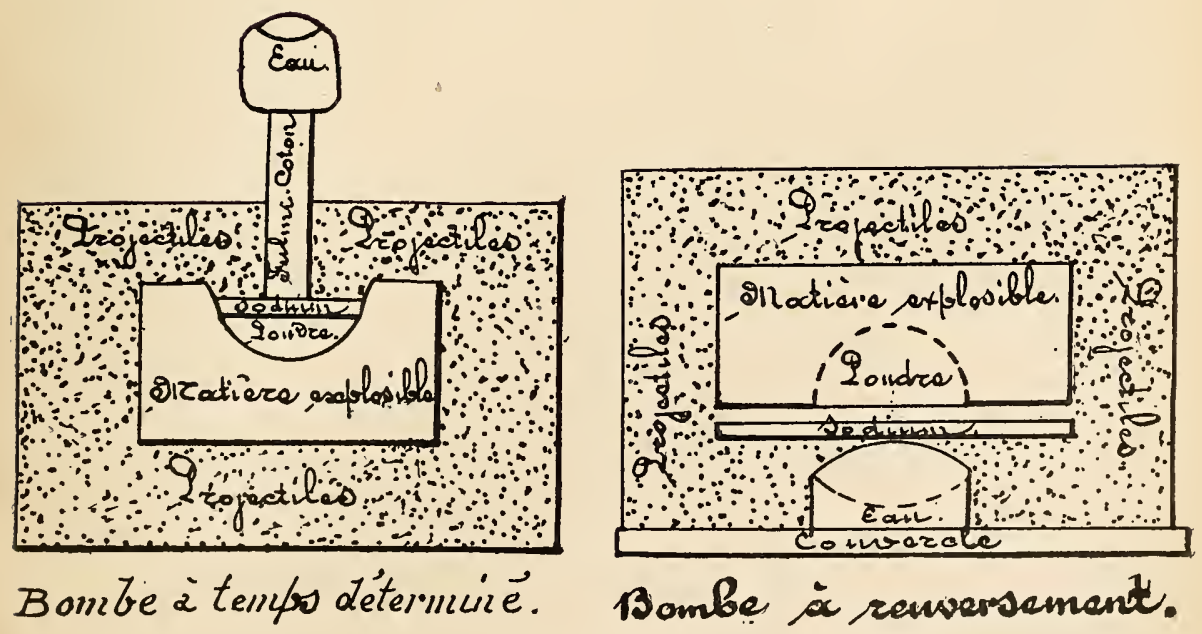

Bombe as renversemente 






